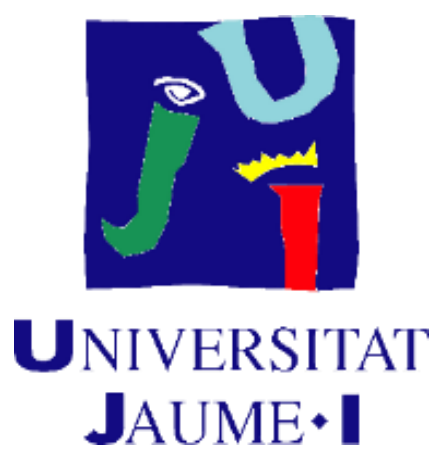

\title{
VIRTUAL REALITY THERAPY FOR THE ENHANCEMENT OF TRADITIONAL THERAPIES FOR POST-NATAL DEPRESSION
}

\author{
by George Stamou
}

Supervisors: Dr Cristina Botella, Dr Azucena García-Palacios

July 2021 


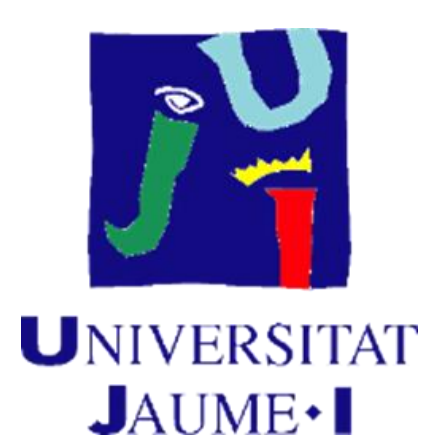

Doctoral Programme in Psychology

Universitat Jaume I Doctoral School

VIRTUAL REALITY THERAPY FOR THE ENHANCEMENT OF TRADITIONAL THERAPIES FOR POST-NATAL DEPRESSION

Report submitted by George Stamou in order to be eligible for a doctoral degree awarded by the Universitat Jaume I

George Stamou

Cristina Botella

Azucena García-Palacios

Castellón de la Plana, July 2021

ii 


\section{Funding}

This thesis was made possible due to the partial funding of WellSouth, the Primary Health Network in Otago \& Southland, New Zealand. 
This thesis is dedicated to my parents,

my father Nikolaos and my mother Antonia

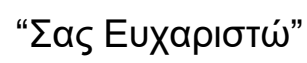

A journey started some years ago... "never give up..." 


\section{Acknowledgments}

I would like to express my gratitude to my wife Renee, and to my three sons, Nikolaos, Heath, and Antonios Aris. I would also like to say a big Thank you to my brother Petros and his family. I would like to Thank my two supervisors, Professor Cristina Botella and Professor Azucena Garcia-Palacios for giving me this opportunity. I would like to thank my co-authors Brendon Woodford and Carlos SusoRibera. I would also like to thank Professor Holger Regenbrecht for his continuous support, and Mohammed Alghamdi for providing the VR system. Lastly, I would like to express my appreciation to the following: Dianne Begg, Joy Pringle, lan Macara, Kaylene Holland, Tina Simmonds, Cushla Phillips, and Chris Mitchell. 


\section{Resumen de la tesis doctoral}

\section{Finalidad y objetivos de la investigación}

El objetivo general de este proyecto de investigación era explorar la combinación de un tratamiento tradicional para la depresión postnatal (DPN), como la terapia cognitivo-conductual (TCC), con el uso de la tecnología de realidad virtual (RV). Este proyecto se propuso responder a cinco objetivos.

El primer objetivo fue estudiar qué tratamientos eran los más eficaces y frecuentes para el tratamiento del DPN. El segundo objetivo se centró en identificar qué componentes de la TCC se utilizaban con más frecuencia para el tratamiento del DPN. El tercer objetivo pretendía identificar si la RV se había utilizado alguna vez para el tratamiento del DPN, y si la RV podía combinarse con una terapia tradicional e implementarse en un entorno clínico. El cuarto objetivo fue estudiar la viabilidad y aceptación de este protocolo de intervención de CBT más RV, es decir, identificar si la combinación de la TCC con la tecnología de RV era factible y aceptable. El quinto objetivo de esta tesis fue explorar la eficacia preliminar de la combinación de la TCC con la RV para el tratamiento del DPN.

\section{Enfoque y metodología utilizados}

Esta tesis doctoral cumple los dos primeros objetivos al incluir una revisión bibliográfica en el segundo capítulo, que identifica los componentes de la TCC más frecuentemente utilizados para el tratamiento del DPN. Se trata de una revisión narrativa que ha sido publicada y que utiliza un enfoque sistemático para identificar los tratamientos de TCC para el TNP. La revisión informa sobre la investigación de cuatro bases de datos sobre la literatura ya publicada sobre la TCC como tratamiento para el DPN. Además, el capítulo también identifica si ha habido alguna investigación que combine la TCC con la RV para el tratamiento del DPN anteriormente. 
El tercer capítulo explora la idea de combinar la TCC con la RV para el tratamiento del DPN. Incluye los resultados de un estudio piloto que ya ha sido publicado e investiga la viabilidad y los niveles de aceptación de dicha combinación en un entorno clínico. Este estudio piloto sirve de guía para crear el protocolo clínico y definir las herramientas de investigación utilizadas en un ensayo clínico posterior.

El ensayo clínico, que se ha presentado a una revista científica, se encuentra en el cuarto capítulo de la tesis. En él se profundiza en los niveles de viabilidad y aceptación en un entorno clínico que combine la TCC y la RV para el tratamiento del DPN. Identifica los parámetros que hacen factible dicha combinación en cuanto al protocolo clínico, el proceso de derivación y el uso de la tecnología, entre otros. También se explora la combinación del tratamiento de TCC y la tecnología de RV en relación con la aceptación y se exploran cuestiones como el disfrute y la comodidad de los participantes al utilizar la tecnología.

El estudio también investiga si la combinación de la TCC con la RV tiene alguna eficacia clínica para tratar con éxito el DPN, que es el quinto objetivo de esta tesis.

\section{Aportaciones originales}

La tesis supone varias aportaciones originales de este proyecto de investigación. Identifica qué tratamientos de TCC se han utilizado con mayor frecuencia para el tratamiento del DPN. También identifica detalles sobre parámetros acerca de cómo se proporcionó la intervención en cada estudio, la naturaleza de la intervención y qué medidas de resultado se utilizaron.

La revisión narrativa de la literatura identifica una laguna en la literatura en la que la RV nunca se había utilizado para el tratamiento del DPN. El proyecto examina la viabilidad y los niveles de aceptación de la combinación de TCC y RV para el tratamiento del DPN. Tanto el estudio piloto como el ensayo clínico examinan la viabilidad y la aceptación, aunque el ensayo clínico examina estos 
aspectos con mayor profundidad. El proyecto identifica las limitaciones de los protocolos clínicos, tanto en el estudio piloto como en el ensayo clínico, en las medidas de resultado que se utilizaron, en las dificultades técnicas relativas al uso de la tecnología de RV y hace sugerencias sobre posibles mejoras en futuros proyectos de investigación. Identifica la eficacia del uso de la TCC y un componente de RV para el tratamiento del DPN en un entorno clínico y explora conceptos como la toma de decisiones, la conciencia acerca del problema, la atención plena y las aplicaciones de la RV en la vida real.

\section{Conclusiones obtenidas y futuras líneas de investigación}

Este proyecto de investigación concluye que la TCC es un tratamiento terapéutico eficaz para la depresión. La técnica de TCC más utilizada fue la psicoeducación, seguida de la reestructuración cognitiva y de la resolución de problemas. Estrategias de manejo de la conducta fueron las siguientes técnicas de TCC más frecuentes, seguidas de la fijación y logro de objetivos y la gestión del estrés. La técnica menos utilizada para el tratamiento del DPN fue la relajación.

Se observó que la TCC es eficaz con poblaciones de diferentes orígenes socioeconómicos. Puede impartirse en diversos entornos o lugares clínicos. Los proveedores pueden ser desde especialistas en salud mental hasta personas no profesionales. La TCC también puede impartirse de forma individual o en grupo.

Otra conclusión de esta tesis es que la RV nunca se ha utilizado para el tratamiento del DPN, como enfoque terapéutico independiente o en combinación con otra terapia.

Otra conclusión es que la combinación de la TCC con la RV es factible, tanto el estudio piloto como el ensayo lo confirman. En cuanto a aceptación, la mayoría de los participantes valoraron positivamente los protocolos, el número de sesiones, la confidencialidad, la ética y el proceso de derivación. Del mismo modo, la combinación de la TCC con la RV fue bien acogida por los participantes, ya que tanto 
los participantes del estudio piloto como los del ensayo clínico, se sintieron cómodos utilizando el sistema de RV, y lo consideraron relevante para sus circunstancias vitales.

También se comprobó que la combinación de TCC y RV era eficaz para el tratamiento del DPN. Aunque, dadas las características del diseño, no es posible concluir con seguridad si la RV puede mejorar la eficacia de la TCC, la combinación de la TCC con la RV fue eficaz.

Esta limitación acerca de poder concluir si la RV puede mejorar la eficacia de la TCC, nos lleva a plantear una futura línea de investigación que suponga realizar un ensayo clínico controlado aleatorizado que permita delimitar la aportación adicional que pueda suponer el uso de la RV a las estrategias tradicionales de TCC en el tratamiento del DPN. 


\section{TABLE OF CONTENTS}

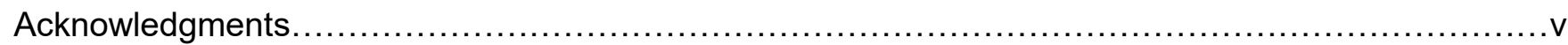

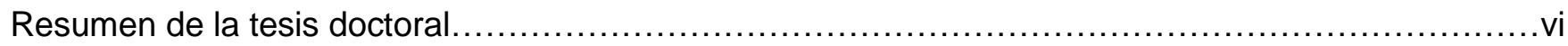

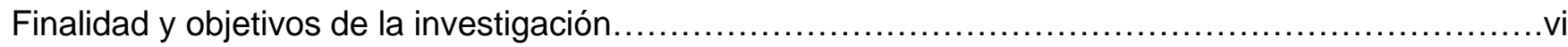

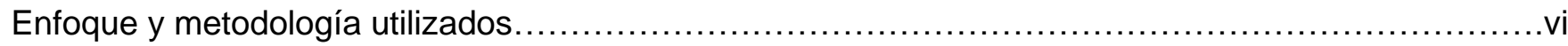

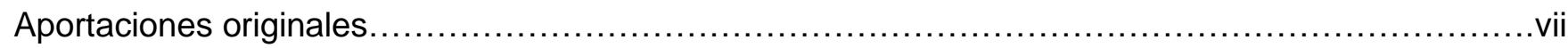

Conclusiones obtenidas y futuras líneas de investigación...................................... vii

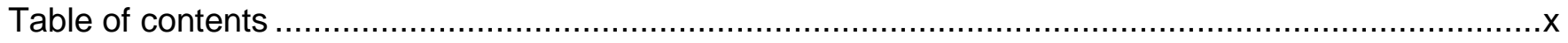

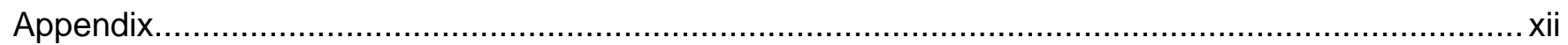

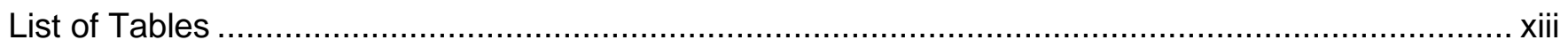

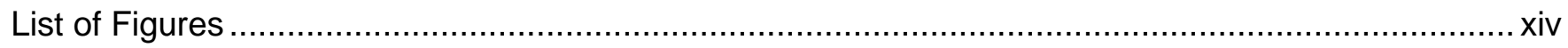

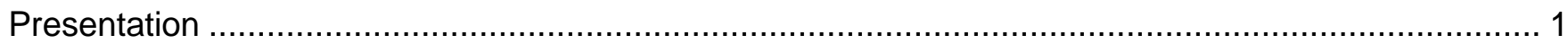

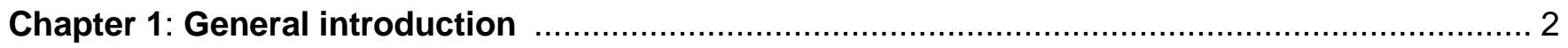

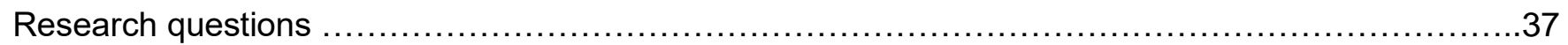

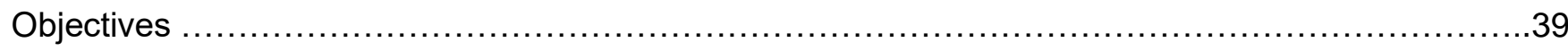

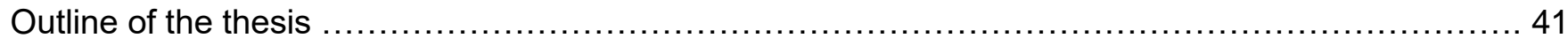

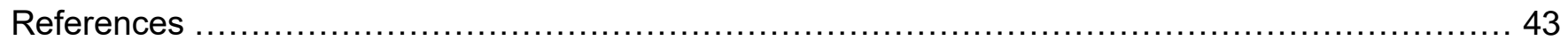


Chapter 2: Cognitive-Behavioural therapy and interpersonal psychotherapy for the treatment of

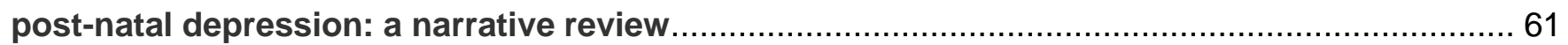

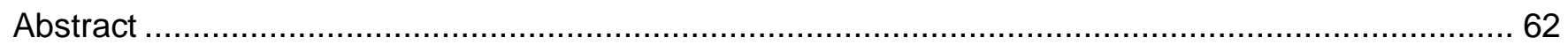

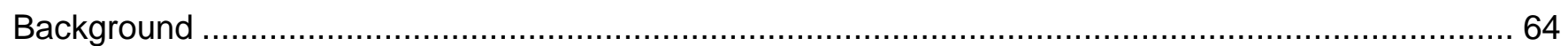

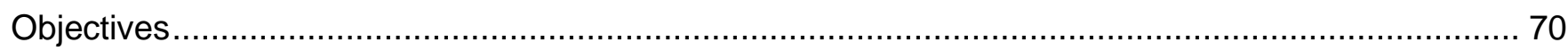

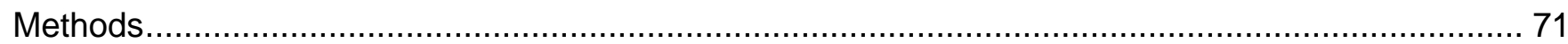

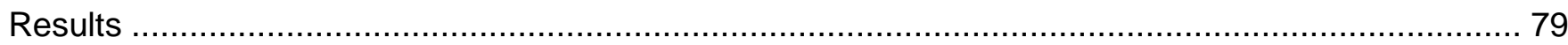

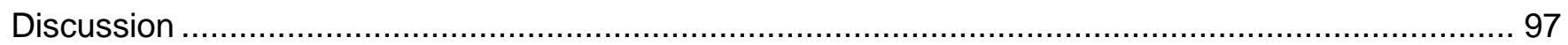

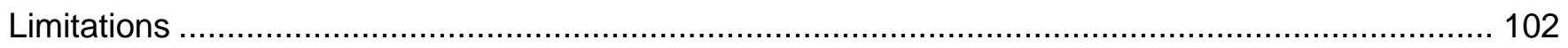

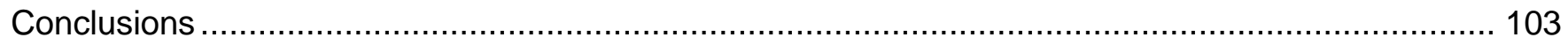

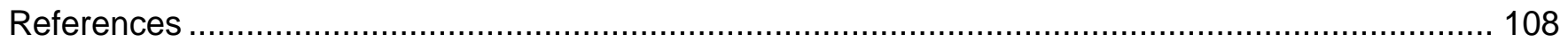

Chapter 3: The combination of cognitive-behavioural therapy with virtual reality for the treatment of post-natal depression. A pilot feasibility

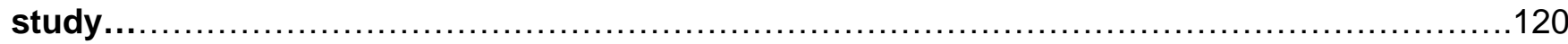

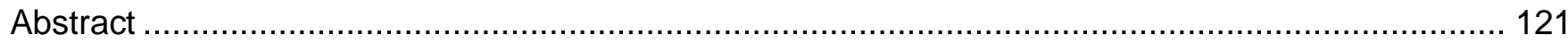

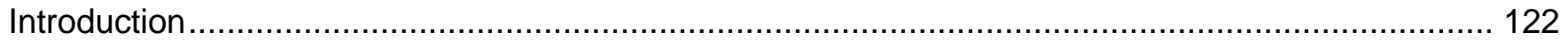

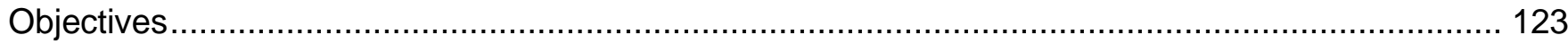

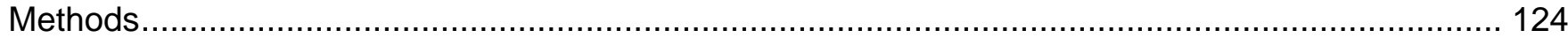

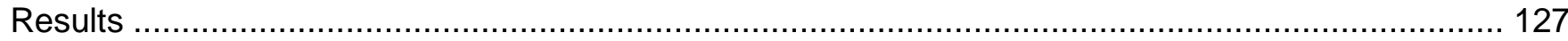

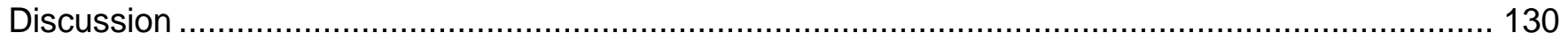

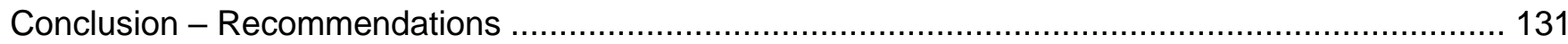

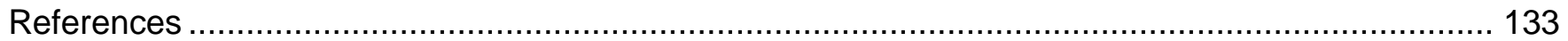


Chapter 4: The combination of cognitive-behavioural therapy with virtual reality for the treatment of post-natal depression in a brief intervention context: A single-case studies trial

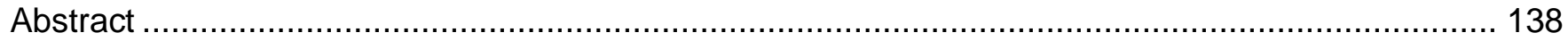

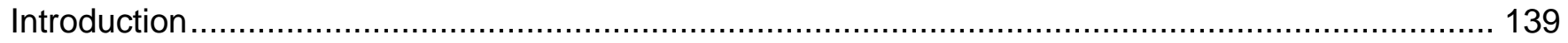

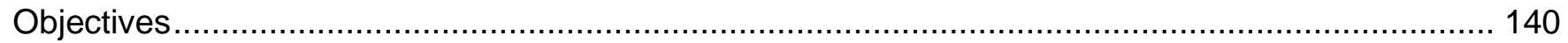

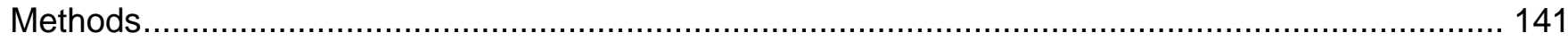

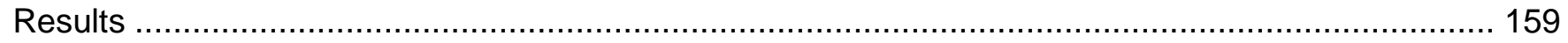

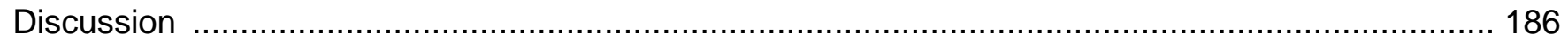

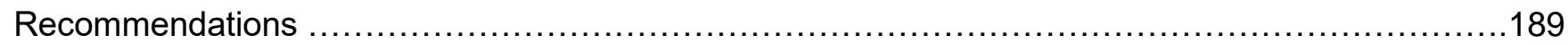

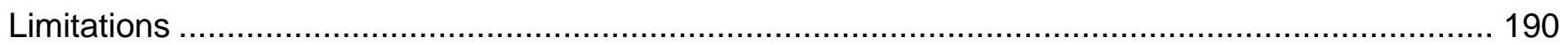

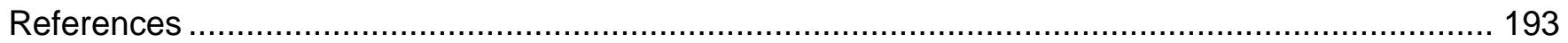

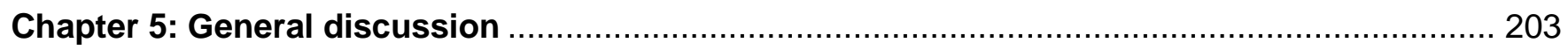

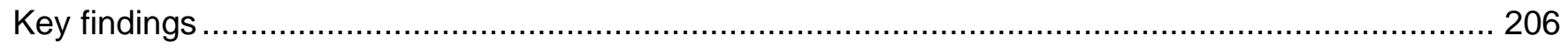

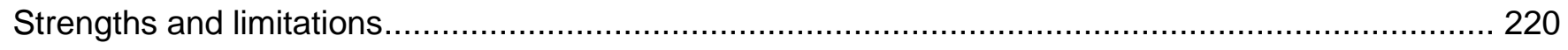

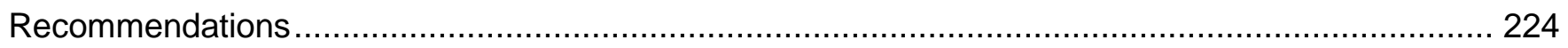

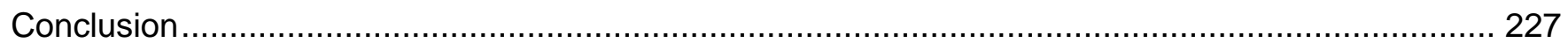

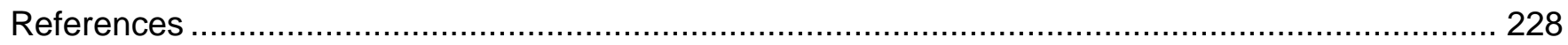

Appendix

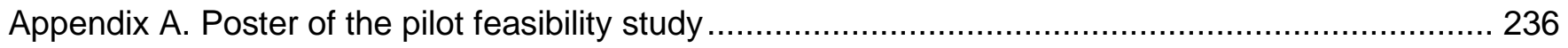

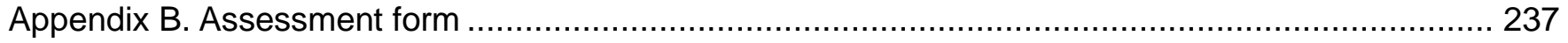

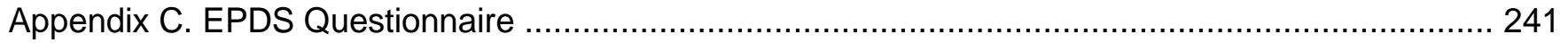

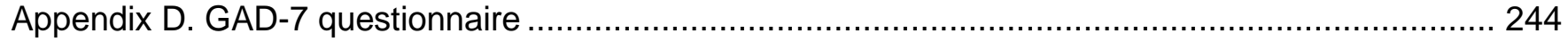


Appendix E. Kessler-10 questionnaire

Appendix F. Baseline and treatment periods questionnaire (measured daily) ............................ 247

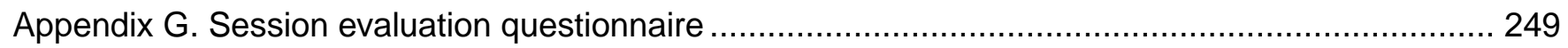

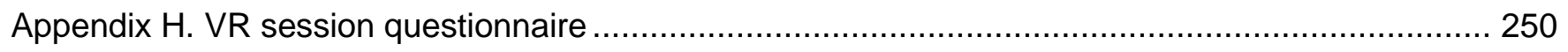

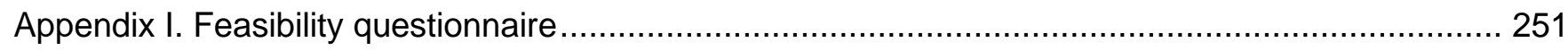

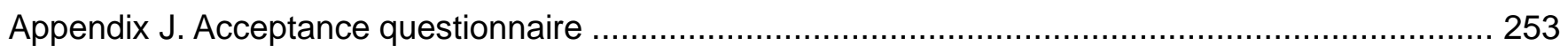

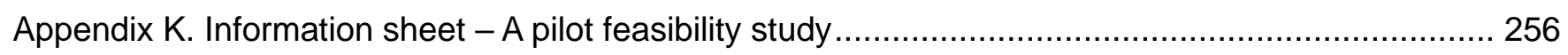

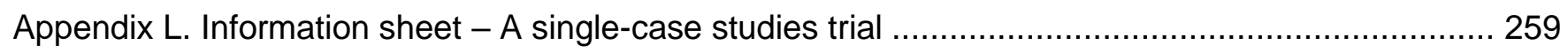

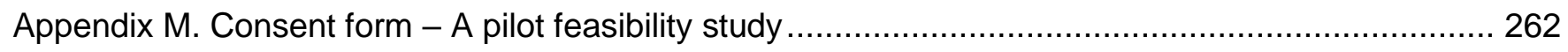

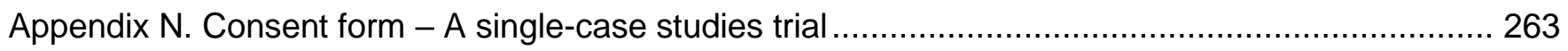

Appendix O. Risk mitigation protocol - A pilot feasibility study ........................................... 265

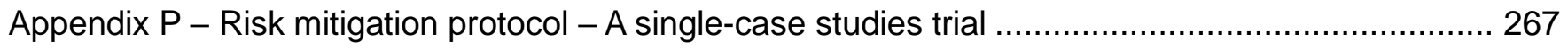

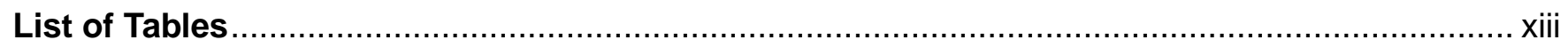

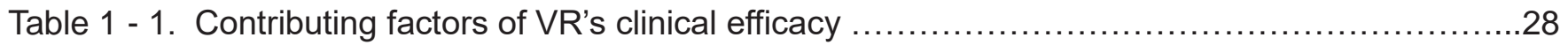

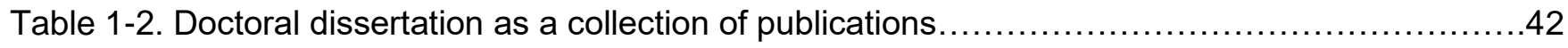

Table 2-1. Summary of the final list of the 15 studies for the treatment of PND and their characteristics 81

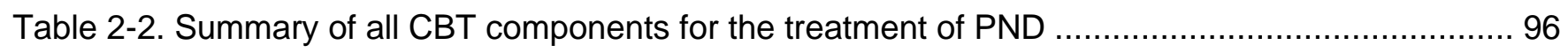

Table 3-1. Stressors and their sequence for each participant............................................. 129

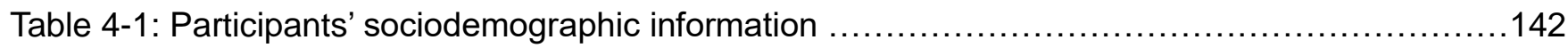

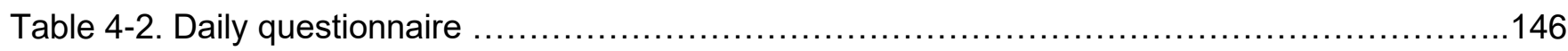

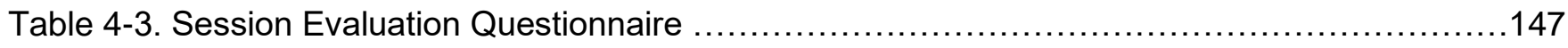

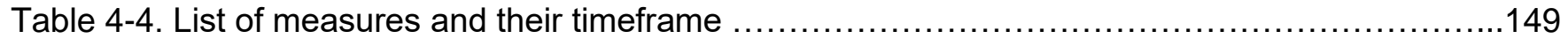


Table 4-5: Virtual stressors and their categories 152

Table 4-6: Mean values and standard deviations for Kessler-10, GAD-7, EPDS questionnaires 161

Table 4-7. Cohen-d - effect size. 161

Table 4-8: Daily questionnaire effect size (d estimate) 166

Table 4-9. Mean values and standard deviations for Feasibility questionnaire 168

Table 4-10. Mean values and standard deviations for the Acceptance questionnaire 170

Table 4-11. Mean values and standard deviations for Session Evaluation Questionnaire..... 173

Table 4-12. Stressors and their sequence 178

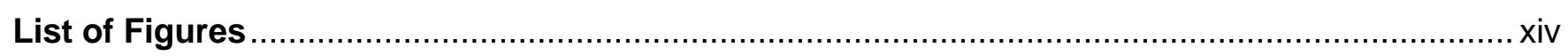

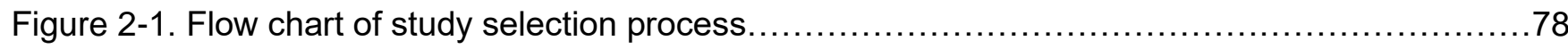

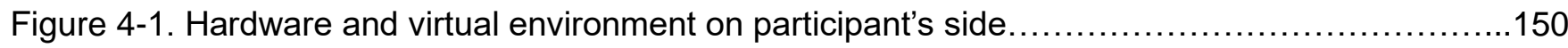

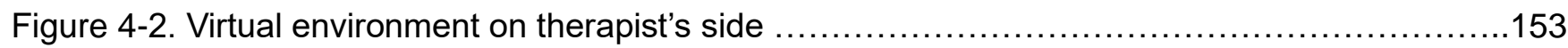

Figure 4-3: Mean* values for Kessler-10, GAD-7, EPDS questionnaires ..............................160

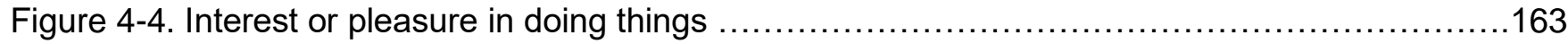

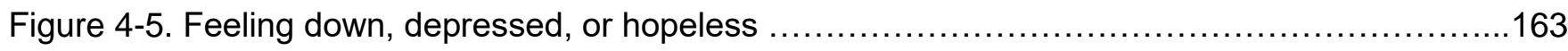

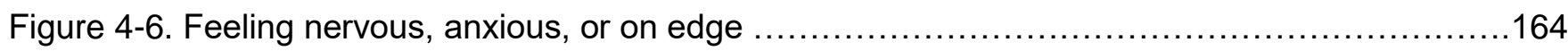

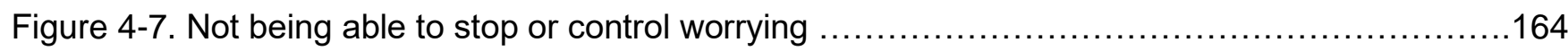

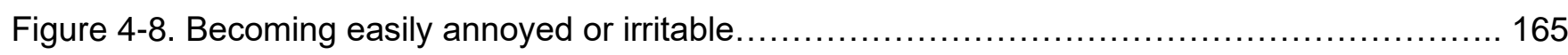

Figure 4-9. How confident do you feel about accomplishing today's tasks? ..........................165 


\section{Presentation}

The current doctoral thesis is a compendium of research articles. There are three publications in total. All the articles in this doctoral dissertation are related to each other to a greater or lesser extent. However, the reader may choose to go through each of them independently because they constitute separate articles. All co-authors have agreed for the doctoral candidate to present all papers as part of his doctoral dissertation.

Chapter 1 is the introduction of the thesis. The three published papers constitute chapters 2,3 , and 4 of the thesis. Chapter 5 includes the general discussion and the conclusion of the thesis, while a list of tables and a list of figures are at the end of the dissertation. 


\section{Chapter 1: General introduction}

This chapter is a general introduction to this thesis. It is a literature review on its own. It presents the concept of what post-natal depression (PND) is, and what makes it a very important mental health issue that needs to be addressed. This introduction also includes the epidemiology around PND, and the frequency of PND's appearance. Next, it describes its symptomatology, and includes an account of risk factors that contribute for an individual to experience PND.

The next part is about the therapeutic approaches that are used for the treatment of PND. There are some therapeutic approaches available such as individual or group therapies, psychological or medical ones. However, the focus is on cognitive-behavioural therapy (CBT). It explains how CBT works, it describes its clinical efficacy, and includes bibliography which underlines its effectiveness as a treatment.

Then, the focus shifts on virtual reality therapy (VR). It explains what VR is and what are some of its clinical benefits. It includes bibliography on VR and other therapies together, and their clinical efficacy. It, then, identifies contributing factors for VR's clinical efficacy such as control, self-efficacy, presence, and immersion. The first two relate more to the clinical efficacy of VR, as it helps the user gain a sense of control, and as a result, they raise their self-efficacy. The elements of presence and immersion focus on the how VR works as a technology and the philosophy behind that. Presence and immersion are inter-related as a VR programme needs to be immersive for the user to feel a sense of presence in it.

This chapter talks about the VR programme that was used in both the pilot study and the clinical trial for the thesis. It describes the system, its characteristics, and the philosophy behind the reasons that this virtual programme was chosen to be tested.

Moreover, the research questions that this thesis aims to answer are presented. There are seven questions in total and a brief explanation about them, which relate to the objectives of this dissertation 
that follow. This part includes the four main objectives that this thesis set out along with an explanation for each objective separately. The chapter concludes with an outline and a brief reference to the remaining chapters of the thesis.

\section{Post-natal depression}

The definitions of PND vary across literature. For example, the Australian Institute of Health and Welfare defines the beginning of post-natal period twenty weeks into pregnancy and ends approximately one month after the birth of the child (Loggie \& Rankin, 2013). On the contrary, the National Institute for Health and Care Excellence (2016) gives emphasis in its end. It defines post-natal period up to one year after the childbirth. According to Miller (2002), a working definition of post-partum period amongst research defines post-partum period up to six months following the delivery of the baby.

According to The Diagnostic and Statistical Manual of Mental Disorders (DSM-5), PND does not meet the clinical criteria for a major depressive episode, thus it is in the category of unspecified depressive disorders with peripartum onset (2013). Its symptoms vary in intensity, from mild to moderate, or severe range.

Ali et al. (2009) describes PND as a universal problem which can affect a big proportion of new mothers. Its symptomatology varies from lack of motivation, affected mood, sleep and appetite also affected, issues of concentration, indecisiveness, and with poor self-care or poor care towards their baby (O'Hara \& Zekoski, 1988; Wisner, Parry, \& Piontek, 2002).

Although PND is an important mental health issue that can affect parents in many different aspects of their lives, it is reported that general practitioners in the primary health care sector do not adequately identify and treat all PND cases, most likely only half of them (Hewitt et al., 2009). This might be an organisational issue many times and the model of care that each institution has adopted. Nevertheless, PND is an important mental health issue that can affect a significant percentage of young parents in 
multiple ways with consequences of varying degree. Thus, it is crucial people who suffer from PND to receive adequate care and treatment by professionals.

\section{Epidemiology}

Belluck (2016) highlights that PND is a frequent psychological phenomenon which begins in pregnancy and calls for more frequent screening to relevant populations. Hendrick (2003) reports that the occurrence of PND in the first six months after childbirth is around 12 to 13 percent of the mothers who give birth. However, in a study by Whitton et al. (1996), they found that most women who suffered from PND did not label their experience of PND as such but rather they felt there was something not right. In addition, the participants of that study of $80 \%$ had not shared with their health practitioner their experience of depression and its symptoms. Roberts et al. (2006) supports the idea that men can also develop PND along with women.

Paulson (2010) describes the development of PND in a bell-shaped pattern. He talks about a preparation or else an incubation period, which is followed by a so-called peak, where the full-blown effect of symptoms of PND happen. Eventually the symptoms will become less intense and less frequent overtime.

\section{Symptomatology}

Meltzer-Brody (2011) distinguishes perinatal depression, depression in both the ante-natal and the post-partum period, into mild to moderate range and moderate to severe. In mild to moderate range the person will not necessarily need support, while in moderate to severe range, suitable support will be required. The author also identifies some of the symptoms of perinatal depression which can be obsessive thoughts where the individual tends to ruminate over unresolved issues, mood issues, a 
sense of agitation, and even suicidal ideation. Spinelli (2009) focuses on the severity of PND where the person is not able to function and exercise her daily routines as she would normally do.

Anxiety and depression are the most common mental health issues experienced during pregnancy and in the post-partum period (Alipour et al., 2012, as cited in Biaggi et al. 2016). The National Institute for Health and Care Excellence (2016) in the United Kingdom states that the person during and after pregnancy is not unusual to experience not only depression and PND, but also anxiety and panic attacks. It is also not unusual that the person might develop phobias of certain people or situations, usually in social settings. Sockol et al. (2014) found that when pregnant women tend to be self-critical, was a reliable predictor of anxiety and depression in terms of symptomatology (as cited in Felder, et al., 2016).

A frequent cognitive phenomenon the individual can experience when feeling depressed in the postpartum period is the tendency to ruminate. Rumination is characterised by repetitive thoughts, usually with negative content (Nolen-Hoeksema, 2003). It does not allow the person to focus on solutions and

resolve the underlying issue, but he/she rather concentrates on the symptoms. It is a cyclical way of thinking which promotes unhelpful negative cognitions and as a result emotional response (MacCoon et al., 2003; Sullivan \& Davila, 2010). That way of thinking results in mood disturbances and the emergence of depressive symptoms.

\section{Aetiology}

Harris et al. (1989) report the high occurrence of PND due to hormonal changes that occur during the postpartum period. However, Goodman (2004) identifies that men, almost equally as women, can suffer from PND.

Hendrick et al. (1998) and Harris (1994) speak about hormonal changes or imbalances, while Miller 
(2002) talks about premenstrual syndrome. Beard et al. (2005) report that iron deficiency can be a risk factor for developing PND, while Sallinen et al. (2006) highlight unrealistic expectations around the concept of motherhood. Hagen (1999) supports that PND is more frequently experienced when the child is first born and there is a lack of familial support, while Donovan and Leavitt (1990) talk about learned helplessness.

Subsequently, McCoy (2006) refers to a combination of factors which might predict the onset of PND such as socio-economic background, family situation, life stressors, lack of support, hereditary factors, alcohol and drug abuse, and unplanned pregnancy. Leigh and Milgrom (2008), who place ante-natal depression, PND, and parenting stress on a continuum, have found that mood, anxiety, limited social support and financial issues are risk factors or good predictors for ante-natal depression. They also concluded that ante-natal depression along with a history of depression of the person can cause PND, which, in turn, can expose the person to stress.

Astbury (1994) examined the risk factors which are associated with depression of mothers after birth. According to the study, factors that are strongly linked with depression are: "having a first child over the age of 34, assisted delivery (caesarean, forceps, vacuum extraction), bottle feeding, dissatisfaction with antenatal care, having unwanted people present at the birth and lacking confidence to look after the baby at the time of leaving hospital. When those factors were considered, being unmarried, being born overseas of non-English-speaking background, being dissatisfied with care in labour and after birth, and not having an active say in decision making" (pg. 176). On the contrary, maternal age and location of residence, were not strongly linked with depression.

Considering the above, it is safe to conclude that the focus in scientific literature, in research and in clinical practice, has shifted from causality of PND such as single or multiple causes to contributing factors for someone who develops PND or depressive symptomatology during the post-partum period. It is often difficult to identify and define single or multiple causes for PND, thus, to identify a cause-and- 
effect relationship. It is rather more beneficial, and possibly easier to identify what aspects of the individual have contributed to the development of PND. In that way, a therapeutic plan for the person can be formulated more easily.

\section{General therapeutic approaches}

According to Kinnaman and Jacobs (2006) there are different therapeutic approaches for the treatment of PND. Some of them are medication, one to one counselling, group therapy, education, and home visits. These therapies are considered general care therapies and are usually offered under routine primary care. There are other therapeutic approaches that can be added to the above list such as hormone replacement therapies or oestrogen therapy, or therapies which focus on the physical aspect of the individual and wellbeing through physical exercise and massage therapy. Other therapies focus on the psychosocial aspect in the individual's life such as the interpersonal psychotherapy (IPT), social skills training, family therapy, psychoeducation, the social cognitive theory, and cognitive-behavioural therapy (CBT) (Klaus \& Kirschman, 2008; Van den Buuse \& Copolov, 2007).

The National Institute for Health and Care Excellence (2014) has developed a comprehensive care plan for the identification and treatment of PND. The care plan can be divided into different stages. The health practitioner is encouraged to explore issues of general well-being and mental health with their clients. The practitioner is expected to make a comprehensive assessment by collecting information on history of depression, health, drug and alcohol, labour difficulties, relationships, bonding issues between mother and baby, family status, and social support, or the lack of it.

The next step is to provide psychoeducation on mental health issues, their impact on the mother and the baby, but also to provide information on the types of treatments available, their benefits, and risks involved. A coordinated care plan will need to be agreed, along with its implementation and the monitoring of the client's progress. It is also encouraged to identify and agree who will be part of the 
care plan, which might involve other parties such as clients' partners, other extended family members, and/or carers. Finally, a decision on the possibility of a referral to more specialised mental health services will need to be made if it is considered necessary.

The Mental Health Foundation (2002) puts emphasis on the holistic recovery of the person from depression. They view recovery, not just in terms of symptomatology, but in a rather holistic manner which involves rights and responsibilities of the person, empowerment, encouragement towards independent decisions, and gaining a sense of hope.

Different studies have been carried out focusing on different approaches that could be useful in this mental health issue. For instance, Daley et al. (2009) conducted a study which investigated whether physical exercise could be beneficial to people with PND. They did a systematic review and a metaanalysis of randomized controlled trials. Although they found a statistical difference between control and experimental groups, they were not able to reach a concrete conclusion. This was due to results heterogeneity in their data analysis, and the study was inconclusive.

Field et al. (2009) investigated whether massage therapy could have any benefits on women after childbirth, who had already developed depression during pregnancy. They also examined any effect on the newborns. In the experimental group, massage therapy was delivered by their loved ones twice a week, sixteen weeks in total. The massage itself was based on progressive muscle relaxation. The data from this study showed that women benefited overall from the massage intervention. On an emotional level, the participants reported less physical pain, and in better mood overall. On a physiological level, participants in the experimental group had found increased levels of serotonin and dopamine and lesser amounts cortisol and norepinephrine. In addition to that, it was observed, but not proven causeand-effect relationship, fewer premature and underweight babies were born.

Onozawa et al. (2001) studied the effect that a mother learning to do massage on her newborn would have on the mother-child communication itself. It was a randomised controlled trial where a small 
sample of depressed mothers was used. They found that mothers who massaged their babies would experience a reduction on their depressive symptoms. The same finding was also found in the control group. However, the main difference between the two was that in the massage group, it was found that mothers massaging their babies had an overall positive effect on the interaction between the mother and the infant. Nevertheless, the authors claimed the study to be inconclusive due to some limitations in the study itself, e.g., small size, high dropout rate, etc.

The MothersMatter Trust (2015) list the possible medications used for treating PND. These are antidepressants such as tricyclics, SSRI's, Citalopram, Fluoxetine, Paroxetine, Sertraline, SNRI's, Venlafaxine, Reboxetine, Buproprion, Mirtazapine, also mood stabilisers such as Carbamazepine, Lithium, Lamotrigine, Sodium Valproate, Topiramate, Second Generation Antipsychotics, Olanzapine, Quetiapine, Aripiprazole, Risperidone, Ziprasidone, Clozapine, first generation antipsychotic, Benzodiazepines and Hypnotics, Modafinil, Methylphenidate, and Omega 3 Fish Oil.

Gregoire et al. (1996) investigated the possibility of treating PND with oestrogen therapy. They found that participants had a positive response to oestrogen and a better outcome than in the placebo group, especially in the first month that therapy started. It was also noted that aspects such as medical or gynaecological history, any history of depression or of other psychiatric nature, had no effect on how the participants responded to the oestrogen therapy. It was not established though what would be the minimum amount, or the duration of the whole therapeutic process be.

TheMothersMatterTrust (2015) talks about interpersonal psychotherapy (IPT). It is a form of psychotherapy, brief, and structured in delivery. It can be delivered by mental health professionals of different backgrounds. IPT was initially developed for treating depression in 1970s but it has been applied to other mental health problems as well since then. Its main therapeutic focus is on the individual's interpersonal relationships. In particular, the therapist helps the individual identify whether PND has triggered or enhanced disagreements or arguments in relationships of the person. It 
investigates grief and loss that the person has experienced, more in particular grief and loss issues that might surround the childbirth. IPT does also identify any changes that occur in roles while pregnant or after the delivery of the baby. Under the IPT perspective, the therapist and client work together to identify any tendencies of the individual to withdraw from social relationships or interpersonal ones and stay within self.

However, Pearlstein et al. (2006) investigated the characteristics of women with PND and what treatment would choose between sertraline and IPT. It was found that most participants' choice of treatment was the IPT over medication. Nevertheless, two main characteristics were identified as a predictor for which treatment was chosen by the participants. The two main characteristics were the history of depression of the individual and breastfeeding. It was found that women with a history of depression tend to choose medication. Women who breastfed tend to choose IPT as their preferred treatment, possibly due to the fear of potential medication side effects which could be passed onto the infant.

TheMothersMatterTrust (2015) also investigated the biopsychosocial rhythms of the individual. The aim is to help the individual identify any patterns, or usual routines that possibly have been disrupted due to various life events. One such very important pattern or routine is that of sleep, which is one of the first indications, if disrupted, that the individual might experience depression or other mental health issues such as anxiety, etc. The aim of working on biopsychosocial rhythms is to help the individual develop new healthy patterns or re-establish the old ones which in a way will contribute to a better emotional stability of the individual. By identifying, setting new goals which need to be realistic, the individual can start redeveloping their routines. This is part of the self-care plan that they also use as part of treating anxiety and depression. Part of the self-care plan is to teach the individual promote a better sense of well-being which is essential for treating depression. They also investigate physical activity and promote the idea of developing a pattern of exercise. 
The self-care plan also investigates the cognitive functioning of the person, where they help them develop and enhance the structured problem-solving approach to a problem. It is believed that when the person can identify a problem situation, break it down into different parts and decided what is the best way to deal with the problem, is a good way of managing feelings or symptoms of anxiety and depression. Looking after someone's physical appearance and developing a good social support circle are also aspects of the self-care plan that ThemothersMatterTrust promotes in dealing with depression and PND successfully.

Wisner et al. (2000) examined the process where future mothers could actively participate in the treatment of depression during pregnancy. In this study they investigated five domains: intrauterine foetal death, physical malformations, growth impairment, behavioural teratogenicity, and neonatal toxicity. They found that the higher the involvement of all parties, the more in-depth analysis of riskbenefit decision for best treatment of depression was. One of the case studies that they used was about the values of the patient which would affect the final decision for treatment of depression and need to be considered by the professionals. Nevertheless, this study did not provide any solid conclusions in relation to other similar studies. Its objective was to help physicians advance treatments for mothers-to-be.

Patel and Wisner (2011) surveyed one hundred women investigating their perspective on decisionmaking process treating depression during pregnancy and in postpartum period. Most participants expressed their preference on being actively involved in the best treatment for depression. Most of them preferred a combination of medication and counselling. Participants also favoured having the choice of making no decision for what treatment would suit their needs best. Being actively involved in the decision making is shown to increase the overall care level.

Green et al. (2007) investigated a large sample of women who were preparing to give birth in six weeks in relation to their sense of satisfaction, their emotional well-being, sense of fulfilment and verbal 
description of women of their babies. It was found that relevant information provided to them by medical staff, and them having a sense of control over events relevant to childbirth showed to be important factors for a positive mental health state before and after birth.

Brugha et al. (2000) put to test the theory that adequate psychosocial support along with ante-natal preparation are enough to prevent the development of PND. They utilised the "Preparing for Parenthood" programme. This is a highly structured intervention which has two goals. The first one is to help boost support for the person through social contacts, and to enhance the person's problem-solving skills. It was found that the participants who received that intervention did not benefit more than the people who did not. This comes into contrast with the widely accepted view that having good problems solving skills, and having adequate support are good predictors for developing or not developing PND. Ante-natal interventions of this kind need to be considered carefully before implementation into clinical practice.

Gibbins and Thomson (2001) investigated the sense of control during childbirth and the effects of it. They found that women were mainly looking for gaining a sense of control during labour and could actively participate in the whole process of childbirth. The level of control depended upon some variables such as information, being supported by partners and midwives, and being actively involved in the decisions being made for them. The authors did suggest that the role of midwives supporting the mothers-to-be was very important and that they should be enquiring what was important to the patients themselves. In that way, the person would gain a better picture and more realistic expectations on the whole process and themselves.

Green et al. (2003) investigated the notion of control in terms of internal locus and external locus of control. It was shown that both internal and external locus of control were effective and enhanced a general sense of well-being of the participants, while they also added to their sense of satisfaction over the experience of childbirth. In particular, and in relation to the three control outcomes, internal control 
was enhanced by the way the participants were helped to deal with their pain. In contrast, when participants had a sense that they did not merely receive care from medical staff, but they were cared for, increased their external sense of control. The difference between care was given to them and being cared for underlines a sense of active participation in the whole process of childbirth.

Reece and Harkless (1998) investigated the notions of parental adaptation, self-efficacy, and stress, and whether they had any effect on parents adapting to parenthood successfully. Their findings varied between the two sexes. It was found that mothers would tend to be more self-efficacious than fathers. They also saw a correlation between self-efficacy and levels of stress. On the other side, fathers saw no relationship between stress and their sense of self-efficacy. The authors of this study found that gender was a good predictor of how confident the individual would experience.

The notion of maternal self-efficacy is an important element for moving into motherhood fluently. Shorey et al. (2014) investigated if there was a correlation between self-efficacy, social support, PND, and socio-demographic variables post-partum. They found that social support, family income, maternal age, and ethnicity were able to predict the levels of self-efficacy that mothers would experience.

So far, a plethora of general treatments for PND is described above. Some of those treatments have a medical focus, others concentrate on the physical aspect of recovery, while a third category focus on the social functioning and support of the individual. There is also an introduction to the concepts of control and self-efficacy which are vital for the improvement of the individual. The next part of this chapter focuses on CBT and its therapeutic components for the treatment of PND.

\section{Cognitive-behavioural therapy for post-natal depression}

CBT includes a substantial number of therapeutic approaches such as rational emotive behaviour therapy, cognitive therapy, self-instructional training, self-control treatments, stress inoculation training, 
problem-solving therapy, structural and constructivist psychotherapy, the "third-wave" CBT such as mindfulness and mindfulness based cognitive approach, CBT group therapy, CBT goal-orientated approach, psychoeducation, problem-solving therapy, and decision-making (Dobson, 2010).

According to TheMothersMatterTrust (2015) CBT examines the dynamic relationship between thoughts, behaviours, and feelings of the individual and how the first two can shape and influence the third one. CBT provides a range of tools that can teach the person to restructure their cognitive and behavioural aspects of their functioning. This can be done not only through acquiring positive thinking but also through challenging the old, and many times biased, or else distorted cognitions of the person. CBT is a short-term intervention, ranging from six to twenty therapeutic sessions. It has been shown to be particularly effective with anxiety and depression, amongst other conditions and, therefore, has been used as a clinical approach for the management of PND.

In a study by Mullet et al. (2002) it was found that CBT had better outcome for preventing and treating PND. In this study, the CBT programme for preventing PND consisted of one intervention while being at the hospital. In the case of treating PND, the therapeutic programme consisted of six to eight home visits.

Morrell et al. (2009) studied any differences of the effect that either CBT or human centred intervention would have on women with PND over standard care at six months, and at one year postpartum. Both psychotherapeutic interventions were delivered by health professionals who had been trained in carrying out clinical assessments where they were able to identify depressive symptoms, but also, they were able to deliver good therapeutic sessions. It was found that both interventions had similar positive effect on the treatment of PND at six months and twelve-month intervals.

Murray et al. (2003) investigated whether there were any differences between CBT, psychodynamic therapy, non-directive counselling and routine primary care. They found that non-directive counselling had a better clinical outcome in terms of the infant's behaviour at 18 months, and better for 
early mother-infant interaction. None of the above-mentioned therapeutic approaches had long-term benefit in terms of mother-child relationship and any behavioural issues of the child. The clinical benefits were mostly of short-term range.

Meager and Milgrom (1996) examined the clinical effectiveness of a group program delivered in a 10week period. The program itself included CBT training, with an emphasis on an educational component and social support. The results of this study support the idea of CBT group therapy of being of therapeutic value on PND.

Kuosmanen et al. (2010) investigated whether CBT and goal-orientated session were of any therapeutic value for the treatment of PND. The authors gave an emphasis in the primary care health sector. They found that brief intervention, (up to two sessions maximum) which had a CBT component, with an emphasis on setting and achieving goals can be of clinical value. They highlighted that the delivery of this clinical intervention can be done in a primary clinical setting where there is the combined effect of supporting mothers and monitoring the health of the infants. Thus, they identified the need for better training amongst health care providers who are not necessarily of a psychiatric background.

Austin et al. (2008) found that most randomised controlled trials which have investigated whether antenatal group interventions were effective at preventing the development of PND, most likely include the component of psychoeducation. Educating a person, who is at risk developing a form of depression, is appropriate and suitable support to teach the person how to identify early symptoms and signs of depression. Both psychoeducation and CBT contribute to a better understanding of cognitive and emotional functioning, and how depression can affect the person.

The MothersMatter Trust (2015) in New Zealand gives emphasis on a structured problem-solving strategy. They consider it to be very important for coping better with anxiety and depression. It deals with the tendency of some people to ruminate over unresolved issues. It helps the person learn how to deal with a problem by focusing on the issue itself. This specific approach follows a protocol which 
helps the individual to identify possible solutions to the problem and choose the best one. They have developed a fact sheet which aims to gather relevant information in a standardised format. It consists of the following five steps: identifying the problem, listing all possible solutions, reviewing each solution, choosing the best or most practical one, and lastly planning.

Bell and D'Zurilla (2009) examined whether problem-solving therapy (PST) can reduce some of the symptoms of depression. PST is under the spectrum of CBT. It focuses on helping the individual to enhance his/her problem-solving skills. In this paper, the authors conducted a meta-analysis of twentyone studies. Their conclusion was that PST was effective in reducing depressive symptoms, in comparison to other therapeutic approaches such as support or attention groups. PST's therapeutic qualities underline a pragmatic and tangible way where the person pays attention to the areas of positive problem orientation, problem definition, finding alternatives, decision making, and solution applying.

Perrig and Grob (2000) talk about Bandura's concept of self-efficacy in social cognitive theory. According to them, people have always striven for gaining a sense of control over external events that might influence their courses of lives. It is generally believed that the level of control that someone has, the more it increases the chances for longer and better quality of life. In contrast, when out of control, people tend to feel unsettled, disorganised, second guessing, unsure, and with lack of confidence. Selfefficacy and sense of control can affect cognitive processes, emotional states, behaviours of the individual or even influence external events in the someone's environment.

Bandura (1997) explores the idea of self-efficacy, the degree a person believes he/she can influence their environment, set goals, and accomplish tasks. He believes that self-efficacy depends on how resilient a person is. This refers to the ability that the person possesses to recover from an adversity or crisis. A prerequisite of resilient efficacy as defined by Bandura, depends on the experiences of the individual that have taught him/her that to succeed, they must make a sustainable effort to complete a 
task. This, in turn, will help the individual enhance their ability of resilience which can be very useful in difficult times. In addition, the author identifies a correlation between self-efficacy and locus of control. According to Bandura, self-efficacy interrelates with motivation, and with a general sense of well-being.

Bandura (1992) defines personal agency as to the extent a person believes his/her ability to control or manage how they function on a cognitive, emotional, and behavioural level. Personal agency expands on how much the person believes can influence or affect external events.

Wisner et al. (2000) examine the process of decision-making in relation to medication during pregnancy. Deciding whether to receive medication or not while pregnant is believed to be a highly stressful situation for all parties involved. They reviewed the process of deciding on medication during pregnancy as one where the individual took on an active role. It is a process where all critical aspects of the risk-benefit argument need to be discussed. The model they propose offers a framework, which helps the individual cope with their anxiety better by making an informed and conscious decision of what is the best course of action. The decision is based on weighing the pros and cons of a potential action and deciding on the one that is in the best interest of the individual based on priorities. This, in turn, enhances the person's sense of control.

Felder et al. (2016) studied the prevention of relapse of depression for perinatal women. They researched a Mindfulness based cognitive approach with the use of the Web. Most participants reported using the system very beneficial. Some of the benefits that the participants experienced were: better prepared to act when they identified early warning signs of depression, an increase sense of control, better awareness of one's cognitions and emotions, treating thoughts as cognitive phenomena and not absolute truths, to come to terms with hard feelings, and improved relationships with loved ones.

Mindfulness is synonym to awareness but not necessarily to judgment (Kumar, 2009). Someone can be mindful of their own internal processes such as thoughts, feelings, physical sensations but not 
necessarily make a judgment about them (Baer, 2003). The idea here is that the person can acknowledge something as it is rather than as what it should be. It then becomes easier for the person to accept it rather than try to change it. This process underlines a form of emotional detachment from thoughts or feelings. The person becomes the observer rather than the actor in that movie script.

There have been many studies that show mindfulness to have a positive effect on the reduction of ruminative thoughts (Deyo, 2006; Didonna, 2009; Shapiro et al., 2008). Mindfulness can help the individual become aware of his thought processes, their content and provide him with ways of how to release them. Mindfulness is not just a theory; it is a way of life for many people. It provides a wealth of practical ways to the individual, whether therapist or client, to learn how to eliminate ruminative thoughts.

There are three main ways of treating rumination and these are: desensitisation, distraction, and mindfulness with the latest one to be considered the most effective (Leahy, 2010). Mindfulness has its roots in Buddhist practice, and it is a form of meditation. In psychology, it is under the spectrum of Cognitive Behavioural School and more specifically Acceptance and Commitment Therapy (ACT) (Flaxman et al., 2010; McCracken \& Vowles, 2014).

Of course, mindfulness is not a panacea, not a solution to every psychological issue or mental disorder. It has limitations. For example, it will not help the person resolve the underlying issue (Beck Institute for Cognitive Behaviour Therapy, 2013). It functions more like an instant relief from the intensity the person might experience when he has repetitive negative thoughts (Beck Institute for Cognitive Behaviour Therapy, 2013). It will rather help the individual clear his mind from unhelpful thoughts or mental jargon which, in turn, will act as a steppingstone for the individual to adopt a more constructive way of thinking.

In summary, CBT is a well-researched therapeutic approach, which is effective for anxiety and depression, and thus, for PND. It highlights the connection between thoughts, feelings, and behaviours. 
CBT identifies and challenges negative and dysfunctional thoughts and beliefs of the individual and promotes new and more functional thoughts and adoptive behaviours. CBT is flexible but also specific as it is goal orientated. It helps the individual to focus on their current life circumstances, which, in turn, enables them to take control and be actively involved in the therapeutic process.

\section{Virtual reality as a therapeutic tool in the psychological treatments field}

Virtual reality (VR) is defined as a computer based, 3-dimensional immersive environment, where its users can interact with the virtual world (Brey, 2008; Mandal, 2013). VR has evolved over the years starting in 1960 with the creation of a simulator called "Sensorama", followed by other projects such as "The Ultimate Display" in 1965 (Mazuryk \& Gervautz, 1996). However, as technology advances in later years, the focus on VR intensifies with research on many disciplines, from architecture to entertainment.

VR has examined a plethora of topics in mental health such as training and education, addictions, anxiety, phobias, and PTSD (Srivastava et al., 2014). According to Krijn (2005) VR has been tested on not just anxiety, but also on pain control, palliative care, addictions, eating disorders and rehabilitation.

VR has been used as a therapy alone, or in a combination with other therapies. VR has been tested in multitude ways, varying from an exposure therapy for anxiety disorders and phobias (Eichenberg \& Wolters, 2012), to a distraction for pain (Wiederhold et al., 2014), or as a way for the individual to enter a meditative stage (Navarro-Haro et al., 2017). VR allows clinical flexibility such as which stimuli to use and in what specific sequence, and it is a cost-effective treatment (Maples-Keller et al., 2017).

Hoffman et al. (2001) examined whether VR could act as a form of distraction for coping with pain, more in particular with dental pain. Although the limitation of the size of the sample was evident in this study with only two subjects, they found that VR could be used as a distraction method. In addition, 
they found that it was the most effective form against dental pain amongst other forms of distraction such as watching a movie or with no intervention at all. According to the authors VR can attract the most attention of the user, possibly due to the user's active engagement with it.

Similarly, Gershon et al. (2003) also investigated whether VR could be a form of distraction for coping with pain caused by cancer. They compared VR distraction using head-mounted display, with non-VR distraction. They measured heart rate, signs of distress, self-reported anxiety and pain levels. They found that VR intervention was more effective than non-VR intervention. Of course, their findings were encouraging but limited in terms of generalization due to this being a case study.

Hoffman et al. (2001) examined the effectiveness of VR as a form of distraction with multiple treatments. They compared it with other forms of distraction such as video games. They found that VR has better outcomes than other forms in terms of pain intensity and time spent by the individual thinking about pain, as it can distract the patient's attention by engaging more physical senses. A very important sense is of the vision. By simply minimising the patient's visual perception of stimuli which are associated with pain from burning by using the VR headset.

Another way for coping with pain is when the VR has shown to help the person enter a meditative stage in the treatment for chronic pain (TransformingPainTV, 2010). There have been many studies which show VR to be an effective way of managing chronic pain effectively (Benzon et al., 2014; TransformingPainTV, 2010; Toth \& Moulin, 2013).

When treating patients with the fear of flying, Botella et al. (2004) found that VR can help the person tackle not only the anticipatory anxiety they would experience before the flight, but also deal with dysfunctional thoughts which contained catastrophic elements.

VR has been tested extensively as an exposure therapy as it implements different exposure techniques. Choi et al. (2001) talk about some of the advantages of virtual reality exposure therapy (VRET) over in vivo and imaginary exposure therapies. They found that VR can be effective in treating 
acrophobia as a disorder. Opris et al. (2012) highlight that VRET is the preferred therapeutic approach for the fear of flying. In addition to that, VR has the capacity to help the individual recall traumatic memories.

Meyebroker and Emmelkamp (2010) found that VRET has shown to be effective with post-traumatic stress disorder (PTSD), but with some limitations. In general, it is difficult to reconstruct a traumatic experience in a virtual environment as such, possibly due to the detail of each individual experience and the constrains of technology. The authors suggest though that future direction of research on VRET should aim to investigate not just the treatment outcome but also the therapeutic process itself.

Difede and Hoffman (2002) investigated VRET and how effective it can be specifically in relation to the 9/11 attacks on World Trade Centre in New York. They found that VRET had a significant impact on severe range of the symptoms of PTSD (acute symptomatology). There was a significant reduction of PTSD symptoms (Baños et al., 2009, 2011). Difede and Hoffman (2002) also highlight that VRET can help the person associate memories of the traumatic event with painful feelings and emotions. VRET can help people who have a difficulty to recall or imagine certain traumatic memories and situations.

North and North (1997) and North et al. (1997) in the first ever pilot study for treating flying disorder found some of the advantages of VR, such as being cost-effective, can save the person from public embarrassment, and ensured confidentiality. In addition, VR has a great sense of control over phobic stimuli in terms of the clinical protocol.

Klein (2000) reports on a case study on the fear of flying combining anxiety management techniques and VRET. He found that the anxiety management techniques, such as thought stopping and relaxation techniques were effective in terms of fear of flying and avoidance. Similarly, Botella et al. (2004) report on the efficacy of VRET and psychoeducation on the fear of flying. In Klein's study, the VRET was done by graded exposure and was found that the same measures of fear of flying and avoidance were further reduced. Nevertheless, it is not known through this study about long-term effects. Another weak 
point is the generability of the findings due to the nature of the study, e.g., case study.

Powers and Emmelkamp (2007) compared VRET with in vivo exposure. They suggest that VRET is promising on disorders such as anxiety with panic, social phobia, fear of spiders, and fear of heights. They also say that VRET is better than in vivo exposure in terms of two variables: control, and safety of the user. In other words, the safer and in control the user feels, the more beneficial he/she will find the virtual environment. Dixon and Regenbrecht (2005) also found that VR can be effective for psychological disorders such as anxiety, phobias, and fears.

Botella et al. (2004) refer to another advantage of VR. They developed a virtual environment to treat panic disorder and agoraphobia. This specific system can expose the individual to an external phobic stimulus which represents a traumatic experience and trigger bodily reactions that have been associated with the traumatic experience itself. The more physical senses are stimulated, e.g., visual, auditory, etc., associated with the external stressful situation, the higher levels or anxiety will be achieved, but also a sense of presence. This, in turn, can create the framework for the individual to be exposed to stress/anxiety in a safe and controlled way by the therapist. This can be very helpful to people who might find in vivo exposure too difficult to cope with.

Botella et al. (2000) found that VRET was effective in relation to the treatment of claustrophobia. There were two main outcomes of their study. The first one is that VRET helped the subjects reduce their levels of fear of close spaces, whether they also tended to avoid less those spaces. The second and very important element was that the participants of the study were able to enhance their sense of selfefficacy in relation to claustrophobic situations.

VR can have the advantage of being practical and accessible to the user. People who suffer from chronic pain might also exhibit mobility issues or low motivation. VR can solve that problem by being more accessible to the user. A VR environment can offer technology with visual and auditory input that can engage the person. It can help the person visualise easier. But VR can also help the person 
become aware of different emotional states they might experience. It can help the person connect the cognitive and the physical aspects of his experience inside the virtual environment using biofeedback (TransformingPainTV, 2010).

Another advantage of VR is how a therapist can control how much the client will be exposed to certain stimuli that usually provoke the feeling of fear for the person (Regenbrecht et al., 2006). They identify two aspects. The first one is the control that the therapist has over the client's exposure to the feared stimuli. The main two ways are by flooding or in a more carefully designed way, gradual exposure which main mechanism is systematic desensitisation. The other aspect is that the client gains a better sense of control by allowing themselves to how much they will face up to the stimuli or avoid it.

North and North (1994) also confirm the relationship between VR and control over how much stimuli the patient is exposed to. They talk about the advantages of VR over in vivo exposure for the treatment of aerophobia, the fear of air travelling. According to them, VR has three main advantages, the first one is greater control of the therapist over the stimuli, whether visual or auditory, in terms of what stressors to use, in what sequence, to what degree. Another advantage is efficiency and economy as it can be delivered in the therapist's office. Garcia-Palacios et al. (2001) found that VR makes therapy more accessible to people in general, in a confidential, safe and with limited resources available.

VR has also been used as a tool which can help its user increase their sense of motivation and enhance the learning process. According to Fernandez et al. (2005) the objective is for the person to learn how to better care for themselves. More importantly, VR can help the user of such technology to make better decisions about their lifestyle, to improve their motivation and to enhance their sense of control. Similarly, interactive virtual reality role-play games for young people in educational settings have shown to have many benefits. Users of such technology can benefit by having improved concentration, better sense of self-esteem and motivation, and were able to tell stories more effectively (Robertson, 2001, as cited in Coyle, et al. 2005). 
Edmans et al. (2004) investigated the use of VR by patients who suffer neurological damage due to certain conditions, e.g. stroke. They found that VR has the advantage of helping the patient rehearse the cognitive functions necessary to complete a task. The task can underline a lost ability that the person had before the medical or neurological condition developed. By using the virtual environment, patients as such can repeat the same tasks as many times as necessary. Also, virtual environments can be designed to be used with little or no supervision at all. They can promote a sense of pleasure and accomplishment. In that way, it makes it easier and more accessible for the patient to use an environment as such. This can have a positive effect on the patient's motivation, which in turn, can engage patients using the virtual environment for longer periods of time. According to the authors, this is the fundamental basis for. Higher levels of motivation which leads to longer periods of practice a task, is the basis for neurological recovery.

Purgato and Gamberini (2005) evaluated a VR environment which aim was to address the risk associated with drug abuse for young people. The second aim was to investigate whether the VR environment could help the users develop healthy coping mechanisms. The authors developed four different scenarios, which created context/meaning. The evaluation of the virtual environments was based on the following variables: levels of presence, the number and the qualitative nature of concepts depicted in the scenarios, and the perception of how useful those concepts were. They found that the virtual scenarios had a good educational component for targeting drug abuse for young people.

Ferrer-García and Gutiérrez-Maldonado (2005) investigated the impact of VR on mood of people with eating disorders. They found that VR can invoke powerful feelings in such patients, such as anxiety and depression. More particularly, users of VR system experienced the highest levels of anxiety and depression in a virtual environment where they had to eat foods with high calories. In addition, their sense of discontent about their body image, and their tendency to compare themselves to others in a negative way, were crucial in negative mood affects to the users as the virtual environment could 
portray those.

Riva et al. (2003) investigate the experiential cognitive therapy for binge eating disorders, a short-term approach that is multi-faceted, e.g. assessment sessions, counselling on nutrition, physical activities monitoring, and psychiatric assessment with pharmacological input. It is carried on an individual basis but also within groups, also in inpatient and in outpatient units. The focus of this treatment is on binge eating but this specific approach is enriched with the VR component. Although there was not enough detail of how the VR component was applied and integrated with the other therapeutic approaches, the authors support the idea that VR is a technology that can enhance the effectiveness of cognitive therapy. They call it "cognitive technology" which focus is to influence cognitive functioning, e.g., thoughts, etc.

Krijn et al. (2004) refers to two studies which dealt with the fear of flying. VRET was employed along with other techniques such as standard exposure, breathing techniques, cognitive restructuring and thought stopping. Both studies, (Rothbaum et al., 2000; Muhlberger et al., 2001) found the combination of VRET with standard exposure and relaxation techniques helpful in the treatment of fear of flying during the treatment period, and a year after. However, they could not safely conclude whether VRET alone was effective for the treatment of acrophobia.

Riva (2005) talks about some of the advantages in research and practice that the person can enjoy using VR. One of its main features and characteristics is that it can empower the person, a very basic and essential ingredient for therapy to occur. The combination of CBT with VR therapy can have a tremendous positive impact on self-esteem, self-confidence, decision-making, and planning and resolving, and enhanced sense of control.

According to Josman et al. (2006) CBT is the main and most effective form of therapy of PTSD. It provides the individual the framework whereby they can develop different, healthier and more functional ways of thinking when are confronted with an anxiety-provoking stimulus, and it can help them recall 
past traumatic memories. In addition to this, VR can strengthen the effect of traditional imaginal exposure treatment by helping sufferers of a traumatic experience not only to recall, but also emotionally process the actual event in a safe and non-threatening environment.

Patterson et al. (2006) report that the use of VR in the form of distraction can have a positive effect on analgesia and can help the individual feel less pain. In addition, VR can be combined with post-hypnotic suggestions to reduce pain effectively. However, the advantage of the use of VR is that it is effective regardless the degree the individual can be hypnotised.

Ba,so glu et al. (2003) investigated what effect, if any, an earthquake simulator would have to people who have suffered an earthquake as part of a treatment. They found that the simulator in combination with a single session had an overall positive effect in terms of sense of control, better motivation, better compliance with the program itself, higher satisfaction ratings, and more resilience. The combined treatment of the earthquake simulator and a single session and their effect had an accumulative effect. The bigger sense of control the users had, the less fear they would experience in relation to earthquakes. Thus, they would feel more motivated to participate in treatment and would comply with the clinical protocol. As a result of all that, the users felt better prepared for future earthquakes. It is very important here to highlight the idea of building resilience that the authors investigated. The result was to help the individuals build resilience, an important factor for combating the fear of earthquakes, or in relation to other phobias.

In conclusion, VR is a therapeutic approach that has been used for the treatment of various mental health issues. It has been used as a stand-alone therapy, but also in conjunction with other therapies successfully. VR can raise motivation and empower a person. It can enhance learning and facilitate change. VR can be conducted in a safe and controlled therapeutic environment where the therapist and user can choose the parameters under which the virtual environment will be used. 


\section{Contributing factors for VR's clinical efficacy}

This part of the chapter investigates the contributing factors for the clinical efficacy of VR in detail. Table 1-1 includes a synopsis of all authors found in literature and the factors that they propose, which make VR an efficacious therapy. Factors such as presence, immersion, self-efficacy, expectations of the user, engagement, and interactivity are suggested by most of the authors.

Dumoulin et al. (2005) who investigated VR as a form of distraction for the reduction of pain found that there are other factors which influence how effective VR can be. These depend on how complicated or difficult the actual task can be, and subsequently how much attention is required for the individual to finish the task. It becomes even more effective whether there is an emotional involvement of the individual. The degree the person is accepting of VR, the level of sense of self-efficacy the person has for therapeutic change to occur (Riva et al., 2016), but also whether their expectations will be met using the VE also contribute to VR acting as an effective form of distraction.

Cote and Bouchard (2009) investigated the cognitive mechanisms that influenced the efficacy of VRET for the treatment of arachnophobia. They found two main mechanisms, the first one was the perceived self-efficacy of the individual by the individual, while the second one was about beliefs. Out of the two, self-efficacy was the most important on influencing outcome of the VR exposure therapy and to reduce the avoidance behaviours of the individual.

Herbelin (2005) in his thesis about VRET for social phobia supports the idea the VR to be effective and sufficient to create the sense of presence, which is necessary for the person to engage in the virtual environment, has to engage/use many different senses. Haptic or else the kinaesthetic communication, recreates the sense of touch through a vibration or motion (Robles-De-La-Torre, 2010). Also, the perceived ability by the user that they can influence the location, or the movement of the virtual objects is very important.

Lear (1997) talks about VR therapy and the different layers of it. According to the author, VR 's 
effectiveness is not just based on graphical images. VR includes elements of control and engages multiple senses. The effectiveness of the VR lies in the ability of each object that represents a real physical object in the real world, to resemble the actual object as close as possible. He provides the example to a virtual spider which needs to look and move as much as possible like a real spider. In addition to that, VR can add other elements such as the sense of touch. In that way, it becomes even more engaging and believable.

Villani and Riva (2008) investigate the effects of VR therapy on mood, and whether it can help the person to learn to relax. To promote relaxation, they use key images, cognitive control, breathing techniques, and muscle relaxation. The authors hypothesise in the form of expectations that VR therapy, which is immersive, can reduce stress and anxiety and promote relaxation.

Table 1 - 1. Contributing factors of VR's clinical efficacy

\begin{tabular}{|l|l|}
\hline Authors & Factors \\
\hline Dumoulin et al. & - Levels of task complexity \\
& - Levels of attention required by the user \\
& - Emotional involvement of the individual. \\
& - The degree of VR acceptance by user \\
& - Self-efficacy \\
\hline Riva et al. (2016) & - User's expectations of virtual environment \\
\hline Cote and Bouchard & - Self-efficacy \\
(2009) & - Beliefs \\
\hline Herbelin (2005) & - Sense of presence \\
\hline
\end{tabular}




\begin{tabular}{|c|c|}
\hline & $\begin{array}{l}\text { - Engage/use many different senses } \\
\text { - Self-efficacy }\end{array}$ \\
\hline Lear (1997) & $\begin{array}{l}\text { - Elements of control and engaging multiple senses } \\
\text { - The ability of each object that represents a real physical object in the } \\
\text { real world } \\
\text { - To resemble the actual object as close as possible. } \\
\text { - Sense of touch } \\
\text { - Engaging and believable }\end{array}$ \\
\hline $\begin{array}{l}\text { Villani and Riva } \\
\text { (2008) }\end{array}$ & $\begin{array}{l}\text { - Key images } \\
\text { - Cognitive control } \\
\text { - Breathing techniques } \\
\text { - Muscle relaxation } \\
\text { - Form of expectations that VR therapy is immersive }\end{array}$ \\
\hline $\begin{array}{l}\text { Emmelkamp et al. } \\
(2001)\end{array}$ & $\begin{array}{l}\text { - Immersion } \\
\text { - Visual components such as computer graphics in real time, sensory input, } \\
\text { body-tracking devices } \\
\text { - Real-life phobic situations in a safe and secure environment away from } \\
\text { expectations, and social pressure }\end{array}$ \\
\hline Botella et al. (2004) & $\begin{array}{l}\text { - Multiple sensorial modalities } \\
\text { - Immersive } \\
\text { - Interactive } \\
\text { - Imaginative }\end{array}$ \\
\hline Schubert et al. (2001) & $\begin{array}{l}\text { - Immersion } \\
\text { - Presence }\end{array}$ \\
\hline
\end{tabular}




\begin{tabular}{|c|c|}
\hline $\begin{array}{l}\text { Regenbrecht et al. } \\
(1998)\end{array}$ & $\begin{array}{l}\text { - Presence - egocentric point } \\
\text { - Immersion - Virtual cues perceived by a fully immersive head-mounted } \\
\text { display, or through a screen using shutter glasses experience }\end{array}$ \\
\hline Riva et al. (2004) & $\begin{array}{l}\text { - Elements of visual representations and graphics } \\
\text { - Sense of presence } \\
\text { - Sense of flow for the user } \\
\text { - Sense of empowerment. } \\
\text { - Optimal experience - high levels of concentration on a task. }\end{array}$ \\
\hline $\begin{array}{l}\text { Bouchard et al. } \\
(2008)\end{array}$ & $\begin{array}{l}\text { - Presence } \\
\text { - Immersive VR environment }\end{array}$ \\
\hline $\begin{array}{l}\text { Sabourin and } \\
\text { Bouchard (2004) }\end{array}$ & $\begin{array}{l}\text { - Sense of presence } \\
\text { - Quality of the interface - a technological aspect of the virtual environment } \\
\text { - Physical senses } \\
\text { - Interaction between the user and the environment - ability to manipulate } \\
\text { data and change the virtual environment itself }\end{array}$ \\
\hline Robillard et al. (2003) & $\begin{array}{l}\text { - Sense of presence } \\
\text { - Levels of immersion }\end{array}$ \\
\hline Klinger et al. (2005) & - Sense of presence \\
\hline Herbelin et al. (2002) & $\begin{array}{l}\text { - Technical details such as realistic images } \\
\text { - Collaboration between therapist and technologist to produce a suitable } \\
\text { virtual environment for phobias. }\end{array}$ \\
\hline Hodges et al. (2001) & $\begin{array}{l}\text { - Activation of the fear } \\
\text { - Recovery }\end{array}$ \\
\hline
\end{tabular}




\begin{tabular}{|c|c|}
\hline Riva et al. (2001) & $\begin{array}{l}\text { - Concept of image } \\
\text { - VR as an "advanced imaginal system" can bring closer imagination and } \\
\text { reality, or else digital reality and "conventional reality. }\end{array}$ \\
\hline Riva (2000) & $\begin{array}{l}\text { - Functionality } \\
\text { - Interactivity } \\
\text { - Presence } \\
\text { - Sense of freedom for the user. } \\
\text { - Context of the environment where the user can make decisions within it. }\end{array}$ \\
\hline Rizzo et al. (2003) & $\begin{array}{l}\text { - Therapists' experience in VR applications } \\
\text { - VR scenarios that might not be produced in the real world } \\
\text { - New skills to be transferred to real-life situation } \\
\text { - Sense of motivation } \\
\text { - Choice or loss of choice } \\
\text { - Match between the purpose and design of VR with the needs of the user }\end{array}$ \\
\hline
\end{tabular}

Emmelkamp et al. (2001) describe the components that are used in a virtual environment, whose purpose is to immerse the user in it. To achieve that, the components that are used are visual such as computer graphics in real time, sensory input, body-tracking devices. VR has the advantage of the user avoiding real-life phobic situations but instead this can be done in a safe and secure environment away from expectations, and social pressure. In that way, it can be cost-effective as well, saving on resources as time and money.

Burdea's (1993) definition of VR talks about multiple sensorial modalities (as cited in Botella et al., 2004). According to that definition, VR is characterised by being immersive or else the user having the sense of being in a digital environment. The second main element is that VR environment needs to be 
interactive, where the user can intervene and change the actual environment, in real time. The third and equally important element is that VR is imaginative, in the sense that it tackles real life problems in different areas of science and the knowledge that the user gains while using it, can be transferred to real life situations or solve real life problems.

Schubert et al. (2001) distinguish immersion and presence. They treat presence as a "psychological phenomenon". The difference between immersion and presence is that immersion refers to the ability of the virtual environment to create the sense that what the person experiences in the virtual environment is real. On the contrary, presence refers to the user of the virtual environment and is defined as the sense of being inside the virtual environment. It can be concluded from the above that presence and immersion are inter-related in some way.

Regenbrecht et al. (1998) gives a model of presence. The starting point is the body of the user, which they call egocentric. The virtual cues, whether they are perceived by a fully immersive head-mounted display, or through a screen using shutter glasses experience, are perceived and they become part of the space of the user. According to the authors presence occurs in the common space that the body of the user, and the visual stimuli co-inhabit.

Riva et al. (2004) talk about the successful use of VR environments. According to the authors' study, the success of the VR consists of elements of not just visual representations and graphics, but also the sense of presence of the user within the environment. According to the authors, deep levels of presence within a virtual environment can trigger a sense of flow for the user, which in turn, can enhance a sense of empowerment. This mechanism can be very dynamic and can help the individual have an optimal experience, such as high levels of concentration on a task.

Bouchard et al. (2008) investigate the notion of presence and anxiety. They wanted to find out whether presence could lead to anxiety for people who had developed phobias. They found that there is not only a correlation between the sense of presence and the levels of anxiety in an immersive VR environment 
which contains phobic stimuli such as snakes. The authors concluded that anxiety could raise the sense of presence in virtual environments.

Sabourin and Bouchard (2004) highlight three elements that are crucial to someone experiencing a sense of presence while within a virtual environment. The first element is the "quality of the interface" which highlights the technological aspect of the virtual environment. The sense of presence also depends on how many physical senses the person utilises while is using the VE, which is the second characteristic. Finally, interaction between the user and the environment, or else the ability to manipulate data and change the virtual environment itself, is the third element and it is of paramount importance.

Robillard et al. (2003) identify a correlation between the sense of presence and feelings of anxiety within a VR experience and levels of immersion. They found that the use of VR can arouse anxiety to people with phobias through exposure to stressful stimuli. In that way, VR can be used as a treatment for phobias.

Klinger et al. (2005) found a two-way relationship between anxiety and presence, where the two can affect each other in a cyclical way. According to this study, the sense of presence can trigger anxiety, which can also enhance the sense of presence. This interaction and relationship between anxiety and presence can be achieved or triggered by VR, e.g., avatars, which do not necessarily represent visually real humans in a perfect way, as it is not a necessary condition.

Another study about VR and whether it can invoke anxiety for its users was confirmed by Herbelin et al. (2002). It was not clear though what elements of the virtual environment would contribute to the best therapeutic outcome for the Social Anxiety Disorder, whether some technical details such as realistic images, high visual quality, or the inclusion of relevant stimuli. The authors do suggest though that close collaboration between the therapist and the technologist is necessary to produce a suitable virtual environment for phobias. 
Hodges et al. (2001) talk about the theory of emotional processing where fears are codes of memories which contain information about relevant stimuli to the fear. Those stimuli include triggers of fear, or causes of fear, reactions or responses of the individual to the fears, and personal meanings or else interpretations. According to the authors, therapy to be effective for treating anxiety needs to satisfy two requirements, the activation of the fear itself, and recovery from it. VR satisfies both conditions adequately.

Riva et al. (2001) talk about the concept of image and how central it has been in therapy used by different schools of thought throughout time. From the psychoanalytic concept of image, as the way to access the unconscious, to Lazarus' technique of projection in time, to the cognitive element of decatastrophizing of the image technique, to the image modelling and substitution. Pictures and images relate to imagination and images are of central importance to therapy. According to neurophysiology, both imagination and perception are in the same cortex of the brain, which shows a close relation between them. The authors treat VR as a sophisticated visual system, where VR can bring closer imagination and reality, or else digital reality and ordinary reality.

Riva (2000) talks about functionality, interactivity, presence, and sense of freedom for the user. According to the author, there are some conditions that need to be met for a VR system to be effective. VR goes beyond graphics and impressive visual representations of the real world. Its essence is in the context and how it is adopted to the needs of the user. VR underlines interaction between the user and the virtual environment. The user needs to have the sense that they can manipulate the environment, that they can change it. Also, it is not just about the task itself. It is about the context of the environment where the user can make decisions within it. Interactivity deepens the sense of presence. Another condition, which is very important, is the sense of freedom. The user needs to be able to interact with the environment, thus, to have a s sense of freedom in their movements, how they make decisions, what decisions they make and how to go about them to execute them. It is more than just the task itself. 
Rizzo et al. (2003) strongly suggest that the therapists who employ VR should be experienced in the VR applications. VR therapy should be viewed and used as a means to an end, in other words, VR should never substitute classical therapies. Its use should aim to enhance the effect of traditional therapies. One of the advantages of VR is that it can produce scenarios that might not be produced in the real world. This is based on the principle of neuroplasticity that the human brain can adopt to new realities, meaning that it can learn new skills, and which in turn can be transferred to a real-life situation.

At the same time, the same authors note that this exact principle can have the opposite effect on the person's sense of motivation, where they will find it more difficult to transfer the newly acquired knowledge to the real world. The therapist can expose the client to possibilities that are not accessible otherwise, to focus on specific elements under complete control of the therapist. From a technical point of view, choice or loss of choice are of paramount importance. The purpose of the virtual environment, its design, and the needs of the user of such technology will ideally fit. As a word of caution, a VR technology needs to be carefully designed, produced, tested, and evaluated in order to reach safe and valid conclusions based on scientific evidence.

So far, no studies have been found in which VR is used as a therapeutic element for the treatment of PND. Therefore, this possibility is worth taking into consideration. This is precisely the objective of this thesis, to examine whether VR, in combination with traditional therapies for PND, can enhance the therapeutic effect of those therapies. This thesis investigates the outcome of such a combination in a clinical setting and for an important clinical matter. It explores parameters that make such a combination, that of VR with traditional therapies such as CBT, possible and identifies what makes such a combination efficacious. For this purpose, a VR programme with certain technological characteristics which are explained below, has been employed to facilitate the investigation process of combining traditional and technological therapies. 


\section{VR programme}

The VR programme used for the pilot feasibility study and the clinical trial of this dissertation was built by Mohammed Alghamdi, a PhD student in the Information Science department at the University of Otago in New Zealand (Alghamdi, 2017). Its original purpose was to be used as a training tool for young parents to build resilience for coping with stress better by using VR. The system had been tested and evaluated throughout its development stages, and the results have been published in literature (Alghamdi et al., 2016; Alghamdi, et al., 2017; Alghamdi, et al., in preparation; Regenbrecht, et al., 2015).

The VR system was chosen for its technical flexible application, and its promising clinical use. On a technical level, the programme consists of multiple stressors. They can be activated by the facilitator, either individually and/or simultaneously. The volume of each stressor and the duration of each stressor being activated can be adjusted. The facilitator can have an adequate overview of each stressor visually on their computer screen, which makes it easy to use and can control each stressor adequately. It can be done in a controlled and safe environment.

On a clinical level, the system's design, and purpose to teach young parents how to manage stress better was considered relevant, as parents often experience stressful situations. A study by Saxbe and Repetti (2010) showed that a cluttered house was associated with increased cortisol or increased levels of anxiety. The virtual environment is a typical middle-class household, with stressors such as untidy rooms and misplaced items. This can be considered a familiar household and family situation to some people. In other words, clutter can trigger anxiety, or other negative feelings such as guilt, or it can even affect our cognitive processes such as the inability to focus (Carter, 2012).

The connection between stress and depression is well established. Bruno (2011) explains that on a biological level, stress leads to increased release of the cortisol which is the stress hormone. Increased use of cortisol decreases the release of neurotransmitters such as dopamine and serotonin which is 
associated with the manifestation of depression. Chronic stress and the inability to cope with it can lead to depression (Hall-Flavin, 2020; Earl, 2020).

In addition, the exposure of the users to virtual stressors, could give them the opportunity to use this to their advantage. The basic idea here was that once the user can learn how to manage stress better and learn how to cope with it in a more efficient ways, that would also have a positive effect on depression and the participants' mood. Shors (2004) explains that stress is usually perceived as an inhibitor of learning and memory. Nevertheless, being able to manage stress can enhance the process of learning as the person gains a sense of confidence.

The hypothesis here was that anxiety and depression co-exist many times (Anniverno et al., 2013). Patients who experience depressive symptoms in the post-partum period, will also experience higher levels of stress and anxiety. People with PND can be more susceptible to stress and thus, exhibit poor coping mechanisms. However, once patients learn how to manage stress better, would be able to implement different strategies and coping skills to deal with depression in a positive manner.

\section{Research questions}

From the brief literature review in the introduction of this thesis, it can be concluded that PND is an important clinical matter that affects of a fair percentage of the population. It has been formalised and recognised as one of the categories of depression in psychiatric manuals for mental health disorders. PND can affect the individual and their families with important consequences on a personal, social, and financial aspects. The individual can experience low mood, low self-esteem and confidence, anxiety and stress, and poor decision-making.

However, there are many therapeutic approaches that are used to help support the person. They vary from CBT, IPS, counselling, group support, and medication. Their focus is to help the individual 
understand what PND is, to identify dysfunctional thoughts and beliefs, and to recognise negative patterns of behaviour. The purpose is to help them change their thoughts to more positive ones, in order to improve their decision-making, to enhance a sense of control and improve a sense of selfefficacy. Ultimately, it is about helping the individual improve their life circumstances and quality of life.

Amongst those therapeutic avenues, VR is a clinical territory that has been used for the treatment of anxiety disorders and phobias, stress management, addictions, rehabilitation, and pain management. It can be used as a distraction method, visualisation, and relaxation. It can raise awareness of emotional states, improve decision making and concentration, can contribute to a better sense of self-esteem and confidence.

VR has been used as a therapeutic approach alone or in conjunction with other therapies. It can be conveniently delivered in a professional's office and can be cost-effective. VR provides an immersive environment with high quality visual and auditory input. Its purpose is to help the individual immerse themselves in the virtual environment.

In the quest for improving current treatments, or finding new ones for PND, it is worthwhile to consider whether VR could be used as a therapeutic avenue for the treatment of PND. Consequently, this thesis addressed the following research questions:

1. What CBT psychological treatments are effective for PND? As CBT is the most well-researched therapy used for PND, we wanted to explore and identify what kind of CBT components were used for PND treatment. We wanted to investigate which components are most used in these CBT-based treatment programs for PND.

2. Has VR been used for the treatment of PND previously? We also wanted to find out whether VR had been used for the treatment for PND. 
3. Is it feasible implementing VR in combination with CBT for the treatment of PND? We wanted to find out whether it was feasible to combine these two therapeutic approaches in a clinical setting.

4. What were the levels of acceptance of the combination of VR with CBT for the treatment of PND? In other words, we wanted to find out if technology and the use of it would be well accepted by the participants. We wanted to identify parameters such as likeness, comfortableness.

5. Is the combination of CBT with a VR component specifically designed for the treatment of PND effective? We wanted to find out whether the combination of CBT and VR had any effect on the treatment of PND.

6. What were methodological problems, flaws, technical difficulties, and/or limitations on the protocols and research tools? We wanted to find out if there were any limitations or problems on a methodological and technical levels.

7. What could be recommended for the better implementation of VR within a traditional clinical setting? We wanted to identify parameters that could improve the processes such as the clinical protocols, but also the therapeutic process for the better implementation of VR technology with CBT treatment.

\section{Objectives}

There were five objectives that this $\mathrm{PhD}$ thesis met:

The first objective was to find out what treatments were the most effective and frequent used for the treatment of PND, while the second objective was to identify what CBT components were used most frequently for the treatment of PND. This was about identifying and defining the parameters of successful clinical outcomes that were found in international literature. The third objective was to 
identify whether VR had ever been used for the treatment of PND. For these reasons, a literature review was conducted where the best and most well-researched treatments for PND were identified, with an emphasis on CBT. The main purpose was to find out what CBT components used most frequently for the treatment of PND successfully.

The fourth objective was to investigate whether VR could be combined with a traditional therapy and implemented in a clinical setting. For this reason, a pilot study was conducted to determine the levels of acceptance and feasibility of such combination. It was important to find out whether there were any difficulties or limitations on various levels of the process regarding the clinical protocol, assessment, or technical difficulties. The definition of parameters that made the clinical combination of traditional therapies with VR technology possible, but also the parameters that possibly hindered that process were considered.

To further investigate the levels of feasibility and acceptance, a clinical trial was conducted where issues regarding the referral process, confidentiality, adequacy of the number of sessions provided, adequacy of time and information provided to amongst other things were considered. The participants' views on the VR technology on whether they felt comfortable, whether they liked the technology, and whether they found it easy to use were identified, along with any technical difficulties.

The fifth objective of this thesis was to explore the efficacy of the combination of CBT with VR for the treatment of PND in the clinical trial. It was important to identify if the combination of a traditional therapeutic approach such as CBT with technology such as VR could be efficacious. In other words, what parameters contributed to the efficacy of CBT with VR on the treatment of PND were identified. 


\section{Outline of the thesis}

This doctoral dissertation is made up of a collection of publications in the form of chapters of the thesis (see Table 1-2 below). Chapter 2 provides the results of a literature review in a narrative form. It includes data about effective therapies for post-natal depression, but also potential therapies. Chapter 3 provides the results of a pilot feasibility study about the possible combination of cognitive-behavioural therapy and virtual reality. Chapter 4 provides the results of a clinical trial combining cognitivebehavioural therapy and virtual reality. Lastly, Chapter 5 provides the reader with a general discussion based on the key findings from the previous chapters, examines critically the strengths and limitations of this thesis, and it provides recommendations for future research. 


\section{Table 1-2. Doctoral dissertation as a collection of publications}

Chapter

2

3

4

\section{Article}

Stamou, G., García-Palacios, A. \& Botella, C. (2018). Cognitive-Behavioural therapy and interpersonal psychotherapy for the treatment of post-natal depression: a narrative review. BMC Psycho/6, 28. https://doi.org/10.1186/s40359-018-0240-5

Stamou, G., García-Palacios, A. \& Botella, C. (2019). The combination of cognitivebehavioural therapy with virtual reality for the treatment of post-natal depression. OZCHI'19: Proceedings of the 31st Australian Conference on Human-ComputerInteraction. Pages 599-603. https://doi.org/10.1145/3369457.3369541

Stamou, G., Garcia-Palacios, A., Woodford, B. J., Suso-Ribera, C., \& Botella, C. (2021). The combination of cognitive-behavioural therapy with virtual reality for the treatment of post-natal depression in a brief intervention context: A single-case studies trial. Journal of Healthcare Engineering. https://doi.org/10.1155/2021/5514770 


\section{References}

-Alghamdi, M., Regenbrecht, H., Hoermann, S., Langlotz, T., \& Aldridge, C. (2016). Social Presence and Mode of Videocommunication in a Collaborative Virtual Environment. In Proceedings of the $20^{\text {th }}$ Pacific Asia Conference on Information Systems (PACIS 2016, June 27 - July 1). Chiayi, Taiwan.

-Alghamdi, M., Regenbrecht, H., Hoermann, S., and Swain, N. (2017). Mild Stress Stimuli built into a Non-Immersive Virtual Environment can elicit actual Stress Responses. Behaviour \& Information Technology. London, UK: Taylor \& Francis.

-Alghamdi, M., Regenbrecht, H., and Swain, N. (in preparation). Perceived Benefits and Costs of Using VR for Parental Stress Resilience Training. To be submitted to Cyberpsychology, Behavior, and Social Networking.

-Ali, N. S., Ali, B. S., \& Azam, I. S. (2009). Post-partum anxiety and depression in peri-urban communities of Karachi, Pakistan: a quasi-experimental study. BMC Public Health BMC series open, 9:384. https://doi.org/10.1186/1471-2458-9-384

-Anniverno, R., Bramante, A., Mencacci, C., \& Durbano, F. (2013). Anxiety disorders in pregnancy and the post-partum period. In F. Durbanon. New Insights into Anxiety Disorders. Open access peerreviewed chapter. https://doi.org/10.5772/52786

-Astbury, J., Brown, S., Lumley, J., \& Small, R. (1994). Birth events, birth experiences and social differences in postnatal depression. Australian Journal of Public Health, Vol 18, Issue 2, pages 176184. https://doi.org/10.1111/j.1753-6405.1994.tb00222.x

-Austin, M. P., Frilingos, M., Lumley, J., Hadzi-Pavlovic, D., Roncolato, W., Acland, S., Saint, K., Segal, N., \& Parker, G. (2008). Brief antenatal cognitive behaviour therapy group intervention for the prevention of postnatal depression and anxiety: A randomised controlled trial. Journal of Affective Disorders, Vol. 105, Issues 1-3, Pages 35-44. 
-Baer, R. A. (2003). Mindfulness training as a clinical intervention: A conceptual and empirical review. Clinical Psychology: Science and Practice, 10, 125-143. https://doi.org/10.1093/clipsy.bpg015

-Bandura, A. (1992). On rectifying the comparative anatomy of perceived control: Comments on "Cognates of personal control". Applied \& Preventive Psychology, 1:121-126. Cambridge University Press.

-Bandura, A. (1997). Self-efficacy in changing societies. Cambridge University Press. Psychology. -Baños, R. M., Botella, C., Guillen, V., García-Palacios, A., Quero, S., Bretón, J. M., y Alcañiz. M. (2009). An adaptive display to treat stress-related disorders: The EMMA's world. British Journal of Guidance \& Counselling, 37(3), 347-356. https://doi.org/10.1080/03069880902957064 -Baños, R. M., Guillen, V., Quero, S., García-Palacios, A., Alcañiz, M., y Botella, C. (2011). A virtual reality system for the treatment of stress-related disorders: A preliminary analysis of efficacy compared to a standard cognitive behavior. International Journal of Human-Computer Studies, 69(9), 602-613. https://doi.org/10.1016/j.ijhcs.2011.06.002

-Ba, so־glu, M., Livanou, M., \& Salcıo glu, E. (2003). A single session with an earthquake simulator for traumatic stress in earthquake survivors. Am J Psychiatry, 160:788-790.

-Beard, J. L., Hendricks, M. K., Perez, E. M., Murray-Kolb, L. E., Berg, A., Vernon-Feagans, L., Irlam, J., Issacs, W., Sive, A, \& Tomlinson, M. (2005). Maternal iron deficiency anaemia affects postpartum emotions and cognition 1, Journal of Nutrition, 135:267-272.

-Beck, C. T. (2001) "Predictors of postpartum depression: An update". Nursing Research (NR) 50 (5): 275-285.

PMID 11570712. https://journals.Iww.com/nursingresearchonline/Abstract/2001/09000/Predictors_of_Postpartum_Depre ssion_An_Update.4.aspx.

-Beck Institute for Cognitive Behaviour Therapy (2013, November 28). Mindfulness techniques involving focus. Beck Institute Workshop. You Tube video. 
https://www.youtube.com/watch?v=zt1jjnmkrOE

-Beck Institute for Cognitive Behaviour Therapy (2013, November 21). The utility of mindfulness-based CBT techniques. Beck Institute Workshop. You Tube video. https://www.youtube.com/watch?v=IHUkG_Btlw4

-Bell, A. C., \& D'Zurilla, T. J. (2009). Problem-solving therapy for depression: A meta-analysis. Clinical Psychology Review, Volume 29, Issue 4, Pages 348-353.

-Belluck, P. (2016). Panel Calls for Depression Screenings During and After Pregnancy. The New York Times. http://www.nytimes.com/2016/01/27/health/post-partum-depression-test-epds-screeningguidelines.html?rref=collection\%2Ftimestopic\%2FPreventive\%20Services\%20Task\%20Force\&action=c lick\&contentCollection=timestopics\&region=stream\&module=stream_unit\&version=latest\&contentPlace ment=1 \&pgtype=collection.

-Benzon, H., Rathmell, P. J., Wu, L. C., Turk, C. D., Argoff, E. C., \& Hurley, W. R. (2014). Practical Management of Pain, Fifth Edition. Mosby of Elsevier Inc.

-Biaggi, A., Conroy, S., Pawlby, S., \& Pariante, C. M. (2016). Identifying the women at risk of antenatal anxiety and depression: A systematic review. Journal of Affective Disorders. Volume 191, pg. 62-77. https://doi.org/10.1016/j.jad.2015.11.014

-Botella, C., Banos, R. M., Villa, H., Perpina, C., \& Garcia-Palacios, A. (2000). Virtual reality in the treatment of claustrophobic fear: a controlled, multiple-baseline design. Behavior Therapy, 31, 583 595.

-Botella, C., Osma, J., Garcia-Palacios, A., Quero, S., \& Baños, R. M. (2004). Treatment of flying phobia using virtual reality: Data from a 1-year follow-up using a multiple baseline design. Clinical Psychology and Psychotherapy, 11(5), 311-323. https://doi.org/10.1002/cpp.404 
-Botella, C., Quero, S., Banos, R. M., Perpina, C., Garcia-Palacios, A., \& Riva, G. (2004). Virtual Reality and Psychotherapy. Cybertherapy Internet and Virtual Reality as Assessment and Rehabilitation Tools for Clinical Psychology and Neuroscience. Stud. Health Technol. Inform, 99, 37-54.

-Botella, C., Villa, H., Garcia-Palacios, A., Banos, R. M., Peprina, C., \& Alcaniz, M. (2004). Treatment of panic disorder and agoraphobia. CyberPsychology \& Behavior, Volume 7, Number 5.

-Bouchard, S., St-Jacques, J., Robillard, G., \& Renaud, P. (2008). Anxiety increases the feeling of presence in virtual reality. Presence: Virtual and Augmented Reality, Vol 17, Issue 4, p.376-391. https://doi.org/10.1162/pres.17.4.376

-Brey, P. (2008). Virtual reality and computer simulation. Chapter 15 in: The Handbook of Information and Computer Ethics, Edited by Kenneth Einar Himma and Herman T. Tavani. John Wiley \& Sons, Inc.

-Brugha, T. S., Wheatley, S., Taub, N. A., Culverwell, A., Friedman, T., Kirwan, P., Jones, D. R., \& Shapiro, D. A. (2000). Pragmatic randomized trial of antenatal intervention to prevent post-natal depression by reducing psychosocial risk factors. Psychological Medicine, Vol 30: Issue 06, pp 12731281. https://doi.org/dx.doi.org/

-Bruno, K. (2011). Stress and Depression. Can stress cause depression? https://www.webmd.com/depression/features/stress-depression\#1.

-Carter, S. B. (2012). Why Mess Causes Stress: 8 Reasons, 8 Remedies. The mental cost of clutter. Psychology Today. https://www.psychologytoday.com/us/blog/high-octane-women/201203/why-messcauses-stress-8-reasons-8-remedies.

-Choi, H. Y., Jang, P. D., Ku, H. J., Shin, B. M., \& Kim, I. S. (2001). Short-term treatment of acrophobia with virtual reality therapy (VRT): a case report. CyberPsychology \& Behavior, Volume 4, Number 3. Mary Ann Liebert, Inc.

-Cote, S., \& Bouchard, S. (2009). Cognitive mechanisms underlying virtual reality exposure. 
CyberPsychol Behav, Apr; 12(2): 121-9. https://doi.org/10.1089/cpb.2008.0008

-Coyle, D., Matthews, M., Sharry, J., Nisbet, A., \& Doherty, G. Personal Investigator A Therapeutic 3D Game for Adolescent Psychotherapy, (2005). Interactive Technology and Smart Education, https://doi.org/10.1108/17415650580000034

-Daley, A., Jolly, K., \& MacArthur, C. (2009). The effectiveness of exercise in the management of postnatal depression: systematic review and meta-analysis. Family Practice, 26 (2): 154-162. https://doi.org/ 10.1093/fampra/cmn101

-Deyo, M. (2006). Mindfulness and rumination: Does mindfulness training lead to reductions in the ruminative thinking associated with Depression? Pacific Graduate School of Psychology.

-Diagnostic and Statistical Manual of Mental Disorders fifth edition. (2013). American Psychiatric Association. Library of Congress Cataloguing-in-Publication Data.

-Didonna, F. (2009). Clinical handbook of mindfulness. Springer Science \& Business Media, LLC. https://doi.org/10.1007/978-0-387-09593-6

-Difede, J., \& Hoffman, G. H. (2002). Virtual Reality Exposure Therapy for World Trade Center PostTraumatic Stress Disorder: a case report. CyberPsychology \& Behavior, Volume 5, Number 6. Mary Ann Liebert, Inc.

-Dixon, B.G., \& Regenbrecht, H. (2005). Cybertherapy at Otago: Virtual Possibilities and Current Realities. Presentation at NZ PsS Conference, University of Otago, September 2005.

-Dobson, S. K. (2010). Handbook of Cognitive-behavioral therapies. Third edition. The Guildford Press.

-Donovan, W. L., \& Leavitt, L. A. (1990). Maternal Self-efficacy: Illusory Control and its effect on Susceptibility to learned helplessness, Child Development, 61 (5): 1638-1647.

-Dumoulin, S., Bouchard, S., \& Rivard, V. (2005). Potential mechanisms underlying the efficacy of 
virtual reality to reduce acute pain: a literature review. Cyberpsychology \& Behavior. Vol 8 (4): 314-315.

-Earl, T. (2020). Stress. Health Navigator New Zealand. https://www.healthnavigator.org.nz/health-az/s/stress/.

-Edmans, J. A., Gladman, J., Walker, M., Sunderland, A., Porter, A., \& Stanton, F. D. (2004). Mixed reality environments in stroke rehabilitation: development as rehabilitation tools. Proc. $5^{\text {th }}$ Intl. Conf. Disability, Virtual Reality \& Assoc. Tech. Oxford, UK.

-Eichenberg, C., \& Wolters, C. (2012). Virtual Realities in the Treatment of Mental Disorders: A Review of the Current State of Research. Dimensions. Virtual Reality in Psychological, Medical and Pedagogical Applications. https://doi.org/10.5772/50094

-Emmelkamp, G. M. P., Bruynzeel, M., Drost, L., \& Vand Der Mast, G. P. A. C. (2001). Virtual reality treatment in acrophobia: a comparison with exposure in vivo. Cyber Psychology \& Behavior, Volume 4, Number 3.

-Felder, J. N., Segal, Z., Beck, A., Sherwood, N. E., Goodman, S., Boggs, J., Lemon, E. \& Dimidjian, S. (2016). An Open Trial of Web-Based Mindfulness-Based Cognitive Therapy for Perinatal Women at Risk for Depressive Relapse, Cognitive and Behavioral Practice. https://doi.org/10.1016/j.cbpra.2016.02.002

-Fernández, N., Hoyo Barbolla, E. D., Ramirez, C., Heras, R. D. L., \& Arredondo, M. T. (2005). Motivational training tool to promote healthy lifestyles. Annual Review of CyberTherapy and Telemedicine.

-Ferrer-García, M., \& Gutiérrez-Maldonado, J. (2005). Assessment of emotional reactivity produced by exposure to virtual environments in patients with eating disorder. Department of Personality, Assessment and Psychological Treatments. Faculty of Psychology. University of Barcelona. 
-Field, T., Diego, M. A., Hernandez-Reif, M., Schanberg, S., \& Kuhn, C. (2009). Massage thera depressed pregnant women. Journal of Psychosomatic Obstetrics \& Gynecology, Vol 25, Issue 2., $20 C$ 115-122. https://doi.org/10.1080/01674820412331282231

-Flaxman, E. P., Blackledge, T. J., \& Bond, W. F. (2010). Acceptance and Commitment Therapy: Distinctive Features. Psychology.

-Garcia-Palacios, A., Hoffman, G. H., See Kwong, S., Tsai, A., \& Botella, C. (2001). Redefining Therapeutic Success with Virtual Reality Exposure Therapy. CyberPsychology \& Behavior, Volume 4, Number 3. Mary Ann Liebert, Inc.

-Gershon, J., Elanazimand, Lemos, R., Rothbaum, B., \& Hodges, L. (2003). Use of Virtual Reality as a Distractor for Painful Procedures in a Patient with Pediatric Cancer: A Case Study. CyberPsychology \& Behavior, Volume 6, Number 6. Mary Ann Liebert, Inc.

-Gibbins, J., \& Thomson, A. M. (2001). Women's expectations and experiences of childbirth. Midwifery, Vol 17, Issue 4, Pages 302-313. http://www.sciencedirect.com/science/article/pii/S0266613801902633.

-Goodman, J. H. (2004). Paternal postpartum depression, its relationship to maternal depression and implications for family health, Journal of advanced Nursing, 45(1)26-35.

-Green, J. M., Coupland, V. A., \& Kitzinger, J. V. (2007). Expectations, experiences, and psychological outcomes of childbirth: A prospective study of 825 women. Wiley Online Library, Vol. 17, Issue 1, pages 15-24. https://doi.org/10.1111/j.1523-536X.1990.tb00004.x

-Green J. M., \& Baston, H. A. (2003). Feeling in control during labour: concepts, correlates, and consequences. Wiley Online Library, Vol. 30, Issue 4, pages 235-247. https://doi.org/10.1046/j.1523536X.2003.00253.x

-Gregoire, J. P., Kumar R., Everitt, B., \& Studd J. W. W. (1996). Transdermal oestrogen for treatment 
of severe postnatal depression. The Lancet, Volume 347, Issue 9006, Pages 930-933. https://doi.org/ $10.1016 / \mathrm{S} 0140-6736(96) 91414-2$

-Hagen, E. H. (1999). The functions of postpartum depression, Evolution and Human Behavior, 20(5): 325-359.

-Hall-Flavin, D. K. (2020). Can chronic stress cause depression? https://www.mayoclinic.org/healthylifestyle/stress-management/expert-answers/stress/faq-20058233.

-Harris, B., Johns, S., Fung, H., Thomas, R., Walker, R., Read, G., \& Riad-Fahmy, D. (1989). The hormonal environment of post-natal depression. The British Journal of Psychiatry, 154 (5) 660-667. https://doi.org/10.1192/bjp.154.5.660

-Harris, B. (1994). Biological and Hormonal Aspects of Postpartum Depressed mood, British Journal of Psychiatry, 164:288-292.

-Hendrick, V. (2003). Treatment of postnatal depression. British Medical Journal, International edition, 2003: 327.7422: 1003-4.

-Hendrick, V., Altshuler, L., \& Suri, R. (1998). Hormonal changes in the Postpartum and implications for postpartum depression. Psychosomatics, 39(2):93-101.

-Herbelin B. (2005). Virtual reality exposure therapy for social phobia. Institut des systèmes informatiques et multimédias. Université Louis Pasteur, Strasbourg, France THĖSE NO 3351. http://128.192.206.60/share/files/papers/virtual\%20humans/virtual\%20reality\%20exposure\%20therapy_ dissertation_herbelin.pdf.

-Herbelin, B., Riquier, F., Vexo, F., \& Thalmann, D. (2002). Virtual reality in cognitive behavioral therapy: A preliminary study on social anxiety disorder. In 8th International Conference on Virtual Systems and Multimedia, VSMM2002 (pp. 1-10). Gyeongju, Korea. 
-Hewitt, C. E., Gilbody, S. M., Brealey, S., Paulden, M., Palmer, S., Mann, R., Green, J., Morrell, J., Barkham, M., Light, K., \& Richards, D. (2009). Methods to identify postnatal depression in primary care: an integrated evidence synthesis and value of information analysis. Health Technol Assess, Jul; 13(36):1-145, 147-230. https://doi.org/10.3310/hta13360

-Hodges, F. L., Anderson, P., Burdea, C. G., Hoffman, G. H., \& Rothbaum, O. B. (2001). Treating psychological and physical disorders with VR. IEEE Computer Graphics and Applications.

-Hoffman, G. H., Garcia-Palacios, A., Patterson, R. D., Jensen, M., Furness, T. III., \& Ammons, F. W. Jr. (2001). The effectiveness of virtual reality for dental pain control: a case study. CyberPsychology \& Behavior, Volume 4, Number 4, 2001.

-Hoffman, G. H, Patterson, R. D., Carrougher, J. G., \& Sharar, R. S. (2001). The effectiveness of virtual reality-based pain control with multiple treatments. Clinical Journal of Pain, 17, 229-235.

-Josman, N., Somer, E., Reisberg, A., Tamar Weiss, P. L., Garcia-Palacios, A., \& Hoffman, H. (2006). BusWorld: designing a virtual environment for post-traumatic stress disorder in Israel: a protocol. Cyberpsychol Behav, 9(2): 241-4. https://doi.org/10.1089/cpb.2006.9.241

-Kinnaman, G., \& Jacobs, R. (2006). Seeing in the dark. Michigan: Baker Publing Group.

-Klaus, N. M., \& Kirschman, K. B. (2008). Internalizing Conditions. Developmental-Behavioral Pediatrics,

Mosby, pg. 627-668, https://doi.org/10.1016/B978-0-323-04025-9.50021-0

-Klein, A. R. (2000). Virtual Reality Exposure Therapy in the Treatment of Fear of Flying. Journal of Contemporary Psychotherapy, Vol. 30, No. 2. https://doi.org/10.1023/A:1026518813266

-Klinger, E., Bouchard, S., Légeron, P., Roy, S., Lauer, F., Chemin, I., \& Nugues P. (2005). Virtual reality therapy versus cognitive behavior therapy for social phobia: a preliminary controlled study. CyberPsychology \& Behavior, Volume 8, Number 1. 
-Krijn, M. (2005). Thesis: Virtual reality and specific phobias. Welcome to the real world. Cover subtitle: Welcome to the real world. The Matrix, 1999. Cybermind Interactive Nederland and CRLO Displays Limited.

-Krijn, M., Emmelkamp, G. M. P., Biemondm R., De Wilde De Lingy, C., Schuemie, J. M., \& Van Der Mast, G. P. A. C. (2004). Treatment of acrophobia in virtual reality: the role of immersion and presence. Behaviour Research and Therapy, 42, 229-239.

-Kumar, M. S., (2009). The mindful path through worry and rumination. Letting go of anxious and depressive thoughts. New Harbinger Publications, Inc.

-Kuosmanen, L., Vuorilehto, M., Kumpuniemi, S., \& Melartin, T. (2010). Post-natal depression screening and treatment in maternity and child health clinics. Journal of Psychiatric and Mental Health Nursing, Vol 17, Issue 6, pages 554-557. https://doi.org/10.1111/j.1365-2850.2010.01578.x

- Leahy, L. R. (2010). Beat the Blues Before They Beat You. Hay House, Inc.

-Lear, C. A. (1997). Virtual reality provides real therapy. Computers Graphics and Applications. 17 (4), pp. 16-20.

-Leigh, B., \& Milgrom, J. (2008). Risk factors for antenatal depression, postnatal depression and parenting stress. BMC Psychiatry BMC series. https://doi.org/10.1186/1471-244X-8-24

-Loggie, C. L., \& Rankin, N. M. (2013). Australian Coding Standards for ICD-10-AM and ACHI. The International Statistical Classification of Diseases and Related Health Problems, tenth revision, Australian Modification. University of Wollongong. Commowealth of Australia. Eighth Edition.

-MacCoon, D., Abramson, L., Mezulis, A., Hankin, B., \& Alloy, L. B. (2003). The role of attention in connecting cognitive vulnerability to rumination: Insights from a self-regulatory Perspective. Manuscript under editorial review. Found in: Papageorgiou, C., \& Wells, A. (2004). Depressive Rumination. Nature, Theory and Treatment. John Wiley and Sons Ltd. 
-Mandal, S. (2013). Brief introduction of virtual reality \& its challenges. International Journal of Scientific \& Engineering Research, Volume 4, Issue 4, 304. -Maples-Keller, J. L., Bunnell, B. E., Kim, S. J., \& Rothbaum, B. O. (2017). The Use of Virtual Reality Technology in the Treatment of Anxiety and Other Psychiatric Disorders. Harvard review of psychiatry, 25(3), 103-113. https://doi.org/10.1097/HRP.0000000000000138

-Mazuryk, T., \& Gervautz, M. (1996). Virtual reality - History, applications, technology and future. Technical Report. TR-186-2-96-06. Institute of Computer Graphics. Vienna University of Technology, Austria. 1996.

-McCoy, S. J. B. (2006). Risk Factors for Postpartum Depression: A Retrospective Investigation at 4Weeks Postnatal and a Review of the Literature. The Journal of the American Osteopathic Association (JAOA), 106 (4): 193-8. PMID 16627773. http://www.jaoa.org/cgi/content/full/106/4/193

-McCracken, M. L., Vowles, E. K. (2014). Acceptance and commitment therapy and mindfulness for chronic pain. American Psychologist, February-March 2014.

-Meager, I., \& Milgrom, J. (1996). Group Treatment for Postpartum Depression: A Pilot Study. Australian and New Zealand Journal of Psychiatry, Vol. 30 no. 6 852-860. https://doi.org/10.3109/00048679609065055

-Meltzer-Brody, S. (2011). New insights into perinatal depression: pathogenesis and treatment during pregnancy and postpartum. Dialogues Clin Neurosci, 2011;13(1):89-100.

-Mental Health Foundation. (2002). MHINZ Booklet: Post Natal Depression. Auckland: Mental Health Foundation.

-Meyebroker, K., \& Emmelkamp, M.G.P. (2010). Virtual reality exposure therapy in anxiety disorders: a systematic review of process-and-outcome studies. Depression and Anxiety, 27:933-944. 


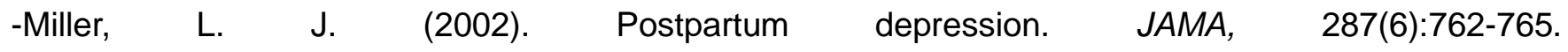
https://doi.org/10.1001/jama.287.6.762

-Morrell, C. J., Slade, P., Warner, R., Paley, G., Dixon, S., Walters, S. J., Brugha, T., Barkham, M., Parry, G. J., \& Nicholl, J. (2009). Clinical effectiveness of health visitor training in psychologically informed approaches for depression in postnatal women: pragmatic cluster randomised trial in primary care. BMJ, 338: a3045.

-MothersMatterTrust (2015). Mothers Matter: He Mana To Te Whare Tangata. https:///www.mothersmatter.co.nz/Treatments/Default.asp.

- Muhlberger, A., Herrmann, M. J., Wiedemann, G., Ellgring, H., \& Pauli, P. (2001). Repeated exposure of flight phobics to flights in virtual reality. Behaviour Research and Therapy, 39, 1033-1050.

-National Institute for Health and Care Excellence (2014). Antenatal and postnatal mental health: clinical management and service guidance. https://www.nice.org.uk/guidance/cg192/chapter/1recommendations\#principles-of-care-in-pregnancy-and-the-postnatal-period-2.

-National Institute for Health and Care Excellence (2016). Recognising mental health problems in pregnancy and the post-natal period and referral. https://www.nice.org.uk/guidance/cg192/chapter/1Recommendations

-Navarro-Haro, M. V., López-del-Hoyo, Y., Campos, D., Linehan, M. M., Hoffman, H. G., \& GarcíaPalacios, A. (2017). Meditation experts try Virtual Reality Mindfulness: A pilot study evaluation of the feasibility and acceptability of virtual reality to facilitate mindfulness practice in people attending a Mindfulness conference. PLoS ONE 12(11): e0187777. https://doi.org/10.1371/journal.pone.0187777

-Nolen-Hoeksema, S. (2003). Women who think too much. New York: Henry Holt and Company.

-North. M., \& North M. S. (1994). Relative effectiveness of virtual environment desensitization and imaginal desensitization in the treatment of aerophobia. Arachnet Electronic Journal on Virtual Culture, 
V2n04.

-North, M., \& North, M. S. (1997). Virtual environments psychotherapy: a case study of fear of flying disorder. Presence: Teleoperators \& Virtual Environments, Vol. 6 Issue 1, p127, 6p, 5 graphs, 1 bw. Computer Source. Forum: Short Papers. EBSCOhost. http://weblinks3.epnet.com/DeliveryPrintSave.asp?tb=1\&_ua=bt+TD...

-North, M. M., North, M. S., \& Coble, R. J. (1997). Virtual reality therapy: an effective treatment for psychological disorders. Virtual Reality in Neuro-Psycho-Physiology.

-O'Hara, M., \& Zekoski, E. M. (1988). Postpartum depression: a comprehensive review. In: Kumar R. C., Brockington I. F., eds. Motherhood and Mental IIIness. Cambridge: Butterworth \& Co.

-Onozawa, K., Glover, V., Adams, D., Modi, N., \& Channi Kumar, R. (2001). Infant massage improves mother-infant interaction for mothers with postnatal depression. Journal of Affective Disorders, Vol. 63, Issues 1-3, Pages 201-207. https://doi.org/10.1016/S0165-0327(00)00198-1

-Opris, D., Pintea, S., Garcia-Palacios, A., Botella, C., Szamoskozi, S., \& David, D. (2012). Virtual reality exposure therapy in anxiety disorders: a quantitative meta-analysis. Depression and Anxiety, 29:85-93.

-Patel, S. R., \& Wisner, K. L. (2011). Decision making for depression treatment during pregnancy and the postpartum period. Issue Depression and Anxiety, Vol. 28. Issue 7, pages 589-595. https://doi.org/10.1002/da.20844

-Patterson, D. R., Hoffman, H., Garcia-Palacios, A., \& Jensen, M. J. (2006). Analgesic effects of posthypnotic suggestions and virtual reality distraction on thermal pain. Journal of Abnormal Psychology, 115(4): 834-41. https://doi.org/10.1037/0021-843X.115.4.834

-Paulson, J. F. (2010). Focusing on depression in expectant and new fathers: prenatal and postpartum depression not limited to mothers. Psychiatry Times, $27 \quad$ (2). 
http://www.psychiatrictimes.com/depression/content/article/10168/1519072.

-Pearlstein, T. B., Zlotnick, C., Battle, C. L., Stuart, S., O’Hara, M. W., Price, A. B., Grause, M. A., \& Howard, M. (2006). Patient choice of treatment for postpartum depression: a pilot study. Archives of Women's Mental Health, Volume 9, Issue 6, pp 303-308.

-Perrig, W. J., \& Grob, A. (2000). Control of human behavior, mental processes, and consciousness. Essays in Honor of the $60^{\text {th }}$ Birthday of August Flammer. Lawrence Erlbaum Associates, Inc. Library of Congress Cataloguing-in-Publication Data.

-Powers, B. M., \& Emmelkamp, M.G.P. (2007). Virtual reality exposure therapy for anxiety disorders: a meta-analysis. Journal of Anxiety Disorders, 22 (2008) 561-569.

-Purgato A., \& Gamberini L. (2005). Playsafety: virtual environments as a persuasive tool to contrast risky behaviors in youth. Annual Review of CyberTherapy and Telemedicine, 3, 243--245.

-Reece, S., \& Harkless, G. (1998). Self-Efficacy, Stress, and Parental Adaptation: Applications to the Care of Childbearing Families. Journal of Family Nursing, Vol. 4 no. 2 198-215. https://doi.org/10.1177/107484079800400206

-Regenbrecht, H., Alghamdi, M., Hoermann, S., Langlotz, T., Goodwin, M., and Aldridge, C. (2015) Social Presence with Virtual Glass, poster presented at IEEE Virtual Reality 23-27 March 2015. (pp 296-270). Arles, Camargue, Provence, France.

-Regenbrecht, T. H., Schubert, W. T., Friedmann, I. F., \& Schiller, F. (1998). Measuring the sense of presence and its relations to fear of heights in virtual environments. International Journal of HumanComputer Interaction, 1W.233-249.

-Regenbrecht, H., Wickeroth, D., Dixon, B., \& Mueller, S. (2006). Collaborative mixed reality exposure therapy. International Conference: CyberWorlds, https://doi.org/10.1109/CW.2006.19 
-Riva, G. (2000). Design of clinically oriented virtual environments: a communicational approach. CyberPsychology \& Behavior, Volume 3, Number 3.

-Riva, G. (2005). Virtual reality in eating disorders and obesity: state of the art and future directions. Cyber Therapy. http://www.cybertherapy.info

-Riva, G., Bacchetta, M., Cesa, G., Conti, S., \& Molinari, E. (2003). Six-month follow-up of in-patient experiential cognitive therapy for binge eating disorders. CyberPsychology \& Behavior, Volume 6, Number 3.

-Riva, G., Baños, R. M., Botella, C., Mantovani, F., \& Gaggioli, A. (2016). Transforming Experience: The Potential of Augmented Reality and Virtual Reality for Enhancing Personal and Clinical Change. Frontiers in psychiatry, 7, 164. https://doi.org/10.3389/fpsyt.2016.00164

-Riva, G., Mantovani, F., \& Gaggioli, A. (2004). Presence and rehabilitation: toward second-generation virtual reality applications in neuropsychology. Journal of neuroengineering and rehabilitation, 1(1), 9. https://doi.org/10.1186/1743-0003-1-9

-Riva, G., Molinari, E., \& Vincelli, F. (2001). Virtual reality as communicative medium between patient and therapist. Communications Through Virtual Technology: Identity community and Technology in the Internet Age.

-Rizzo, Skip. A., Schultheis, T. M., \& Rothbaum, O. B. (2003). Ethical issues for the use of virtual reality in the psychological sciences. Ethical Issues in Clinical Neuropsychology. Eds: Bush, S. S. \& Drexler, M. L., \& Lisse, N. L.: Swets \& Zeitlinger Publishers, 243-280.

-Roberts, S. L., Bushnell, J. A., Collings, S. C., \& Purdie, G. L. (2006). Psychological Health of Men with Partners who have PPD. Australian and New Zealand Journal of Psychiatry, 40: 704-11.

-Robillard G, Bouchard S, Fournier T, \& Renaud P. (2003). Anxiety and presence during VR immersion: a comparative study of the reactions of phobic and non-phobic participants in therapeutic virtual 
environments derived from computer games. Cyberpsychol Behav, 6(5):467-76. https://doi.org/10.1089/109493103769710497

-Robles-De-La-Torre, G. (2010). International Society for Haptics: Haptic technology, an animated explanation. Isfh.org. Found in Wikipedia. Haptic technology. https://en.wikipedia.org/wiki/Haptic_technology.

-Rothbaum, B. O., Hodges, L., Smith, S., Lee, J. H., \& Price, L. (2000). A controlled study of virtual reality exposure therapy for the fear of flying. Journal of Consulting and Clinical Psychology, 68, 10201026.

-Sabourin, C., Bouchard, S. (2004). The impact of instructions on the feeling of presence during virtual immersions. Cybertherapy 2004 Abstracts.

-Sallinen, B. A, Gilles, A. A., \& Hayes, M. J. (2006). Psychobiology and culture in the development of postpartum depression, in Rosenfield, A. I. (ed.) New Research on Postpartum Depression. New York: Nova Publishers. pg 1-28.

- Saxbe D., \& Repetti, R. L. (2010). For better or worse? Coregulation of couples' cortisol levels and mood states. J Pers Soc Psychol, 98(1):92-103. DOI: 10.1037/a0016959. Found in Le Beau Lucchesi, E. (2019). The Unbearable Heaviness of Clutter. The New York Times. https://www.nytimes.com/2019/01/03/well/mind/clutter-stress-procrastination-psychology.html.

-Schubert, T., Friedmann, F., \& Regenbrecht, H. (2001). The experience of presence: factor analytic insights. DaimlerChrysler Research and Technology. Presence, Vol. 10, No. 3, 266-281.

-Shapiro, S. L., Oman, D., Thoresen, C. E., Plante, T. G., \& Flinders, T. (2008). Cultivating mindfulness: effects on well-being. Journal of Clinical Psychology, 2008: 64, 840 - 862.

-Shors, T. J. (2004). Learning during stressful times. Learning \& memory (Cold Spring Harbor, N.Y.), 11(2), 137-144. https://doi.org/10.1101/lm.66604 
-Shorey, S., Wai-Chi Chan, S., Seng Chong, Y., \& He H. (2014). Predictors of maternal parental selfefficacy among primiparas in the early postnatal period. West $J$ Nurs Res, DOI: $10.1177 / 0193945914537724$.

-Spinelli, G. M. (2009). Postpartum psychosis: detection of risk and management". The American Journal of Psychiatry (AJP), 166 (4): 405-408. https://doi.org/10.1176/appi.ajp.2008.08121899

-Srivastava, K., Das, R.C., \& Chaudhury, S. (2014). Virtual reality applications in mental health: Challenges and perspectives. Industrial psychiatry journal, 23(2):83-5. https://doi.org/10.4103/09726748.151666

-Sullivan, T. K., \& Davilla, J. (2010). Support Processes in Intimate Relationships (Google eBook). Oxford University Press.

-Toth, C., \& Moulin, E. D. (2013). Neuropathic pain. Causes, Management and Understanding. Cambridge University Press.

-TransformingPainTV. (2010, April 3). Managing chronic pain through virtual reality. YouTube. https://www.youtube.com/watch?v=O4qrQOU-iEs.

-TransformingPainTV. (2010, November 4). The meditation chamber. YouTube. https://www.youtube.com/watch?v=v_WrGoJMMEY.

-TransformingPainTV. (2010, March 26). Transforming pain group: Immersive VR for chronic pain. YouTube. https://www.youtube.com/watch?v=kkOAOzr8Skk.

-Van den Buuse, M, \& Copolov, D (2007). Schizophrenia. Encyclopedia of Stress (Second Edition), pg. 418-422. https://doi.org/10.1016/B978-012373947-6.00336-6

-Villani, D., \& Riva, G. (2008). Presence and relaxation: A preliminary controlled study. PsychNology Journal, Vol 6, Number 1, 7-25. 
-Whitton, A., Warner, R., \& Appleby, L. (1996). The pathway to care in post-natal depression: women's attitudes to post-natal depression and its treatment. The British journal of general practice: the journal of the Royal College of General Practitioners, 46(408), 427-428.

-Wiederhold, B. K., Gao, K., Sulea, C., \& Wiederhold, M. D. (2014). Virtual reality as a distraction technique in chronic pain patients. Cyberpsychology, behavior and social networking, 17(6), 346-352. https://doi.org/10.1089/cyber.2014.0207

-Wisner, K. L., Parry, B. L., \& Piontek, C. M. (2002). Postpartum depression. The New England Journal of Medicine, 347:194-199. https://doi.org/10.1056/NEJMcp011542

-Wisner, K. L., Zarin, D. A., Holmboe, E. S., Appelbaum, P. S., Gelenberg, A. J., Henrietta, L. L., \& Frank, E., (2000). Risk-benefit decision making for treatment of depression during pregnancy. The American Journal of Psychiatry, 157:1933-1940. http://doi.org/10.1176/appi.ajp.157.12.1933 
Chapter 2: Cognitive-Behavioural therapy and interpersonal psychotherapy for the treatment of post-natal depression: a narrative review.

This chapter has been published as:

Stamou, G., García-Palacios, A., \& Botella, C. (2018). Cognitive-Behavioural therapy and interpersonal psychotherapy for the treatment of post-natal depression: a narrative review. BMC Psycho/6, 28. https://doi.org/10.1186/s40359-018-0240-5 


\section{Abstract}

\section{Background}

Post-natal Depression (PND) is a depressive disorder that causes significant distress or impairment on different levels in the individual's life and their families. There is already evidence of the efficacy of psychological treatments for PND. We conducted a narrative review and researched the literature for identifying systematic reviews and studies for the best psychological treatments of PND, and examined what parameters made those treatments successful.

\section{Methods}

We searched 4 electronic databases. We included reviews and randomised controlled clinical trials for our research. We excluded other types of studies such as case studies and cohort studies.

We followed a specific search strategy with specific terms and a selection process. We identified risk of bias in reviews and studies, and identified their limitations. We synthesized the data based on particular information, including: name of the authors, location, research type, target, population, delivery, outcome measures, participants, control groups, types of intervention, components of treatments, providers, experimental conditions amongst others.

\section{Results}

We found 6 reviews and 15 studies which met our inclusion criteria focusing on Cognitive Behavioural Therapy (CBT) for PND.

Among the main findings we found that CBT can be delivered on an individual basis or within a group. It can be effective in the short-term, or up to six months post-intervention. CBT can be delivered by professionals or experts, but can also be practiced by non-experts. 
We found 7 components of CBT, including psychoeducation, cognitive restructuring, and goal setting.

We also researched whether virtual reality (VR) has ever been used for the treatment of PND, and found that it has not.

\section{Conclusion}

From our review, we have concluded that CBT is an effective treatment for PND. We have explored the utility of VR as a possible therapeutic modality for PND and have decided to run a pilot feasibility study as a next step, which will act as the foundational guide for a clinical trial at a later stage. 


\section{BACKGROUND}

\section{Post-natal depression: Definition, clinical features, risk factors, and effects}

Post-partum period has been associated with mood disturbances since Hippocrates' times [1]. It is reported that PND started being officially used in psychiatric manuals in 1994 [2]. It was "officially objectified" in the 1950s [3]. PND was given some "diagnostic criteria" at that time as practitioners began to notice that some women, after giving birth, would experience a psychological pattern with depressive characteristics.

In the earlier days, science was trying to understand PND in the context of causes. These varied from the socio-economic background of the individual to unplanned pregnancy [4]. In more recent years, clinicians have gained a better understanding of PND. They give emphasis to the combination of risk factors rather than single causes [5]. Risk factors can vary from low socio-economic background, family history of depression or personal history of mental health issues, low social support, smoking habits, sexuality issues, and immigration issues [6].

The Diagnostic and Statistical Manual of Mental Disorders - fourth edition (DSM-IV) [7] initially linked PND with major depression with post-partum onset within 4 weeks of birth. However, a study for the treatment of PND [8] highlights the variations amongst studies which define the onset of PND, from the first month up to the end of the first year following the infant's birth.

The Diagnostic and Statistical Manual of Mental Disorders, DSM-5 [9] places PND in the category of unspecified depressive disorders where the main symptoms can cause significant distress or impairment on various levels in the individual's life. PND includes different sub-categories called specifiers, amongst which are the peri-partum onset. This refers to the onset of depression during pregnancy or postpartum for the time following the birth of the child. According to the same manual, a 
large number of postpartum major depressive episodes begin during pregnancy, thus they are also called peri-partum episodes. These episodes range from mild to severe, with or without psychotic features. The individual may also experience hallucinations or delusions.

A study by Hewitt et al. [10] describes depression as a very serious mental health problem with important consequences on a societal level. In this study they estimate that depression will become the second-highest health problem by 2020 . According to the same authors, PND is considered to be a very important category of depression with often serious consequences. It can affect both the mother and the infant, as well as the immediate and/or the extended family. PND can have long-lasting effects on the development of the infant on a cognitive and emotional level, including attachment issues amongst others [11].

PND can cause significant distress or impairment on various levels in the individual's life, e.g. lack of motivation, affected mood, sleep and appetite issues, lack of concentration, rumination, unintentional or intentional suicidal ideation, or psychotic phenomena such as hallucinations or delusions.

PND affects $13 \%$ of women [12], and between 4 and $25 \%$ in men in the first 2 months after the baby is born [13]. Other research suggests that the proportion of mothers who suffer from PND is one in seven [14]. According to the same article, the mentality of organisations and health providers is changing, especially in the United States where there is a shift towards more systematic screening of mothers-tobe or young mothers who might experience symptoms of depression.

\section{Psychological treatments of PND}

Regarding treatment for PND, Rudlin lists its main therapeutic approaches [15]. They vary from medication, home visits, education, phone contact, one-to-one counselling, group therapy, and self-help 
resources such as books. CBT, together with interpersonal psychotherapy (IPT) are considered two efficacious non-pharmacological treatments for PND [16].

A meta-analysis [17] examined how effective psychological treatments are for PND in primary care. It was found that psychological interventions such as CBT and IPT, along with counselling, psychodynamic therapy and support groups can be very effective in reducing the symptoms of depression up to 6 months post-intervention.

CBT's main focus is identifying distorted negative thinking patterns. It emphasises the link between thoughts, feelings and behaviour. Dalby [18] highlights Albert Ellis's theory of irrational thinking patterns and how they could trigger emotional disturbance to the individual.

A common characteristic of people who suffer from depression is their tendency to experience automatic thoughts, usually of negative content. Beck [19] highlights that the negative automatic thoughts usually carry negative meaning in relation to the notion of the past or the future, about the individual themselves, and/or the world around the person.

CBT helps the individual to understand that identifying their own distorted negative thinking patterns allows them an opportunity to change them. By changing their thinking, the individual can change how they view and feel about themselves, and ultimately, change their behaviour [20]. CBT integrates many approaches in clinical practice such as problem solving, modelling, and cognitive restructuring, amongst others [21].

IPT focuses on four areas in the person's life: grief about someone's own sense of self or changes within their relationships, changes in roles, unresolved disagreements in interpersonal relationships, and a lack of life events. It focuses on strengthening the relationships of the individual, on increasing social support, and improves communication [22]. 
Conversely, Barlow [23] refers to the negative effects, or no effects of psychological interventions for various disorders, including trauma and addictions. Dimidjian and Hollon [24] talk about the adverse effect of psychotherapy, but this is yet to be researched adequately. There is no real agreement in the scientific community about ways to investigate and identify harmful psychological interventions. A review [25] published by the World Health Organisation (WHO) for psychological interventions on depression discusses the under-investigated but very real possibility of a negative effect of psychological therapies on depression. Some of those effects include the symptomatology of the individual becoming exacerbated or the individual experiencing a "relapse".

Lambert [26] makes the point that psychological treatments for depression and other disorders have shown to be effective overall. Positive outcomes depend on the patients' characteristics, but also the therapists' "actions" or "inactions". Lambert also highlights the reality of negative clinical outcomes for patients who experience depression. Lambert does, however, identify ways to minimise clinical negative impact and maximise positive outcomes which can be achieved through "measuring, monitoring, and tracking client treatment response with standardised scales".

A meta-analysis by Cuijpers et al. [27], which we did not include in our initial search, investigates the effect of psychological treatments for PND. It was found that CBT, IPT, counselling and social support have an overall positive effect on PND, but they were less effective than what they have been on other psychological disorders. There was no real difference in therapeutic outcome between different psychological therapies. The same study also concluded that medication and electroconvulsive therapy can have higher effect size for PND than psychological treatments but that needs to be further investigated. In addition, it was found that the initial positive therapeutic effect of psychological treatments on PND could not be confirmed 6months or longer post-intervention. However, the authors of this meta-analysis highlight that some of these findings need to be interpreted with caution due to the small number of studies included, and that the quality of the studies was not the highest. 


\section{Virtual reality: Definition and its advantages}

A question worthy of investigating in relation to the treatments of PND is whether they can be improved for better clinical outcomes using other treatments, such as virtual reality (VR).

VR is defined as "a way for humans to visualise, manipulate, and interact with computers, and it can be viewed as an advanced form of human-computer interface that allows the user to interact immersed in more intuitive and naturalistic fashion" [28].

VR promotes a sense of presence for the user in an environment which is computer based. According to Turner and Casey [29], VR can enhance the therapeutic effectiveness of psychological interventions. It expands beyond the strict boundaries of technology. VR is seen as a form of communication. It comprises elements such as an experience, visualisation and interaction [30].

Some of VR's advantages in research and practice is that it can act as a powerful and effective tool which can complement traditional therapies such as CBT [31]. It is a form of therapy which enhances sense of control and raises self-efficacy. It uses technological means to help the individual. It is 3dimensional and interactive. The VR user has the ability to "explore and engage" within the virtual environment.

VR can be delivered in a safe and controlled way [28]. It can be affordable, easy to access, and the therapist themselves can have control of how, what and when it is to be applied, which creates a sense of safety for the user [32]. One of VR's main features and characteristics is that it can empower the individual, a very basic and essential ingredient in order for therapy to occur. The combination of CBT with VR can have a tremendous positive impact [29].

VR or virtual reality exposure therapy (VRET) has been used to explore a large number of topics, from stress, anxiety, phobias, acute pain, body image disturbances, eating disorders, training of children in 
spatial and navigation learning skills, functional skills [28], post-traumatic stress disorder (PTSD) [33,34,35], fear of heights and also fear of flying [36, 37].

\section{Improvement of traditional treatments for PND}

There appears to be a gap in the literature relating to the combination of VR with traditional therapies for the treatment of PND. A brief literature review so far identified only one study on the efficacy of VR on depression. A pilot study conducted by Falconer et al. investigated the concept of compassion and self-criticism in a virtual environment [38]. They examined whether compassion could be taught to subjects in a virtual environment. The study revealed that its participants, all adults with depression, were able to practice compassion both as a life-sized avatar and as a child avatar interacting with one another through the process of embodiment. Although this particular study was limited, being a small group ( $n=15$ ), and having no control group, its results were promising. Results indicated that most of the study's participants had become more compassionate and less self-critical one-month postintervention.

Our research group is exploring the utility of using VR in the treatment of PND, the final aim being to improve the treatment that mothers with PND receive. This could potentially be beneficial for the health and well-being of mothers, their families, and society in general. The investigation of the combination of CBT and VR could possibly provide a better treatment for PND from a clinical point of view, which could save on resources including time and money spent at an organisational level.

In order to explore the possibility of combining psychological therapies with VR for the treatment of PND, we decided to review past and current published literature on traditional therapies for PND. We wanted to find out what therapies work best, and under what circumstances. Our investigation researched other reviews, within the same clinical subject area. However, our review differs from other reviews, whether systematic or narrative reviews, in three methodological aspects. It focuses purely on 
the treatment of PND, rather than prevention, or prevention and treatment of PND. A second difference is that this review investigates mainly CBT as treatment for PND. A third advantage of this review is around population characteristics. We focused our research mainly on the post-partum clinical population and not on other types such as the ante-natal population. However, there was one exception where the clinical population was in the last trimester of their pregnancy in the beginning of the study, but it became post-partum at a later stage. We believe this three research characteristics help this research project make a clear contribution to the literature.

\section{Objectives}

We formulated the design of this review based on the working hypothesis that CBT is a successful treatment for various psychological disorders, amongst them PND. It is a therapeutic approach which is scientific based. It can follow a clinical protocol, where its clinical methods can be replicated. Its clinical efficacy can be tested and measured. We hypothesised that CBT is the most widely used and efficacious treatment for depression and PND.

We searched for specific parameters which we believe contribute to the efficacy of CBT. We wanted to pay particular attention to the types of participants, especially the ones who had been diagnosed with PND through a structured clinical interview. Another parameter was around the types of interventions or treatment components of CBT for PND. We searched for specific aspects of the CBT approach, in particular, cognitive restructuring, goal setting, and problem-solving.

In order to start this line of research and to design our PND intervention protocol, supported with VR, our first aim is to review the scientific literature relating to the most effective CBT treatments for PND. Then to identify the parameters that make those treatments effective. It will also investigate whether VR has previously been used as a treatment for PND. 
More specifically, this review will answer the following three research questions:

1. What CBT psychological treatments are effective for PND?

2. What are the parameters that make those treatments have a successful clinical outcome?

3. Has VR previously been used for the treatment of PND?

\section{METHODS}

Studies for this review were selected according to specific criteria. The studies which we included for this review were reviews and randomised controlled trials. Case studies, cohort studies, or cluster trials were excluded. The reason for including randomised controlled trials and excluding other types of studies, such as case studies, was that randomised controlled trials are considered to be the "gold standard of clinical trials" [39].

We included studies which investigated the treatment of PND. We excluded studies that investigated the prevention of PND or treatment of post-natal anxiety. We included studies where treatments were delivered in home based or in public settings such as clinics or hospitals.

There were no restrictions around the intervention providers in the included studies. They varied from professionals who are experts on CBT or are experts in other therapeutic approaches, General Practitioners, trained nurses, and non-professionals, such as women who had been diagnosed with PND themselves or who had experienced depressive episodes.

The targeted population of this review were 16 years or older. It was a requirement that they had either been diagnosed as suffering from PND and/or reported that they had been experiencing depressive 
symptomatology through self-report measures. Any studies with a population who were under the age of 16 , or with a population that had been diagnosed or were suffering from other mental health or chronic health issues concurrently, in other words if they were mixed samples, were excluded. The mental health issues which were excluded were: personality disorders, developmental disorders, severe depression, anxiety, cognitive impairment, bipolar disorder, and psychotic disorders. The chronic physical health issues were diabetes, neurological disorders, stroke, physically handicapped, gastrointestinal problems, asthma, obesity, Alzheimer's disease, Parkinson's disease, and heart problems. Factors such as the socioeconomic background of the participants, educational level and/or marital status did not influence the selection of the targeted population.

For the purpose of this review, we included the following psychological interventions for the treatment of PND: CBT, cognitive therapy, psychoeducation, advice given, cognitive restructuring, behaviour management, goal setting, goal achieving, problem-solving therapy, mindfulness, stress management, relaxation, and breathing exercises.

A randomised controlled trial by Milgrom et al. [40] which we have also included in our Results Section, and which investigates the efficacy of CBT for PND through the internet, provides a comprehensive CBT model. It is called MumMoodBooster and it consists of six sessions. Each session focuses on different aspects of CBT and PND. The first session focuses on psychoeducation where information about PND and treatments are provided. The second session is about mood management and it talks about stress and anxiety, relaxation, and goals. The third session uses behaviour management where it explores issues such as life balance, goals, time management, and practicing change. The fourth session is about managing negative thoughts, while the fifth session focuses on increasing positive thoughts. The last session is about future planning where it explores the concepts of strategies, new routines, and commitment to change. 
In addition the same program provides resources and has information on stress management, finding support, time management, and problem solving. It explores the concept of personal relationships with the focus on the person's needs and also their partner's. The program encourages the mother to meet the baby's needs by "reading the cues" in the baby's behaviour and to enhance the interaction between them through play. The basic need for sleep and strategies for improving it are also highlighted.

We excluded any studies from other schools of thought in psychology, such as the psychodynamic or humanistic approach, unless they were combined with other psychological approaches such as CBT, or in comparison to it for treating PND. The two main reasons for this choice were that CBT is "one of the best treatments which provides empirical evidence" [41], while psychodynamic or other psychotherapeutic therapies such as non-directive counselling are "unstructured and non-manualised" [42].

We included studies with control conditions that met the following criteria: typical primary care, waiting list, GP visits, clinic visits, home visits, anti-depressant medication, postnatal care, enhanced routine care with regular weekly or monthly visits by trained health workers, community treatment, referral to specialty services, and a single session focusing on debrief.

We conducted comparisons between various therapeutic approaches based on the following criteria:

1. The ratio of success of each treatment;

2. The duration of success of each treatment in terms of follow-ups. We included studies and follow-ups which varied in duration from one-week post-intervention to up to 5 years post-intervention;

3. The components of each treatment, e.g. what made each treatment successful. 
We included studies in this review that used measures based on self-report questionnaires, such as the Edinburgh Postnatal Depression Scale [43], a valid and reliable scale that identifies the possibility of risk for the individual to develop perinatal depression [44], Hamilton Depression Rating Scale, Beck Depression Inventory, Global Assessment of Functioning Scale, Consumer Satisfaction Rating, Revised Clinical Interview Schedule, Therapist Rating Scale, Kruskal Wallis Test, Postpartum Adjustment Questionnaire, Social Adjustment Scale-Self-Report, and the Montgomery-Asberg Depression Rating Scale. We also included other studies which used formal diagnosis of PND based on clinical interviews of manuals such as the Structured Clinical Interview for DSM-III-R and DSM-IV.

We included studies which used measures such as depressive symptomatology, mood, coping strategies, social support, marital relationships, anxiety, social adjustment, relationship quality with partner, mother-infant relationship, suicidal ideation, suicide attempts, level of functioning, quality of life, health status, and sense of well-being.

There were no timing restrictions in terms of when studies were conducted. Studies included all types of settings. We reviewed studies published in the English language. Studies from research sources such as grey literature were not included.

We conducted a narrative review of the literature in four databases: Cochrane, PubMed, Scopus, and PsycINFO. The search took place on the 22nd and 23rd of December 2016. Reference lists of studies that were chosen initially from the four bibliographic databases were also reviewed and acted as secondary sources of information. Those reference lists were scanned, reviewed, and reported in detail accordingly. We also conducted another search in the same four bibliographical databases on the 23rd of December 2017. We wanted to find out whether there had been any published reviews or clinical trials for the treatment of PND from a psychological perspective in the year 2017. 
We used 9 terms for our search: "postpartum depression" OR "treatment" OR "cognitive-behavioural therapy" OR "clinical trials" OR "randomised controlled trials" OR "reviews" OR "systematic reviews" OR "follow up", AND "postpartum depression" OR "treatment" OR "virtual reality" OR "clinical trials" OR "reviews". Our search took place in two parts. The first part focused on finding reviews and/or clinical studies on effective psychological evidence-based treatments for PND [45]. The second part focused on finding studies or reviews on VR as a treatment for PND.

We paid particular attention to clinical trials and randomised controlled trials, reviews and systematic reviews, CBT - VR treatment for PND. The search process and the inclusion and exclusion of reviews were cross checked by all authors independently. Any disagreements were resolved through consensus and with the support of an additional reviewer when necessary.

The selection process followed the following three steps:

1. Screened titles of studies to identify which could possibly fit the inclusion criteria;

2. Screened abstracts of the already chosen studies to further identify which better matched the inclusion criteria;

3. Screened the whole text in order to make sure that the studies chosen fit the inclusion criteria of our review.

If the authors identified any areas that needed clarification, they contacted the authors of those studies for ensuring those studies either fit the inclusion criteria or fit the exclusion criteria accurately. We kept a journal in which we recorded the reasons each study was included or excluded during the review process. 
For the purpose of avoiding any risk of overlapping reports of the same study and to ensure avoiding bias and/or errors during the extraction data process, the extraction process was initially carried out by one reviewer. Data which focused on specific information, such as demographics, method, interventions, and outcomes were verified by the other reviewer(s) at a later stage. Any identified conflicts, misinterpretations, vague or grey areas were clarified by discussions between the reviewers and/or by contacting the authors of the studies selected, where necessary.

The results from our literature review search were recorded in an Excel spreadsheet with all relevant categories, such as studies, research design, intervention, and population, amongst others. The results were uploaded clearly and concisely based on the inclusion criteria and the keywords used for the search previously described.

We reduced bias and errors as all authors reviewed the studies separately and then later discussed any discrepancies identified.

They also identified the level of bias in terms of reporting. The authors divided the quality of each study into the following categories: yes, low, unclear, not strong, fair, and good. The decision for each of these categories for each study was based on the identification of reporting bias within the studies themselves. We considered issues in relation to selection bias, reporting bias, randomisation process, blinding of the participants, sample size, heterogeneity of methods used, generalisability of results, and limitations of each study.

We initially found 26 reviews in total. We also found 10 additional reviews through reference list searches, bringing the total of reviews up to 36 . We examined all 36 reviews' titles, names of authors, and year of publications and removed 14 reviews as duplicates. We examined the titles and abstracts 
of the remaining 22 reviews and we excluded 16 reviews as they did not meet the inclusion criteria of our review. We examined the remaining 6 reviews for eligibility and we included them in our review.

We examined the 6 reviews that met our inclusion criteria and we found that they included 106 studies. We examined the names of the authors, and the year of publication, and we removed 12 of those studies as duplicates. We examined the title and abstract of the remaining 94 studies and we removed 79 as they did not meet our inclusion criteria. The final number of included studies was 15 (see Fig. 21 attached). Figure 2-1 is a flow chart which summarises the process of selection for the studies based on PRISMA template [46] which had been found up to December 2016. The authors of this review resolved any disagreement through discussion with further consultation from an additional reviewer, where necessary. 

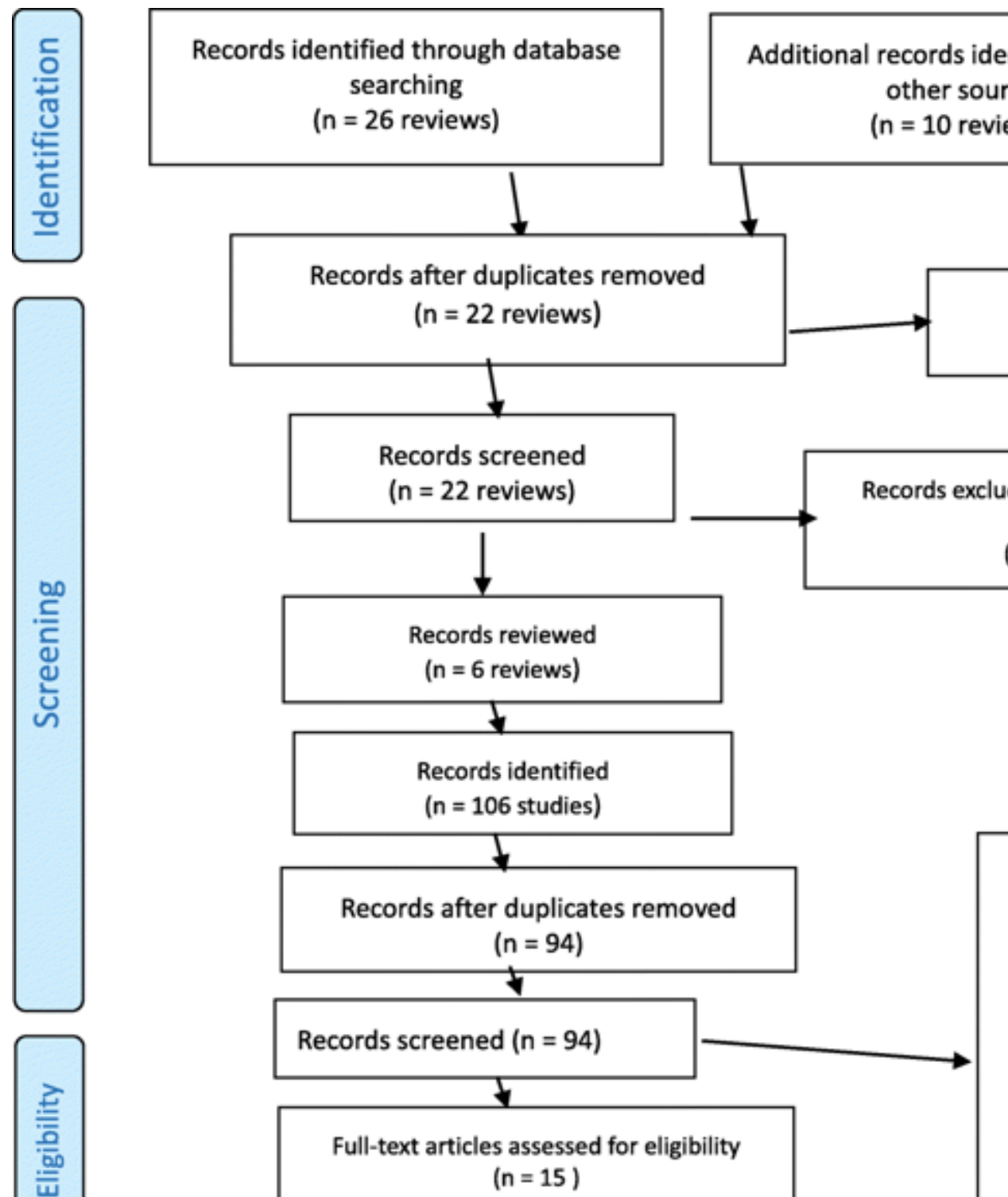

Duplicates

( $n=14$ reviews)

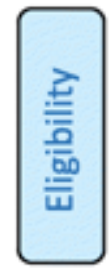

Full-text articles assessed for eligibility

$$
(n=15)
$$

Full-text articles excluded, with reasons
$(n=79)$

Focus on diagnosis of PND and use of measures $n=27$

- Use of medication $n=9$

- Different outcome measures $n=3$

- Different study design $n=$ 10

- Focus on pre-natal stages $\mathrm{n}$ $=5$

Studies included in qualitative synthesis (narrative review)

- Different treatments $n=25$ $(n=15)$

Studies included in quantitative synthesis (metaanalysis)

$(n=0)$

Figure 2-1. Flow chart of study selection process 


\section{RESULTS}

On our final list were 6 systematic reviews, one of which was a meta-analysis [47]. All six reviews included treatment studies with two reviews to include both prevention and treatment $[47,48]$. We found no reviews or clinical trials published in the year 2017 that met our inclusion criteria.

All six reviews initially reviewed 1015 studies, of which 950 were excluded with the total of final studies included 106. The population of the six reviews was 24,231 in total. However review [48] did not provide the number of participants in the intervention group for two studies $[49,50]$, while in a second review [51], the number of participants in the intervention group was only reported in one out of the 10 included studies of that review.

There was a mix of pregnant and post-partum women, mothers, newly delivered mothers, and mothers and infants. Some participants had been screened for depression through a clinical interview, while others had reported depressive symptomatology through self-report measures.

The delivery of the interventions was a mixture of community based, including clinics and hospitals [47], home based $[48,51,52]$, and a combination of individual and group therapy $[47,53]$. One review [54] did not provide any information relating to the delivery intervention.

It was assumed that the number of interventions equalled the number of sessions, a total of 538.5. Some of the reviews provided information about the number of clinical hours used for the intervention $[48,53,54]$, while one review did not provide any information relating to the number of clinical hours [51]. Some reviews reported missing information about the exact number of interventions in the studies they had reviewed $[47,51,54]$. 
The outcome measures were varied and included the Hamilton Depression Rating Scale, Beck Depression Inventory, with the most commonly used one being the Edinburgh Postnatal Depression Scale. There was an intention-to-treat analysis in four reviews $[51,52,53,54]$.

There were a multitude of interventions reported in the six reviews, ranging from CBT, IPT, to psychodynamic, non-directive counselling, infant massage and others. The most frequently used intervention being CBT, followed by the IPT model.

The providers of the interventions were a mixture of professionals from various backgrounds, including psychologists, GPs, nurses and non-professionals such as lay women. There was no available information about the providers in two reviews $[53,54]$. There is some missing data in terms of the duration of treatment and the number of sessions. We estimated the number of sessions to be approximately 610.5. There was a follow up assessment or intervention in 5 of the reviews, with only one exception [48].

In order to conduct a deeper analysis of the scientific literature, we applied our inclusion and exclusion criteria and extracted fifteen studies from the six reviews that met the inclusion criteria (see Table 2-1), 13 of them were randomised controlled trials, two studies were cluster randomised controlled trials $[55,56]$, and one was a randomised controlled trial with factorial design [50]. In the following sections we will describe the characteristics of the studies. 
Table 2-1. Summary of the final list of the 15 studies for the treatment of PND and their characteristics 
Table 2-1. Summary of the final list of the 15 studies for the treatment of PND and their characteristics

\begin{tabular}{|c|c|c|c|c|c|c|c|c|c|c|c|c|c|c|c|c|c|c|c|}
\hline Name of author(s) & $\begin{array}{l}\text { Setting- } \\
\text { Location - } \\
\text { dates }\end{array}$ & Target & Population & $\begin{array}{l}\text { Delivery } \\
\text { mode }\end{array}$ & $\begin{array}{l}\text { Screening } \\
\text { procedures }\end{array}$ & $\begin{array}{l}\text { Outcome } \\
\text { measures }\end{array}$ & Participants & $\begin{array}{l}\text { Control } \\
\text { group }\end{array}$ & $\begin{array}{l}\text { Treatmen } \\
\mathrm{t} \text { group }\end{array}$ & $\begin{array}{l}\text { Nature of } \\
\text { Intervention }\end{array}$ & $\begin{array}{l}\text { Intervention } \\
\text { provider }\end{array}$ & $\begin{array}{l}\text { Experimental } \\
\text { conditions }\end{array}$ & $\begin{array}{l}\text { Duration } \\
\text { and number } \\
\text { of sessions }\end{array}$ & $\begin{array}{l}\text { Measure/ } \\
\text { timescale }\end{array}$ & $\begin{array}{l}\text { Follow } \\
\text { up }\end{array}$ & $\begin{array}{l}\text { Summary of } \\
\text { main } \\
\text { outcomes }\end{array}$ & $\begin{array}{l}\text { Quality of } \\
\text { study }\end{array}$ & $\begin{array}{l}\text { Reporting } \\
\text { bias }\end{array}$ & Limitations \\
\hline $\begin{array}{l}\text { [59] } \\
\text { Ammerman et al } \\
(2013) \\
\text { Adopted by [53] }\end{array}$ & USA & Treatment & Postpartum & $\begin{array}{l}\text { Individual } \\
\text {, home } \\
\text { visits }\end{array}$ & $\begin{array}{l}\text { EPDS, } \\
\text { SCID, MDD } \\
\text { diagnosis, } \\
\text { HDRS, BDI- } \\
\text { II, GAF, } \\
\text { OTTF }\end{array}$ & $\begin{array}{l}\text { SCID, } \\
\text { HDRS, } \\
\text { EPDS, } \\
\text { BDI-II, } \\
\text { GAF, } \\
\text { OTTF, } \\
\text { consumer } \\
\text { satisfactio } \\
\text { n rating }\end{array}$ & 93 & $\begin{array}{r}46, \text { control } \\
\text { condition= } \\
\text { home visits } \\
\text { along with } \\
\text { receiving } \\
\text { treatment in } \\
\text { the } \\
\text { community }\end{array}$ & 47 & $\begin{array}{l}\text { CBT related } \\
\text { approach } \\
\text { focused on } \\
\text { stress } \\
\text { management, } \\
\text { goal setting, and } \\
\text { problem solving }\end{array}$ & Clinicians & $\begin{array}{l}\text { CBT vs } \\
\text { routine } \\
\text { primary care }\end{array}$ & $\begin{array}{l}15 \text { hours of } \\
\text { contact }\end{array}$ & $\begin{array}{l}4.75,7.75 \\
\text { months follow up }\end{array}$ & Yes & $\begin{array}{l}\text { Overall } \\
\text { positive } \\
\text { outcome in } \\
\text { favor of CBT } \\
\text { versus } \\
\text { typical care, } \\
\text { "results } \\
\text { found benefit } \\
\text { at } 4.5 \text { and } \\
7.5 \text { months } \\
\text { follow up" }\end{array}$ & $\begin{array}{l}\text { Fair = good } \\
\text { information on } \\
\text { demographic } \\
\text { population, } \\
\text { same } \\
\text { instruments } \\
\text { administered } \\
\text { in pre- } \\
\text { treatment, } \\
\text { post-treatment } \\
\text { and follow } \\
\text { ups, }\end{array}$ & Yes & $\begin{array}{l}\text { "Population exhibited } \\
\text { mild to moderate } \\
\text { depression and the } \\
\text { findings of this study } \\
\text { cannot be generalised } \\
\text { to the whole of } \\
\text { population, e.g. severe } \\
\text { depression, psychosis, } \\
\text { etc., reporting bias, } \\
\text { small study size, } \\
\text { limited screening } \\
\text { instruments, short term } \\
\text { follow up, overall } \\
\text { positive outcome in } \\
\text { favor of CBT versus } \\
\text { typical care but results } \\
\text { were not statistically } \\
\text { signnificant" }\end{array}$ \\
\hline $\begin{array}{l}{[49]} \\
\text { Appleby et al. } \\
\text { (1997) } \\
\text { Adopted by [48, } \\
\text { 51, 53] }\end{array}$ & $\begin{array}{l}\text { South } \\
\text { Manchester, } \\
\text { England, May } \\
\text { 1993-Feb } \\
1995\end{array}$ & Treatment & $\begin{array}{l}\text { "Urban, } \\
\text { community } \\
\text { sample", } \\
\text { postpartum }\end{array}$ & $\begin{array}{l}\text { Individual } \\
\text {, home } \\
\text { visits }\end{array}$ & $\begin{array}{l}\text { EPDS, } \\
\text { HAM-D, } \\
\text { "Revised } \\
\text { Clinical } \\
\text { Interview } \\
\text { Schedule" }\end{array}$ & $\begin{array}{l}\text { "Revised } \\
\text { Clinical } \\
\text { Interview } \\
\text { Schedule"- } \\
\text { EPDS, } \\
\text { HDRS }\end{array}$ & 87 & $\begin{array}{l}\text { Not } \\
\text { applicable } \\
\text { as all four } \\
\text { study } \\
\text { groups } \\
\text { received } \\
\text { some kind } \\
\text { of } \\
\text { intervention }\end{array}$ & 87 & $\begin{array}{l}\text { Placebo and 6 } \\
\text { CBT sessions } \\
\text { fortnightly - CBT } \\
\text { focused on } \\
\text { techniques such } \\
\text { as challenging } \\
\text { and moditying } \\
\text { negative } \\
\text { automatic } \\
\text { thoughts and } \\
\text { "dysfunctional } \\
\text { beliefs", } \\
\text { increasing } \\
\text { pleasant stimuli } \\
\text { and reducing } \\
\text { behaviours which } \\
\text { could have a } \\
\text { negative effect }\end{array}$ & $\begin{array}{l}\text { Psychologist } \\
\text { with no } \\
\text { previous } \\
\text { clinical } \\
\text { experience }\end{array}$ & $\begin{array}{l}\text { Medication } \\
\text { (Fluoxetine) } \\
\text { and } 1 \text { CBT } \\
\text { session, } \\
\text { medication } \\
\text { and } 6 \text { CBT } \\
\text { sessions, } \\
\text { Placebo and } 1 \\
\text { CBT session, } \\
\text { Placebo and } 6 \\
\text { CBT sessions }\end{array}$ & $\begin{array}{l}\text { "6 biweekly } \\
\text { CBT } \\
\text { sessions" }\end{array}$ & $\begin{array}{l}\text { 1, 4, and } 12 \\
\text { weeks post- } \\
\text { treatment }\end{array}$ & Yes & $\begin{array}{l}\text { "Immediately } \\
\text { post- } \\
\text { intervention, } \\
\text { all } 4 \text { groups } \\
\text { showed } \\
\text { significant } \\
\text { improvement } \\
\text { on the } \\
\text { Revised } \\
\text { Clinical } \\
\text { Interview } \\
\text { Schedule, } \\
\text { Fluoxetine, } \\
\text { an anxiolytic } \\
\text { antidepressa } \\
\text { nt, is an } \\
\text { effective } \\
\text { treatment for } \\
\text { PND, A }\end{array}$ & $\begin{array}{l}\text { "Fair as } \\
\text { clinical } \\
\text { interview was } \\
\text { used but } \\
\text { results of CBT } \\
\text { effect is } \\
\text { unclear as the } \\
\text { use of } \\
\text { medication is } \\
\text { used in one of } \\
\text { the groups, } \\
\text { however they } \\
\text { used } \\
\text { independent } \\
\text { assessors to } \\
\text { evaluate study } \\
\text { outcomes, not } \\
\text { clear about } \\
\text { allocation }\end{array}$ & Unclear & $\begin{array}{l}\text { "30\% attrition rates, } \\
\text { exclusion of } \\
\text { participants with } \\
\text { chronic depression, } \\
\text { combination of } \\
\text { medication and CBT as } \\
\text { the results were less } \\
\text { successful in } \\
\text { comparison to the use } \\
\text { of medication itself" }\end{array}$ \\
\hline
\end{tabular}


advantage in

receiving

medication

and

counselling

at the same

time, the

simples

treatment

after a single

session of

CBT may be

fluoxetine as

it removes

the need for

additional

counselling

Many

women with

PND are

reluctant to

medication"

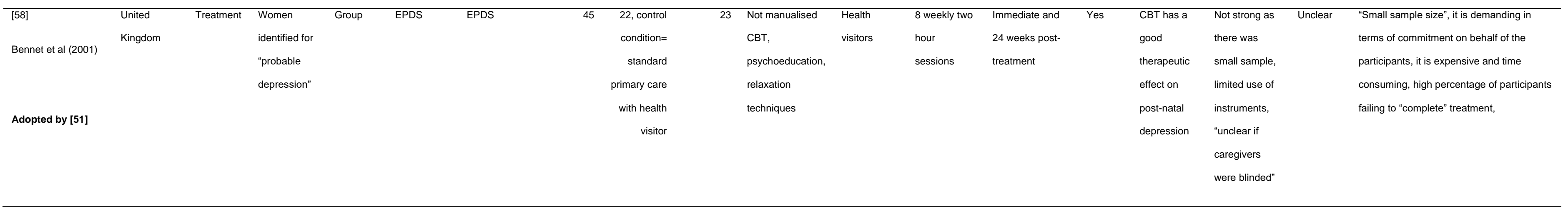




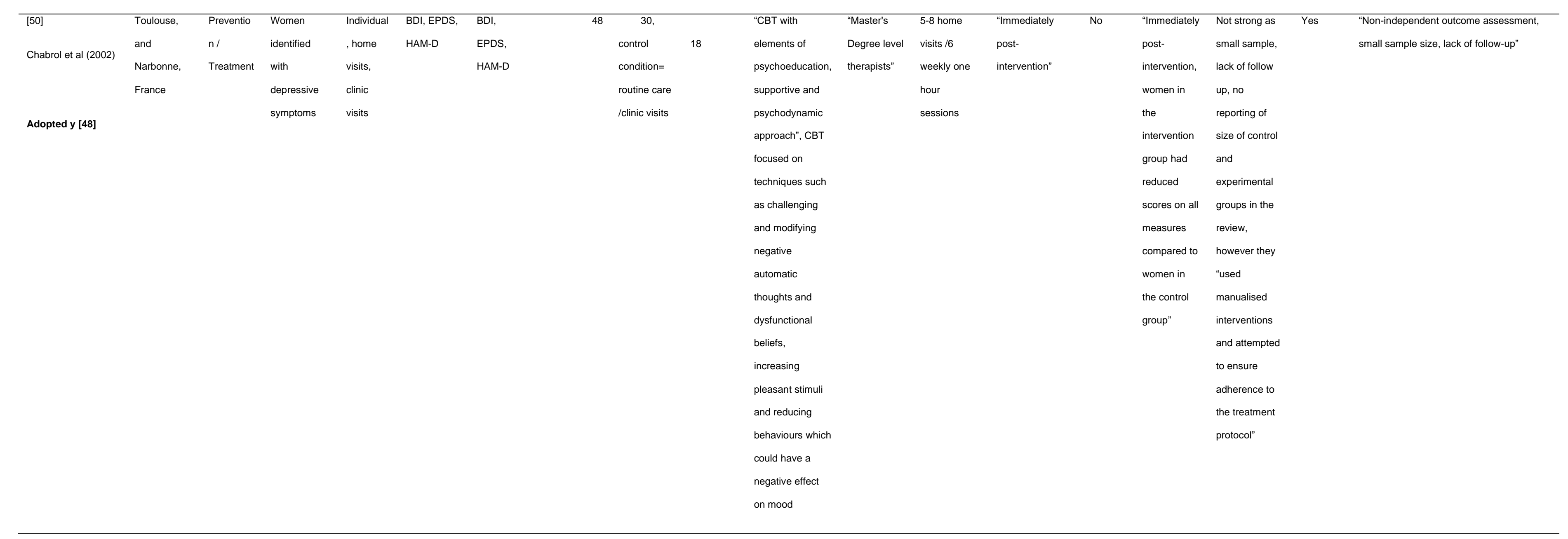




\begin{tabular}{|c|c|c|c|c|c|c|c|c|c|c|c|c|c|c|c|c|c|c|c|}
\hline Name of author(s) & $\begin{array}{l}\text { Setting - } \\
\text { Location - } \\
\text { dates }\end{array}$ & Target & Population & $\begin{array}{l}\text { Delivery } \\
\text { mode }\end{array}$ & $\begin{array}{l}\text { Screening } \\
\text { procedures }\end{array}$ & $\begin{array}{l}\text { Outcome } \\
\text { measures }\end{array}$ & Participants & $\begin{array}{l}\text { Control } \\
\text { group }\end{array}$ & $\begin{array}{l}\text { Treatment } \\
\text { group }\end{array}$ & $\begin{array}{l}\text { Nature of } \\
\text { Intervention }\end{array}$ & $\begin{array}{l}\text { Intervention } \\
\text { provider }\end{array}$ & $\begin{array}{l}\text { Experimental } \\
\text { conditions }\end{array}$ & $\begin{array}{l}\text { Duration } \\
\text { and number } \\
\text { of sessions }\end{array}$ & $\begin{array}{l}\text { Measure / } \\
\text { timescale }\end{array}$ & $\begin{array}{l}\text { Follow } \\
\text { up }\end{array}$ & $\begin{array}{l}\text { Summary of } \\
\text { main } \\
\text { outcomes }\end{array}$ & $\begin{array}{l}\text { Quality of } \\
\text { study }\end{array}$ & $\begin{array}{l}\text { Reporting } \\
\text { bias }\end{array}$ & Limitations \\
\hline $\begin{array}{l}60] \\
\text { Cooper et al (2003) } \\
\text { Adopted by }[48,53]\end{array}$ & $\begin{array}{l}\text { Participants } \\
\text { homes, } \\
\text { hospital } \\
\text { settings- } \\
\text { Cambridge, } \\
\text { England, Jan } \\
\text { 1990- Aug } \\
1992\end{array}$ & Treatment & $\begin{array}{l}\text { Women with } \\
\text { post-partum } \\
\text { depression, } \\
\text { being } \\
\text { primiparous, } \\
\text { living close } \\
\text { to maternity } \\
\text { hospital, and } \\
\text { English as } \\
\text { their first } \\
\text { language }\end{array}$ & $\begin{array}{l}\text { Individual } \\
\text {, home } \\
\text { visits }\end{array}$ & EPDS & $\begin{array}{l}\text { Therapist } \\
\text { Rating } \\
\text { Scale, } \\
\text { Kruskal- } \\
\text { Wallis test, } \\
\text { EPDS, } \\
\text { DSM-III-R } \\
\text { (SCID) }\end{array}$ & 193 & $\begin{array}{l}52, \\
\text { control } \\
\text { conditio } \\
\text { ns: } \\
\text { routine } \\
\text { primary } \\
\text { care } \\
\text { provide } \\
\text { d by the } \\
\text { general } \\
\text { practitio } \\
\text { ner and } \\
\text { health } \\
\text { visitors }\end{array}$ & $\begin{array}{l}\text { Counselling=4 } \\
\text { 8, CBT=42, } \\
\text { Psychodynami } \\
\mathrm{C}=48\end{array}$ & $\begin{array}{l}\text { "Psychodynamic, } \\
\text { non-directive } \\
\text { counselling, and } \\
\text { CBT which } \\
\text { focused on } \\
\text { issues in relation } \\
\text { to the infant that } \\
\text { the mothers } \\
\text { would find } \\
\text { difficult to cope } \\
\text { with, and on } \\
\text { issues in the } \\
\text { mother's } \\
\text { relationship with } \\
\text { the infant, } \\
\text { mothers were } \\
\text { given support } \\
\text { through advice to } \\
\text { manage } \\
\text { difficulties, used } \\
\text { problem-solving } \\
\text { techniques, } \\
\text { challenged } \\
\text { thinking patterns" }\end{array}$ & $\begin{array}{l}6 \text { in total } \\
\text { where } 3 \\
\text { experts in } \\
\text { each one of } \\
\text { the three } \\
\text { treatments, } \\
\text { and three } \\
\text { non- } \\
\text { specialists } \\
\text { health } \\
\text { visitors }\end{array}$ & $\begin{array}{l}\text { "Routine } \\
\text { primary care, } \\
\text { non-directive } \\
\text { counselling, } \\
\text { CBT, } \\
\text { psychodynami } \\
\text { c therapy" } \\
\end{array}$ & $\begin{array}{l}10 \text { weekly } \\
\text { sessions of } \\
\text { either CBT, } \\
\text { psychodyna } \\
\text { mic, or non- } \\
\text { directive } \\
\text { counselling }\end{array}$ & $\begin{array}{l}.5 \text { months, } 9 \\
\text { months, } 18 \\
\text { months, } 5 \text { years } \\
\text { post-partum }\end{array}$ & Yes & $\begin{array}{l}\text { "All three } \\
\text { interventions } \\
\text { had better } \\
\text { clinical } \\
\text { outcomes } \\
\text { than the } \\
\text { control } \\
\text { group, the } \\
\text { psychodyna } \\
\text { mic group } \\
\text { had a } \\
\text { superior } \\
\text { clinical effect } \\
\text { in } \\
\text { comparison } \\
\text { to the other } \\
\text { two } \\
\text { treatments } \\
\text { and to the } \\
\text { control } \\
\text { group on } \\
\text { depression } \\
\text { at } 4.5 \\
\text { months post- } \\
\text { partum, this } \\
\text { changed } \\
\text { subsequentl } \\
\text { y at } 9 \\
\text { months, } 18 \\
\text { months and } \\
\text { five years, } \\
\text { where no } \\
\text { real } \\
\text { difference } \\
\text { between } \\
\text { control and } \\
\text { intervention }\end{array}$ & $\begin{array}{l}\text { Good as they } \\
\text { "ensured } \\
\text { adherence to } \\
\text { the clinical } \\
\text { protocol" }\end{array}$ & Yes & $\begin{array}{l}\text { "Not all specialists } \\
\text { were familiar with } \\
\text { home visiting but only } \\
\text { the health visitors, thus } \\
\text { some of the } \\
\text { therapeutic outcomes } \\
\text { in the groups of } \\
\text { participants run by } \\
\text { specialists, CBT and } \\
\text { non-directive } \\
\text { counselling were very } \\
\text { low" }\end{array}$ \\
\hline
\end{tabular}




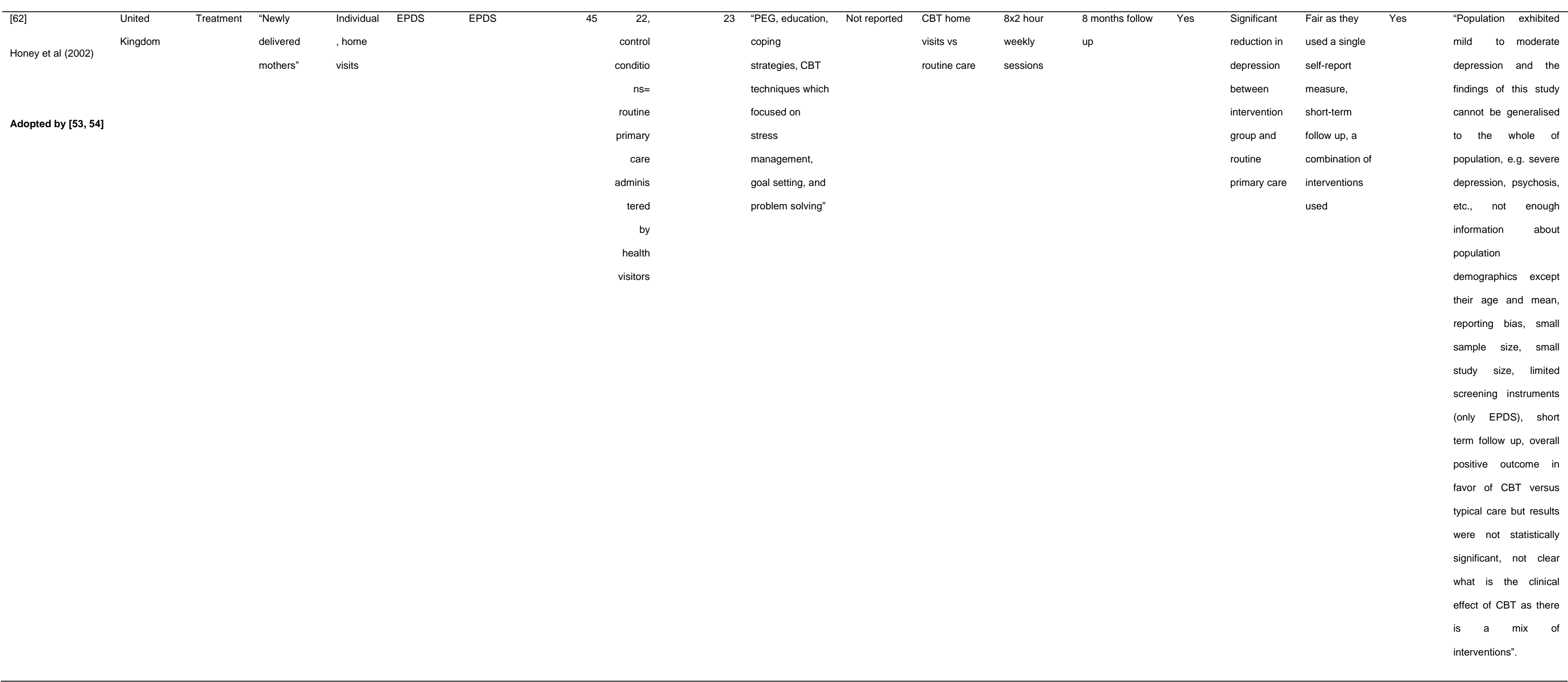




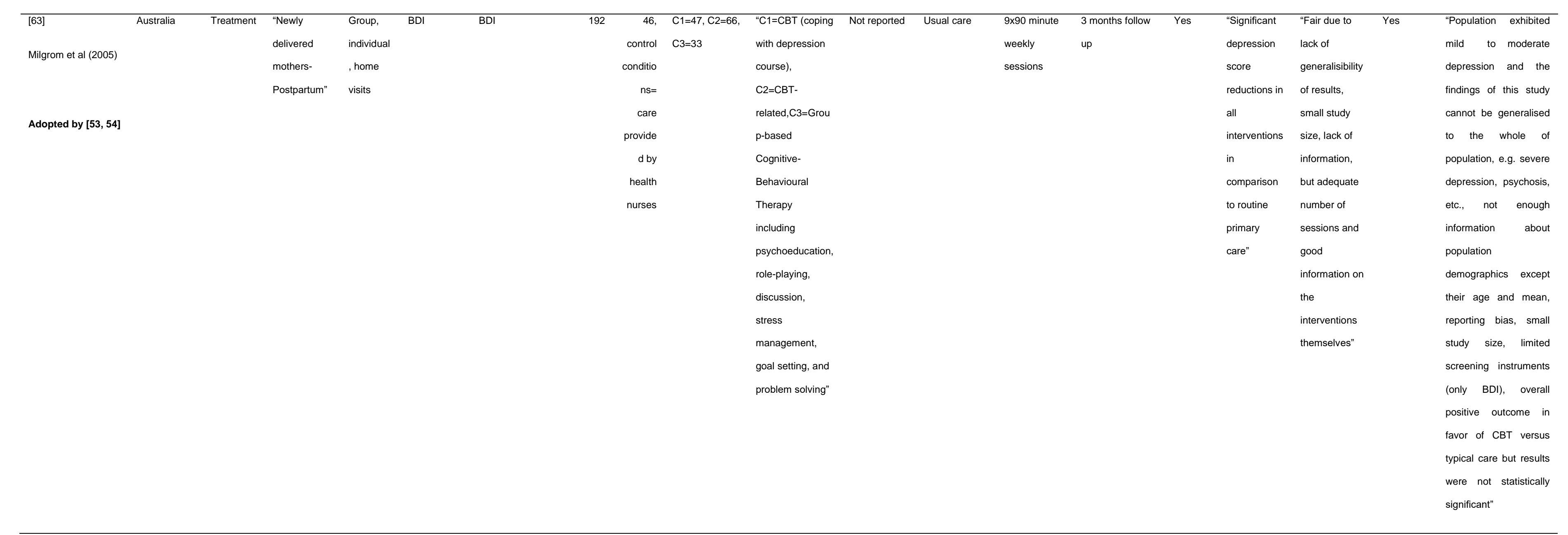




\begin{tabular}{|c|c|c|c|c|c|c|c|c|c|c|c|c|c|c|c|c|c|c|c|}
\hline Name of author(s) & $\begin{array}{l}\text { Setting- } \\
\text { Location - } \\
\text { dates }\end{array}$ & Target & Population & $\begin{array}{l}\text { Delivery } \\
\text { mode }\end{array}$ & $\begin{array}{l}\text { Screening } \\
\text { procedures }\end{array}$ & $\begin{array}{l}\text { Outcome } \\
\text { measures }\end{array}$ & Participants & $\begin{array}{l}\text { Control } \\
\text { group }\end{array}$ & $\begin{array}{l}\text { Treatment } \\
\text { group }\end{array}$ & $\begin{array}{l}\text { Nature of } \\
\text { Intervention }\end{array}$ & $\begin{array}{l}\text { Intervention } \\
\text { provider }\end{array}$ & $\begin{array}{l}\text { Experimental } \\
\text { conditions }\end{array}$ & $\begin{array}{l}\text { Duration } \\
\text { and number } \\
\text { of sessions }\end{array}$ & $\begin{array}{l}\text { Measure/ } \\
\text { timescale }\end{array}$ & $\begin{array}{l}\text { Follo } \\
\text { w up }\end{array}$ & $\begin{array}{l}\text { Summary of } \\
\text { main } \\
\text { outcomes }\end{array}$ & $\begin{array}{l}\text { Quality of } \\
\text { study }\end{array}$ & $\begin{array}{l}\text { Reportin } \\
g \text { bias }\end{array}$ & Limitations \\
\hline $\begin{array}{l}{[65]} \\
\text { Milgrom et al. (2011) } \\
\text { Adopted by [53] }\end{array}$ & Australia & Treatment & Postpartum & $\begin{array}{l}\text { Individual } \\
\text {, public } \\
\text { hospital, } \\
\text { home } \\
\text { visit, GP } \\
\text { practice }\end{array}$ & $\begin{array}{l}\text { EPDS, BDI- } \\
\|\end{array}$ & BDI-II & 68 & $\begin{array}{l}\text { Not } \\
\text { applica } \\
\text { ble }\end{array}$ & $\begin{array}{l}\text { GP } \\
\text { management= } \\
23, \text { counselling } \\
+ \text { CBT } \\
\text { delivered by } \\
\text { nurse-22, } \\
\text { counselling + } \\
\text { CBT delivered } \\
\text { by } \\
\text { psychologist=2 } \\
3\end{array}$ & $\begin{array}{l}\text { "CBT approach } \\
\text { focused on } \\
\text { stress } \\
\text { management, } \\
\text { goal setting, and } \\
\text { problem solving" }\end{array}$ & $\begin{array}{l}\text { GPs, primary } \\
\text { nurses, } \\
\text { psychologist } \\
\mathrm{s}\end{array}$ & $\begin{array}{l}\text { Management } \\
\text { by trained GP } \\
\text { vs. } \\
\text { Counselling- } \\
\text { CBT delivered } \\
\text { by a trained } \\
\text { nurses vs. } \\
\text { Counselling- } \\
\text { CBT delivered } \\
\text { by a } \\
\text { psychologist }\end{array}$ & $\begin{array}{l}3 \text { hours of } \\
\text { contact }\end{array}$ & $\begin{array}{l}2 \text { months follow } \\
\text { up }\end{array}$ & Yes & $\begin{array}{l}\text { All three } \\
\text { interventions } \\
\text { were effective } \\
\text { for treating } \\
\text { PND }\end{array}$ & $\begin{array}{l}\text { Not strong due } \\
\text { to lack of } \\
\text { control group, } \\
\text { short term } \\
\text { follow up, a } \\
\text { mix of } \\
\text { intervention } \\
\text { providers were } \\
\text { used }\end{array}$ & Yes & 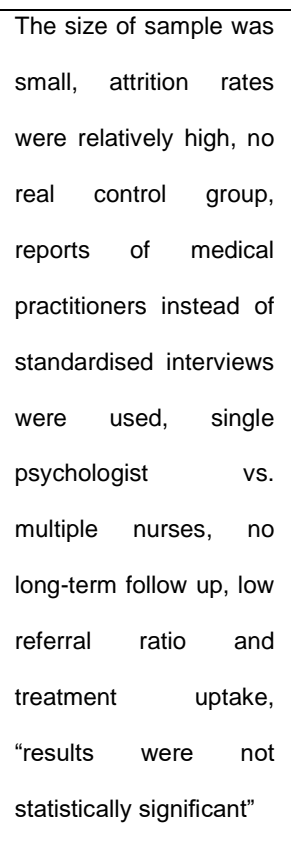 \\
\hline $\begin{array}{l}\text { [61] } \\
\text { Misri (2004) } \\
\text { Adopted by [51] }\end{array}$ & Canada & Treatment & $\begin{array}{l}\text { Postpartum } \\
\text { women } \\
\text { having been } \\
\text { diagnosed } \\
\text { with } \\
\text { depression }\end{array}$ & Individual & $\begin{array}{l}\text { HRSD, } \\
\text { EPDS }\end{array}$ & $\begin{array}{l}\text { HRSD, } \\
\text { EPDS }\end{array}$ & 35 & $\begin{array}{r}16, \\
\text { typical } \\
\text { care= } \\
\text { antidep } \\
\text { ressant } \\
\text { medicat } \\
\text { ion in a } \\
\text { hospital } \\
\text { outpatie } \\
\text { nt } \\
\text { progra } \\
\text { m }\end{array}$ & 19 & $\begin{array}{l}\text { "CBT which was } \\
\text { based on a } \\
\text { treatment manual } \\
\text { focused on } \\
\text { challenging and } \\
\text { moditying } \\
\text { dysfunctional } \\
\text { beliefs, and } \\
\text { correcting the } \\
\text { information } \\
\text { processing of the } \\
\text { individuals" }\end{array}$ & Psychologist & $\begin{array}{l}\text { Weekly 1-hour } \\
\text { CBT sessions } \\
\text { plus } \\
\text { antidepressan } \\
\text { t medication } \\
\text { vs standard } \\
\text { care } \\
\text { (antidepressa } \\
\text { nt medication) }\end{array}$ & $\begin{array}{l}12 \text { one hour } \\
\text { sessions plus } \\
\text { medication }\end{array}$ & $\begin{array}{l}12 \text { weeks post- } \\
\text { treatment }\end{array}$ & Yes & $\begin{array}{l}\text { CBT has a } \\
\text { good } \\
\text { therapeutic } \\
\text { effect on PND }\end{array}$ & $\begin{array}{l}\text { Not strong as } \\
\text { "it provided } \\
\text { data on } \\
\text { anxiety", "the } \\
\text { timing of the } \\
\text { final outcome } \\
\text { assessment } \\
\text { was } \\
\text { immediately } \\
\text { post- } \\
\text { treatment", } \\
\text { "blinding of } \\
\text { caregivers } \\
\text { was not } \\
\text { possible as } \\
\text { they were } \\
\text { involved in the } \\
\text { intervention" }\end{array}$ & Yes & $\begin{array}{l}\text { Small sample size, it is } \\
\text { demanding in terms of } \\
\text { commitment on behalf } \\
\text { of the participants, it is } \\
\text { expensive and time } \\
\text { consuming, high } \\
\text { percentage of } \\
\text { participants failing to } \\
\text { "complete" treatment, } \\
\text { CBT is combined with } \\
\text { medication, no } \\
\text { reporting of size of } \\
\text { control and } \\
\text { experimental groups, } \\
\text { however they "used } \\
\text { manualised } \\
\text { interventions and } \\
\text { attempted to ensure } \\
\text { adherence to the } \\
\text { treatment protocol" }\end{array}$ \\
\hline
\end{tabular}




\begin{tabular}{|c|c|c|c|c|c|c|c|c|c|c|c|c|c|c|c|c|c|c|c|}
\hline \multirow{4}{*}{$\begin{array}{l}55] \\
\text { Morrell (2006) }\end{array}$} & United & \multirow[t]{20}{*}{ Treatment } & Postpartum & $\begin{array}{l}\text { Individual } \\
\end{array}$ & EPDS & EPDS & 595 & 191, & 404 & "CBT treatment & "Health & A weekly & 8 one-hour & 24,52, and 72 & Yes & "It compared & Not strong as & Not clear & It is demanding in terms \\
\hline & Kingdom & & women & , home & & & & control & & focused on & visitors, & basis for one & sessions & weeks & & psychological & big sample & & of commitment on \\
\hline & & & identifying & visits & & & & conditio & & modifying & nurses" & hour up to a & & postpartum & & with & size but no & & behalf of the \\
\hline & & & with & & & & & $\mathrm{ns}=$ & & dystunctional & & maximum of 8 & & & & psychosocial & information on & & participants, it is \\
\hline \multirow{16}{*}{ Adopted by [51] } & & & depressive & & & & & particip & & beliefs, and & & weeks, $C B T$, & & & & interventions" & the number of & & expensive and time \\
\hline & & & symptomatol & & & & & ants & & correcting the & & and non- & & & & CBT has a & participants on & & consuming, high \\
\hline & & & ogy through & & & & & referred & & information & & directive & & & & good & control and & & percentage of \\
\hline & & & self-report & & & & & to & & processing of the & & counselling & & & & therapeutic & experimental & & participants falling to \\
\hline & & & measures & & & & & general & & individuals" & & vs. standard & & & & effect on post- & groups in the & & "complete" treatment, \\
\hline & & & & & & & & practitio & & & & primary care & & & & natal & review, use of & & high attrition rate at 24 \\
\hline & & & & & & & & ners by & & & & & & & & depression, & self-report & & weeks post-partum, no \\
\hline & & & & & & & & health & & & & & & & & non-directive & measures & & information on the \\
\hline & & & & & & & & visitors & & & & & & & & counselling & & & number of participants \\
\hline & & & & & & & & & & & & & & & & can also be & & & on the control group \\
\hline & & & & & & & & & & & & & & & & effective in & & & and intervention group \\
\hline & & & & & & & & & & & & & & & & treating post- & & & \\
\hline & & & & & & & & & & & & & & & & natal & & & \\
\hline & & & & & & & & & & & & & & & & depressive & & & \\
\hline & & & & & & & & & & & & & & & & symptomatolog & & & \\
\hline & & & & & & & & & & & & & & & & y & & & \\
\hline \multirow{5}{*}{$\begin{array}{l}{[16]} \\
\text { O'Hara (2000) }\end{array}$} & United & \multirow[t]{22}{*}{ Treatment } & Women & Individual & $\mathrm{SCID}$ & HRSD, & 120 & 51 & 48 & Interpersonal & "Trained & Interpersonal & 12 hour & 44,8, and 12 & No & "IPT is an & Fair as the & Not clear & No follow up so long- \\
\hline & States & & identified & & HRSD, BDI, & $\mathrm{BDI}, \mathrm{PAQ}$ & & control & & psychotherapy & therapists" & psychotherapy & sessions over & weeks post- & & efficacious & sample size is & & term effect of treatment \\
\hline & & & through a & & $\mathrm{PAQ}$ & SASSR & & conditio & & using & & vs waiting list & 12 weeks & randomisation" & & treatment for & descent, & & is unknown, doesn't \\
\hline & & & multi-stage & & SASSR & & & $\mathrm{ns}=$ & & psychosocial and & & & & & & postpartum & population is & & measure \\
\hline & & & community & & & & & wating & & psychological & & & & & & depression. It & diagnosed & & relationship between \\
\hline \multirow{17}{*}{ Adopted by [51, 52] } & & & screening & & & & & list & & components & & & & & & reduced & with major & & mother and newborn \\
\hline & & & process for & & & & & & & compared to a & & & & & & depressive & depression, & & baby, not clear if the \\
\hline & & & depression, & & & & & & & waiting list & & & & & & symptoms and & use of multiple & & intervention \\
\hline & & & "social & & & & & & & & & & & & & improved & instruments, & & delivered at home or \\
\hline & & & adjustment, & & & & & & & & & & & & & social & use of trained & & was clinically based \\
\hline & & & marital & & & & & & & & & & & & & adjustment, & therapists, but & & \\
\hline & & & relations, and & & & & & & & & & & & & & and represents & no follow up, & & \\
\hline & & & postpartum & & & & & & & & & & & & & an alternative & positive results & & \\
\hline & & & adjustment" & & & & & & & & & & & & & to & on mother- & & \\
\hline & & & & & & & & & & & & & & & & pharmacothera & infant & & \\
\hline & & & & & & & & & & & & & & & & py, particularly & relationships & & \\
\hline & & & & & & & & & & & & & & & & for women who & do not reflect & & \\
\hline & & & & & & & & & & & & & & & & are & the & & \\
\hline & & & & & & & & & & & & & & & & breastffeeding", & relationship & & \\
\hline & & & & & & & & & & & & & & & & improvement & with the & & \\
\hline & & & & & & & & & & & & & & & & on all & newborn baby & & \\
\hline & & & & & & & & & & & & & & & & questionnaires & & & \\
\hline
\end{tabular}




\begin{tabular}{|c|c|c|c|c|c|c|c|c|c|c|c|c|c|c|c|c|c|c|c|}
\hline Name of author(s) & $\begin{array}{l}\text { Setting - } \\
\text { Location - } \\
\text { dates }\end{array}$ & Target & Population & $\begin{array}{l}\text { Delivery } \\
\text { mode }\end{array}$ & $\begin{array}{l}\text { Screening } \\
\text { procedures }\end{array}$ & $\begin{array}{l}\text { Outcome } \\
\text { measures }\end{array}$ & Participants & $\begin{array}{l}\text { Control } \\
\text { group }\end{array}$ & $\begin{array}{l}\text { Treatment } \\
\text { group }\end{array}$ & $\begin{array}{l}\text { Nature of } \\
\text { Intervention }\end{array}$ & $\begin{array}{l}\text { Interventio } \\
n \text { provider }\end{array}$ & $\begin{array}{l}\text { Experimental } \\
\text { conditions }\end{array}$ & $\begin{array}{l}\text { Duration } \\
\text { and number } \\
\text { of sessions }\end{array}$ & $\begin{array}{l}\text { Measure/ } \\
\text { timescale }\end{array}$ & $\begin{array}{l}\text { Follo } \\
\text { w up }\end{array}$ & $\begin{array}{l}\text { Summary of } \\
\text { main } \\
\text { outcomes }\end{array}$ & $\begin{array}{l}\text { Quality of } \\
\text { study }\end{array}$ & $\begin{array}{l}\text { Reportin } \\
g \text { bias }\end{array}$ & Limitations \\
\hline $\begin{array}{l}{[57]} \\
\text { Prendergast and } \\
\text { Austin (2001) }\end{array}$ & Australia & Treatment & $\begin{array}{l}\text { Women } \\
\text { identified } \\
\text { with } \\
\text { depression- } \\
\text { "Community } \\
\text { sample"- } \\
\text { postpartum }\end{array}$ & Individual & $\begin{array}{l}\text { DSM-IV, } \\
\text { EPDS }\end{array}$ & $\begin{array}{l}\text { EPDS, } \\
\text { MADRS }\end{array}$ & 37 & $\begin{array}{r}20, \\
\text { control } \\
\text { conditio } \\
\text { ns= } \\
\text { "standa } \\
\text { rd care } \\
\text { with } 6 \\
\text { weekly } \\
\text { clinic } \\
\text { visits } \\
\text { lasting } \\
20 \text { to } \\
60 \\
\text { minutes } \\
\text { " }\end{array}$ & 17 & $\begin{array}{l}\text { Home visits- } \\
\text { "CBT sessions", } \\
\text { CBT focused on } \\
\text { techniques such } \\
\text { as challenging } \\
\text { and modifying } \\
\text { negative } \\
\text { automatic } \\
\text { thoughts and } \\
\text { dysfunctional } \\
\text { beliefs, } \\
\text { increasing } \\
\text { pleasant stimuli } \\
\text { and reducing } \\
\text { behaviours which } \\
\text { could have a } \\
\text { negative effect } \\
\text { on mood }\end{array}$ & $\begin{array}{l}\text { "Early } \\
\text { Childhood } \\
\text { Nurses" }\end{array}$ & $\begin{array}{l}\text { CBT vs } \\
\text { standard care } \\
\text { ("weekly clinic } \\
\text { visits") }\end{array}$ & $\begin{array}{l}\text { "6 weekly } \\
\text { CBT } \\
\text { sessions" }\end{array}$ & $\begin{array}{l}10 \text { weeks post- } \\
\text { partum }\end{array}$ & Yes & $\begin{array}{l}\text { No difference } \\
\text { between the } \\
\text { two groups } \\
\text { post- } \\
\text { intervention but } \\
\text { better outcome } \\
\text { for the } \\
\text { intervention } \\
\text { group six } \\
\text { months follow } \\
\text { up but not } \\
\text { statistical } \\
\text { significicant }\end{array}$ & $\begin{array}{l}\text { Fair as "they } \\
\text { followed } \\
\text { participants } \\
\text { over time" } \\
\text { "used } \\
\text { manualised } \\
\text { interventions } \\
\text { and attempted } \\
\text { to ensure } \\
\text { adherence to } \\
\text { the treatment } \\
\text { protocol" }\end{array}$ & Not clear & $\begin{array}{l}\text { "Although the efficacy } \\
\text { of the interventions has } \\
\text { been demonstrated for } \\
\text { some outcomes, } \\
\text { effectiveness studies } \\
\text { are required to } \\
\text { establish whether such } \\
\text { benefits would be } \\
\text { obtained in routine } \\
\text { practice", 55\% drop out } \\
\text { rate for control group, } \\
\text { small sample size, no } \\
\text { "intention-totreat } \\
\text { analysis" }\end{array}$ \\
\hline $\begin{array}{l}\text { [56] } \\
\text { Rahman (2008) } \\
\text { Adopted by [47] }\end{array}$ & Pakistan & Treatment & $\begin{array}{l}\text { Pregnant } \\
\text { women, who } \\
\text { were } \\
\text { married, } \\
\text { between 16- } \\
45 \text { years old, } \\
\text { and had } \\
\text { depression }\end{array}$ & Individual & $\begin{array}{l}\text { DSM-IV } \\
\text { clinical } \\
\text { interview, } \\
\text { HDRS }\end{array}$ & $\begin{array}{l}\text { DSM-IV } \\
\text { clinical } \\
\text { interview, } \\
\text { HDRS }\end{array}$ & $\begin{array}{l}903 \text { (105 lost } \\
\text { in follow up) }\end{array}$ & $\begin{array}{l}440 \text { (54 } \\
\text { lost in } \\
\text { follow } \\
\text { up), } \\
\text { control } \\
\text { conditio } \\
\text { ns= } \\
\text { routine } \\
\text { care } \\
\text { with } \\
\text { regular } \\
\text { weekly } \\
\text { visits in } \\
\text { the last } \\
\text { month } \\
\text { before } \\
\text { birth, } \\
\text { and } \\
\text { monthly }\end{array}$ & $\begin{array}{l}463 \text { (51 lost in } \\
\text { follow up) }\end{array}$ & $\begin{array}{l}\text { Home based } \\
\text { CBT intervention } \\
\text { which was part of } \\
\text { a community } \\
\text { health program } \\
\text { called "Thinking } \\
\text { Healthy", CBT } \\
\text { approach used } \\
\text { pictures and } \\
\text { structured } \\
\text { activities for } \\
\text { achieving } \\
\text { specilic everyday } \\
\text { goals }\end{array}$ & $\begin{array}{l}\text { "Community } \\
\text { health } \\
\text { workers" }\end{array}$ & $\begin{array}{l}\text { "Enhanced } \\
\text { care involving } \\
\text { home visits" } \\
\text { vs. usual care }\end{array}$ & $\begin{array}{l}16 \text { sessions } \\
\text { in } 11 \text { months, } \\
1.5 \text { sessions } \\
\text { per month }\end{array}$ & $\begin{array}{l}6 \text { and } 12 \text { months } \\
\text { postnatally }\end{array}$ & Yes & $\begin{array}{l}\text { "Non-mental } \\
\text { health } \\
\text { professional } \\
\text { can deliver } \\
\text { positive } \\
\text { psychosocial } \\
\text { interventions } \\
\text { with good } \\
\text { therapeutic } \\
\text { outcomes in } \\
\text { middle-income } \\
\text { countries" }\end{array}$ & $\begin{array}{l}\text { Fair as this } \\
\text { study } \\
\text { examined } \\
\text { antenatal and } \\
\text { post-natal } \\
\text { depression } \\
\text { and the timing } \\
\text { of the } \\
\text { intervention } \\
\text { was delivered } \\
\text { in two stages, } \\
\text { in the third } \\
\text { trimester of } \\
\text { pregnancy and } \\
\text { ten months } \\
\text { postnatally, } \\
\text { adequate info } \\
\text { on attrition } \\
\text { rates of }\end{array}$ & $\begin{array}{l}\text { Yes, "low } \\
\text { risk of } \\
\text { bias on } \\
\text { blinding } \\
\text { of } \\
\text { participan } \\
\text { ts and } \\
\text { personnel } \\
\text {, and of } \\
\text { outcome } \\
\text { assessm } \\
\text { ent, and } \\
\text { no } \\
\text { selective } \\
\text { reporting" }\end{array}$ & $\begin{array}{l}\text { "Highlights stigma of } \\
\text { depression on mothers } \\
\text { and unrealistic to } \\
\text { expect mothers would } \\
\text { be supported to } \\
\text { participate in studies as } \\
\text { such, resource } \\
\text { demanding in resource } \\
\text { limited countries due to } \\
\text { the use of professionals } \\
\text { over a lengthy period of } \\
\text { time, disadvantaged } \\
\text { over preventive } \\
\text { treatments, also } \\
\text { disadvantaged due to } \\
\text { individual delivery vs. } \\
\text { Group based", " unable } \\
\text { to carry out a subgroup } \\
\text { analysis of treatment }\end{array}$ \\
\hline
\end{tabular}




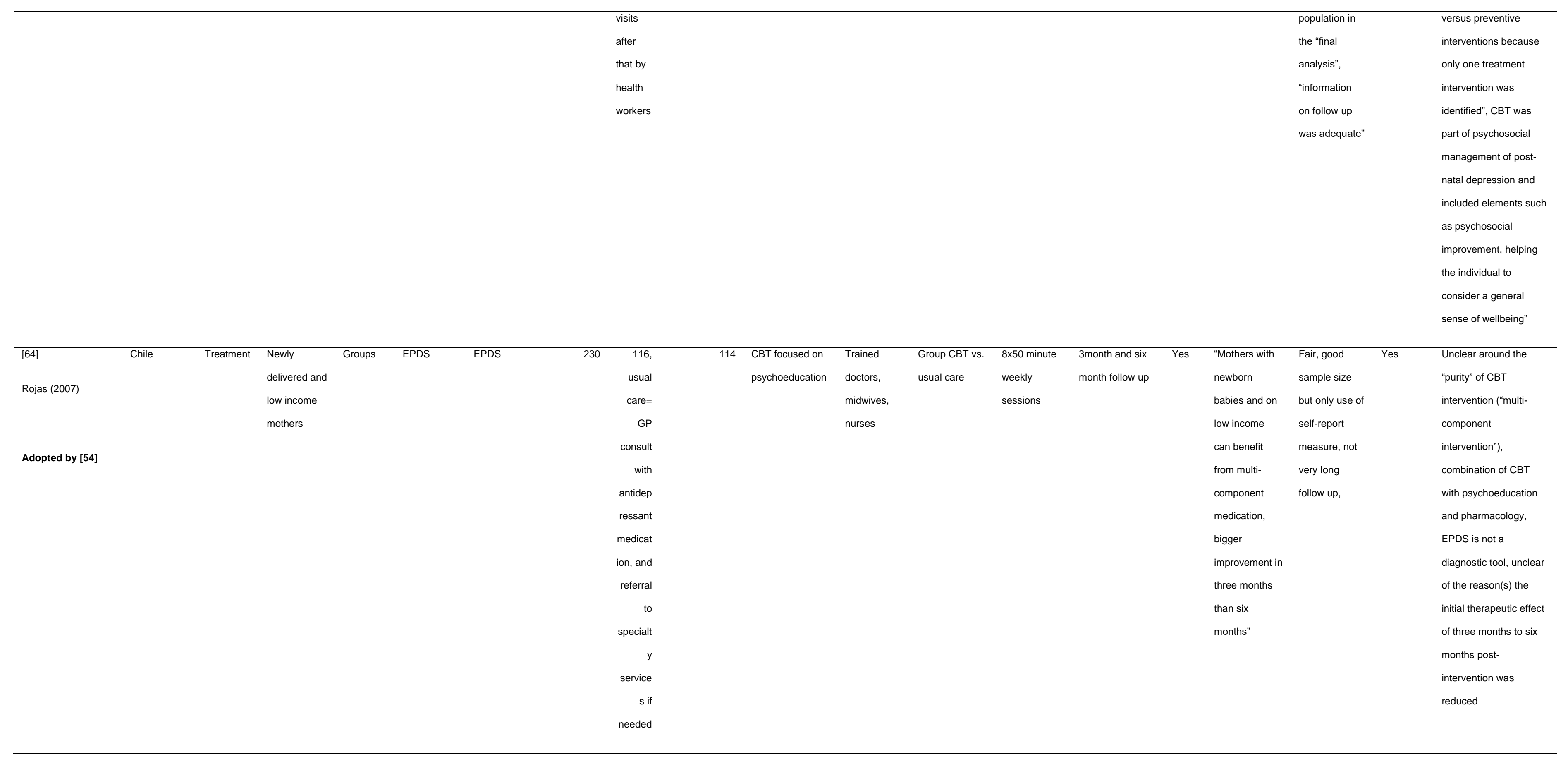




\begin{tabular}{|c|c|c|c|c|c|c|c|c|c|c|c|c|c|c|c|c|c|c|c|c|}
\hline Name of author(s) & $\begin{array}{l}\text { Setting - } \\
\text { Location - } \\
\text { dates }\end{array}$ & Target & Population & $\begin{array}{l}\text { Delivery } \\
\text { mode }\end{array}$ & $\begin{array}{l}\text { Screening } \\
\text { procedures }\end{array}$ & $\begin{array}{l}\text { Outcome } \\
\text { measures }\end{array}$ & Participants & $\begin{array}{l}\text { Control } \\
\text { group }\end{array}$ & $\begin{array}{l}\text { Treatment } \\
\text { group }\end{array}$ & & $\begin{array}{l}\text { Nature of } \\
\text { Intervention }\end{array}$ & $\begin{array}{l}\text { Intervention } \\
\text { provider }\end{array}$ & $\begin{array}{l}\text { Experimental } \\
\text { conditions }\end{array}$ & $\begin{array}{l}\text { Duration } \\
\text { and number } \\
\text { of sessions }\end{array}$ & $\begin{array}{l}\text { Measure/ } \\
\text { timescale }\end{array}$ & $\begin{array}{l}\text { Follo } \\
\text { wup }\end{array}$ & $\begin{array}{l}\text { Summary of } \\
\text { main } \\
\text { outcomes }\end{array}$ & $\begin{array}{l}\text { Quality of } \\
\text { study }\end{array}$ & $\begin{array}{l}\text { Reportin } \\
g \text { bias }\end{array}$ & Limitations \\
\hline $\begin{array}{l}\text { [66] } \\
\text { Wiklund et al (2010) } \\
\text { Adopted by [53] }\end{array}$ & Sweden & Treatment & $\begin{array}{l}\text { Postpartum - } \\
\text { mothers with } \\
\text { signs of } \\
\text { depression }\end{array}$ & $\begin{array}{l}\text { Individual } \\
\text {, } \\
\text { maternity } \\
\text { clinic }\end{array}$ & EPDS & EPDS & 67 & $\begin{array}{r}34, \\
\text { standar } \\
\mathrm{d} \text { care= } \\
\text { a single } \\
\text { session } \\
\text { with a } \\
\text { midwife } \\
\text { or } \\
\text { obstetri } \\
\text { cian } \\
\text { focusin } \\
\text { g on } \\
\text { debrief }\end{array}$ & & 33 & $\begin{array}{l}\text { CBT approach } \\
\text { focused on } \\
\text { "stress } \\
\text { management, } \\
\text { goal setting, and } \\
\text { problem solving" }\end{array}$ & Midwives & $\begin{array}{l}\text { CBT vs } \\
\text { standard care }\end{array}$ & $\begin{array}{l}21 \text { hours of } \\
\text { contact }\end{array}$ & $\begin{array}{l}2.75 \text { months } \\
\text { follow up }\end{array}$ & Yes & $\begin{array}{l}\text { "Brief CBT is } \\
\text { effective in } \\
\text { treating women } \\
\text { with signs of } \\
\text { depression" }\end{array}$ & $\begin{array}{l}\text { Fair as small } \\
\text { sample size } \\
\text { and use of } \\
\text { self-report } \\
\text { measure, } \\
\text { sufficient time } \\
\text { of intervention } \\
\text { allocation, } \\
\text { short-term } \\
\text { follow up }\end{array}$ & Yes & $\begin{array}{l}\text { "Population had not } \\
\text { been diagnosed with } \\
\text { post-natal depression, } \\
\text { and thus findings of this } \\
\text { study cannot be } \\
\text { generalised, not } \\
\text { enough information } \\
\text { about population } \\
\text { demographics, } \\
\text { reporting bias, small } \\
\text { study size, limited } \\
\text { screening instruments } \\
\text { (only EPDS), short term } \\
\text { follow up, results not } \\
\text { statistically significant, } \\
\text { not certain on long-term } \\
\text { effectiveness of CBT, } \\
\text { lack of clinical } \\
\text { diagnostic procedure" }\end{array}$ \\
\hline
\end{tabular}

*all sentences in "quotes" are an exact copy of the original statement from the authors, and all abbreviations are included after the limitations section 


\section{Quality of studies}

The quality of the studies varied from not strong to very good, with most to be considered fair.

This was based on the randomisation process, sample size, heterogeneity of methods, use of instruments, treatment protocol, generalisability and statistical significance of results, follow ups, and limitations of each study. Most studies reported bias except five studies for which it was unclear $[16,49,55,57,58]$.

\section{Treatment focus}

Fourteen studies focused solely on the treatment of PND, one on the treatment of ante-natal depression and PND [56], and one on prevention and treatment of PND [50].

Almost all studies, except one [16], focused mostly on depressive symptomatology of the mother as a primary outcome measure.

\section{Population studied}

In the 15 studies the population, which in total were 2758 , were either diagnosed with depression or had identified themselves as depressed. More specifically in six of the 15 studies the population were post-partum women who had been diagnosed through a clinical interview based on the DSMIV $[16,49,57,59,60,61]$. In one of them, the population were 16 years and older [56]. In the remaining 9 studies the participants would mostly identify with depressive symptomatology, mostly through interview based questionnaires such as HAM-D, or self-report questionnaires such as EPDS. In 2 out of the 9 studies the populations were "newly delivered mothers" [62, 63], and in one study, they were newly delivered mothers with low income [64]. 


\section{Control groups}

The control groups were made up of participants who would usually receive typical primary care, or they were on a waiting list. However, two out of the fifteen studies in the review did not have a control group [49,65]. For example, the study by Appleby et al. [49] included four study groups which all received some kind of intervention. The study by Milgrom et al. [65] included three groups which all had some type of intervention.

In addition, it was not clear what the control conditions were for two other studies [58,62]. For example, in the study by Honey et al. [62] the control conditions were routine primary care administered by health visitors, and in the study by Bennet et al. [58] the control conditions were standard primary care with a health visitor. However it was not clear whether, in either studies, the routine primary care involved GP visits, medication, both, or none.

In the remaining 11 studies, the control conditions were as follows: waiting list [16], health visitors contacting participants, and defining their postnatal care with the use of questionnaires and referring them to their general practitioners [55], enhanced routine care with regular weekly visits in the last month before birth, 1 month post birth and monthly visits for the next 9 months by routinely trained health workers who received regular supervision but they were not specialised in CBT [56], routine care in the form of clinic visits [50], home visits which focused on "child health and development, nurturing mother-child relationship, maternal health and self-sufficiency", along with receiving treatment in the community [59], routine primary care which "would be typically provided by the primary health care team such as the general practitioner and health visitors with no additional input from the research team" [60], antidepressant medication received by control group subjects in a hospital outpatient program [61], "standard care with 6 weekly clinic visits lasting 20 to 60 minutes" [57], health nurses who would manage case by case the participants and refer them to other services where appropriate [63], antidepressant medication, brief psychotherapeutic interventions, GP consult, or referral to specialty services [64], and a single session with a midwife or obstetrician focusing on debrief [66]. 


\section{Delivery of the interventions}

In terms of the delivery of the interventions, 12 were individual-based and home visits, 2 were group-based [58,64], and 1 study was carried out on an individual basis and was also group based [63]. Most interventions were delivered in the homes of the participants. One study was delivered at home and in a public hospital. One study provides no data relating to delivery of the intervention.

\section{Locations of the studies}

Five studies took place in the United Kingdom, three studies in Australia, two studies in the United States, one study in France, one study in Canada, one in Pakistan, one study in Chile, and one study in Sweden.

\section{Number of sessions and content of the interventions}

The interventions in all of the studies varied in terms of the number of clinical hours and number of sessions. The majority of studies provided the number of sessions and number of clinical hours. However, 4 of the 15 studies $[49,56,57,60]$ provided only the number of sessions and not the number of clinical hours. The total number of clinical hours was approximately 168.5 , with 1648 people having been provided with at least one of those interventions. The average number of clinical hours for each participant was 9.78. The average treatment period was 12.1 weeks.

The interventions were CBT based and most studies were a comparison between CBT and usual primary care. However one study compared 4 groups which all received some kind of treatment. The experimental conditions were medication with 1 CBT session, medication with 6 CBT sessions, placebo with 1 CBT session, and placebo with 6 CBT sessions [49]. Another study also did not have a control group but rather three intervention groups [65]. 2 CBT interventions included elements of psychoeducation, cognitive restructuring, and relaxation exercises [58,63], one study compared CBT delivered at home vs CBT delivered in a clinic [50], one study compared the three 
main interventions, i.e. CBT, non-directive counselling, and psychodynamic, and in comparison with usual care [60], one study used CBT and the psychodynamic approach [5], one intervention compared CBT delivered either by psychologists, nurses, and GPs [65], another study compared CBT in combination with medication vs. primary care [61], and lastly one study compared interpersonal psychotherapy vs. a waiting list [16]. In Table 2-2 we included a summary of the components included in the intervention protocols and the number of studies that used each of the components.

Table 2-2 Summary of all CBT components for the treatment of PND

\begin{tabular}{l|l}
\hline Treatment & Number of studies \\
\hline Psychoeducation (i.e., Advice given for supporting mothers to & 9 \\
manage difficulties, mother-infant relationship issues) & \\
\hline Cognitive restructuring (i.e. Challenging and modifying negative & 9 \\
automatic thoughts and dysfunctional beliefs, information & \\
processing correction) & \\
\hline Problem solving & 7 \\
\hline Behaviour management: Increasing pleasant stimuli or reducing & 6 \\
behaviours which could have a negative effect on mood & \\
\hline Goal setting and Goal achieving daily using pictures and & 6 \\
structured activities & 6 \\
\hline Stress management & 1 \\
\hline Relaxation & \\
\hline
\end{tabular}




\section{Intervention providers}

The intervention providers varied from nurses, psychologists, GPs, health visitors, and midwives. Almost all, except two studies [16, 50], included follow-ups varying from 1 week postpartum to 5 years following the birth of the child. The average period of follow-ups was 6.14 months.

\section{Clinical trials using VR for the treatment of PND}

We found no clinical trials that used VR for the treatment of PND. However, we found three studies in total $[40,67,68]$ which used some form of technology. Two of them $[67,68]$ used video recordings, mostly for supervision purposes. The third study [40] was internet based for the delivery of CBT.

\section{DISCUSSION}

\section{What CBT psychological treatments are effective for PND?}

All fifteen studies included in our review used CBT as the main treatment for PND. However, there were 9 studies which compared CBT to other treatments such as non-directive counselling, psychodynamic and primary care, and 3 studies where CBT was combined with non-directive counselling, psychodynamic and primary care.

It appears that CBT can be viewed as a large clinical territory with many different techniques for the treatment of the same mental health issue. For example, in one study, CBT emphasised psychoeducation [64] while in other studies CBT focused on challenging negative thoughts and dysfunctional beliefs $[55,57]$. In another study CBT was part of a wider community based program [64]. In the study by Rojas, the "purity" of the CBT approach was questionable [64]. 
We measured 7 components of CBT that were used for the treatment of PND, which were psychoeducation, cognitive restructuring, problem-solving, behaviour management, goal setting and goal achieving, stress management, and relaxation (Table 2-2).

The two most frequent used CBT interventions were found to be psychoeducation and challenging negative thoughts and beliefs with 9 studies in total having employed both at different times.

The second most frequent CBT intervention that was used was problem solving, while the third most frequently used CBT interventions were goal setting, behaviour management, and stress management.

\section{What are the parameters that make those treatments having a successful clinical outcome?}

This review shows the general outcome is that CBT as a therapeutic intervention is effective for the treatment of PND. It has an advantage over primary care for reducing depressive symptomatology in the post-partum period. However, the severity of PND varied in the included studies in our review, with most of the participants to be in the mild to moderate range. Thus it is unknown whether the same positive clinical results of CBT would be obtained for the more severe range of depression.

Another issue that was identified in relation to the effectiveness of CBT was the significance of the results. In five out of fifteen studies $[60,62,63,65,66]$ it was found that their results on CBT's effectiveness were positive overall but not statistically significant.

It is important to mention that although our review focused on CBT there were studies that compared CBT with other psychotherapeutic approaches that also showed effectiveness. It was found that non-directive counselling and psychodynamic approaches also had a positive effect 
on the reduction of symptoms of PND. To be more precise in the study conducted by Cooper et al. [60] which examined CBT, non-directive counselling and psychodynamic therapy, and compared them with typical primary care, it was found that all three interventions were effective. CBT was more effective on cognitive focus, behavioural tasks, and organisation. Nonetheless, the psychodynamic approach was more effective on relationships. It was also superior to the other two interventions in terms of depressive symptomatology according to structured interviews, especially up until the fifth month post-intervention. However, past that point, the initial therapeutic effect of all three interventions had started diminishing. From 9 months onwards up until 5 years post-intervention, the initial therapeutic effect was virtually nonexistent.

Other studies have found similar results, whether the outcome is measured by self-reported measures or by a mental health professional conducting a clinical interview. CBT can be an effective treatment for PND in the short-term but its clinical effect long-term is questionable [65]. The same study measured the combination of CBT with counselling delivered either by a psychologist or a nurse. They found that the two approaches and a third one which was GP management, mainly through medication, had a good overall effect in the treatment of PND. We can conclude that CBT is an effective approach that can be delivered by various mental health professionals of different backgrounds, or even delivered by non-experts, such as lay people, or health visitors $[56,58]$.

It can also be concluded that CBT can be delivered in a flexible manner, whether through a home visit, or in a public place such as a hospital or clinic $[65,66]$. There does, however, appear to be a preference toward home visits as it is believed to be more convenient and accessible to post-partum women with depression.

In addition to the treatment type and location CBT can be delivered in a brief manner which can have good therapeutic outcomes. According to Wiklund et al. [66] there is some evidence that 
brief CBT can benefit PND in the mild to moderate range. However it is worth noting that the population of that study were women who had not been diagnosed with depression but who only experienced signs of depression.

From the studies of this review we can conclude that CBT can also be delivered on an individual level or in a group $[58,63]$. It seems that the individual delivery of the intervention is preferential and maybe the potential of the group intervention of CBT has not been adequately investigated. We can safely assume though that group intervention might have some advantages over individual treatment such as utilising less resources. At the same time it might be a disadvantage in terms of participants who might be more reluctant to participate initially in a group setting, where its participants share the same psychological experiences. This possibly underlines stigma on a societal level but this needs to be further investigated.

The studies of this review also show that CBT's positive therapeutic outcome on PND is not impacted by the socioeconomic status of the population. Post-partum women with depression can benefit equally whether they are from a lower-middle income country or high income country. This review includes studies from different countries and continents and are categorised differently according to the GDP per capita, e.g. Australia vs. Chile $[64,65]$.

Another conclusion of this review is around the outcome measures. Most studies in this review measured individual depressive symptomatology in the post-partum period. However, one study [16] focused on the mother's depression and measured it as a primary outcome. The authors included additional information, e.g. mother-infant relationship. It is worth mentioning here that the relationship between mother-infant was not in relation to the newborn baby, but rather on the already existing children in the family.

An issue that was raised was in relation to the target disorder and the self-reported measures which were used by the participants of some of the studies. The self-reported measures indicate 
depressive methodology but they do not necessarily ensure a formal diagnosis of depression. There was a lack of clinical diagnostic protocols in some of the studies.

A difficulty that one of the studies highlights was in relation to CBT. CBT was considered to be time consuming and highly demanding in terms of resource intervention [55]. Treating PND with populations of low socioeconomic characteristics, or in countries of low to middle income would prove to be a challenging task. Providing treatment to depressed mothers overall has been proven to be a challenging task on its own, especially in relation to the delivery of intervention. It becomes clear that home visits are a preferable way of delivery over GP practice or a public hospital for varying reasons. A young mother, or a mother with a high-demanding household might find it difficult to transport herself outside her home for a number of reasons, including a lack of transportation, money or time.

Another issue that was highlighted in our research was around the stigma of mental health issues. One study highlights the difficulties a clinical population, or mental health professionals might encounter in rural areas or low-income countries [56]. One way that the authors were able to deal with this issue was to support the idea that the CBT intervention was part of a larger community health program. Another way was that they promoted the idea of the infant's health and well-being as a priority.

Some studies had a high attrition rate up to $30 \%$ but not all of them. It was reported that some participants did not complete the treatment. There was also a variation in terms of their length, and number of phases in the follow up process. All studies except two $[16,50]$ had follow ups with variations in frequency the follow ups were conducted for the majority of the studies and the span of the time period over which this happened, e.g. 2 months versus 5 years.

Almost all studies included different criteria in relation to population, e.g. primiparous vs. pregnant women vs. post-partum women, with different socioeconomic backgrounds and from different countries. We also did not have enough or adequate demographic information for all 
the included studies, which would allow us further analysis and conclusion reaching in our review process.

\section{Has VR been used in the treatment of PND?}

From our investigation, we found no clinical trials that had used VR as a form of treatment for PND. However, we found three studies which used technological means in clinical practice. One study investigated the efficacy of Toddler-Parent Psychotherapy (TPP), for the improvement of parents' and infants' mental health [67]. The technological means that were employed during this study were videotapes which had recorded the interaction between the mother and the infant. However, the videotapes were used for supervision purposes to ensure the "fidelity of the intervention" itself.

Another study investigated whether CBT could be delivered through the internet [40]. They used a specific program called MumMoodBooster. However, this did not include any VR elements.

A third study used video recordings to assess the interaction between mothers and infants [68]. The intervention used in the study was infant massage in a support group.

We have identified the lack of clinical trials using VR for the treatment of PND as a gap in the literature. For this reason we are planning to conduct two clinical studies following this review. The first one will be a pilot study which will measure the feasibility of using VR for the treatment of PND. This will act as a prerequisite which will guide us to conduct a clinical trial where we will investigate what effect, if any, VR has on traditional therapies for PND.

\section{Limitations}

As a narrative review, this study has some limitations. It is missing some of the qualities and advantages of the methodologies that a systematic review and/or a meta-analysis can provide. 
This review does not give strong emphasis on the methodological flaws of the initial studies included in it. It also does not provide any statistical analysis of the data of the included studies which could highlight issues around variations in individual studies, heterogeneity, or effect size. In addition this review does not assess risk of bias in a systematic way. It does not use any specific tool to assess bias in regards to allocation concealment, blinding of participants, incomplete outcome data, and selective reporting. This review reports on the quality of studies and the reporting of bias within the studies but rather in a brief and not in-depth way.

Another limitation was around the strict inclusion/exclusion criteria we used, and as a result, the total number of studies included was limited. We excluded studies of different type, such as pilot studies, observational studies, and case studies. We also excluded grey literature such as unpublished data, which otherwise might have offered a different or richer perspective.

We excluded studies which had a different target disorder. In most cases, we included studies only for the treatment of PND. We did not touch upon the prevention of PND, prevention or treatment of ante-natal depression, management of ante-natal or post-natal anxiety or distress.

We decided not to include any studies which did not measure as a primary outcome, the depressive symptomatology of the participants. For example we excluded studies which had different outcome measures such as mother-infant relationship. Although, it is known that the mother's emotional state can affect the infant in different aspects of their lives at a later stage, such as their cognitive or emotional development. However, for the purpose of this review, we decided to exclude any studies that did not have the depressive symptomatology of the participants as the main or primary outcome measure, which is limiting in itself.

\section{Conclusions}

Taking into consideration the limitations of a narrative review, we believe our study contributes to the literature on various levels. 
We were able to identify reviews in the literature which had examined various treatments for PND. These varied from psychosocial and psychological interventions, to health promotion, massage, and exercise. However, we wanted to focus on CBT treatments for PND. For this reason, we searched for clinical trials which had used CBT as their main treatment. We were able to extract data on what CBT treatments have been used. We identified 7 main CBT components frequently used for the treatment of PND.

Researching mainly CBT treatments for the treatment of PND is one of the main contributions of this review to the current literature as we offer a rich CBT perspective for the treatment of PND. In other words we subtracted only the studies from the reviews that met our inclusion criteria in relation to types of interventions. For example, review [53] included 18 studies but only 8 of them met our inclusion criteria as that review investigated not only treatment but also screening of depression ante-natal and post-natal population. We borrowed only 6 out of 10 studies in another review [51] as it investigated a broader range of treatments for PND. Review [49] provided us with 4 suitable to our criteria studies out of 6 studies in total due to its focus on treatment but also prevention of PND, while review [54] with 3 out of 7 studies due to different study designs. Lastly, two reviews $[47,52]$ provided us with only one study each, with the first review having included 10 studies, and the second one with 8 included studies. The reasons were due to different types of interventions and different outcome measurements respectively. In addition, only two studies $[48,56]$ had been used by three different reviews at the same time $[48,51,53]$.

Another important contribution of this review was the identification of CBT's parameters and what makes it an efficacious clinical approach for PND. We identified parameters such as the delivery of CBT, the providers, and what measures were used, amongst others. An interesting finding was that intervention providers come from wide and varied backgrounds, both professionals and lay women. 
The multitude of CBT parameters also depicts a richness of therapeutic approaches within the CBT spectrum, which highlights flexibility. CBT can be delivered by various providers, and in different ways. It is a highly effective clinical approach, but it has its clinical limitations. For example, CBT's efficacy is time limited in the sense that it is effective for up to 6 months. Its impact plateaus after that time.

We also found a gap in the literature indicating there have been no studies using VR for the treatment of PND. This leads us to the question of whether VR could be used as a possible treatment intervention method of PND. The next step will be to test this intervention. We aim to run a pilot study and measure its feasibility as a preparation for conducting a clinical trial at a later stage. 


\section{Abbreviations}

12-I-GHQ: 12 Item General Health Questionnaire

ASSP: Ainsworth Strange Situation Procedure

BDI: Beck Depression Inventory

BDI-II: Beck Depression Inventory

BSID: Bayley Scales of Infant Development

BSQ: Behavioural Screening Questionnaire

CBT: Cognitive-behavioural therapy

CES-D: Centre for Epidemiologic Studies Depression Scale

DMC: Dyadic Mutuality Code

DSM-5: Diagnostic and Statistical Manual of Mental Disorders - Fifth Edition

DSM-III-R (SCID): Diagnostic and Statistical Manual of Mental Disorders - III - R

DSM-IV: Diagnostic and Statistical Manual of Mental Disorders - Fourth Edition

EPDS: Edinburgh Postnatal Depression Scale

ESDS: Epidemiological Studies Depression Scale

GAF: Global Assessment of Functioning Scale

GHQ: General Health Questionnaire

GSPI: Goldberg's Standardised Psychiatric Interview

HAM-D: Hamilton Depression Rating Scale

HDRS: Hamilton Depression Rating Scale

HIV: Human Immunodeficiency Virus

HRSD: Hamilton Rating Scale for Depression

IPT: Interpersonal Psychotherapy

K-10-IS: Kessler 10-Item Scale

MABI: Mother's Assessment of the Behaviour of the Infant

MADRS: Montgomery-Asberg Depression Rating Scale

MDD: Major Depressive disorder 
MDIBSID: Mental Development Index of the Bayley Scales of Infant Development MSCA: McCarthy Scales of Children's Abilities

NBAS: Neonatal Behavioural Assessment Scale

OTTF: Outside Treatment Tracking Form

PAQ: Postpartum Adjustment Questionnaire

PBCL: Pre-school Behaviour Checklist

PCERA: Parent-Child Early Relational Assessment

PCMD: Perinatal Common Mental Disorders

PEG: Controlled Psychoeducational Group

PHQ: Patient Heath Questionnaire

PND: Post-Natal Depression

PPAQ: Postpartum Adjustment Questionnaire

PPD: Post-Partum Depression

PSI: Parenting Stress Index

RCT: Randomised Controlled Trials

SAS: Social Adjustment Scale

SASSR: Social Adjustment Scale-Self-Report

SCID: Structured Clinical Interview for DSM-IV

SRQ: Self-Reporting Questionnaire

WPPSI: Wechsler Preschool and Primary Scales of Intelligence 


\section{References}

1. Miller LJ. Postpartum depression. JAMA. 2002; https://doi.org/10.1001/jama.287.6.762.

2. Sparks R. Sadness and support: a short history of postpartum depression. Roberts Sparks Essay

Contest

2013. http://medicine.uiowa.edu/md/sites/medicine.uiowa.edu.md/files/wysiwyg_uploads/Sadne ss\%20and\%20Support-A\%20Short\%20History\%20of\%20Postpartum\%20Depression.pdf.

Accessed 28 Mar 2018.

3. Everingham CR, Heading G, Connor L. Couples experiences of postnatal depression: a framing analysis. Soc Sci Med. 2006;62:1745-56.

4. Martindale M. What causes postnatal depression? 2017. https://www.babycentre.co.uk/x1036937/what-causes-postnatal-depression. Accessed 30 Mar 2017.

5. Stewart DE, Robertson E, Dennis C-L, Grace SL, Wallington T. Postpartum depression: literature review of risk factors and interventions: University Health Network Women's Health Program;

2003. http://www.who.int/mental_health/prevention/suicide/lit_review_postpartum_depression.p df. Accessed 9 Nov 2016

6. Ross LE, Steele L, Saprio B. Perceptions of predisposing and predictive factors for perinatal depression in same-sex parents. J Midwif Women's Health. 2005;50(6):e65-e70.

7. American Psychiatric Association. diagnostic and statistical manual of mental disorders. 4th ed. Washington, DC: American Psychiatric Association; 1994.

8. Hendrick V. Treatment of postnatal depression. Brit Med J Int Ed. 2003;327(7422):1003-4. 
9. American Psychiatric Association. Diagnostic and statistical manual of mental disorders. 5th ed. Arlington: American Psychiatric Association; 2013.

10. Hewitt CE, Gilbody SM, Brealey S, Paulden M, Palmer S, Mann R, Green J, Morrell J, Barkham M, Light K, Richards D. Methods to identify postnatal depression in primary care: an integrated evidence synthesis and value of information analysis. Health Technol Assess. 2009; https://doi.org/10.3310/hta13360.

11. Bernard-Bonnin AC. Maternal depression and child development. Paediatr Child Health. $2004 ; 9(8): 575-83$.

12. Leahy-Warren P, McCarthy G. Postnatal depression: prevalence, mothers' perspectives, and treatments. Arch Psychiatr Nurs (2007); https://doi.org/10.1016/j.apnu.2006.10.006.

13. Kim P, Swain SE. Sad dads. Paternal postpartum depression. Psychiatry (Edgmont). 2007;4(2):35-47.

14. Belluck P. Panel calls for depression screenings during and after pregnancy. In: The New York times; 2016. http://www.nytimes.com/2016/01/27/health/post-partum-depression-test-epdsscreening-

guidelines.html?rref=collection\%2Ftimestopic\%2FPreventive\%20Services\%20Task\%20Force\& action=click\&contentCollection=timestopics\&region=stream\&module=stream_unit\&version=late st\&contentPlacement=1\&pgtype=collection. Accessed 16 Feb 2017.

15. Rudlin K. About parenting, what is cognitive-behavioural therapy (CBT). 2016. http://parentingteens.about.com/od/parentingtroubledteens/a/Teens-CBT-CognitiveBehavioral-Therapy.htm. Accessed 9 Mar 2017.

16. O'Hara MW, Stuart S, Gorman LL. Efficacy of interpersonal psychotherapy for postpartum depression. Arch Gen Psychiatry. 2000; https://doi.org/10.1001/archpsyc.57.11.1039. 
17. Stephens S, Ford E, Paudyal P, Smith H. Effectiveness of psychological interventions for postnatal depression in primary care: a meta-analysis. Ann Fam Med. 2016; https://doi.org/10.1370/afm.1967.

18. Dalby TJ. Dr Albert Ellis and rational-emotive therapy. Alberta Psychol. 1987;16:3.

19. Beck Institute for Cognitive Behavior Therapy. History of cognitive behavior therapy. 2016. https://beckinstitute.org/about-beck/our-history/history-of-cognitive-therapy/. Accessed 23 Mar 2018.

20. Longmore RJ, Worrell M. Do we need to challenge thoughts in cognitive behavior therapy? Clin Psychol Rev. 2007;27:173-87.

21. Benjamin CL, Puleo CM, Settipani CA, Brodman DM, Edmunds JM, Cummings CM, Kendall PC. History of cognitive-behavioral therapy (CBT) in youth. Child Adolesc Psychiatr Clin N Am. 2011; https://doi.org/10.1016/j.chc.2011.01.011.

22. Kripke K. 8 types of psychotherapy for postpartum depression treatment. 2013. http://www.postpartumprogress.com/8-types-of-psychotherapy-for-postpartumdepression-treatment. Accessed 15 Feb 2017.

23. Barlow DH. Negative effects from psychological treatments: a perspective. Amer Psychol Amer Psychol Ass. 2010;65:13-20.

24. Dimidjian S, Hollon SD. How would we know if psychotherapy were harmful? Am Psychol. 2010; https://doi.org/10.1037/a0017299.

25. MhGAP. Antidepressant medication in comparison with psychological treatment for moderate-severe depressive disorder. 2015. http://www.who.int/mental_health/mhgap/evidence/resource/depression_q7.pdf?ua=1. Accessed 30 Mar 2017. 
26. Lambert MJ. Outcome in psychotherapy: the past and important advances. Amer Psychol Assoc Psychother. 2013; https://doi.org/10.1037/a0030682.

27. Cuijpers $P$, Brännmark JG, van Straten A. Psychological treatment of postpartum depression: a meta-analysis. J Clin Psychol. 2008;64:103-18.

28. Rizzo Skip A, Schultheis TM, Rothbaum OB. Ethical issues for the use of virtual reality in the psychological sciences. Ethical Iss Clin Neuropsychol. 2003:243-80.

29. Turner WA, Casey ML. Outcomes associated with virtual reality in psychological interventions: where are we now? Clin Psychol Rev. 2014;34:634-44.

30. Riva G, Alcañiz M, Anolli L, Bacchetta M, Baños R, Buselli C, Beltrame F, Botella C, Castelnuovo G, Cesa G, Conti S, Galimberti C, Gamberini L, Gaggioli A, Klinger E, Legéron P, Mantovani F, Mantovani G, Molinari E, Optale G, Ricciardiello L, Perpiñá C, Roy S, Spagnolli A, Troiani R, Weddle C. The vepsy updated project: clinical rationale and technical approach. Cyber Psychol Beh. 2004; https://doi.org/10.1089/109493103322278835.

31. Riva G. Virtual reality in the treatment of eating disorders and obesity: state of the art and future challenges. Cyber Therapy. 2005; http://www.academia.edu/2716218/Virtual_reality_in_the_treatment_of_eating_disorders_ and_obesity_State_of_the_art_and_future_challenges. Accessed 15 Mar 2017.

32. Opris D, Pintea S, Garcia-Palacios A, Botella C, Szamoskozi S, David D. Virtual reality exposure therapy in anxiety disorders: a quantitative meta-analysis. Depress Anxiety. 2012;29:85-93.

33. Botella C, Garcia-Palacios A, Banos R, Guillen V, Quero S, Lasso De La Vega N, Osma J. Engaging media for mental health applications: EMMA Project: The treatment of emotions in a virtual world. Cyber Psychol Beh. 2003; https://doi.org/10.1089/109493103769710596. 
34. Botella C, Serrano B, Baños RM, Garcia-Palacios A. Virtual reality exposure-based therapy for the treatment of post-traumatic stress disorder: a review of its efficacy, the adequacy of the treatment protocol, and its acceptability. Neuropsychiatr Dis Treat. 2015; https://doi.org/10.2147/NDT.S89542.

35. Gonçalves R, Pedrozo AL, Coutinho ESF, Figueira I, Ventura P. Efficacy of virtual reality exposure therapy in the treatment of PTSD: a systematic review. PLoS One. 2012; https://doi.org/10.1371/journal.pone.0048469.

36. Meyebroker K, Emmelkamp MGP. Virtual reality exposure therapy in anxiety disorders: a systematic review of process-and-outcome studies. Depress Anxiety. 2010;27:933-44.

37. Botella C, Osma J, Garcia-Palacios A, Quero S, Baños RM. Treatment of flying phobia using virtual reality: data from a 1-year follow-up using a multiple baseline design. Clin Psychol Psychother. 2004;11:311-23.

38. Falconer CJ, Rovira A, King JA, Gilbert P, Antley A, Fearon P, Ralph N, Slater M, Brewin CR. Embodying self-compassion within virtual reality and its effects on patients with depression. Br J Psychiatry. 2016; https://doi.org/10.1192/bjpo.bp.115.002147.

39.

Wikipedia.

Randomised

controlled

Trials

2017. https://en.wikipedia.org/wiki/Randomized_controlled_trial. Accessed 9 June 2017.

40. Milgrom J, Danaher BG, Gemmill AW, Holt C, Holt CJ, Seeley JR, Tyler MS, Ross J, Ericksen J. Internet cognitive behavioral therapy for women with postnatal depression: a randomised controlled trial of MumMoodBooster. $J$ Med Internet Res. 2016; https://doi.org/10.2196/jmir.4993.

41. Leahy RL. Cognitive-behavioral therapy: proven effectiveness. Psychol Today 2011. http://www.psychologytoday.com/us/blog/anxiety-files/201111/cognitive-behavioral-therapyproven-effectiveness. Accessed 30 Mar 2018. 
42. Fitelson E, Kim S, Baker AS, Leight K. Treatment of postpartum depression: clinical, psychological and pharmacological options. Intl $J$ Women's Health. 2011; https://doi.org/10.2147/IJWH.S6938.

43. Cox JL, Holden JM, Sagovsky R. Detection of postnatal depression: development of the 10item Edinburgh postnatal depression scale. Br J Psychiatry. 1987;150:782-6.

44. Wisner KL, Parry BL, Piontek CM. Postpartum depression. N Engl J Med. 2002;347:194-9.

45. Mental Health Foundation of New Zealand: postnatal depression. 2017. www.mentalhealth.org.nz/get-help/a-z/resource/26/postnatal-depression. Accessed 30 Mar 2017.

46. Moher D, Liberati A, Tetzlaff J, Altman DG, The PRISMA group. Preferred reporting items for systematic reviews and meta-analyses: the PRISMA statement. PLoS Med. 2009; https://doi.org/10.1371/journal.pmed1000097.

47. Clarke K, King M, Prost A. Psychosocial interventions for perinatal common mental disorders delivered by providers who are not mental health specialists in low- and middleincome countries: a systematic review and meta-analysis. PLoS Med. 2013; https://doi.org/10.1371/journal.pmed.1001541.

48. Leis JA, Mendelson T, Tandon SD, Perry DF. A systematic review of home-based interventions to prevent and treat postpartum depression. Arch Womens Ment Health. 2009; https://doi.org/10.1007/s00737-008-0039-0.

49. Appleby L, Warner R, Whitton A, Faragher BA. A controlled study of fluoxetine and cognitive-behavioural counselling in the treatment of postnatal depression. BMJ.1997;314:9326. 
50. Chabrol H, Teissedre F, Saint-Jean M, Teisseyre N, Roge B, Mullet E. Prevention and treatment of post-partum depression: a controlled randomized study of women at risk. Psychol Med. 2002;32:1039-47.

51. Dennis CL, Hodnett ED. Psychosocial and psychological interventions for treating postpartum depression. Cochrane Database Syst Rev. 2007; https://doi.org/10.1002/14651858.CD006116.pub2.

52. Poobalan AS, Aucott LS, Ross L, Smith WCS, Helms PJ, Williams JHG. Effects of treating postnatal depression on mother-infant interaction and child development. $\mathrm{Br} J$ Psychiatry. 2007; https://doi.org/10.1192/bjp.bp.106.032789.

53. O'Connor E, Rossom RC, Henninger M, Groom HC, Burda BU. Primary care screening for and treatment of depression in pregnant and postpartum women. Evidence report and systematic review for the US preventive services task force. JAMA. 2016; https://doi.org/10.1001/jama.2015.18948.

54. Scope A, Leaviss J, Kaltenthaler E, Parry G, Sutcliffe P, Bradburn M, Cantrell A. Is group cognitive behaviour therapy for postnatal depression evidence-based practice? A systematic review. BMC Psychiatry. 2013; https://doi.org/10.1186/1471-244X-13-321.

55. Morrell CJ, Warner R, Slade P, Dixon S, Walters SJ, Paley G, et al. The PoNDER trial, email communication 2006. Morrell J. Psychological interventions for postnatal depression randomised controlled trial and economic evaluation. National Research Register 2004; https://doi.org/10.1002/14651858.CD006116.pub2.

56. Rahman A, Malik A, Sikander S, Roberts C, Creed F. Cognitive behaviour therapy-based intervention by community health workers for mothers with depression and their infants in rural Pakistan: a cluster-randomised controlled trial. Lancet. 2008;372:902-9. 
57. Prendergast J, Austin M-P. Early childhood nurse-delivered cognitive behavioural counselling for post-natal depression. Aust Psychiatry. 2001;9:255-9.

58. Bennett $P$. The costs and benefits of treatment of post-natal depression in the community. Nat Res Reg. 2001; https://doi.org/10.1002/14651858.CD006116.pub2.

59. Ammerman RT, Putnam FW, Altaye M, Stevens J, Teeters AR, Van Ginkel JB. A clinical trial of in-home CBT for depressed mothers in home visitation. Behav Ther. 2013;44(3):359-72.

60. Cooper PJ, Murray L, Wilson A, Romaniuk H. Controlled trial of the short- and long-term effect of psychological treatment of post-partum depression: impact on maternal mood. $\mathrm{Br} J$ Psychiatry. 2003;182:412-9.

61. Misri S, Reebye P, Corral M, Milis L. The use of paroxetine and cognitive-behavioral therapy in postpartum depression and anxiety: a randomised controlled trial. $J$ Clin Psychiatry. 2004;65:1236-41.

62. Honey KL, Bennett P, Morgan M. A brief psycho-educational group intervention for postnatal depression. Br J Clin Psychol. 2002;41:405-9.

63. Milgrom J, Negri LM, Gemmill AW, McNeil M, Martin PR. A randomized controlled trial of psychological interventions for postnatal depression. Br J Clin Psychol. 2005;44:529-42.

64. Rojas GF. Treatment of postnatal depression in low-income mothers in primary-care clinics in Santiago, Chile: a randomised controlled trial. Lancet. 2007;370:1629-37.

65. Milgrom J, Holt CJ, Gemmill AW, et al. Treating postnatal depressive symptoms in primary care: a randomized controlled trial of GP management, with and without adjunctive counselling. BMC Psychiatry. 2011;11:95. 
66. Wiklund I, Mohlkert P, Edman G. Evaluation of a brief cognitive intervention in patients with signs of postnatal depression: a randomized controlled trial. Acta Obstet Gynecol Sand. 2010; https://doi.org/10.3109/00016349.2010.500369.

67. Cicchetti D, Rogosch FA, Toth SL. The efficacy of toddler-parent psychotherapy for fostering cognitive development in offspring of depressed mothers. J Abnorm Child Psychol. 2000;28:135-48.

68. Onozawa K, Glover V, Adams D. Infant massage improves mother-infant interaction for mothers with postnatal depression. J Affect Disord. 2001;63:201-7. 


\section{Acknowledgments}

We would like to thank Professor Holger Regenbrecht from the University of Otago, New Zealand for his support, and guidance on VR matters.

\section{Funding}

This review has been funded by WellSouth, the Primary Health network in Otago and Southland, New Zealand. The funder did not have any participation or contribution in the collection of the data, its analysis, and conclusion(s) of this review.

\section{Availability of data and materials}

All data generated or analysed during this study are included in this manuscript.

\section{Author information}

\section{Affiliations}

1. Brief Intervention Service, WellSouth, 333 Princes Street, Dunedin, New Zealand

- George Stamou

2. Universitat Jaume I, Castellón, Spain

- George Stamou

3. Department of Basic and Clinical Psychology and Psychobiology, Universtitat Jaume I, Department of Psychology, Castellón, Spain

- Azucena García-Palacios

○ \& Cristina Botella

\section{Contributions}

All three authors have made substantial contributions to the manuscript, in terms of the identification and development of protocols, design of the study, choice of inclusion and 
exclusion criteria, selection of studies, critical revision, and identification of potential biases relating to the study. GS was responsible for the collection of the data, its analysis, the interpretation of the results, and the drafting of the manuscript. AG-P carried the co-supervision, critical evaluation and guidance of the research process, and contributed to the final draft of the manuscript. CB carried the co-supervision, guidance throughout the research process, critical evaluation, and ensured the overall scientific and research quality of this review.

\section{Corresponding author}

Correspondence to George Stamou.

\section{Ethics declarations}

\section{Authors' information}

GS works as a Mental Health Practitioner at WellSouth, New Zealand. AG-CB is a Professor of Abnormal Psychology at the Psychology Department at the Universitat Jaume I, Spain. CB is a Full Professor of Clinical Psychology at the Psychology Department at the Universitat Jaume I, Spain.

\section{Ethics approval and consent to participate}

Not applicable.

\section{Competing interests}

The authors declare that they have no competing interests.

\section{Publisher's Note}

Springer Nature remains neutral with regard to jurisdictional claims in published maps and institutional affiliations. 


\section{Rights and permissions}

Open Access This article is distributed under the terms of the Creative Commons Attribution 4.0 International License (http://creativecommons.org/licenses/by/4.0/), which permits unrestricted use, distribution, and reproduction in any medium, provided you give appropriate credit to the original author(s) and the source, provide a link to the Creative Commons license, and indicate if changes were made. The Creative Commons Public Domain Dedication waiver (http://creativecommons.org/publicdomain/zero/1.0/) applies to the data made available in this article, unless otherwise stated. 
Chapter 3: The combination of cognitive-behavioural therapy with virtual reality for the treatment of post-natal depression. A pilot feasibility study.

This chapter has been published as:

George Stamou, Azucena Garcia-Palacios, and Cristina Botella. (2019). The combination of cognitive-behavioural therapy with virtual reality for the treatment of post-natal depression. OZCHI'19: Proceedings of the 31st Australian Conference on Human-Computer-Interaction, pages 599-603. https://doi.org/10.1145/3369457.3369541 


\begin{abstract}
Cognitive-behavioural therapy (CBT) is an effective treatment for post-natal depression (PND), a depressive disorder experienced in the post-partum period. Virtual reality (VR) has never been used for the treatment of PND. This pilot study investigated the feasibility of combining CBT and VR for the treatment of PND. It tests the entire treatment protocol, including the VR system. The results show that the combination of CBT and VR is feasible. The study identifies limitations and technical difficulties. It provides recommendations for the better implementation of VR within the treatment protocol based on the participants' feedback.
\end{abstract}

\title{
Ccs concepts
}

- Human-centered Design • Virtual Reality

\section{Keywords}

Post-natal Depression, Cognitive-Behavioural Therapy, Virtual Reality, Pilot Feasibility Study

\section{ACM Reference format:}

George Stamou, Azucena Garcia-Palacios, and Cristina Botella. 2019. The combination of cognitive-behavioural therapy with virtual reality for the treatment of post-natal depression. In $31^{\text {st }}$ AUSTRALIAN CONFERENCE ON HUMAN-COMPUTER-INTERACTION (OZCHI'19), December 2-5, 2019, Fremantle, WA, Australia. ACM, New York, NY, USA, 4 pages. https://doi.org/10.1145/3369457.3369541 ${ }^{1}$

\footnotetext{
${ }_{1}^{1}$ Permission to make digital or hard copies of part or all this work for personal or classroom use is granted without fee provided that copies are not made or distributed for profit or commercial advantage and that copies bear this notice and the full citation on the first page. Copyrights for third-party components of this work must be honoured. For all other uses, contact the owner/author(s). OZCHI' 19, December 2-5, 2019, Fremantle, WA, Australia @ 2019 Copyright held by the owner/author(s). ACM ISBN 978-1-4503--76969/19/12. https://doi.org/10.1145/3369457.3369541
} 


\section{INTRODUCTION}

Post-natal depression (PND) is a depressive disorder experienced in the post-partum period by up to $25 \%$ of new mothers [4]. Cognitive-behavioural therapy (CBT) is a highly researched treatment for PND [30]. CBT is defined as a psychological treatment where the focus is on identifying and challenging the individual's dysfunctional thoughts in order to find more adaptive behaviours [11].

In the literature review we had conducted previously, we identified mainly CBT treatments for PND [29]. We found 7 CBT components in total, with cognitive restructuring and psychoeducation being the most frequently used. The second most frequent CBT technique was problem solving, while behaviour management, goal setting, goal achieving, and stress management were used less frequently.

Cognitive restructuring is in the heart of cognitive therapy and a CBT component that contributes significantly to positive therapeutic outcomes [16] [17]. Cognitive distortions such as negative predictions, or ruminative thoughts, are frequent mental phenomena [7] and a focus of CBT [21]. CBT's purpose is for the client to identify and modify their maladaptive cognitive processes, including polarised thinking, overgeneralizing and catastrophizing [9] [15].

An aspect of CBT is about helping the individual to learn to manage stress in more constructive ways, using positive coping responses [24]. Another focus of CBT is about setting goals which are specific, measurable, achievable, realistic, and timed [31].

These CBT components have many similarities between them. Robinson et al talk about stress management as goal setting [22]. They have developed a "stress relief toolbox" with 14 activities, such as keeping a journal, going for a walk, and gardening amongst others. WebMD offers some ways of stress management through relaxation techniques [33]. They suggest meditation as one of the main stress management techniques with guided imagery, breathing exercises, and progressive muscle relaxation. 
Schultheis and Rizzo define virtual reality (VR) as a human-computer interface where the user can immerse themselves in a virtual environment with "real life" qualities [25]. That state of immersion underlines a sense of presence in the virtual world [26]. The user can re-act or learn to manage effectively a stressful situation which was created in a lab and transfer that new knowledge successfully to real-life situations [14]. High levels of presence are associated with realistic and compelling virtual environments [6], while lower levels of presence with the content of the virtual environment being considered not believable [23].

A meta-analysis by Fodor et al reports that VR based interventions were more effective than control conditions, but with no real differences from other therapeutic interventions for anxiety and depression [13]. A systematic review by Valmaggia et al reports VR as an effective treatment for a range of severe mental health issues [32]. VR can be effective for anxiety disorders and specific phobias, pain alleviation, and autism amongst others [18].

Although there have been studies that use VR for parental stress resilience training with healthy subjects [2], there have not been any studies that combine VR and CBT with clinical population, in other words, with people who experience PND [29]. This, along with some recommendations for future work, are the main contributions of this study to the literature. This paper will act as a guide for a clinical trial at a later stage, testing whether VR can enhance the outcome of traditional therapies for PND.

\section{Objectives}

We ran a small sample pilot study to assess whether VR can be implemented with a traditional CBT treatment for PND. We wanted to measure levels of feasibility and of acceptance, and its practical parameters of the combination of VR and CBT. We aimed to identify any methodological problems, flaws, technical difficulties, and/or limitations on the protocols and research tools. 


\section{METHODS}

\section{Study design}

This is a feasibility pilot study. CBT treatment for PND was up to 6 sessions, while using VR in session 4. Questionnaires were completed in the initial assessment and final session, along with semi-structured interviews conducted in the end. The trial took place in the Brief Intervention Service at WellSouth in Dunedin, New Zealand.

\section{Participants}

The sample was taken from local GP practices and other health care providers in Dunedin, New Zealand, without restrictions in ethnicity, socioeconomic background and employment status. There were 6 female participants with their ages varying between 25 and 40 years old, and the average age being 33.83. Six participants were married, and five employed. Four participants identified as NZ European, one as Other European, and one as Other Asian.

Two participants had been diagnosed with depression and anxiety, two exhibited symptoms of post-natal depression, one participant with post-natal depression, and another one with recurrent depression. Three participants had a history of anxiety and depression. Four participants were on medication. No participants had any physical health and mental health comorbidities, or drug and alcohol issues. All participants presented no or very low risk to self or to others.

\section{Recruitment}

The facilitator of this pilot study, a mental health practitioner, contacted different GP practices and other health care providers in the area. He provided adequate information about the purpose of the study, referral process, ethics approval, issues of confidentiality, inclusion and exclusion criteria, assessment and clinical protocols. 
Once the referrals were received and triaged, the facilitator contacted the participants over the phone to answer any questions or make any clarifications.

\section{Procedure}

Participants followed a six-session programme which consisted of CBT primarily. In the first session, data on demographics was collected. The participants signed the consent form which explained about confidentiality and their right to withdraw from the study at any point. They completed the Edinburgh Postnatal Depression Scale (EPDS) and the Generalised Anxiety Disorder Questionnaire (GAD-7) questionnaires. The facilitator did a comprehensive assessment and took into consideration clinical parameters such as family status, social circle, employment, medication, diagnosis, onset of symptoms, sleep, appetite, drug and alcohol, and levels of risk [8].

In the second and third sessions, the facilitator provided psychoeducation around PND, identification of contributing factors and early signs [28]. The focus was also on stress management, cognitive restructuring, and goal setting. In the last part of the third session, participants were introduced to the VR programme.

In the fourth session, the participants trialed the VR system, where they were exposed to a series of virtual stressors, while at the same time, they were asked to tidy up the virtual house. The VR session was divided into the introduction of 10 minutes, the main part of 15 minutes, and the end of 5 minutes. The fifth session focused on reinforcement of the techniques learned from the VR session.

In the final session, participants completed four questionnaires: EPDS, GAD-7, Feasibility questionnaire, and Acceptance questionnaire. They gave feedback on their overall VR experience including levels of stress and levels of presence by answering open-ended questions. 


\section{Measures}

EPDS is a ten-item questionnaire which can identify symptoms or signs of depression in the post-partum period [10] [12]. GAD-7 is a seven-item questionnaire which is a reliable and valid measure of anxiety [27].

The feasibility questionnaire has 11 questions with five-point rating scale answers and measures the level of comfortableness, adequacy of information during the referral process, the ethics approval, and time allocation. The acceptance questionnaire has 17 questions with fivepoint rating scale answers and 6 open-ended questions and measures time usage, level of easiness and acceptance, and identifies where there is any room for improvement. It was adopted from the ETIOBE study for the treatment and prevention of childhood obesity [5].

\section{VR system}

This VR system was designed and developed in the Information Science Department at the University of Otago in New Zealand. It has been used in three published studies [1] [3] [20].

The VR environment depicts a middle-class house with two bedrooms, a bathroom, an open plan kitchen, a dining room, a living room, and a corridor. In its exterior, there is a front and back yard. The VR stressors can be manipulated by the therapist in terms of intensity (from 0-6), frequency, duration, and applied individually or simultaneously [2]. They are divided into three main categories and include amongst others: loud music, telephone ringing, newborn baby crying, toddler reaching for medication, power outage, fire in the kitchen, next door neighbours arguing, and next-door party.

\section{Ethical considerations}

Ethics approval was obtained for the study. 


\section{RESULTS}

The attrition rate for this pilot study was zero and all six participants completed the study. There were zero non-attendances without notification, and three cancellations during the trial.

The number of sessions varied between 5 and 8 sessions, with most participants to have received six sessions, depending on their individual mental health needs at the time of the study. All six participants tried the VR system.

There was a consistent reduction of final scores for both EPDS and GAD-7 questionnaires for five participants except one who scored higher by two points in EPDS and the same in GAD-7. The maximum score for EPDS is 30, while for GAD-7 is 21 .

There was a consensus amongst participants that the amount of information provided about the referral process, the ethics approval, and confidentiality were sufficient. All six participants felt comfortable throughout the recruitment process, and they found the implementation of the VR trial in session 4 suitable. The total number of sessions provided to the participants were considered adequate in addressing their mental health needs.

Participants reported that there was adequate time to prepare for the VR session, while they found the VR system itself easy to use. However, more information and guidance were needed in the initial instructions provided. Participants identified the need of having different scenarios available, with positive elements and rewards. They also identified the need for the minimisation of obstructions in order to focus while they highlighted some technical problems, mainly a freeze in the system, and the functionality of the joystick.

Participants reported that the questionnaires captured the essence of their mental health issues, that there was enough time allocated for the questionnaires to be answered, and that the setting and the location of the study was suitable.

The time that the VR system was used by the participants varied between 10 and 30 minutes. Participants felt that the system was relatively easy to use and quick to learn, without 
necessarily the need of professional support of having specialised knowledge of some sort. The system integrated well its different possibilities and it was not fragile.

Participants felt comfortable and confident when using the system and that the choice of tasks within the treatments module were relatively easy to handle. They also felt the application was useful and practical. It could enhance decision-making such as prioritizing. The system could also raise awareness of how the participants have usually coped with stressful situations in the past and think about alternative ways of how to cope better.

In contrast, there was doubt raised whether the system could speed up participants' recovery, while at the same time it was expressed by some participants that they would not use the system frequently. Three participants experienced motion sickness, with a varying degree between them. They all described it as an unpleasant experience. Two of the participants were susceptible to motion sickness. However, the first participant who experienced motion sickness happened after a systemic failure. Another participant was not familiar with the functionality of the joystick, while the third participant navigated at a fast pace.

Participants gave positive feedback about the debrief provided at the end of the session, that the VR programme was reliable, and that it started a conversation about stress triggers in real life and possible solutions. The VR experience was also seen as a training tool, being able to practice different skills such as prioritizing, and that it had similarities with real life.

However, participants also provided feedback about some aspects of their VR experience which they did not like, such as some stressors being irrelevant, the navigation within VR was difficult, the virtual baby was too easy to look after, some tasks were simple and predictable. There was also a lack of options of resolving issues or completing tasks, not enough play time with the virtual baby, and a lack of instruction during their induction to the VR environment.

All stressors and the sequence they were activated was appropriate and well accepted by the participants (please see Table 3-1). However, some participants' feedback was that they would have preferred more activated stressors simultaneously in order to raise stress. 
Table 3-1. Stressors and their sequence for each participant

\begin{tabular}{|c|c|c|c|c|c|c|c|}
\hline \multirow{2}{*}{$\begin{array}{l}\text { Partic } \\
\text { ipant }\end{array}$} & \multicolumn{7}{|c|}{ Stressor } \\
\hline & Baby & Fire & Knife & & & & \\
\hline 2 & Baby & $\begin{array}{l}\text { Door } \\
\text { bell }\end{array}$ & Baby & Phone & Fire & $\begin{array}{l}\text { TV- } \\
\text { Music }\end{array}$ & Knife \\
\hline 3 & Baby & $\begin{array}{l}\text { Door } \\
\text { bell }\end{array}$ & Fire & TV & Knife & & \\
\hline 4 & Baby & $\begin{array}{l}\text { Door } \\
\text { bell }\end{array}$ & Fire & TV & $\begin{array}{l}\text { TV- } \\
\text { Music }\end{array}$ & & \\
\hline 5 & Baby & $\begin{array}{l}\text { Door } \\
\text { bell }\end{array}$ & Phone & Fire & Baby & $\begin{array}{l}\text { High } \\
\text { chair }\end{array}$ & Knife Music \\
\hline 6 & Baby & $\begin{array}{l}\text { Door } \\
\text { bell }\end{array}$ & Fire & Knife & Music & & \\
\hline
\end{tabular}

The levels of stress varied depending on the stressors, and other parameters. The most stressful aspect of the VR environment was when two or more stressors were activated at the same time. The toddler being next to the fire was highly stressful, while the crying baby and the doorbell ringing were also perceived as stressful. Equally, not being able to complete a task in a timely manner was stressful, while the phone ringing, the toddler next to the TV, the toddler next to the knife, the toddler in the highchair, and the music from the TV were the least stressful.

The levels of presence varied. It was noted that participants felt mostly present in the VR environment when they perceived the stressors as realistic as possible. However, participants found some aspects of the environment such as the amount of rubbish relevant but unrealistic, in other words the content was not believable.

Participants suggested some changes regarding the system itself or around the process surrounding the use of it. One common theme was time, and the need for more time before or during the trial, or at the completion of each task. Another theme was about needing more information to be provided about the VR system, while having the option to multi-task or being guided by a more positive scenario such as rewards and acknowledging participants' efforts and achievements were seen as potentially beneficial by the participants.

Participants acknowledged potential benefit using the VR programme and varied from the system acting as a reinforcement and a reminder of already possessed skills they had, such as prioritizing and decision making which they found reassuring. The programme also raised 
insight about a tendency by some to be self-critical, or lacking good stress management skills, such as being reactive or lacking boundaries in their personal relationships. The programme also raised awareness around health and safety issues in their own living conditions.

The VR environment included positive elements such as the background music, which was found to be relaxing and rewarding, the baby's bedroom which felt comfortable to be in, while the idea of finding a parcel at the door was exciting.

\section{DISCUSSION}

In this pilot study, all six participants reported feeling better, more relaxed and with improved mood, better self-esteem, and improved sleep and appetite at the end of therapy. They were using good coping strategies for anxiety and depression, such as time out, gardening, and yoga, being able to reprioritize, and single task. There was also a reduction in their ruminative thinking.

Some participants had started being more responsive than reactive to stressful situations, having more realistic self-expectations, and connecting with family and friends. Two participants were preparing to transition back to employment with confidence. Although some participants still experienced some anxiety at the end of the study, they had gained good insight around triggers and coping strategies.

The levels of feasibility and acceptability for the combination of VR with CBT were satisfactory. All participants felt comfortable during the pilot study and its processes. However, they felt some information was missing regarding the VR system, its stressors and the theoretical background. They found the system easy to use, and without any major professional input. However, they were skeptical about using it again, or about its usefulness and therapeutic element. This is also possibly since half of the participants experienced motion sickness, and some felt that it was not challenging enough, and the tasks were simplistic. However, the system had a good psychoeducational element with practical applications. 
We identified several limitations in this pilot study which will create the framework for the improved implementation of VR with CBT at a later stage. One limitation is the lack of a follow up post-intervention. Although all six participants showed improvement in terms of anxiety and depression, we don't know their progress post-intervention.

The selection of the VR stressors was problematic. We hypothesized that all stressors would be stressful, however some were irrelevant or not challenging enough for the participants, and thus not realistic.

Finally, there was a lack of positive reward or relaxing time within the virtual experience. Some participants reported they would have preferred more options such as holding the virtual baby and sitting on the sofa, trying to relax or acknowledging their achievements.

\section{CONCLUSION - RECOMMENDATIONS}

In summary, VR can potentially be implemented in a traditional clinical setting such as CBT for the treatment of PND. CBT and VR share some common therapeutic elements such as decision making, prioritizing, insight, and stress management. VR can potentially compliment CBT in the treatment of PND, but this is yet to be tested.

Taking into consideration the conclusion and the limitations of this pilot study, and for the better implementation of VR with CBT, some changes are recommended. One change would allow the participants to choose the stressors that they consider to be the most relevant to them.

Another recommendation is for the facilitator to spend adequate time explaining the programme and stressors to the participants, and to provide them with a theoretical background for better understanding and acceptance of the system.

Another recommendation is around motion sickness and its minimisation. It is recommended that participants should be invited to spend adequate time before the trial begins in order to become familiar with the system, its components, and the tasks to be completed [19]. It is also recommended for the VR trial to be divided in two parts with a 5-minute break in between. 
Another solution is about the participants to be reminded to slow the pace of navigation within the virtual environment. It is also advised that if the participant is susceptible to motions sickness, to encourage the idea of non-prescribed medication for motion sickness to be taken an hour before the trial begins.

\section{Acknowledgments}

We would like to thank WellSouth; Mohammed Alghamdi; Joy Pringle - Plunket Service; and Brendon Woodford - University of Otago. 


\section{References}

[1] Mohammed Alghamdi, Holger Regenbrecht, Simon Hoermann, Tobias Langlotz, and Colin Al-dridge (2016). Social Presence and Mode of Videocommunication in a Collaborative Virtual Environment. In Proceedings of the $20^{\text {th }}$ Pacific Asia Conference on Information Systems (PACIS 2016, June 27 - July 1). Chiayi, Taiwan. (Chapter 5).

[2] Mohammed Alghamdi (2017). Enabling parental stress resilience training with virtual reality. A thesis submitted for the degree of Doctor of Philosophy. University of Otago, Dunedin, New Zealand.

[3] Mohammed Alghamdi, Holger Regenbrecht, Simon Hoermann, and Nicola Swain (2017). Mild Stress Stimuli built into a Non-Immersive Virtual Environment can elicit actual Stress Responses. Behaviour \& Information Technology. London, UK: Taylor \& Francis. (Chapter $6)$.

[4] American College of Obstetricians and Gynecologists (ACOG). ACOG Today (June 2010); Health Care Reform: What it means for you and your patients. Pp 8-9. Found in American Psychological Association (2019). Women's Health. https://www.apa.org/advocacy/health/women. Retrieved 1 June 2019.

[5] Rosa M Banos, Ausias Cebolla, Cristina Botella, Azucena Garcia-Palacios, Eric Oliver, Irene Zaragosa, Mariano Alcaniz (2011). Improving Childhood Obesity Treatment Using New Technologies: The ETIOBE System. Clinical Practice \& Epidemiology in Mental Health. US National Library of Medicine: National Institutes of Health.

[6] Patrick S Bordnick, Amy Traylor, Hilary L Copp, Ken M Graap, Brian Carter, Mirtha Ferrer, Alicia P Walton (2008). Assessing reactivity to virtual reality alcohol based cues. Addictive Behaviors. 33 (2008) 743-756. DOI: 10.1016/j.addbeh.2007.12.010.

[7] Allison Boyes (2013). Cognitive restructuring: Six ways to do cognitive restructuring. Found on www.psychologytoday.com/blog/in-practice/201301/cognitive-restructuring. Retrieved 10 December 2017.

[8] Brief Intervention Service (2016). Clinical assessment form. WellSouth. Dunedin. New Zealand. 
[9] David D Burns (1980). Feeling good: The new mood therapy. New York, NY, USA: Signet.

[10] Centre of Perinatal Excellence (2014). Using the EPDS as a screening tool. http://cope.org.au/health-professionals-3/perinatal-mental-health-disorders/calculating-scoreepds/. Retrieved 20 February 2019.

[11] Pim Cuijpers, Filip Smit, Ernst Bohlmeijer, Steven D Hollon, and Gerhard Andersson (2010). Efficacy of cognitive-behavioural therapy and other psychological treatments for adult depression: Meta-analytic study of publication bias. British Journal of Psychiatry. 196(3), 173-178. DOI: 10.1192/bjp.bp.109.066001.

[12] Edinburgh Postnatal Depression Scale (2018). https://psychology-tools.com/epds/. Retrieved 11 February 2018.

[13] Liviu A Fodor, Carmen D Cotet, Pim Cuijpers, Stefan Szamoskozi, Daniel David, loana A Cristea (2018). The effectiveness of virtual reality-based interventions for symptoms of anxiety and depression: A meta-analysis. Scientific Reports. 8(1): 10323-10323.

[14] William D Gouvier, Alice A Barker, Mandi W Musso (2018). Ecological validity. Psychology. Encyclopaedia Britannica. https://www.britannica.com/topic/ecological-validity. Retrieved 18 January 2018.

[15] John M Grohol (2017). 15 Common cognitive distortions. Psych Central. https://psychcentral.com/lib/15-common-cognitive-distortions/. Retrieved 22 January 2018.

[16] Linda Harvey, Stephanie J Inglis, Colin A Espie (2002). Insomniacs' reported use of CBT components and relationship to long-term clinical outcome. Behaviour Research and Therapy. Volume 40, Issue 1, January 2002, Pages 75-83. DOI: doi.org/10.1016/S00057967(01)00004-3.

[17] Patty Mulder (2017). Cognitive restructuring. Retrieved from ToolsHero: https://www.toolshero.com/stress-management/cognitive-restructuring/. Retrieved 10 December 2017.

[18] Mi Jin Park, Dong Jun Kim, Unjoo Lee, Eun Jin Na, Hong Jin Jeon (2019). A Literature Overview of Virtual Reality (VR) in Treatment of Psychiatric Disorders: Recent Advances and Limitations. Frontiers in Psychiatry. 10(505). 
[19] Andrew Paroz and Leigh Ellen PoSer (2018). Impact of Air Flow and a Hybrid Locomotion System on Cybersickness. In Proceedings of $30^{\text {th }}$ Australian Conference on HumanComputer Interaction, Melbourne, Vic, Australia, December 2018 (OZCHI 2018), 5 pages. DOI: 10.1145/3292147.3292229.

[20] Holger Regenbrecht, Mohammed Alghamdi, Simon Hoermann, Tobias Langlotz, Mitchell Goodwin, and Colin Aldridge (2015). Social Presence with Virtual Glass, poster presented at IEEE Virtual Reality 23-27 March 2015. (pp 296-270). Arles, Camargue, Provence, France. (Chapter 5).

[21] Katerina Rnic, David J A Dozois, and Rod A Martin (2016). Cognitive Distortions, Humor Styles, and Depression. Europe's Journal of Psychology. 12(3), 348-362. DOI: 10.5964/ejop.v12i3.1118.

[22] Lawrence Robinson, Melinda Smith, Robert Segal (2017). Stress management: Using selfhelp techniques for dealing with stress. Found on: https://www.helpguide.org/articles/stress/stress-management.htm. Retrieved 12 December 2017.

[23] Sol Rogers (2017). Why is presence important for virtual reality? VR Focus. Found on: https://www.vrfocus.com/2017/11/why-is-presence-important-for-virtualreality/. Retrieved 2 July 2019.

[24] Kathleen Romito, Donald Sproule, Adam Husney, Steven E Locke, and Christine R Maldonado (2017). Common coping responses for stress: Topic overview. https://www.webmd.com/balance/stress-management/tc/common-coping-responses-forstress-topic-overview. Retrieved 22 January 2018.

[25] Maria T Schultheis and Albert Rizzo (2001). The application of virtual reality technology in $\begin{array}{llll}\text { rehabilitation. } & \text { Rehabilitation } & \text { 296-311. }\end{array}$ https://www.researchgate.net/publication/232580487. Retrieved 18 January 2018.

[26] William R Sherman and Alan B Craig (2003). Understanding virtual reality: Interface, application, and design. Morgan Kauffmann Publishers. Elsevier Science. 
[27] Robert L Spitzer, Kurt Kroenke, and Janet B W Williams (2006). A Brief Measure for Assessing Generalised Anxiety Disorder The GAD-7. Arch Intern Med. 2006;166(10): 10921097. DOI: $10.1001 /$ archinte.166.10.1092.

[28] Prashant Srivastava and Rishi Panday (2017). Psychoeducation an Effective Tool as Treatment Modality in Mental Health. International Journal of Indian Psychology, Volume 4, Issue 1, No. 82, ISSN: 2348-5396 (e), ISSN:2349-3429 (p), DIP: 18.01.153/20160401, ISBN: 978-1-365-59365-9.

[29] George Stamou, Cristina Botella, and Azucena Garcia-Palacios (2018). The Psychological Treatment of Post-Natal Depression: A Narrative Review. BMC Psychiatry. DOI: 10.1186/s40359-018-0240-5.

[30] Sian Stephens, Elizabeth Ford, Priya Paudyal, and Helen Smith (2016). Effectiveness of Psychological Interventions for Postnatal Depression in Primary Care: A Meta-Analysis. Annals of Family Medicine. Vol. 14, No. 5. September / October 2016. Vol. 14, No. 5. 463472. DOI: 10.1370/afm.1967.

[31] Fran Tredget (2016). Goal setting and cognitive behavioural therapy. https://www.touchstonesupport.org.uk/2016/05/8422/. Retrieved 22 January 2018.

[32] Lucia R Valmaggia, Leila Latif, Matthew J Kempton, Maria Rus-Kalafell (2016). Virtual reality in the psychological treatment for mental health problems: A systematic review of recent evidence. Psychiatry Research. 236: 189-195.

[33] WebMd (2017). Stress management. Tips for reducing stress. www.webmd.com/balance/stress-management/stress-management-relieving-stress\#2. Retrieved 12 December 2017. 
Chapter 4: The combination of cognitive-behavioural therapy with virtual reality for the treatment of post-natal depression in a brief intervention context: A single-case studies trial.

This chapter has been published as:

Stamou, G., Garcia-Palacios, A., Woodford, B. J., Suso-Ribera, C., \& Botella, C. (2021). The combination of cognitive-behavioural therapy with virtual reality for the treatment of post-natal depression in a brief intervention context: A single-case studies trial. Journal of Healthcare Engineering. https://doi.org/10.1155/2021/5514770 


\section{Abstract}

Post-natal depression (PND) is a mood disorder with potentially devastating effects to the individual on many levels. It can affect cognitive functioning, motivation, and self-esteem. The person can socially withdraw from their immediate familial or social circle. It can affect bonding and quality time between mother and baby. There are many effective therapeutic treatments used for the treatment of PND such as cognitive-behavioural therapy (CBT) and interpersonal psychotherapy (IPT). This study using a single-case studies trial with 15 participants investigates the clinical usefulness of combining CBT with virtual reality (VR). Results show that the combination of CBT with VR is an effective treatment for PND. In addition, VR can enhance awareness, decision making, and self-appreciation within the individual, and can also have reallife applications. This study also shows that the combination of VR and CBT is feasible, while the use of such a technology is well accepted.

\section{Ethics}

This trial has been approved by the ethical committee of Universitat Jaume I with file number "CD/33/2019". It was conducted in accordance with the Declaration of Helsinki (1964), and with the participants' understanding and consent. 


\section{INTRODUCTION}

Post-natal depression (PND) is a mental health issue which is frequently experienced by mothers and fathers in the post-partum period [1]. It is a depressive disorder and is characterised by symptoms such as low mood, low motivation, feelings of hopelessness, being tearful, feeling unsupported, and negative self-esteem amongst others [2]. It can have devastating effects on the individual but also on the family if undiagnosed or left untreated.

Recently, institutions and health systems have started paying close attention to this frequently experienced mental phenomenon and have started implementing measures for providing adequate treatment to the individuals and families directly affected.

There are different psychological treatments used for PND. The two most prominent ones are cognitive-behavioural treatment (CBT), and interpersonal psychotherapy (IPT) which are effective in treating PND in the mild to moderate range [3]. CBT can be delivered successfully in a brief and structured way and it can have good therapeutic outcomes on people with depression in the post-partum period [4]. In addition, other treatments can be very successful and are used frequently such as person-centered counselling, group therapy, couple's therapy, solution focused brief psychotherapy, eye movement desensitization and reprocessing, psychodynamic psychotherapy, and dialectical behavioural therapy [5].

The use of virtual reality (VR) has proven effective and clinically useful in the treatment of various psychological problems, especially anxiety disorders [6]. The Institute for Cognitive and Clinical Neurosciences at Monash University has been conducting promising research on the effect of VR on addictions such as gambling [7]. They use reverse engineering to train the users of the virtual environment to identify the cues that trigger their gambling behaviour. Reverse engineering is the process where a product is copied and analysed to obtain more precise information about it that is unavailable otherwise, or to recreate the product itself [8]. Other research defines reverse engineering as the breakdown of a system which helps us understand 
better about its functioning, complex issues surrounding it, to recover information, and to identify any side effects [9].

Image data analysis or processing has been used extensively in science and has many applications in different fields. The objective of image processing is to draw out useful information such as estimating distances and detecting objects, amongst others [10]. It can be utilised for identifying external characteristics of an object such as surfaces, texture, and lines, or it can be used for the identification of the internal components of an object [11].

VR can enhance this process in a fast and efficient way [12], and it can be combined with reverse engineering and image data analysis to improve hardware or software. Research has shown that laser scans using $3 d$ mesh and jointly with surface texturing can measure objects and virtually reconstruct them accurately using reverse engineering [13, 14].

Although VR has many applications, to our knowledge, the use of such technology for the treatment of PND has not been investigated yet. This is an unexplored clinical territory that could potentially be of great clinical value for an important clinical matter such as PND.

\section{Objectives}

There were three objectives for this clinical trial: efficacy, feasibility, and acceptance. More specifically, we wanted to explore whether the combination of CBT with VR can be effective for the treatment of PND. We wanted to investigate whether VR can influence the therapeutic outcome of traditional therapies for PND. If so, in what ways?

Another aim was to investigate the feasibility of combining VR and CBT for PND. We wanted to find out about the referral process and confidentiality, the number of sessions provided to the participants, whether they had enough time and information amongst other things. 
A final objective was to investigate the levels of acceptance, and whether participants had accepted the VR technology. We investigated parameters such as likeness, and levels of comfortableness by the participants using such technology.

\section{METHODS}

\section{Participants}

The total number of participants were 15. They had been referred by their GP or other health/mental health providers in the city of Dunedin, New Zealand. Participants were eligible for health care in New Zealand and were not excluded from this trial based on their ethnicity, socioeconomic status, and employment status. Table 4-1 includes all socioeconomic characteristics of the participants of this study.

Participants were selected for the trial if they were at least 18 years old, if they were in the postpartum period, if they had been diagnosed with PND by their GP or health provider, if they selfreported they were suffering from PND or if they were experiencing depressive symptomatology in the post-partum period, or if they were in the mild to moderate range of depression, and if they were in good physical health.

In contrast, the participants were excluded if they suffered from physical health co-morbidities which were disabling such as brain injury, if they had an alcohol and/or drug dependency, if they had concurrent mental health problems, with a history of depression, if they had been hospitalised for mental health issues in the year before the trial started, if they were receiving any psychological treatment for depression at the time of the trial, and if they exhibited moderate to high risk of self-harm or suicide. 
Table 4-1: Participants' sociodemographic information

\begin{tabular}{|c|c|}
\hline Participants & $n=15$ \\
\hline Age & Mean age $=29.06$ years \\
\hline Sex & Female $=15$ \\
\hline Ethnicity & $\begin{array}{l}\text { NZ European } / \text { Pakeha }=11 \\
\text { Europeans = } 2 \\
\text { Maori }=1 \\
\text { Filipino = } 1\end{array}$ \\
\hline Marital status & $\begin{array}{l}\text { Married }=10 \\
\text { In partnership = } 5\end{array}$ \\
\hline Education & $\begin{array}{l}\text { Post-graduate level = } 1 \\
\text { Undergraduate level = } 3 \\
\text { Secondary level = } 11\end{array}$ \\
\hline Employment status & $\begin{array}{l}\text { Employed / maternity leave }=7 \\
\text { Unemployed }=7 \\
\text { Student }=1\end{array}$ \\
\hline Medication & $\begin{array}{l}\text { Medication = } \\
\text { Fluoxetine } \\
\text { Citalopram } \\
\text { Sertraline }\end{array}$ \\
\hline Alcohol/drug use & $\begin{array}{l}\text { No alcohol or drug use }=12 \\
\text { Minimum use of alcohol }=3\end{array}$ \\
\hline
\end{tabular}

\section{Participants' clinical situation}

Participants initially exhibited sleep issues, anxiety and stress, difficulty to cope, mood issues, health related stress for themselves or their babies, poor self-care, bonding issues, anxiety 
about death or dying, lack of enjoyment, transition difficulties, confidence and self-esteem issues, and poor self-care.

Most participants had good pregnancies with no major complications, with one participant having been proactive and enjoyed an ante-natal class. However, some participants had experienced complications during the labor, with one participant having had undergone a Csection, while another had an operation for the placenta to be extracted.

More than half of the participants $(n=8)$ were breastfeeding during their participation in the trial, with most of them having had experienced some complications in relation to the breastfeeding, mainly pain or some infection such as mastitis. It was noted that some participants' difficulty to breastfeed their babies underlined feelings of guilt.

Most participants $(n=13)$ experienced sleep issues such as lack of routine or lack of sleep hygiene. Participants' tendency to ruminate was a contributing factor to maintenance or exacerbation of sleep issues. Another factor was feeding their babies in the middle of the night. On the other hand, almost all participants had steady and good appetite which was rich in nutrients for themselves and their babies.

Participants identified specific areas they wanted to improve in their lives such as anxiety and depression. They wanted to learn to manage stress better and to relax more easily. They wanted to reduce their rumination, to be able to reprioritize better, and to become empowered and confident. Other areas they wanted to work on was to improve their communication skills for having more meaningful personal relationships. They wanted to regain a sense of control and to move forwards in their lives.

All participants were reactive, feeling irritable and getting angry more easily than usual. One participant presented bonding issues with her baby. Most participants were exhibiting social withdrawal to an extent, but they all had at least one person they confided with. Another theme identified was around stress and worry, and some participants would feel more worried about health issues, mainly around their baby's health. As a result, some participants would present 
some cognitive deficits such as catastrophizing, focusing on the negatives amongst other things, or having high and unrealistic self-expectations. Two participants were exhibiting repetitive behaviour such as washing hands. Some participants would tend to feel overwhelmed with tasks that they had mastered before the birth of their babies. Lack of personal space and time were common elements in the participants' life circumstances.

\section{Measures}

In Table 4-4 are presented all the measures included in this study and the timeframe they were administered. There were eight questionnaires used in this trial: the Edinburgh Postnatal Depression Scale (EPDS), the Generalised Anxiety Disorder 7-item (GAD-7), the Kessler-10 questionnaires (Kessler-10), the Daily questionnaire, the Session evaluation questionnaire, the VR session questionnaire, the Feasibility questionnaire, and the Acceptance questionnaire.

The first three questionnaires, EPDS, GAD-7, and Kessler-10 were borrowed from international literature and their English version was used for this study. The remaining five questionnaires were produced by the authors of this study, with the Feasibility and Acceptance questionnaires having been based on two questionnaires used in a pilot study previously but with some minor modifications [15].

EPDS is a screening tool which has 10 items and can identify symptoms of depression during pregnancy and in the post-partum period [16]. It has good psychometric characteristics such as good sensitivity in identifying PND [17]. EPDS also has good internal consistency reliability [18], and good validity in terms of sensitivity and specificity, even cross-culturally [19]. It has also been used in different languages [20, 21].

GAD-7 is a screening tool with 7 items that can screen for generalised anxiety disorder and assess symptom severity. It has good validity [22], and reliability [23].

Kessler-10 is a 10 -item screening tool that has good psychometric properties [24]. It has also good levels of internal consistency and validity [25]. 
The Daily questionnaire (Table 4-2) consisted of 6 items. The first 2 questions were borrowed from the PHQ-9 questionnaire which asked about interest or pleasure in doing things, and feeling down, depressed or hopeless. The next three questions were borrowed from the GAD-7 questionnaire which asked about feelings of nervousness, worrying, and irritability. The last question measured confidence and self-efficacy. The participants were required to complete this questionnaire daily throughout the trial and the week leading to the follow up interview.

It is worth clarifying here that for questions 1 and 6 of the Daily questionnaire an upward trend would reflect an improvement in the participants' symptomatology, while a downward trend would show deterioration in symptomatology. In other words, 0 meant that participants would feel not interested and not confident respectively, while 10 meant that participants found interest in activities, and felt confident. In contrast, for questions 2, 3, 4, and 5 a downward trend would show an improvement, while an upward trend would show deterioration in participants' symptomatology. In other words, 10 meant that participants would feel depressed, anxious and worried, while 0 meant that participants' mood had improved, felt calm, and relaxed. 
Table 4-2. Daily questionnaire

Please answer the following questions by ticking the box which best describes how you feel today.

On a scale between 0-10:

1) Interest or pleasure in doing things

$\begin{array}{lllllllllll}0 & 1 & 2 & 3 & 4 & 5 & 6 & 7 & 8 & 9 & \begin{array}{l}10 \\ \text { (ngeat } \\ \text { interest) }\end{array}\end{array}$

2) Feeling down, depressed, or hopeless

$\begin{array}{lllllllllll}0 & 1 & 2 & 3 & 4 & 5 & 6 & 7 & 8 & 9 & \begin{array}{l}10 \text { (not } \\ \text { depressed } \\ \text { at all) }\end{array} \\ \begin{array}{l}\text { (very } \\ \text { depressed) }\end{array} & & & & & & & & & & \end{array}$

3) Feeling nervous, anxious, or on edge

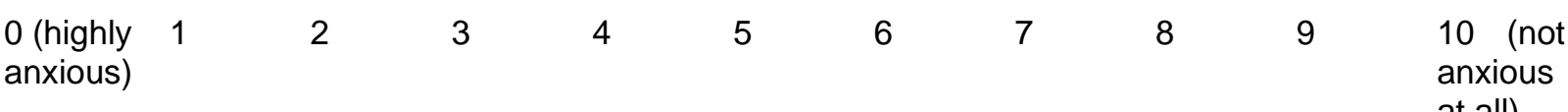

4) Not being able to stop or control worrying

$\begin{aligned} & 0 \quad \text { (very } \\ & \text { much }\end{aligned}$
worried)

\begin{tabular}{|c|c|c|c|c|c|c|c|c|c|c|}
\hline 5) Becomin & g ea & nnc & r irr & & & & & & & \\
\hline $\begin{array}{l}0 \\
\text { (annoyed) }\end{array}$ & 1 & 2 & 3 & 4 & 5 & 6 & 7 & 8 & 9 & $\begin{array}{l}10 \\
\text { (calm) }\end{array}$ \\
\hline
\end{tabular}

6) How confident do you feel about accomplishing today's tasks?

$\begin{array}{lrlllllllll}0 \quad \text { (not } & 1 & 2 & 3 & 4 & 5 & 6 & 7 & 8 & 9 & 10 \text { (highly } \\ \text { confident) } & & & & & & & & & & \text { confident) }\end{array}$

The Session Evaluation Questionnaire (Table 4-3) measured the usefulness and relativity of each session, while the VR session questionnaire measured whether the VR session was useful to the participants and relevant to their life circumstances. Both questionnaires used the same questions, but the VR session questionnaire focused on the use of VR in therapy. 
Table 4-3. Session Evaluation Questionnaire

1) On a scale $0-10$, how would you rate the usefulness of today's session?

$\begin{array}{lllllllllll}0 & 1 & 2 & 3 & 4 & 5 & 6 & 7 & 8 & 9 & 10 \text { (very } \\ \text { (not } & & & & & & & & & & \end{array}$

2) On a scale 0-10, how relevant did you find today's session to your life circumstances?

$\begin{array}{lllllllllll}0 \text { (not } & 1 & 2 & 3 & 4 & 5 & 6 & 7 & 8 & 9 & 10 \text { (very } \\ \text { relevant) }\end{array}$

3) Was there anything in particular that you liked about today's session?

Yes, it was...

4) Was there anything in particular you did not like about today's session?

Yes, it was....

The Feasibility questionnaire (Appendix A) has 11 questions with a 5-point Likert scale and asked about levels of comfortableness during recruitment, whether the facilitator gave enough information about referral process, ethics approval, and confidentiality, about the VR session being implemented in the fourth session, about the number of sessions and whether adequately addressed the mental health needs of the participants, whether there was adequate time to prepare for the VR session, whether the setting and the location of the study were suitable, whether the follow up call after the VR session in case participants experienced motion sickness was useful, and whether they would change anything in the whole process.

The Acceptance questionnaire (Appendix B) had initially been based on a questionnaire borrowed from the ETIOBE study which investigated childhood obesity [26]. It has 16 questions with a 5-point Likert scale and four open ended questions. It asked questions about total time use of the system, whether the system was easy to use, or whether they would like to use it 
often, about levels of difficulty degree of the system and if it could be easier to use, whether they needed the support of an expert, whether the different possibilities of the system are well integrated, whether the system was too fragile, whether it would be easy to use or was it too long and complicated, levels of comfortableness and confidence using the system, whether they needed to prepare a lot in order to use the system, whether the choice of tasks within the treatment modules were easy or difficult to handle, whether the system could speed up their recovery, whether they would use it frequently, and whether the application was useful. There was also the remarks section in the end which asked about what they liked most and least, whether there was something missing, and what tasks or things could they do better in their daily routines after having used the VR system. 
Table 4-4. List of measures and their timeframe

\begin{tabular}{|c|c|c|}
\hline Phases & Measures & Timeframe \\
\hline $\begin{array}{l}\text { Pre- } \\
\text { treatment }\end{array}$ & $\begin{array}{l}\text { - Daily questionnaire } \\
\text { - EPDS, GAD-7, Kessler-10 } \\
\text { - Session evaluation questionnaire }\end{array}$ & $\begin{array}{l}\text { - Answered daily } \\
\text { - Initial assessment } \\
\text {-At the end of the session }\end{array}$ \\
\hline $\begin{array}{l}\text { During } \\
\text { treatment }\end{array}$ & $\begin{array}{l}\text { - Daily questionnaire } \\
\text { - VR session questionnaire } \\
\text { - Session evaluation questionnaire }\end{array}$ & $\begin{array}{l}\text { - Answered daily } \\
-4^{\text {th }} \text { session } \\
\text { - At the end of each session }\end{array}$ \\
\hline $\begin{array}{l}\text { Post- } \\
\text { treatment }\end{array}$ & $\begin{array}{l}\text { - EPD-S, GAD-7, Kessler-10, Feasibility } \\
\text { and Acceptance questionnaires, Daily } \\
\text { questionnaire, Interviews with open- } \\
\text { ended questions } \\
\text { - Session evaluation questionnaire }\end{array}$ & - At the end of the session \\
\hline Follow-up & $\begin{array}{l}\text { - EPD-S, GAD-7, Kessler-10, Daily } \\
\text { questionnaire, Interviews with open- } \\
\text { ended questions }\end{array}$ & - 3 months post-treatment follow-up \\
\hline
\end{tabular}

\section{VR system}

The VR system [27] used for this trial was the same as for the pilot study previously [15]. The VR hardware is comprised of two computer sets, a pair of headsets each, a video camera each, a mouse, and a joystick (please see Figure 4-1). The technical characteristics of the VR hardware were as follows: "Windows 7, Dell OptiPlex 3020 PC (Intel Core TM i5-4670 @3.40 GHZ, RAM 8 GB), LCD screen (Dell E1910C, 19", 1440 × 900), Logitech HD webcam C270, Tritton Kunai stereo headset, and Logitech X3D for a joystick" [28, pg. 921]. The mouse was used by the therapist, while the joystick is used by the participants to navigate themselves in the virtual environment. 
The audio and video communication between the two computers used "Video Chat" developed by Midnight Status, which increased the quality of the picture and the sound [29].

Both computer sets communicate with an Ethernet cable. The therapist and participants can communicate with each other via the headphones, and they are also able to see the other person via a videoconferencing window in the top part of the screen. This reflects the design and purpose of building this system which was for the users to operate and in a joint virtual environment. It also allows for remote communication between the two parties.

Figure 4-1. Hardware and virtual environment on participant's side

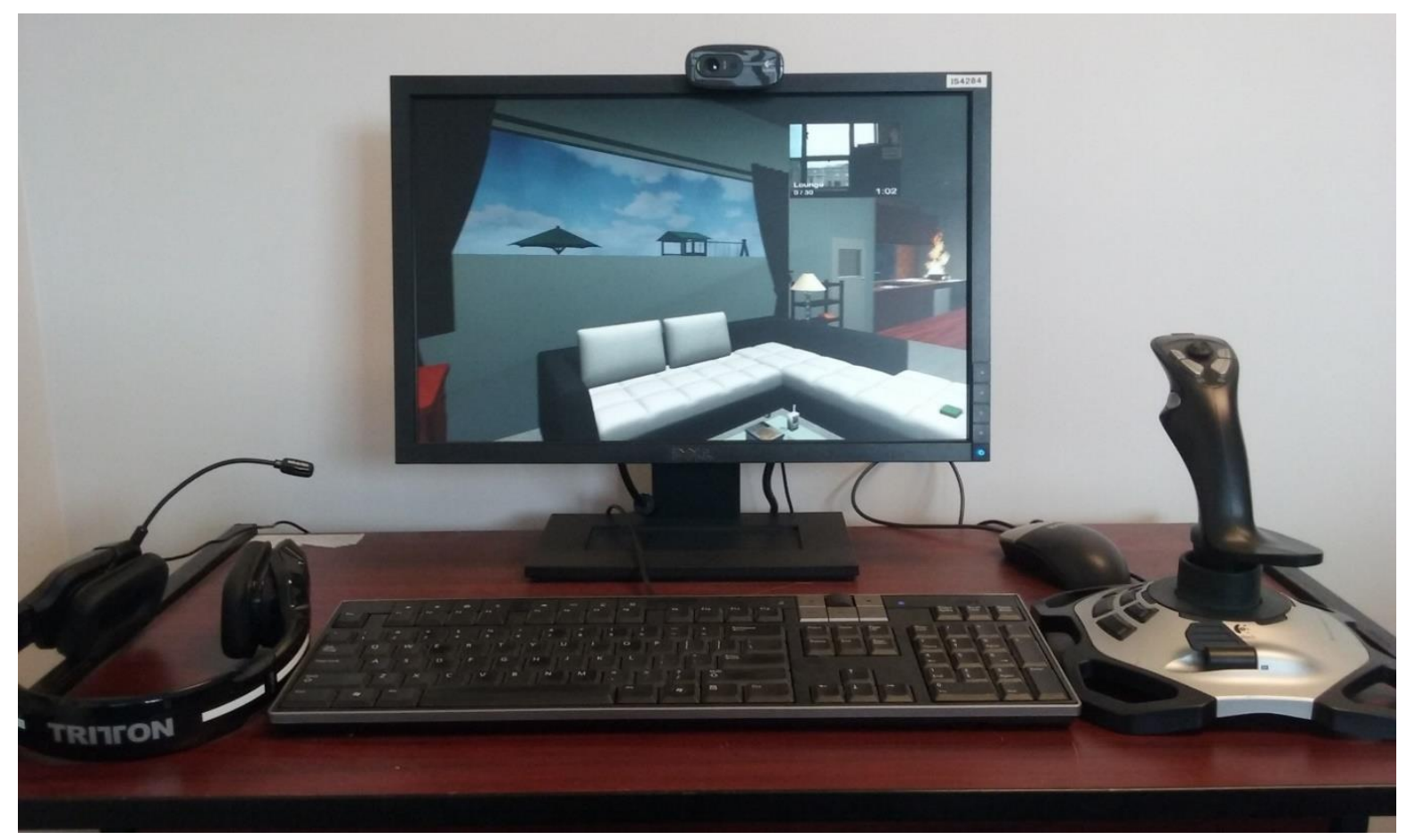

The virtual environment depicts a middle-class house, with two bedrooms, a bathroom, a kitchen - dining room, and a living room, all with suitable furniture such as beds, sofas, drawers, curtains, kitchen appliances, and bathroom utilities. There is also an outside area with a garden and a playground. 
In a study [29] conducted for exploring the feasibility and utility of the VR system, mental health professionals of different backgrounds, such as psychology and psychotherapy, felt that the system could be used as a stress resilience tool for different mental health disorders. It was hypothesised that this VR system could be used for: phobias, stress and anxiety, PTSD, mood disorders, autism, ADHD, eating disorders, personality disorders, sexual dysfunction, and psychotic disorders. Although it is not certain at this stage how the VR system could be utilised for a vast array of mental health issues, the initial feedback is promising.

\section{Virtual stressors}

The stressors of the VR programme were divided into three main categories. These were the Home stressors, the Toddler's stressors, and the Neighbour stressors. Table 4-5 below describes the stressors in each category and has been adopted [27]. 
Table 4-5: Virtual stressors and their categories

Category

Home stressors

\begin{tabular}{|c|c|}
\hline & Pet noise (cats meowing) \\
\hline & Noisy loud music from the radio \\
\hline & Loud doorbell \\
\hline & Loud and constantly telephone ringing \\
\hline & Loud and constantly crying newborn baby \\
\hline & Power outage scenario \\
\hline \multirow[t]{4}{*}{ Toddler } & Natural movement in the same location with talking \\
\hline & Moving next to the TV \\
\hline & Trying to reach the telephone \\
\hline & Climbing a high-chair \\
\hline
\end{tabular}

Trying to reach some medications

Trying to reach and grab a knife

Being next to a fire in the kitchen scenario
Peaceful sounds (birds)

Loud traffic

\section{Loud dogs barking}

Loud sirens

Loud party

Neighbours arguing and fighting loudly

Neighbours extreme violence scenario

One of the functions of the programme was that each stressor could be adjusted by the therapist in terms of volume and the length of being used. They could also be activated 
separately or simultaneously (see Figure 4-2). In general, the use of the stressors was flexible and adopted to the different needs of each user of the VR programme.

Figure 4-2. Virtual stressors activated simultaneously

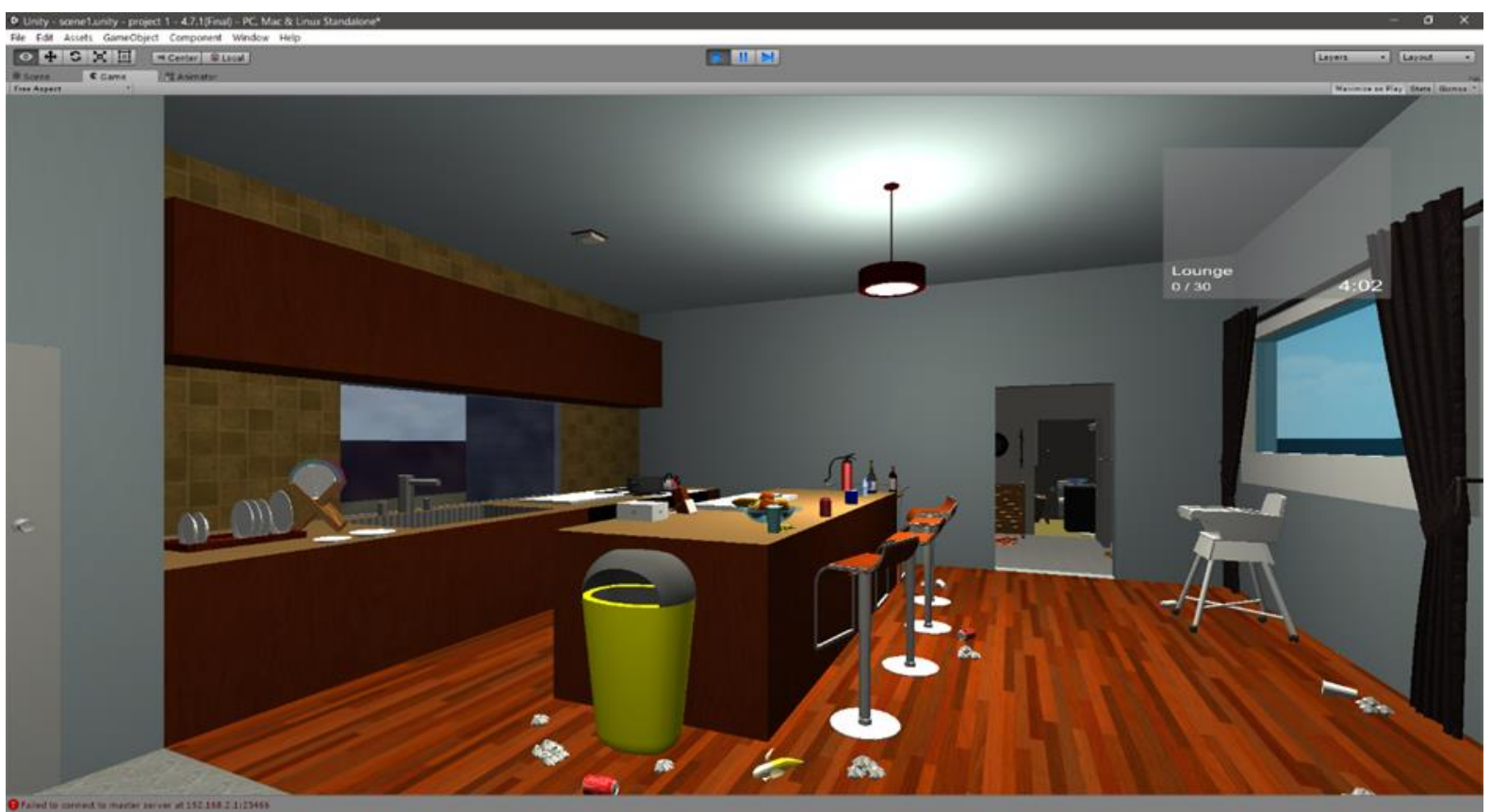

\section{Experimental Design}

This was a single case design trial. There are different single case designs such as $A B, A B A$, $\mathrm{ABAB}$, multiple baselines, alternating treatments, changing criterion, or a combination of them [30]. We chose the multiple baseline design as its design allowed us to explore the efficacy of a single treatment in a relatively small number of participants, without having to use a control group [31]. Single case studies require less resources and can highlight individual differences [32].

Single case designs require the repeated measurement of the dependent variable in specific time intervals as the independent variable gets manipulated [32]. To ensure the external validity 
of the treatment, three different baselines were defined. For both baseline and treatment stages, 5 assessment points were also defined to ensure the generalizability of findings [33].

We collected data daily using the Daily questionnaire which consisted of six questions. The data collected is presented in the different Figures in the Results section, which include the mean values of the participants' scores from the three baselines. The Figures are the visual representation of the data which highlights the overall progress of the participants starting from baseline, during treatment, and up until the follow up period. In that way, we were able to conclude safely whether the introduction of the treatment had an effect, and whether any therapeutic gains were maintained in the follow up period. We were also able to compare and identify any similar trends in the progress of the participants from each baseline separately which helped us answer some of the research questions easier.

Single case designs allow for a greater flexibility in designs compared with traditional largerscale trials, including the ability to change the ongoing treatment if this proves to be problematic $[34,35]$. In the present study, a CBT treatment was offered, a well-researched and widely accepted psychological intervention [36]. In addition, VR was also offered and was part of the treatment protocol. However, participants had the option to withdraw at any point during the study in case they would have chosen to.

Randomisation of participants was done by an independent researcher from Universitat Jaume I. The duration of baselines was based on three restrictions: the minimum duration of the baselines would be 8 days, while the maximum duration was 14 days. The result of the baseline randomisation was for baseline 1 to be 9 days, baseline 2 was 11 days, while the third baseline group was 14 days. Participants were assigned to the baselines based on the order of recruitment. As a result, baseline 1 had five participants, baseline 2 had 4 participants, while the third baseline had six participants. However, baseline 1 and baseline 3 had two participants each who dropped out of the study following the initial assessment. Considering that the dropouts were distributed in 2 baselines, this minimized the risk of threats to the validity. 


\section{Procedure}

The therapist, a Mental Health practitioner with over 18 years of clinical experience on mental health issues including PND, contacted GP practices and other health providers in the Dunedin area, New Zealand. He provided detailed information about the trial, the inclusion and exclusion criteria, the process of recruitment, the ethics, confidentiality, and risk mitigation process.

The therapist triaged the incoming referrals initially to assess whether they met the inclusion criteria of the study and which ones were not accepted. The ones, which did not meet the inclusion criteria, were declined and referred back to their health provider. There was an initial brief phone consultation between the researcher and the potential participants to assess each participant's interest in the study, to explain the treatment rationale and clarify any doubts that participants may have, and to answer any questions that the participants had about the trial.

Once the number of participants who had agreed to participate in the study was reached, the therapist obtained the participants' consent verbally and recorded their demographic data. Next, the therapist and the participants arranged for the initial assessment in a mutually agreed day and time. The initial assessment occurred in three groups in three consecutive days. This was necessary as the initial assessment for each participant were facilitated by the therapist himself and without somebody else's input.

In the pre-treatment phase, the therapist conducted a complete initial assessment, with the participants completing four questionnaires, EPDS, GAD-7, Kessler-10, and Session evaluation questionnaire. Following the initial assessment, the participants were asked to start completing the Daily questionnaire on all phases of the trial, the pre-treatment, throughout all phases of treatment, post-treatment, and follow up. There were also given the option to receive a text message to their mobile phones as a reminder for completing the Daily questionnaire.

During treatment, the facilitator and each participant would work on specific areas of clinical importance following the clinical protocol and in accordance with the clinical presentation of each participant. They were encouraged to implement the skills and strategies they had learned 
in the clinical room and transfer them to their everyday lives. In addition, participants were asked to keep completing the Daily questionnaire. They were also asked to complete the Session evaluation questionnaire at the end of each session. The questionnaire about the VR session was completed once, right at the end of the VR trial session. They were asked for their feedback about their VR experience following the VR session.

In the VR session, the facilitator and each participant were in to two different rooms which the facilitator had prepared accordingly. The therapist ensured the correct functioning of the technology, the visual and audio communication between facilitator and participants before the trial started. The facilitator introduced the users of the programme to the virtual environment, where the participants were able to navigate themselves within it in order to get a "feeling" of the environment. The participants' introduction to the VR system would last approximately five minutes, the main part lasted thirty minutes, while the conclusion five minutes. However, the main part was divided in two parts and a break in between for the participants who were susceptible to motion sickness. In the last part of the session, the facilitator invited the participants to give feedback on their experience overall which also acted as a debrief.

During the VR trial, the facilitator used different psychological techniques when collaborated with the participants during the VR session, such as guidance, reflective listening, and acknowledging. The facilitator guided the participants when it was necessary. This was mainly for navigation purposes around the virtual environment. For example, the facilitator would remind participants to move forward, slow down, or go to the left or right. The facilitator would draw their attention to specific content of the environment, when needed. This could be around specific visual and auditory cues. The facilitator would ask the participants to change their view of the virtual environment, if needed, by pressing the lever, or guide them of how to overcome some technical difficulties.

The second technique was about reflective listening and checking with the client how they felt which underlined a feeling of immediacy. The purpose of that was for the facilitator to get a clear 
idea of what was happening for the participants, and for them to be able to articulate about their emotional states clearly. The third approach was about acknowledging and rewarding the participants' efforts. The facilitator would comment upon their actions taken within the virtual environment, or how they responded or reacted to a virtual stressor. This would create a sense of direction and positive reinforcement.

At post-treatment, the participants were asked to complete 7 questionnaires, that of EPDS, GAD-7, Kessler-10, Feasibility and Acceptance questionnaires, Session evaluation questionnaire, along with the Daily questionnaire for the whole week before the last session (refer to Table 4-5). They were also asked, in semi-structured interviews with open-ended questions, to provide feedback on their experience about the VR programme and their progress during the trial overall.

There was a follow-up phone interview three months post-intervention where the participants completed the Daily questionnaire, EPDS, GAD-7, and Kessler-10 questionnaires. During the interview, they gave their feedback on their progress for the last three months in a semistructured way with open-ended questions.

\section{Treatment}

This trial examined the effect of VR with CBT on mild to moderate range depression in the postpartum period. The number of sessions were 6 in total. The facilitator used CBT techniques in four different components of clinical interest: psychoeducation, stress management, cognitive restructuring, and goal setting and achieving.

The first session was mainly the comprehensive assessment which covered issues such as background history of the participants, family status, employment, presenting problem, symptomatology, history of pregnancy, labour issues, breastfeeding difficulties, medication, physical health status, drug and alcohol use, sleep, appetite, and risk. 
The second session focused on psychoeducation and stress management. The facilitator gave information to the participants about symptomatology of PND with an emphasis on sleep hygiene and how to develop good sleeping patterns. The stress management focused on mindfulness as it is an effective way to cope with rumination better. The facilitator was able to show some practical exercises such as grounding in the present moment, and diffusion of the ruminative thoughts.

The third session focused on identifying stressors for each individual participant. The stressors varied from family dynamics and relationship issues, breastfeeding difficulties, attachment issues, bonding between mother and infant, lack of support, and financial issues. The focus was also on cognitive restructuring where the facilitator and participants worked on themes such as unrealistic expectations, polarised thinking, jumping to conclusions, and catastrophising. The last part was about identifying goals that the participants would like to achieve and identified practical ways to do that. In the end, the participants were introduced to the VR programme. The facilitator explained about the purpose of the system, and how it worked. He introduced them to the virtual stressors where the participants were able to choose which were most relevant to them and in what sequence they would be activated. The participants also used the VR programme briefly.

In the fourth session, the participants used the VR system. The participants were exposed to a series of stressors, while they had to tidy up the virtual house. They had to pick up the rubbish from the floor, and place some of the objects, which were located on the floor back to their original place, e.g., wine bottles back to the wine rack, knives back to the knife rack, etc. The goal was for the participants to learn how to manage their stress better and was based on prioritization, decision making, grounding self onto the present moment, and self-awareness.

In the fifth session, the focus was the maintenance of already achieved goals and working through obstacles. However, the participants worked on identifying new skills learned from the 
VR trials. The facilitator helped them identify ways of implementing them into their everyday lives.

The sixth and final session was about evaluation and closure. The participants gave an overview of the sessions, their experience, and an update of their overall progress since they started therapy.

\section{Statistical analysis}

We wanted to determine whether there was an effect of the whole therapeutic approach on the participants of this trial. For this reason, we ran the Cohen-d test for the following questionnaires: EPDS, GAD-7, and Kessler-10. We found the mean values and standard deviations for all participants for the baseline, post-treatment, and follow up periods and compared them with each other. To determine whether VR had any effect, and to what extent, on the overall therapeutic outcome for PND, the mean values and standard deviations were found. We ran the Cohen-d test for the Daily questionnaire and compared the mean values between baseline vs session 2 vs session 3 vs VR session vs session 5 vs follow up. The mean values and standard deviations for both the Feasibility and Acceptance questionnaires were also calculated.

\section{RESULTS}

First, for better statistical power, all 11 participants who completed the trial were combined. Figure 4-3 shows the results from the questionnaires Kessler-10, GAD-7, and EPDS. They include the baseline, the post-treatment, and follow up periods. All three questionnaires show a clear reduction in the post-treatment and follow up periods following the baseline time frame. Table 4-6 includes the mean values and standard deviations of the same three questionnaires in the three different time periods. 
Cohen-d test (see Table 4-7) shows that the differences in the mean values in all questionnaires and in all in between comparison between timeframes are large with one exception being medium. For example, in the comparison between baseline vs post-treatment in Kessler-10, the d estimate is medium with a 95 percent confidence interval. However, comparing the posttreatment vs follow up in the same questionnaire, the $d$ estimate is considered large. In the GAD-7 questionnaire, the $d$ estimates when comparing baseline vs post-treatment and posttreatment vs follow up are both large with a 95 percent confidence interval. Similarly, the $d$ estimates between baseline and post-treatment, and post-treatment and follow up for the Kessler-10 questionnaire are both estimated large with a 95 percent confidence interval.

Figure 4-3: Mean* values for Kessler-10, GAD-7, EPDS questionnaires

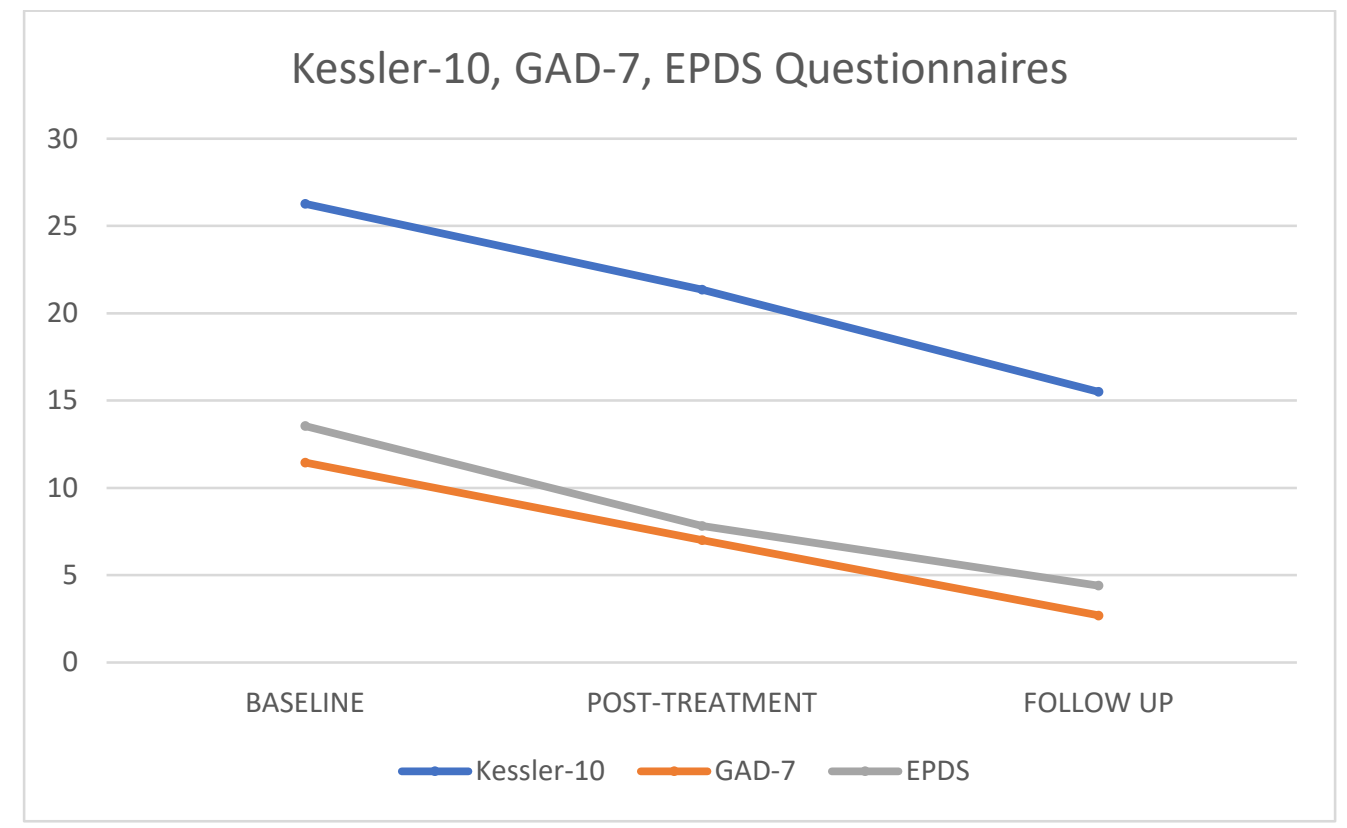

*left column represents the mean values of the questionnaires 
Table 4-6: Mean values and standard deviations () for Kessler-10, GAD-7, EPDS questionnaires

\begin{tabular}{cccc}
\hline Measures & Baseline & Post-treatment & Follow-up \\
\hline Kessler-10 & 26.27 & 21.36 & 15.50 \\
\hline GAD-7 & $(7.36)$ & $(7.36)$ & $(3.06)$ \\
\hline EPDS & 11.45 & 7.00 & 2.70 \\
& $(4.65)$ & $(3.71)$ & $(1.63)$ \\
\hline & 13.54 & 7.81 & 4.40 \\
\hline
\end{tabular}

Table 4-7. Cohen-d - effect size

Questionnaires Baseline vs Post-treatment Post-treatment vs Follow Up

\begin{tabular}{ccc}
\hline Kessler-10 & 0.67 (medium) & 1.02 (large) \\
\hline GAD-7 & 1.06 (large) & 1.47 (large) \\
\hline EPDS & 1.17 (large) & 0.83 (large)
\end{tabular}

Figures 4-4 until 4-9 show the results from the Daily questionnaire. Their format is presented based on [37]. There is a clear improvement from session to session, starting from baseline until the follow up periods in the participants from the three different baselines established. However, the improvement in symptoms becomes clearer following the VR session (see Table 4-8). For 
example, in the first question about interest or pleasure in doing things, there is an increase following the initial assessment, with that increase being more noticeable following the VR session. That improvement is also apparent during the follow up period 3 months posttreatment. The d estimate was negligible between sessions 1 and 2, but large in the rest of the sessions.

In the second question about feeling down, depressed, or hopeless, the improvement that participants experienced in the beginning following the initial assessment was large but the effect was medium and negligible until the VR session. Nevertheless, the effect size following the VR session was large up until the follow up period.

Similarly, in the question about feeling nervous, anxious, or on edge, participants showed an improvement overall with the effect size to vary between small, large, and negligible until the VR session. Participants showed an even bigger improvement with the effect size to be both large following the VR session up until the follow up session.

In question 4 about not being able to stop or control worrying, there is an overall improvement throughout the therapeutic intervention up until the follow up period, but the improvement becomes more noticeable following the VR session with the $d$ estimate to be large.

In the question about becoming easily annoyed or irritable, the improvement was steady with the $d$ estimate to be medium, with the exception between VR session and session 5 where the $d$ estimate was large.

Lastly, for question that measured confidence, participants felt steadily more confident throughout therapy with the $d$ estimate following the initial assessment up until the VR session to be medium and large. However, the improvement was more noticeable following the VR session up until the follow up period with the d estimate to be large. 
Figure 4-4. Interest or pleasure in doing things

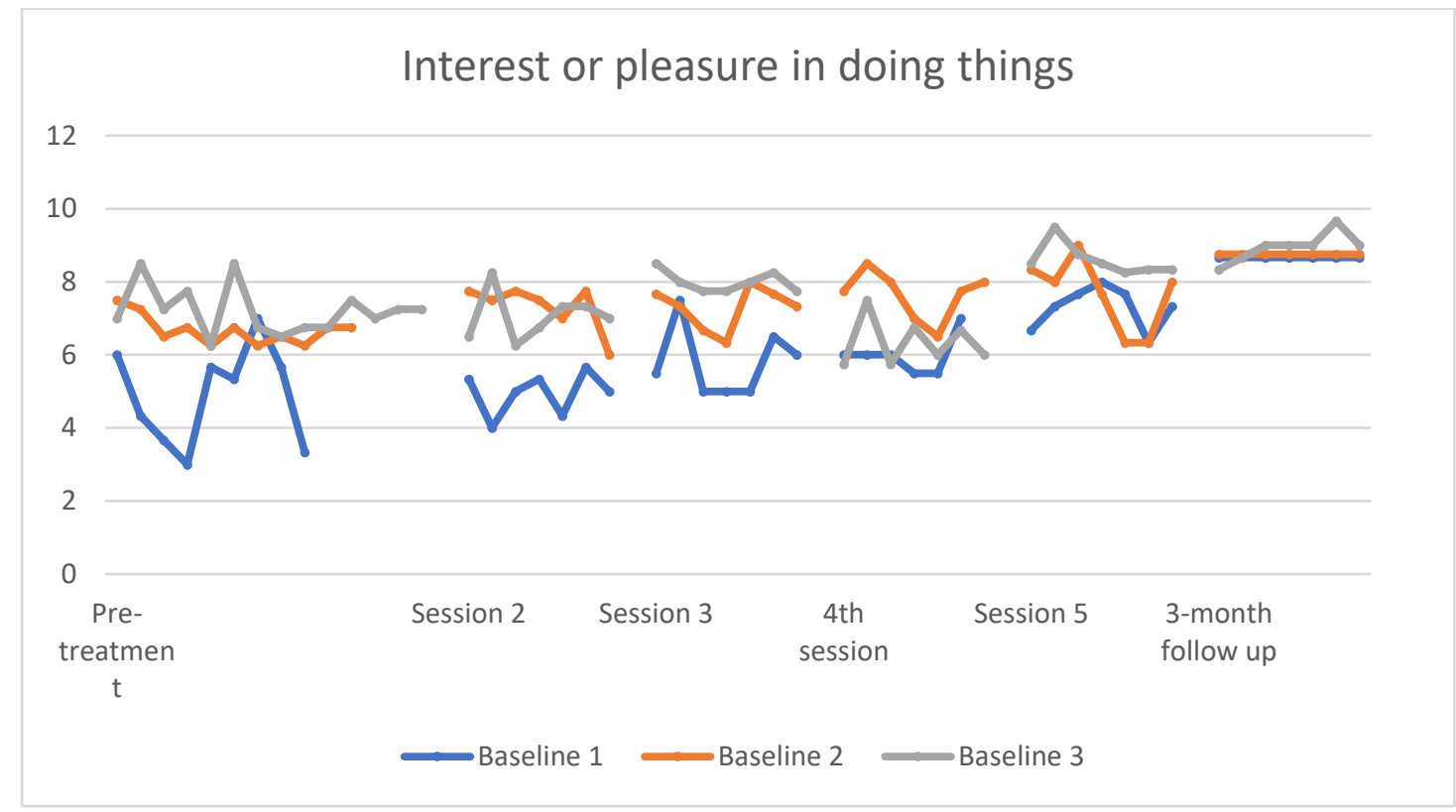

Figure 4-5. Feeling down, depressed, or hopeless

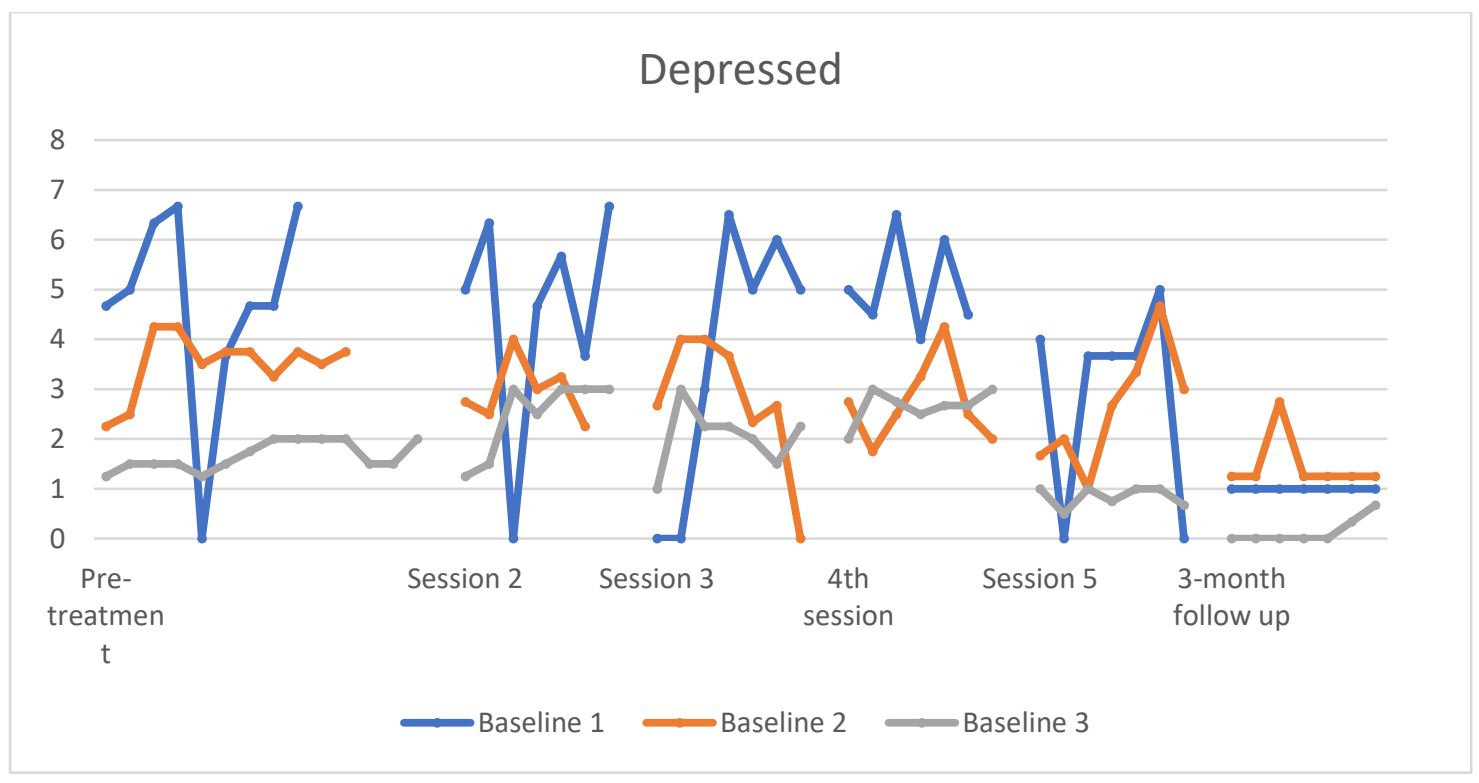


Figure 4-6. Feeling nervous, anxious, or on edge

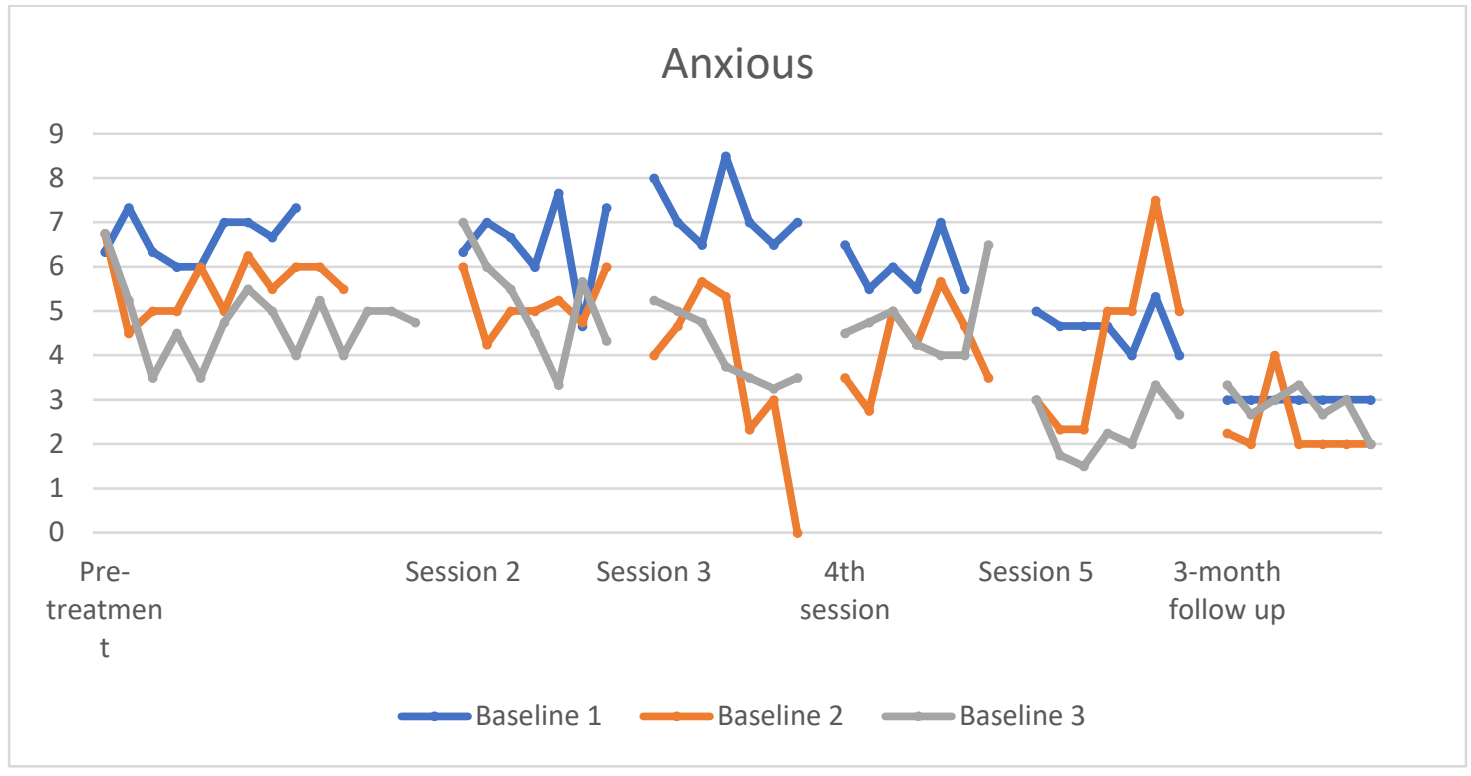

Figure 4-7. Not being able to stop or control worrying

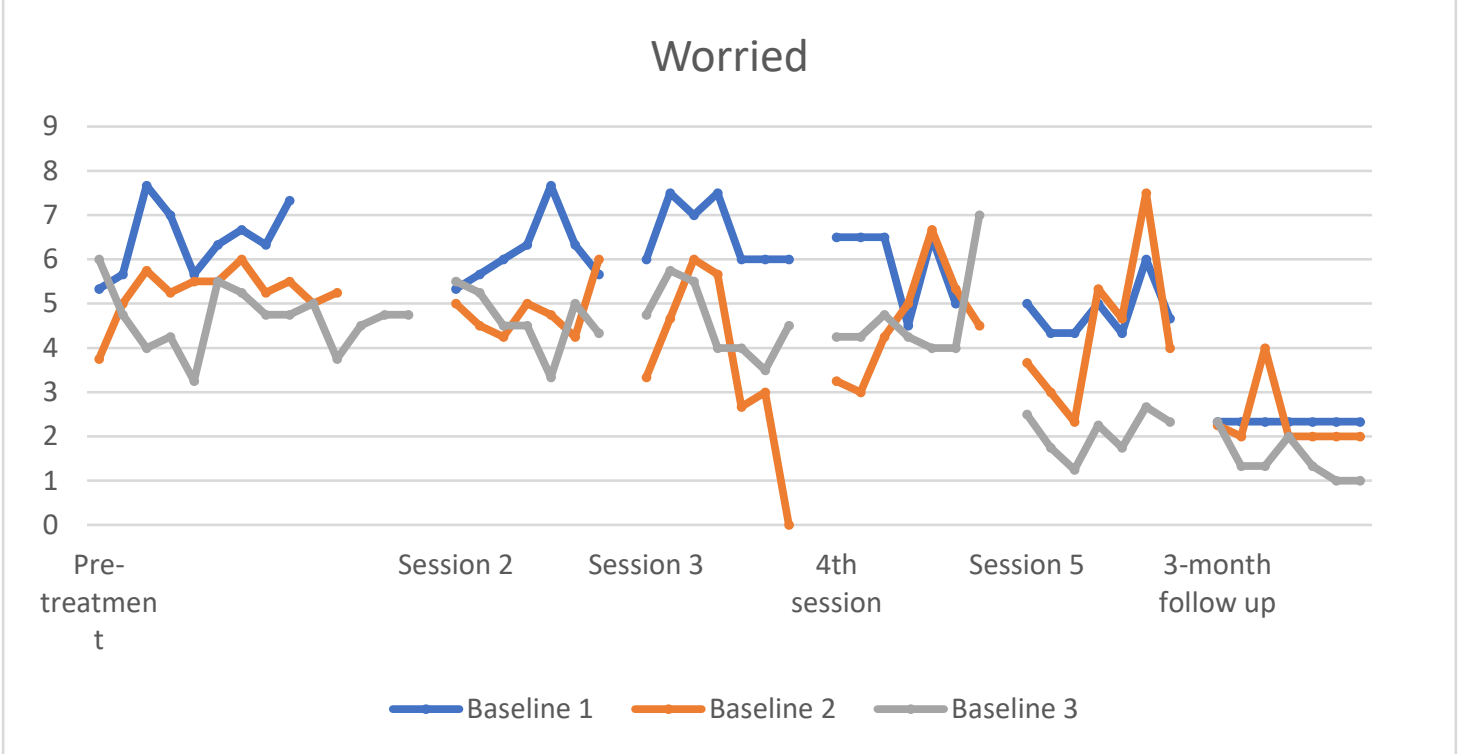


Figure 4-8. Becoming easily annoyed or irritable

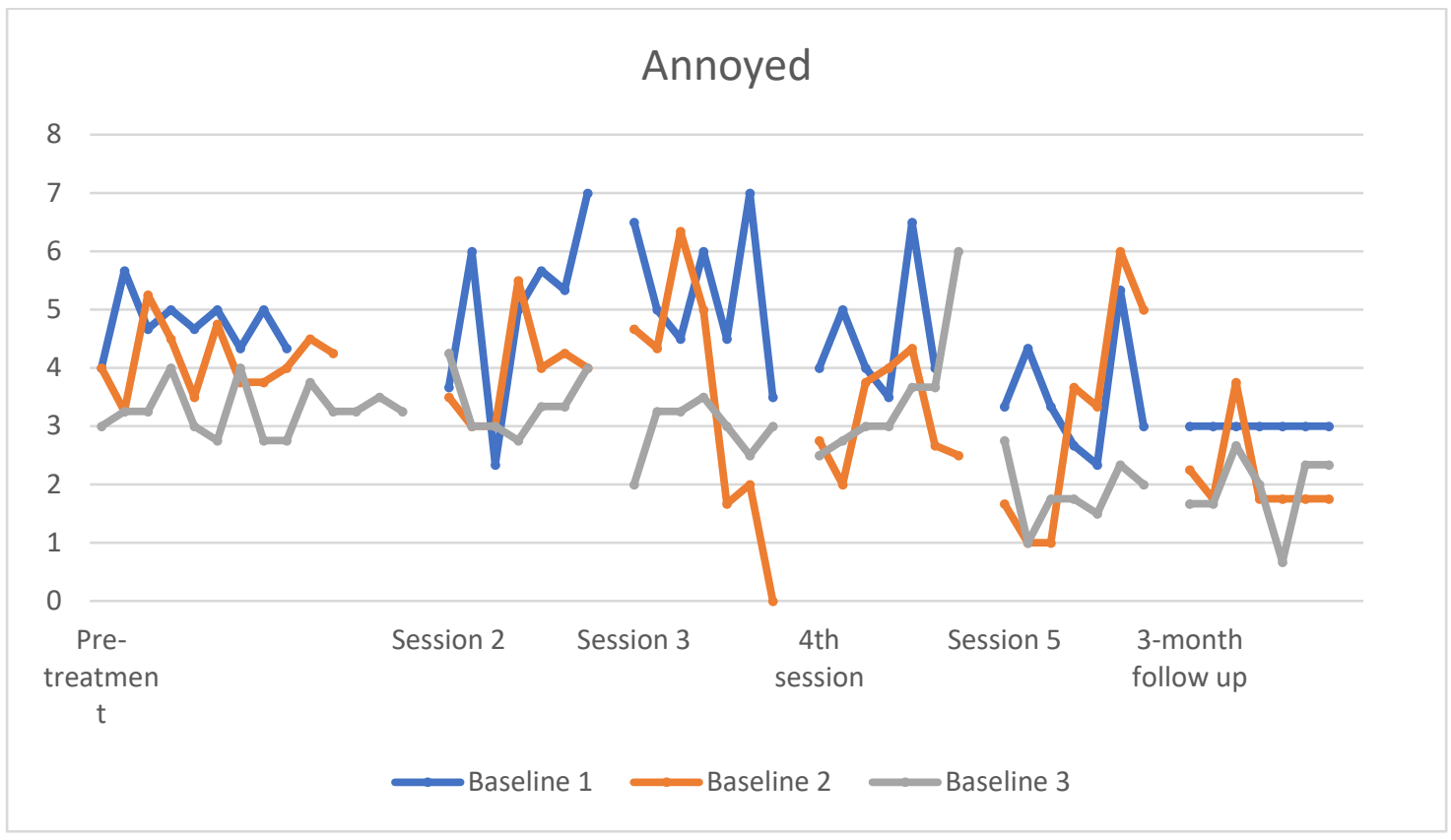

Figure 4-9. How confident do you feel about accomplishing today's tasks?

\section{Confidence}

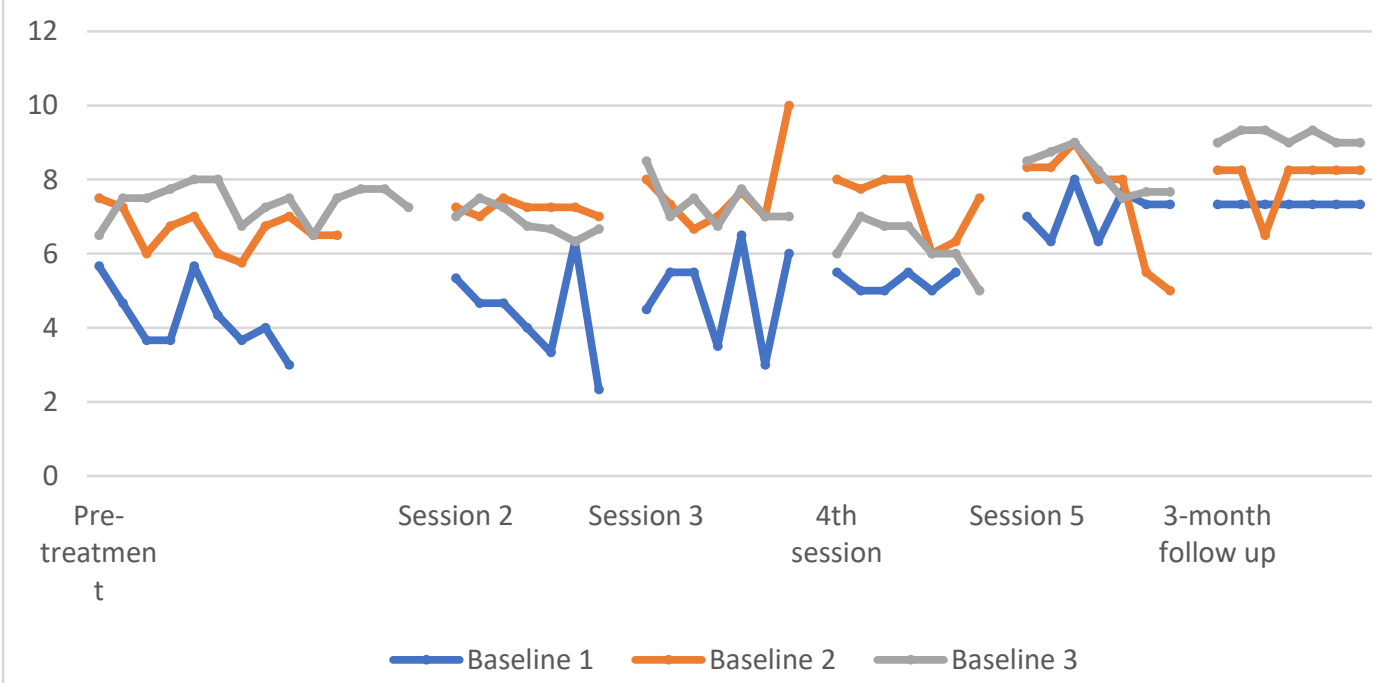


Table 4-8: Daily questionnaire effect size (d estimate)

\begin{tabular}{|c|c|c|c|c|c|c|}
\hline Questions* & Disinterested & Depressed & Anxious & Worried & Annoyed & Confident \\
\hline $\begin{array}{c}\text { Session } 1 \\
\text { vs Session } \\
2\end{array}$ & $\begin{array}{c}0.18 \\
\text { (negligible) }\end{array}$ & $\begin{array}{c}0.83 \\
\text { (large) }\end{array}$ & $\begin{array}{l}-0.39 \\
\text { (small) }\end{array}$ & $\begin{array}{c}0.03 \\
\text { (negligible) }\end{array}$ & $\begin{array}{c}0.53 \\
\text { (medium) }\end{array}$ & $\begin{array}{c}0.60 \\
\text { (medium) }\end{array}$ \\
\hline $\begin{array}{c}\text { Session } 2 \\
\text { vs Session } \\
3\end{array}$ & $\begin{array}{l}-1.93 \\
(\text { large })\end{array}$ & $\begin{array}{c}-0.71 \\
\text { (medium) }\end{array}$ & $\begin{array}{c}1.25 \\
(\text { large })\end{array}$ & $\begin{array}{c}0.47 \\
\text { (small) }\end{array}$ & $\begin{array}{c}-0.51 \\
\text { (medium) }\end{array}$ & $\begin{array}{l}-1.02 \\
(\text { large) }\end{array}$ \\
\hline $\begin{array}{c}\text { Session } 3 \\
\text { vs VR } \\
\text { Session }\end{array}$ & $\begin{array}{c}0.91 \\
\text { (large) }\end{array}$ & $\begin{array}{c}0.06 \\
\text { (negligible) }\end{array}$ & $\begin{array}{c}0.0074 \\
\text { (negligible) }\end{array}$ & $\begin{array}{c}-0.05 \\
\text { (negligible) }\end{array}$ & $\begin{array}{c}-0.79 \\
\text { (medium) }\end{array}$ & $\begin{array}{c}0.62 \\
\text { (medium) }\end{array}$ \\
\hline $\begin{array}{c}\text { VR } \\
\text { Session vs } \\
\text { Session } 5\end{array}$ & $\begin{array}{l}-2.05 \\
\text { (large) }\end{array}$ & $\begin{array}{l}-1.23 \\
\text { (large) }\end{array}$ & $\begin{array}{c}1.80 \\
\text { (large) }\end{array}$ & $\begin{array}{c}1.76 \\
\text { (large) }\end{array}$ & $\begin{array}{l}-0.87 \\
\text { (large) }\end{array}$ & $\begin{array}{l}-2.28 \\
\text { (large) }\end{array}$ \\
\hline $\begin{array}{l}\text { Session } 5 \\
\text { vs Follow } \\
\text { Up }\end{array}$ & $\begin{array}{l}-2.35 \\
\text { (large) }\end{array}$ & $\begin{array}{l}-3.40 \\
\text { (large) }\end{array}$ & $\begin{array}{c}1.45 \\
\text { (large) }\end{array}$ & $\begin{array}{c}2.83 \\
\text { (large) }\end{array}$ & $\begin{array}{c}-0.55 \\
\text { (medium) }\end{array}$ & $\begin{array}{l}-0.96 \\
\text { (large) }\end{array}$ \\
\hline
\end{tabular}

*For the full set of questions, please refer to Table 2.

\section{Feasibility questionnaire}

On a scale between $1-5$, where 1 meant yes and 5 meant they answered negatively, the mean score of the participants for levels of comfortableness throughout the referral process was 1.09 $(S D=0.30)$, (see Table 4-9) while the mean values for having been given adequate information about the referral process, ethics approval and confidentiality was $1.00(S D=0.00)$. The mean values for both the VR being implemented in the fourth session, and the number of sessions being adequate for addressing their mental health needs was $1.54(\mathrm{SD}=0.82)$. 
The mean values for the question of having enough information about the VR system and how it worked was $1.18(\mathrm{SD}=0.60)$, while whether they had adequate time to prepare for the VR session was $1.18(\mathrm{SD}=0.40)$. The mean value on whether the questionnaires captured the participants' mental health needs was $1.45(S D=0.52)$, while the majority of participants did not feel the number of questionnaires they completed was excessive, where the mean value was $0.64(\mathrm{SD}=1.02)$ on a scale between 1 and 5 where 1 meant they agreed the number of questionnaires was excessive. The setting and location were considered suitable as the mean value of the participants' answers were $1.36(S D=0.92)$. Lastly, the mean value for the phone call after participants had experienced motion sickness was not applicable to all, while the mean value for the ones who received a phone call was $1.66(\mathrm{SD}=0.57)$.

In the question whether the participants would change anything in the whole process, nine participants answered negatively, while two participants answered positively. One participant expressed that she wanted to be able to tidy up the whole virtual house, while the second participant reported that she felt that the virtual environment could not replicate real stressors and it did not reflect her own real-life stressors such as having one baby and a toddler. 
Table 4-9. Mean values and standard deviations for Feasibility questionnaire

Questions

Mean values Standard

deviations

\begin{tabular}{llll}
\hline Did you feel comfortable throughout the recruitment 1.09 & 0.30
\end{tabular} process?

\begin{tabular}{lll}
\hline Did the facilitator of the study give enough information 1.00 & 0.00
\end{tabular} about the referral process, ethics approval, and confidentiality?

\begin{tabular}{lll}
\hline Was it a good idea for the VR session to be implemented 1.54 & 0.82
\end{tabular} in the fourth session?

$\begin{array}{lll}\text { Did you feel the total number of sessions were adequate } & 1.54 & 0.82\end{array}$ to address your mental health needs?

$\begin{array}{lll}\text { Did you have enough information about the VR system } 1.18 & 0.60\end{array}$ and how it works before you started using it?

$\begin{array}{llll}\text { Did you have adequate time to prepare for the VR } 1.18 & 0.40\end{array}$ session?

Did the questionnaires capture the essence of your $1.45 \quad 0.52$ mental health issues?

\begin{tabular}{lllllllll}
\hline Do you feel you had to complete too many 0.64 & 1.02
\end{tabular} questionnaires?

\begin{tabular}{llll}
\hline Was the setting and the location of the study suitable? & 1.36 & 0.92
\end{tabular}

If you experienced motion sickness when you used the $1.66 \quad 0.57$ VR system, did you think the follow up phone call was useful? 


\section{Acceptance questionnaire}

Most participants used the VR system between 20 and 30 minutes, one participant used it for between 15-20 minutes approximately, while two participants did not answer that question.

On a scale between 1 and 5 with 1 meant that the participants fully agreed, where they felt that the system was relatively easy to use, the mean value was 1.18 ( $S D=0.98)$, while some participants would like to use the system often where the mean value was $1.82(S D=1.32)$ (see Table 4-10). Participants did not feel the system was difficult or that it could be easier to use, where the mean value was $2.09(\mathrm{SD}=1.04)$ on a scale between 1 and 5. 
Table 4-10. Mean values and standard deviations for the Acceptance questionnaire

\begin{tabular}{|c|c|c|}
\hline Questions & Mean values & $\begin{array}{l}\text { Standard } \\
\text { deviations }\end{array}$ \\
\hline I believe the system is easy to use & 1.18 & 0.98 \\
\hline I believe l'd like to use this system often & 1.82 & 1.32 \\
\hline I believe the system is difficult and it could be easier to use & 2.09 & 1.04 \\
\hline I believe l'd need the support of an expert to use the system & 1.54 & 0.82 \\
\hline $\begin{array}{l}\text { I believe the different possibilities of the system are well } \\
\text { integrated }\end{array}$ & 0.91 & 0.83 \\
\hline I believe the system is too fragile & 1.54 & 0.68 \\
\hline $\begin{array}{l}\text { I believe most people would learn very quickly to use the } \\
\text { system }\end{array}$ & 0.82 & 0.87 \\
\hline $\begin{array}{l}\text { When going through the system, I found it too long and } \\
\text { complicated }\end{array}$ & 1.54 & 0.82 \\
\hline I felt very comfortable and confident when using the system & 1.00 & 0.89 \\
\hline $\begin{array}{l}\text { I need to learn a lot of things before knowing well how to use } \\
\text { the system }\end{array}$ & 1.63 & 0.80 \\
\hline The choice of tasks within the treatment's module is & 2.00 & 1.00 \\
\hline The system can speed up my recovery & 2.72 & 1.27 \\
\hline If it was available, l'd use it frequently & 3.18 & 1.25 \\
\hline In general terms, the application was easy to use & 1.81 & 0.75 \\
\hline In general terms, I believe the application is useful & 2.18 & 1.25 \\
\hline
\end{tabular}


Most participants did not believe they would need the support of an expert to use the system where the mean value was $1.54(\mathrm{SD}=0.82)$. Most participants felt that the possibilities of the system were well integrated with mean value $0.91(S D=0.83)$.

Most of the participants felt that the system was not fragile with mean value 1.54 ( $S D=0.68)$, and that they believed that most people would learn to use the system quickly with mean value $0.82(\mathrm{SD}=0.87)$.

The process of using the system was not long and complicated for all participants with mean value $1.54(S D=0.82)$, and the majority also felt comfortable and confident using the system with mean value of $1.00(\mathrm{SD}=0.89)$.

All participants feedback that they did not need any special knowledge for using the system with mean value $1.63(S D=0.80)$. On a scale between 1 and 5 , where 1 meant easy to handle and 5 difficult to handle, participants reported that the tasks were relatively easy to handle with the mean value was $2.00(S D=1.00)$. Similarly, participants felt the VR system was easy to use, with the mean value to be $1.81(\mathrm{SD}=0.75)$.

Participants were divided about whether the system would speed up their recovery, with the mean value to be $2.72(S D=1.27)$. The majority answered negatively about using the system more frequently if it was available, with the mean value to be $3.18(S D=1.25)$, while at the same time, they found the application to be useful for the most part, with the mean value to be 2.18 $(S D=1.25)$, where 1 meant they fully agreed in a scale between 1 and 5 .

What almost half of the participants liked the most about the VR system was that it was relevant and realistic, and they could apply it in real day to day activities. One participant felt "it was a good analogy for trying to navigate a house when tripping over toys, carrying a baby" while another liked picking up rubbish. One participant did not answer that question, while another participant liked the fact that she stayed calm while tidying up. One participant liked that the 
tasks were manageable, while another that it was easy to learn how to use the system. One participant liked that she was learning to take things slow.

In the question what they liked the least, two participants did not answer, while one reported "none". One participant answered that "the virtual environment was not completely immersive and did not feel totally involved in the system". Two participants did not like that they could not pick items up, while another participant did not like she could not soothe the baby by changing its nappy. One participant did not like the system freezing, while another felt it was "hard to control at times". Three participants did not like the dysfunctionality of the joystick.

However, five participants did not feel there was something missing, while three others did not comment. One participant felt that "the headset version would make the system more immersive", while another felt that it was "as real and good as it could be". One participant felt that what "was missing was the ability to multi-task".

Most participants felt that the system was a good stress management tool. Three participants felt they had become better at prioritising tasks in their daily routines having used the virtual programme, while another one had become more mindful while completing tasks. One participant had become better at recognizing when she was getting stressed and so it was easier to cope with stressful situations by taking some deep breaths and calm down before she got too overwhelmed. Another participant was better at cleaning / organizing, while another did not answer. One participant was better able to do the housework easier without feeling panicked, while another one was also prioritising better and was able to acknowledge minor achievements. One participant could slow down and not rush and, in that way, she could contain her stress, while another was able to take things easier. 


\section{Session evaluation questionnaire}

Participants graded the relevance and usefulness of each session high (see Table 4-11). They found all sessions useful with many components relevant to their life circumstances. They liked most components of the sessions, with a few exceptions.

Table 4-11. Mean values and standard deviations for Session Evaluation Questionnaire

\begin{tabular}{|c|c|c|}
\hline Questions & Useful & Relevant \\
\hline \multirow[t]{2}{*}{ Session 1} & 8.73 & 8.60 \\
\hline & $(0.96)$ & (1.18) \\
\hline \multirow[t]{2}{*}{ Session 2} & 9.00 & 9.27 \\
\hline & $(0.89)$ & $(0.90)$ \\
\hline \multirow[t]{2}{*}{ Session 3} & 8.64 & 8.91 \\
\hline & $(1.21)$ & (1.04) \\
\hline \multirow[t]{2}{*}{ Session 4} & 8.00 & 8.27 \\
\hline & (1.67) & $(1.79)$ \\
\hline \multirow[t]{2}{*}{ Session 5} & 9.18 & 9.18 \\
\hline & $(0.75)$ & $(0.98)$ \\
\hline \multirow[t]{2}{*}{ Session 6} & 9.10 & 9.20 \\
\hline & $(0.88)$ & (1.03) \\
\hline
\end{tabular}

Session 1: most participants found the assessment useful and relevant to their life circumstances as it shed light in different aspects of their functioning such as physical health, medication, sleep, appetite, presenting problem, history of anxiety and/or depression, amongst others. 
Session 2: there was a consensus among participants that the sleep hygiene was useful, by learning how to create good healthy sleep patterns. They also liked learning about mindfulness, such as grounding themselves into the present moment, and found acknowledging their ruminative thoughts as such thoughts, without placing judgments on them, very useful.

Session 3: participants liked gaining better awareness about their mental health. They found useful identifying dysfunctional cognitive schemas and finding new and more constructive ways of thinking. Participants also liked exploring different ways of coping better by managing stress differently.

Session 4: participants liked the VR session because they gained better awareness and became more mindful by learning to ground selves to the present moment. They also found useful being able to prioritise better and learned new ways of managing stress.

Session 5: there was a general positive agreement amongst participants about working on high or unrealistic expectations, but also on priorities and psychological flexibility. They liked working on finding more positive ways of thinking and explored further stress management techniques such as creating daily plans and improving their routines.

Session 6: participants liked talking about their overall progress since the beginning of the trial. They reflected upon their progress they had made and the specific changes they had implemented. Participants liked talking about how they benefited from therapy overall. In addition, they also liked identifying ways of how to keep making positive steps after the trial had ended.

Participants also identified some aspects of individual sessions they did not like. Some participants felt the initial assessment included too many questionnaires that they were repetitive, asking similar questions. Also, two participants did not like the motion sickness they experienced during their VR experience, and feedback that the programme could have been shorter. Nevertheless, there was nothing identified they did not like about the remaining sessions. 


\section{Follow ups}

Out of the 11 participants who completed the trial, 10 of them responded during the follow up contact made by the facilitator. In general, the majority $(n=7)$ reported being able to maintain all the positive changes they had achieved during the trial in the three months follow up. Their symptoms and levels of anxiety and depression had subsided to a good and functioning level. Their mood, sleep and appetite had either improved or were stable, while it was noted that they had become more mindful and their ruminative thoughts were less. As a result, their anxiety levels had been reduced, and had started socialising more than previously, which underlined improved self-care. They were able to reprioritise, to gain cognitive clarity and had better decision making. Another important change was about transitioning back to employment and coping with the change well.

One participant reported that her mood and appetite were stable, and her sleep had improved. Her anxiety was manageable and could cope better with stress. She felt more motivated and had created a good routine around her studying.

Another participant reported that her mood was stable, and that she could cope better. Her sleep had improved and was relatively stable. Her appetite was steady and was feeling less anxious. Although her personal circumstances had changed since her participation in the trial where she separated from her partner, she felt that she could cope and that she was moving on through the grieving and transitional process.

A third participant reported that although she had been making good progress while in therapy, her mood became unstable in the first two months after trial ended due to series of events such as a knee injury she sustained and her baby getting sick due to a virus. As a result, she was not able to exercise which she valued so much. However, she reported that things improved when her baby recovered. As a result, she started being more physically active, was going for 
walks, and had started physiotherapy for her knee. She also reported that her interpersonal relationships had also improved and had become more responsive than reactive. She had started reprioritising and was spending quality time with her husband. She felt more positive overall and started having more realistic expectations. She had become more mindful which was helping with her anxiety and stress levels and was also practicing better self-care.

Another participant had also become more mindful. There was a substantial reduction in her ruminative thinking and was feeling more resilient. She was enjoying her work, had gained cognitive clarity with better decision making. Her sleep had dramatically improved and had not experienced any more nightmares. Her appetite was steady. She had become more physically active and more social. She was able to plan and able to prioritise easier. She and her partner had finalised their decision to sell their house which was very positive, and it was not a daunting process any longer.

Four of the participants managed to transition back to employment successfully. They were getting back to routine which was positive as it created a sense of stability. Their sleep and appetite had also improved and were stable. They had become more mindful and ruminating less because of that. One of them had started spending quality time with her baby and was moving forward in her life. All four participants had become less anxious and their mood had improved. One of them described that her relationship had also improved and was feeling better within self. Another reported that she had become less pre-occupied with issues of health of herself and her baby's. She had also started reconnecting with the people around her. Another participant was able to let go some of her unresolved issues from the past and move on. This underlined a feeling of happiness and contentment.

Nevertheless, there were also three participants who reported that they had started feeling better during the trial, but their mood had declined after the trial ended, with an increase in anxiety. Those participants were not able to maintain the benefits they had gained during therapy. However, the same participants had been proactive as they were able to ask for help from their GPs and had started anti-depressant medication. 


\section{VR session evaluation - identifying themes}

Overall, there was positive feedback on the VR system and the participants' experience with that. All participants found something positive and beneficial in that which could be applied in everyday life. Table 4-12 shows the stressors for each participant and the sequence they were activated. 
Table 4-12. Stressors and their sequence

\begin{tabular}{lccccccccccc}
\hline Participant 1 & M & N & U & Sm & No & Ph & & & \\
& & & & & & & & & \\
\hline Participant 2 & B & C & Me & F & B & S & B & M & \\
& & & & & & & & & \\
\hline Participant 3 & D & Ph & B & Sh & Tr & & & & & \\
& & & & & & & & & & & \\
\hline Participant 4 & B & E & Ph & D & C & F & K & T & A & M \\
& B & & & & & C & F & & & & \\
\hline Participant 5 & B & Cat & D & Ph & B & Ph & F & B & & \\
& B & & & & & & & & & \\
\hline Participant 6 & B & D & C & K & F & P & & & & \\
\hline Participant 7 & D & B & B & D & Ph & Ph & E & B & P & \\
\hline
\end{tabular}

\begin{tabular}{llllllllll}
\hline Participant 8 & B & Ph & Me & B & Me & F & P & B \\
& B & & & & & & & \\
& B & & & & & & \\
\hline Participant 9 & B & D & B & Do & E & F & & \\
& B & & & & & & &
\end{tabular}

\begin{tabular}{llllllll}
\hline Participant 10 & B & Ca & B & T & E & F
\end{tabular}

\begin{tabular}{lllllll}
\hline Participant 11 & B & K & C & F & A \\
& B & & & & \\
B & & & & &
\end{tabular}

\footnotetext{
${ }^{2}$ See footnote for abbreviations
}

There was a consensus amongst participants that the use of the VR programme was found helpful in different ways. For example, some participants felt that the VR programme helped them make better decision making, and to prioritise better. It helped them become more

\footnotetext{
${ }^{2} \mathrm{~A}=$ Argument, $\mathrm{B}=$ Crying baby, $\mathrm{Ca}=\mathrm{Cat}, \mathrm{C}=$ Highchair - toddler, $\mathrm{D}=$ Doorbell, Do $=$ Dog, $\mathrm{E}=$ Electricity, $\mathrm{F}=$ Fire - toddler, $\mathrm{K}=$ Knife - toddler, $\mathrm{M}=$ Multi-task, $\mathrm{Ph}=$ Telephone, $\mathrm{Me}=$ Medication, $\mathrm{N}=$ Noise, No $=$ Not to be interrupted, $\mathrm{P}=\mathrm{Party}, \mathrm{S}=\mathrm{Sirens}, \mathrm{Sh}=$ Shoes, $\mathrm{Sm}=$ Small space, $\mathrm{T}=\mathrm{Traffic}, \mathrm{Tr}=$ Trash, $\mathrm{U}=$ Untidy place
} 
social, felt more motivated, gained confidence, and improved their self-esteem. They were learning to manage stress better when organising or completing tasks, and as a result, they had started becoming less reactive and more responsive. Participants experienced more selfappreciation, applied better self-care, and had more realistic self-expectations. In general, they felt less anxious, and had become more mindful where they were able to slow things down being able to ground themselves to the present moment more.

There was an agreement amongst the participants that they were finding a better balance in their lives, were finding it easier to ask for help, were more psychologically flexible, and that they were coming to terms with some limitations regarding their life circumstances, and with a better sense of acceptance.

Overall, there were 4 themes identified where participants benefited from using the VR programme. The themes were being able to prioritize more easily with better decision making, gaining awareness, being mindful and gaining self-appreciation, and VR having real-life applications.

\section{Prioritising - decision making}

There was a consensus amongst participants $(n=6)$ that VR enhanced their decision-making skills and prioritisation abilities. Below are some comments indicative of how participants were able to prioritise and make decisions:

"It was a bit stressful, but it is easy to prioritise, when the baby cries, he is the priority..."

"I would put the parcel down... and then (of course with the door shut) I would go for the baby, check upon him...because he can get quite loud. So, first is safety and then checking upon the baby...yeah, because I don't think it is a good idea to leave the baby howling for ages...so you are prioritizing, making decisions..." 
"I can leave the mess and pick up the baby first, but when the baby is settled then I go back to picking up the mess....It is very important...yes...I think that it is...prioritizing is the main thing....I can associate with what happened.... with emergency...I mean it is not real, but I can imagine...safety comes first...it is about priority, safety, organizing in a balance..."

"I guess when the baby was crying, and lots of things were happening, I was happy to ignore everything....and focus on the baby...so being able to prioritise....because there is a party happening, the noise, the electricity, but I was able to prioritise, holding the baby, that was important..."

"There was a moment when the phone was ringing and the baby was crying at the same time...it was ok...being able to prioritise again...keeping calm right...yeah...I guess it helps me focus on priorities, you know ...I don't know if I am always that conscious when I am doing it...you are so busy....in real life I prioritise without having to think about it consciously...I just do it...deal with everything... and that makes it more of a priority call...and that makes me acutely aware of it...especially when I navigated in the system...I had to think about all the movements, left, turn around...etc...so from that point...it makes you realise about priorities...how I am prioritising..."

"It was hard all the things at once...was overwhelming...something I am used to sometimes...I usually cope by locking the cat out, putting the phone away, dealing with the baby...again it is about prioritising...baby comes first...cat is locked out, the baby is number one..."

\section{Awareness}

Awareness was another theme identified. For nine participants, the use of the virtual environment helped them gain better self-awareness on issues such as how they usually tackle a task, of having unrealistic self-expectations, of bonding issues with the baby, of creating better daily routines which contributed to a better sense of stability. 
Below are some comments made by the participants:

"I just learned something about myself...so being able to be more aware of priorities and decision making...how I make decisions...I mean a lot of these things are instinctual...I don't have to think about them...but I learned about how I prioritise..."

"That is when I would talk to baby, and make him food, but say could you wait? But often I expect too much from him...I often assume he is more mature than his age, so I get frustrated at him although expecting for him/ he should know better...but then I should know better, that he is only three, expecting him to have self-control and patience....and then I snap at him and react badly, but I don't want to do that. So, I guess it is about becoming a bit more mindful and extra patient, to remind myself, that he is still a young person."

"The VR system helped me realise how mundane I find the household activities, lack of interest in them as it is quite repetitive tidying up, but quite calming I guess... and it gives a bit of structure that mundane and repetitive activity..."

"I guess this is my interpretation of feeling within ourselves...No, not really...but being selfcritical, or someone else being self-critical...how I look, how is the room...maybe it is about expectations...I think my parents expect too much...it makes me sad..."

"I always thought with love you get this warm fuzzy feeling...that you are going to be loyal to them, at the same time I don't have that warm fuzzy feeling...but I don't know what love is...maybe it is part of love...but I guess I am missing that warm fuzzy feeling...maybe it is about my own expectations... of how to have the feeling of "I am good enough" (self-esteem) to create a positive momentum..."

"I just realized I probably do too much all at once, I tidy up the place and then the little one will start getting upset...and then go deal with that and come back and I would get annoyed if I can't tidy up the place..." 


\section{Mindfulness- Self-appreciation}

Another important theme identified using the VR programme was about participants becoming more mindful, by slowing things down while doing tasks. Six participants felt that using the VR system helped them becoming more mindful by slowing things down and applying that in everyday life, or by focusing on the process rather than the outcome or focusing on the task itself when doing it rather than being preoccupied with the number of tasks that had to be completed.

The comments below are indicative:

"I would be able to slow things down...pay attention to the breathing, slow things down...so instead of focusing on accomplishing the task and how many things I need to accomplish, it is more about focusing on the task I was doing, not so much how much I need to do, but focusing more on what I do..."

"I guess what is helpful in relation to the system is to learn to take my time with things, not rush things, I did it in the beginning, usually at home I try to get things down quickly...sometimes it is not that great...that is interesting because ideally would be about slowing things down later, but this was reverse, I started calm, relaxed and as time went on...because I thought I was getting used to it, and then there was a point when I was not getting used to it, and it was frustrating...but when I take my time it is much better..."

"But I need to acknowledge when I do things, everyday things...sometimes I do things on automatic pilot, but I need to acknowledge and praise myself..."

"I think I was looking at everything that needed to be done... and I was like rushed to complete all tasks...to finish everything...and then when I could not get to everything...I felt frustrated... and then I had to take a step back and slow things down...to stop for a moment, stepping back, acknowledging everything that is happening and then hopefully coming up with a bit of a solution of how to proceed..." 
"I am good about what needs to be done...but I am not always good looking at what I have achieved... what I have managed to do the whole day...but I think sometimes... it is too easy to overlook... why I have not done that...instead of taking a five minute break to have a cup of tea for example...that sometimes it is about saying that stuff that needs to be done but also all that stuff I have done...this is part of self-care... and having a baby is very important...and being able to look after the baby is very important..."

"I think I need to slow down a bit, and when I finish something, acknowledge it at the moment, and not to stress about if I can't finish everything...so focusing on the present moment, focusing at the breathing, praising myself about what I have achieved..."

\section{Real life applications - useful}

Lastly, participants feedback that parts of their VR experience could be useful and applicable in everyday life situations, such as organising their routines better. Five participants talked about having more of a structured and organised way of accomplishing tasks at home which, in turn, would help them cope with their anxiety better and gaining a better sense of control, or being able to rationalise easier, or being able to break down a task to smaller tasks in order to deal with a stressful situation better in the future.

Below are some indicative comments participants made:

"It is like how I deal with things at home...I declutter and then I go and start doing other tasks, focus on the task, yes very accurate, very organised, structured and routine... and probably my work, being a manager in that busy place, helps me be structured".

"It was a nice apartment...modern and streamlined...easy to clean...Although lots of rubbish...Well I would not let the house get so dirty...well, my boyfriend and I both are natural untidy people but once I got pregnant, we made a real effort not to make or leave it messy...I do get quite stressed out when it gets quite messy...tidiness creates structure, a sense of control in a way". 
"It was all that together...and the baby crying...it was just...you know, and the child being there...it was quite overwhelming...it is like today, for example when I lost my ATM card...and then I have to think about the money, and how to get the gas...all those things... sometimes things happen all at once".

"I guess the thing about tidying, you have to do it all the time, it is constant....but I guess with the VR, if I kept going, I would have tidy up everything...I guess that would help...again methodically being able to tidy things up was quite good because usually if I feel overwhelmed, my brain goes haywire...then putting my brain in order".

"Sometimes it is not so much about how many tasks I complete, but being there in the moment, doing the task and focus on the task...I can try to do that, because I need to learn to slow things down, write a small list and take my time...don't stress, not everything has to be perfect at home when you have a baby, everything is different, the baby is number one...cleaning is important but baby is more important".

\section{Difficulties encountered when using the VR system}

Regarding some of the technical issues we encountered during the use of VR system were: the difficulty for the participants to pick up different items, such as the banana located on the floor, the toddler, the baby, some pair of shoes located next to the door, some books close to the bookshelves, and the shovel which was located outdoors. On one occasion, the blue circle would not appear on the screen of the participants, while in another, an item that the participant had just picked up and placed appropriately still showed on the screen as it had not been placed in the location destination.

Another difficulty was around the inability to multi-task. Although the programme has been designed for the participants to only single task, most participants felt this was a limitation. One reason was that it did not resemble real life where they usually are able to multi-task to complete tasks in a timely manner. Some participants would have preferred to have the option 
to sit down on the couch with the baby, which would promote a feeling of well-being and relaxation for them.

A major technical difficulty was the system freeze. All participants experienced a system freeze at least once. This would happen randomly as no specific sequence was observed. There were two main effects from this technical issue. One issue was that the picture would freeze, while another issue was that the speech of the participants would be repeated for a short period of time. That would in effect have a communication break between the facilitator and the participants, and in some cases, the VR trial having to be restarted.

Another technical complication was about the navigation within the virtual environment which participants found frustrating and awkward. Seven participants had trouble in navigating themselves. This issue was most noticeable when entering a room or going around furniture such as the kitchen bench. Some participants feedback that they felt that it was due to a joystick malfunction, or to their lack of experience with the virtual environment.

Motion sickness was experienced by two participants, with one of them having taken the pill for motion sickness. One difficulty was that the blue circle which indicated a specific spot that an item needed to be placed within the virtual environment, when it would appear on the screen, participants were not being able to place the item appropriately. The second participant identified that she had not eaten enough to feel well during the trial. There was a time gap between her last meal and the VR trial.

There was also feedback on the design of the environment and its functionality. One issue that was raised by some participants was not being able to open the parcel found at the door. Some participants were also concerned about not being able to close the door behind them, something which raised the issue of safety. It was also noticed that there was no fuse box in the virtual house and thus made it less real and limiting in terms of their inability to act and fully resolve the situation after the stressor, in this case the electricity, had been activated. Another matter was regarding the mess depicted in the virtual environment, with the consensus amongst 
participants that it seemed unrealistic simply because it was too much. It did not reflect the situation of a typical day-to-day house.

\section{DISCUSSION}

This trial is a continuation of the pilot study we conducted previously [15]. It is based on the findings of the pilot study where we established the assessment and clinical protocols. The main contribution of this paper to the literature is to explore whether the combination of CBT with VR can be an efficacious treatment for PND. Another contribution of this paper is about identifying the levels of acceptability and feasibility of combining technology with traditional therapies. A final contribution is to provide recommendations about future work that can be made such as improvements on the protocol and the technology itself. Ultimately, our aim is to explore whether we can enrich traditional CBT treatments for PND with the use of technology, more specifically VR.

There were three main objectives that we investigated in this study. Firstly, we wanted to examine whether the combination of CBT with a VR component designed for PND was efficacious. Overall, we found that the clinical protocol was effective for PND as the participants of this study benefited on many levels. Data showed that the improvement in Kessler-10, GAD7, and EPDS questionnaires was significant in all three of them, with the effect size to be mainly large, with only one exception of being medium which was between baseline and post-treatment for the Kessler-10 questionnaire.

More specifically, for Kessler-10 questionnaire, the difference in the mean values between the baseline period and post-treatment period was reducing from moderate distress to mild distress, while for the follow ups, the participants maintained and even improved by further reducing the scores which meant they were relatively well [38]. For GAD-7 questionnaire, the reduction in the mean values from baseline to post-treatment was also reduced from moderate down to mild anxiety, with no noticeable anxiety in the follow up period [39]. Finally, for EPDS questionnaire, 
there was a steady decline between baseline, post-treatment, and follow up. The reduction in the mean values between baseline and post-treatment was significant, while the reduction trend between post-treatment and follow up continued and was maintained in the "low risk depression" area [40].

In terms of the question whether VR has any effect on the therapeutic outcome and what kind, if any, the study found that VR has a significant effect on the overall therapeutic outcome on a quantitative but also qualitative level. VR was found to be useful in four different aspects of clinical interest, that of awareness, decision making, mindfulness, and real-life applications. It is worth noting here that these four areas are inter-connected.

An aspect of VR's usefulness is that it can help the individual raise awareness. In this trial, some participants reported they became aware of aspects of their personal and professional lives that they were out of balance which in turn helped them think about different and more fruitful ways of what they needed to change. Other participants became aware of how they would usually cope with their anxiety and depression and what they needed to improve. It underlined better determination for action taken.

VR can help the individual make better decisions and prioritise more effectively. As the individual becomes more aware of their emotional states or of certain behaviours, they can create the space to develop different ways of making decisions.

The individual can also become more mindful using VR technology by becoming less reactive and more responsive to stressful events. This is very helpful as the individual creates more emotional space to deal with stressful situations better in the future. In that way, the individual can accept and let go of negative thoughts and feelings, and in that way, they can move forward more easily.

Data also shows that VR has real-life applications. Considering the participants' feedback, VR can help the individual prioritise most efficiently, make better decisions, complete tasks without 
feeling anxious or panicky, acknowledge minor achievements which creates a sense of appreciation, and manage stress better.

The second objective of this study was about the feasibility of using VR and CBT for the treatment of PND. We found that the levels of such a combination in a clinical setting were satisfactorily. The results show that VR can be implemented within a traditional therapy for depression in the post-partum period. There was an overall positive feedback on elements such as the referral process, confidentiality, number of sessions and sufficient time. There was also positive feedback on the questionnaires and that they reflected the mental health needs of the participants satisfactorily. The location and setting were both suitable. Most participants would not change anything in the whole process which was very encouraging. Participants felt they had enough information about the trial itself, and that the VR trial that took place in the fourth session was suitable, while they had enough time to prepare for it.

The third objective of the study was about the acceptability of using VR technology in a clinical setting. Data shows that the levels of acceptance were high, as the participants graded high various elements such as levels of likeness and comfortableness while using the system. Participants spent adequate time with the system and found it easy to use. They also found it relevant and realistic with real life applications. Overall, they found the system to have different possibilities well integrated.

Nevertheless, there was mixed feedback regarding whether participants felt the system was useful and whether they would use it frequently if they could. The consensus was that the VR system was valuable, and it could speed up their recovery, but there was scepticism whether they would use it often. This might be explained by some technical difficulties participants encountered while using the system. 


\section{Recommendations}

Based on the results, a series of recommendations and/or changes can be made. Firstly, based on the evidence of this trial and to shed light in the relationship between VR and CBT for the treatment of PND, a randomized controlled trial can be conducted. This can be the next step in the research process as it can help clarify what are the therapeutic properties of the use of VR, and how it affects traditional therapies such as CBT for PND.

Secondly, some aspects of the clinical protocol would need to change to make it more efficacious in a clinical sense. One change could be about allowing the participants to use the VR system in more than one session. Research shows that repeated use of VR can have continuous positive effect on health issues such as controlling pain [41]. This would provide them with more time to get used to the system, its functionality, and to understand more about its purpose. As a result, the VR system could be used in a different session than the fourth one, or the VR session could happen in two sessions instead of a single session, consecutively or not.

Thirdly, the VR system could be also upgraded. Considering some of the technical issues the VR system in this study presented such as the freeze or the communication breaks which occurred between the facilitator and the participants, the system could be improved for future use. An upgrade of the VR system could be the use from the desktop version to a headset version. This could possibly deepen the sense of presence for the participants and contribute to a better acquisition of new skills [42]. One way to do that could be by using image data analysis and reverse engineering. The convergence of image data analytics and reverse engineering means we can have more realistic digital representations of real-world artifacts that VR assists in presenting to the user that may enhance presence or the overall experience. The software could be upgraded for better navigation within the virtual environment by the user, the minimisation of system freezes for future use, but also enhancing an immersive virtual experience. 
Another recommendation would be about using a VR system that could provide more scenarios to the participants. This specific system provided one scenario, that of tidying up the virtual space, while being exposed to virtual stressors. The hypothesis made here was that by activating some stressors, participants would experience anxiety, thus they would have the opportunity to learn some new coping skills for anxiety. The focus was more on anxiety rather than depression.

Two more recommendations are regarding the stressors used in the virtual programme. One change could be about adding more stressors to the existing ones to enrich the virtual environment for the participants. However, another change could be about adding more positive visual or auditory stimuli that could be a replacement to the existing stressors or individually act as a reward once they were activated.

There was a consensus amongst participants that they would have preferred to have more options when using the VR programme as it would be more realistic. Some options could be about the participants being able to look after the baby in more ways than just meeting its basic needs, or being able to pick up the toddlers, or to be able to sit down on the couch and relax with the baby, or to make the task of looking after the baby more challenging.

Lastly, a change on the focus of the VR session could be considered about focusing on one single skill that each participant needed to learn better and teach them by using the VR system, rather than having a broader clinical focus. It might be that the VR system and how it was used underlined an expectation of mastering too many skills, while the opposite could have been more helpful. Maybe, it would be about simplifying the process and the virtual experience for the participants.

\section{Limitations}

There were several limitations that we encountered in this study. An important limitation about this trial is that it is a single case studies trial and not a randomized controlled trial. Single case 
studies have certain advantages and can be suitable for small-scale projects such as this current trial. However, they cannot establish causality and external validity of the results of the trial, something that a randomized controlled trial would be able to provide. In addition, this also highlight the limited number of participants who participated in this trial.

One limitation was regarding the attrition rate in the beginning of the trial. Four participants dropped out of the trial following the initial assessment. Two of them reported that they did not want to keep participating in the trial as they had changed their minds, while there was no information for the other two as the facilitator had lost contact with them. Nevertheless, the 4 dropouts were from two different baselines, baseline 1 and 3. As a result, this did not threaten the validity of the study.

Another limitation in the study was the number of therapy sessions cancellations. There were 12 cancellations and two non-attendances without notice throughout the trial. The total number of sessions offered to the 15 participants were 84 , while the total number of sessions that occurred were 70 . Most cancellations were due to the physical illness of the participants or of their family members, while one participant cancelled due to important travelling reasons.

However, although there are certain limitations, this work has the merit of being the first study that uses VR as an adjunct to improve the treatment of PND. Future work will have to improve this line of research, for the moment we have shown that the use of VR for the treatment of PND is feasible and seems to have clinical utility.

\section{Data Availability}

All data analysed during this study are included in the manuscript.

\section{Conflicts of Interest}

The authors declare that there is no conflict of interest regarding the publication of this article. 


\section{Acknowledgments}

We would like to thank Mohammed Alghamdi, Joy Pringle - Plunket Service, Dianne Begg, and the Brief Intervention Service at WellSouth. 


\section{References}

1. NHS (2018). Overview: post-natal depression. Found on: https://www.nhs.uk/conditions/postnatal-depression

2. Plunket (2020). Postnatal depression. https://www.plunket.org.nz/being-a-parent/lookingafter-you/parent-mental-health/postnatal-depression/\#about-postnatal-depression

3. Mental Health Foundation of New Zealand (1999). Postnatal Depression - Healthpoint. https://www.healthpoint.co.nz/download,136218.do

4. Piacentini, D., Mirabella, F., Leveni, D., Primerano, G., Cattaneo, M., Biffi, G., Rozzoni, C., Arcaini, F., \& Gigantesco, A. (2011). Effectiveness of a manualized cognitive-behavioural intervention for postnatal depression. Rivista di psichiatria, 46, 3.

5. Kripke, K. (2013). 8 types of psychotherapy for Postpartum Depression treatment. Found on https://postpartumprogress.com/8-types-of-psychotherapy-for-postpartum-depression-treatment

6. Coelho, C. M., Waters, A. M., Hine, T. J., \& Wallis, G.(2009). The use of virtual reality in acrophobia research and treatment. Journal of Anxiety Disorders. 23 (5), 563-574. https://doi.org/10.1016/j.janxdis.2009.01.014

7. Monash University, (2015, October 26). Using Virtual Technology to reverse engineer the gambler's addiction. https://medicalxpress.com/news/2015-10-virtual-technology-reversegambler-addiction.html

8. Górski, F.; Kuczko, W.; Wichniarek, R., \& Zawadzki, P. (2010). Application of close-range photogrammetry in reverse engineering. 7th International DAAAM Baltic Conference Industrial Engineering 22-24 April 2010, Tallinn, Estonia. http://innomet.ttu.ee/daaam10/proceedings/PDF/gorski.pdf

9. Miłkowski, M. (2013). Reverse Engineering in Cognitive Science. In M. Miłkowski \& K. Talmont-Kamiński (Eds.), Regarding the Mind, Naturally: Naturalist Approaches to the Sciences 
of the Mental (pp. 12-29). Newcastle upon Tyne: Cambridge Scholars Publishing., 2013

10. Miti rtmfm (2020, June 5). Image Processing Using Virtual Reality. YouTube. Mohamed El Meheiry - Decision \& Bayesian Computation, Department of Neuroscience, Institut Pasteur, Light-based observation and Control of Cellular Organization, Physico-Chimie Curie, Institut Curie https://www.youtube.com/watch?v=If_hYq4Wzb4

11. Mendoza, F., \& Lu, R. (2015). Basics of Image Analysis. In book: Hyperspectral Imaging Technology in Food and Agriculture. https://doi.org/10.1007/978-1-4939-2836-1_2

12. College of Engineering, Carnegie Mellon University, (2018, January 31). Bob lannucci: Virtual image processing environment for research. YouTube. https://www.youtube.com/watch?v=G5zPIPw8EUE

13. Fucile, P., Papallo, I., Improta, G., De Santis, R., Gloria, A., Onofrio, I., D’ Anto, V., Maietta, S., \& Russo., T. (2019). Reverse Engineering and Additive Manufacturing towards the design of 3D advanced scaffolds for hard tissue regeneration. 2019 /I Workshop on Metrology for Industry 4.0 and loT (Metrolnd4.0\&loT), pp. 33-37, https://doi.org/10.1109/METROI4.2019.8792891

14. De Santis, R., Gloria, A., Viglione, S., Maietta, S., Nappi, F., Ambrosio, L., \& Ronca, D. (2018). 3D laser scanning in conjunction with surface texturing to evaluate shift and reduction of the tibiofemoral contact area after meniscectomy. Journal of the Mechanical Behavior of Biomedical Materials. 88, 41-47. https://doi.org/10.1016/j.jmbbm.2018.08.007

15. Stamou, G., Garcia-Palacios, A., \& Botella, C. (2019). The combination of cognitivebehavioural therapy with virtual reality for the treatment of post-natal depression: A pilot study. https://doi.org/10.1145/3369457.3369541

16. Cox, J. L., Holden, J. M., \& Sagovsky, R. (1987). The Edinburgh postnatal depression scale (EPDS). Found on https://www.blackdoginstitute.org.au/docs/default-source/psychologicaltoolkit/edinburgh-postnatal-depression-scale.pdf?sfvrsn=8 
17. Harris, B., Huckle, P., Thomas, R., Johns, S., \& Fung, H. (1989). The use of rating scales to identify post-natal depression. The British Journal of Psychiatry, 154 (6) 813-817; https://doi.org/10.1192/bjp.154.6.813

18. Bunevicius, A., Kusminskas, L., \& Bunevicius, R. (2009). P02-206 Validity of the Edinburgh postnatal depression scale. European Psychiatry, Vol $24 \quad$ (1), 896. https://doi.org/10.1016/S0924-9338(09)71129-0

19. HFS (2020). Edinburgh Postnatal Depression Scale. HFS. Medical Providers. Maternal and Child Health. Illinois Department of Healthcare and Family Services. https://www.illinois.gov/hfs/MedicalProviders/MaternalandChildHealth/Pages/Edinburgh.aspx

20. Matthey, S., Barnett, B., Kavanagh, D. J., \& Howie, P. (2001). Validation of the Edinburgh Postnatal Depression Scale for men, and comparison of item endorsement with their partners. Journal of Affective Disorders. 64(2-3), 175-184. https://doi.org/10.1016/S0165-0327(00)002366

21. Toreki, A., Andó, B., Dudas, R. B., Dweik, D., Janka, Z., Kozinszky, Z., \& Keresztúri, A. (2014). Validation of the Edinburgh Postnatal Depression Scale as a screening tool for postpartum depression in a clinical sample in Hungary. Midwifery, Aug; 30(8): 911-8. https://doi.org/ 10.1016/j.midw.2014.02.008.

22. Spitzer, R. L., Kroenke, K., Williams, J. B., \& Lowe, B. (2006). A brief measure for assessing generalized anxiety disorder: the GAD-7. Arch Intern Med, 166(10):1092-7.

23. Johnson, S. U., Ulvenes, P. G., Øktedalen, T., \& Hoffart, A. (2019). Psychometric Properties of the General Anxiety Disorder 7-Item (GAD-7) Scale in a Heterogeneous Psychiatric Sample. Frontiers in Psychology. Vol (10), 1713, https://doi.org/10.3389/fpsyg.2019.01713

24. Kessler, R. C., Andrews, G., Colpe, L. J., Hiripi, E., Mroczek, D. K., Normand, S. -L. T., Walters, E. E., \& Zaslavsky, A. M. (2002). Short screening scales to monitor population 
prevalences and trends in non-specific psychological distress. Psychological Medicine, 32, 959976. https://doi.org/10.1017/S0033291702006074

25. Hides, L., Lubman, D. I., Devlin, H., Cotton, S., Aitken, C., Gibbie, T., \& Hellard, M. (2007). Reliability and Validity of the Kessler 10 and Patient Health Questionnaire among Injecting Drug Users. Australian \& New Zealand Journal of Psychiatry. Vol (41) 2166 - 168; https://doi.org/10.1080/00048670601109949

26. Banos, R. M., Cebolla, A., Botella, C., Garcia-Palacios, A., Oliver, E., Zaragosa, I., \& Alcaniz, M. (2011). Improving Childhood Obesity Treatment Using New Technologies: The ETIOBE System. Clinical Practice \& Epidemiology in Mental Health. US National Library of Medicine: National Institutes of Health.

27. Alghamdi, M. (2017). Enabling parental stress resilience training with virtual reality. A thesis submitted for the degree of Doctor of Philosophy. University of Otago, Dunedin, New Zealand.

28. Alghamdi, M., Regenbrecht, H., Hoermann, S., and Swain, N. (2017). Mild Stress Stimuli built into a Non-Immersive Virtual Environment can elicit actual Stress Responses. Behaviour \& $\begin{array}{lllll}\text { Information Technology. } & \text { Vol } & 36, & \text { No. } & 9,\end{array}$ https://doi.org/10.1080/0144929X.2017.1311374

29. Alghamdi, M., Regenbrecht, H., and Swain, N. (in preparation). Perceived Benefits and Costs of Using VR for Parental Stress Resilience Training. To be submitted to Cyberpsychology, Behavior, and Social Networking.

30. Kratochwill, T. R., \& Levin, J. R. (2014). Meta- and statistical analysis of single-case intervention research data: Quantitative gifts and a wish list. Journal of School Psychology, 52(2), 231-235. https://doi.org/10.1016/j.jsp.2014.01.003 
31. Ryan, K., \& Filene, J. (2012). Single case design brief. Selecting appropriate single case designs for evaluating MIECHV funded home visiting programs. https//www.jbassoc.com/wpcontent/uploads/2018/03/Selecting-Single-Case-Designs.pdf

32. Lobo, M. A., Moeyaert, M., Baraldi Cunha, A., \& Babik, I. (2017). Single-Case Design, Analysis, and Quality Assessment for Intervention Research. Journal of neurologic physical therapy: JNPT, 41(3), 187-197. https://doi.org/10.1097/NPT.0000000000000187

33. Kratochwill, T. R., Hitchcock, J. H., Horner, R. H., Levin, J. R., Odom, S. L., Rindskopf, D. M., \& Shadish, W. R. (2012). Single-Case Intervention Research Design Standards. Remedial and Special Education, 34(1), 26-38. https://doi.org/10.1177/0741932512452794

34. Blampied, N. M. (2001). The Third Way: Single-Case Research, Training, and Practice in $\begin{array}{llll}\text { Clinical } & \text { Psychology. } \quad \text { Australian } & \text { Psychologist, } & \text { 36(2), }\end{array}$ https://doi.org/10.1080/00050060108259648

35. Hurtado-Parrado, C., \& López-López, W. (2015). Single-Case Research Methods: History and Suitability for a Psychological Science in Need of Alternatives. Integrative Psychological and Behavioral Science, (62), 323-349. https://doi.org/10.1007/s12124-014-9290-2

36. Hofmann, S. G., Asnaani, A., Vonk, I. J., Sawyer, A. T., \& Fang, A. (2012). The Efficacy of Cognitive Behavioral Therapy: A Review of Meta-analyses. Cognitive therapy and research, 36(5), 427-440.

37. Krasny-Pacini, A., \& Evans, J. (2018). Single-case experimental designs to assess intervention effectiveness in rehabilitation: A practical guide. Annals of Physical and Rehabilitation Medicine, 61, 164-179.

38. Kessler, R. C., Barker, P. R., Colpe, L. J., Epstein, J. F., Gfroerer, J. C., Hiripi, E., Howes, M. J., Normand, S. -L. T., Manderscheid, R. W., Walters, E. E., \& Zaslavsky, A. M. (2003). 
Screening for serious mental illness in the general population. Arch Gen Psychiatry, 60(2):184-

9.

39. Seo, J-G., Cho, Y. W., Lee, S-J., Lee, J-J., Kim, J-E., Moon, H-J., \& Park, S-P. (2014). Validation of the generalized anxiety disorder-7 in people with epilepsy: a MEPSY study. Epilepsy \& Behavior, 35, 59-63.

40. Knights, J. E., Salvatore, M. L., Simpkins, G., Hunter, K., \& Khandelwal, M. (2016). In search of best practice for postpartum depression screening: is once enough? European Journal of Obstetrics \& Gynecology and Reproductive Biology. 206, 99-104.

41. Faber, A. W., Patterson, D. R., \& Bremer, M. (2013). Repeated Use of Immersive Virtual Reality Therapy to Control Pain During Wound Dressing Changes in Pediatric and Adult Burn Patients, Journal of Burn Care \& Research, $34 \quad(5), \quad 563$ 568, https://doi.org/10.1097/BCR.0b013e3182777904

42. Grassini, S., Laumann, K., \& Skogstad, M. R. (2020). The Use of Virtual Reality Alone Does Not Promote Training Performance (but Sense of Presence Does). Front. Psychol. 11: 1743. https://doi.org/10.3389/fpsyg.2020.01743 
Appendix A. Feasibility questionnaire

The participants were asked to complete a questionnaire with 11 items in a 5 point Likert scale.

1) Did you feel comfortable throughout the recruitment process?

Yes

No

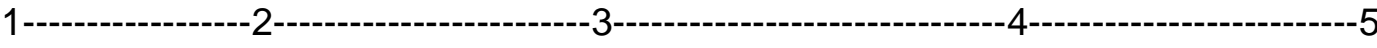

2) Did the facilitator of the study give enough information about the referral process, ethics approval, and confidentiality?

Yes

No

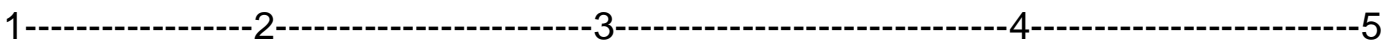

3) Was it a good idea for the VR session to be implemented in the fourth session?

$\begin{array}{lll}\text { Yes } & \text { No }\end{array}$

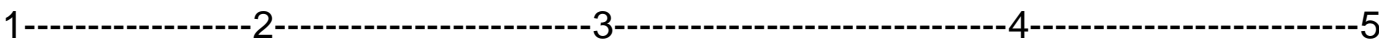

4) Did you feel the total number of sessions were adequate to address your mental health needs?

Yes

No

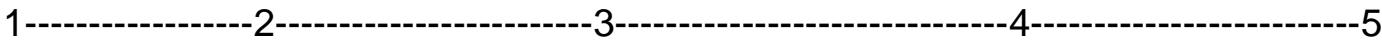

5) Did you have enough information about the VR system and how it works before you started using it?

Yes

No

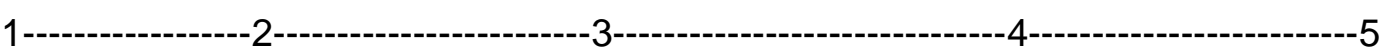

6) Did you have adequate time to prepare for the VR session?

Yes

No

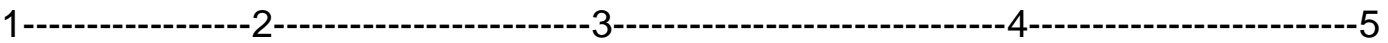

7) Did the questionnaires capture the essence of your mental health issues?

Yes

No

$1-$

$-2-$

$-3$

$-4-$

$-5$

8) Do you feel you had to complete too many questionnaires? 
9) Was the setting and the location of the study suitable?

Yes No

$$
1-
$$
$-2$ $-3$ $-4-$ $-5$

10) If you experienced motion sickness when you used the VR system, did you think the follow up phone call was useful?

Yes

No

$1-$

$-2-$ $-3$ $-4-$ $-5$

11) Would you change anything in the whole process? Yes / No

If yes, what would that be?

Appendix B. Acceptance questionnaire

1. Total time I used the system...

- Less than 10 minutes

- $\quad 10-15$ minutes

- $\quad$ 15-20 minutes

- $\quad$ 20-30 minutes

- More than 30 minutes

2. I believe the system is easy to use.

Fully agree

Do not agree at all

1

2---------------------- 3

4 5

3. I believe l'd like to use this system often.

Fully agree

Do not agree at all

1 2 3 4 $-5$

4. I believe the system is difficult and it could be easier to use. 
5. I believe I'd need the support of an expert to use the system.

Do not agree at all

6. I believe the different possibilities of the system are well integrated.

Fully agree

Do not agree at al 1 2 3 4 5

7. I believe the system is too fragile.

Do not agree at all Fully agree 1 2 3 4 5

8. I believe most people would learn very quickly to use the system.

Fully agree Do not agree 1 2 $-3$ 4 5

9. When going through the system, I found it too long and complicated.

Do not agree at all Fully agree

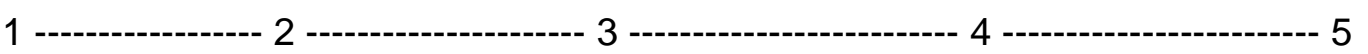

10. I felt very comfortable and confident when using the system.

Fully agree Do not agree at all 1 2 $-3$ 4 5

11. I need to learn a lot of things before knowing well how to use the system.

Do not agree at all

Fully agree 1 2 3 4 5

12. The choice of tasks within the treatment module is...

Easy to handle

Difficult to handle $1-$ $-2$ $-3$ $-4$ $-5$

13. The system can speed up my recovery.

Fully agree Fully disagree 
14. If it was available, l'd use it frequently.

Fully agree

Fully disagree

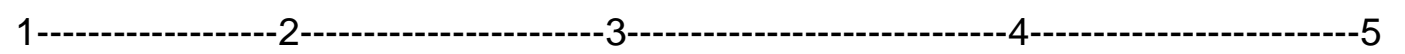

15. In general terms, the application was easy to use.

Fully agree

Fully disagree

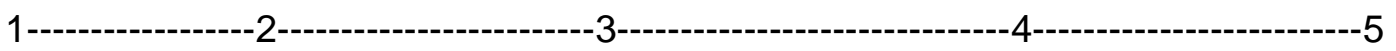

16. In general terms, I believe the application is useful

Fully agree

Fully disagree

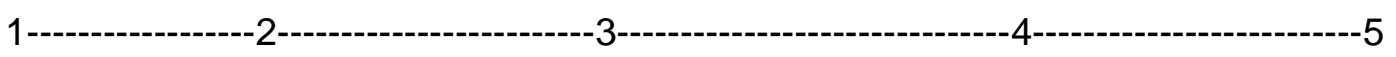

Remarks

○ What I liked the most was......

$\circ$ What I liked the least was......

○ I believe there was something missing. It was.....

○ What things/tasks do I do better in my daily routines after I have used the clinical support system? 


\section{Chapter 5: GENERAL DISCUSSION}

PND is a serious mental health issue that affects the individual on various levels. It is a subcategory of depression which manifests itself in the post-partum period. There is not a single cause for PND but rather risk factors which can contribute to the development or experience of PND. Stewart et al. (2003) categorise risk factors or predictors of PND in to three main categories depending on their possible effect on the individual. The strong predictors are considered to be anxiety during pregnancy, life stressors, and lack of support, while stress around childcare matters, self-esteem issues, and a demanding baby are considered to be moderate predictors. Lastly, small predictors can be pregnancy issues, relationship issues or financial difficulties.

PND can affect people from all socioeconomic backgrounds or education levels. The person can experience an array of symptoms varying from low mood, mood swings, irritability, anger, lack of concentration, feeling of numbness, worry, guilt, poor motivation, low self-esteem and confidence amongst others (Goutam and Kaushal, 2019).

PND can have devastating effects on the individual but also to the people around them such as close family and friends. It can affect the bonding time or quality of relationship between mother and infant with poor stimulation input for the baby which puts it into a disadvantage form (O'Higgins et al., 2013). PND has also financial implications as the person has less chances of transitioning back to work, or it can reduce the chances of finding employment.

According to research, traditional treatments for PND such as CBT, interpersonal psychotherapy, and non-directive counselling are effective (Mulcahy et al., 2010; Wylie et al., 2011). Those treatments have shown to have good therapeutic outcomes. However, each therapeutic approach has a special effect on specific aspects of the person's functioning. For example, CBT is highly effective on cognitive functioning, where it helps the person on various levels such as enhancing cognitive skills, behavioural tasks and having better organisational skills. Psychodynamic therapy is shown to help the person improve interpersonal relationships 
as its therapeutic focus is on the therapeutic relationship between practitioner and patient. Nevertheless, it is worth noting here that all three approaches are effective on reducing depressive symptomatology, especially the psychodynamic psychotherapy approach.

The therapeutic focus can change depending on the therapy itself. Some therapies focus on thought processes, while others on symptomatology such as mood. Other therapies focus on the social life of the individual and try to help them enhance their social circle for more support. In addition, some of the therapies also overlap with each other as they have common grounds. Beck (2002) discusses five different models used for the treatment of PND depending on the theoretical framework therapists use: the medical model, the feminist approach, interpersonal theory, the attachment theory, and the self-labelling theory. Stuart and O'Hara (1995) talk about interpersonal psychotherapy and its focus on the social and relationship functioning of the individual, where the individual is supported to either restructure the relationships themselves or modify their expectations of them.

There are also other approaches less clinical that can be delivered by lay people or be done as home visits, or other modalities for providing treatment, for instance, O'Mahen et al. (2013) report that CBT therapy can also be delivered via the internet effectively, in a timely manner. In fact, technology has also become part of the therapy arena. Cook and Doyle (2002) compared online therapy to face-to-face therapeutic sessions in order to find out whether a working alliance, or else a therapeutic relationship could be established equally between the client and the therapist or not. They found that online sessions can promote a working alliance between the two parties adequately. Shorey et al. (2019) report that technology such as web-based interventions delivering peer support can be used effectively for treating PND.

Kaltenthaler et al. (2004) conducted a meta-analysis to compare traditional CBT and computerised CBT for the treatment of depression, anxiety and phobias. According to them, traditional CBT has been proven highly effective for these disorders, but it can be limited patients' ability to access. The authors found that computerised CBT was equally effective as traditional CBT in five out of sixteen studies. In one of the studies, they found that traditional 
CBT was much more beneficial than the computerised CBT. Two of their studies found that computerised CBT was no more effective than traditional therapies. Another study showed that computerised CBT was more effective than bibliotherapy. Considering their findings, it can be said that the use of technology (in this case computerised CBT using the internet) has been shown to be useful in the treatment of depression and other emotional problems.

Virtual reality $(\mathrm{VR})$, augmented reality $(\mathrm{AR})$, and/or mixed reality are different forms of therapy that have been used to treat various mental health problems. A good example is for VR having been used to treat pain (Hoffman et al., 2000), PTSD (Rothbaum et al., 1999), and phobias such as spider phobia (Garcia-Palacios et al., 2002). However, there has been lack of research on using technology such as VR to treat PND.

For this reason, this thesis explored the possibility of using VR for the treatment of PND. One of its objectives was to investigate whether VR can be used as a therapeutic modality for PND and to identify the parameters that can make that possible. More specifically, it investigated whether VR as a technological modality can be implemented in a clinical setting, and whether the combination of CBT with VR can be an effective therapy for PND.

Below are the seven research questions raised in this thesis and have also been included in Chapter one. These are:

\section{What CBT psychological treatments are effective for PND?}

2. Has VR been used for the treatment of PND previously?

3. Is it feasible implementing VR in combination with CBT for the treatment of PND?

4. What were the levels of acceptance of the combination of VR with CBT for the treatment of PND?

5. Is the combination of CBT with a VR component specifically designed for the treatment of PND effective? 


\section{What were methodological problems, flaws, technical difficulties, and/or limitations on the protocols and research tools?}

\section{What could be recommended for the better implementation of VR within a traditional clinical setting?}

The answers to those questions as key findings are included, along with the reference to strengths and limitations found in the different chapters of this dissertation. Lastly, recommendations for future research along with the conclusion of the thesis are included in the end.

\section{Key findings}

\section{What CBT psychological treatments are effective for PND?}

CBT is an effective therapeutic treatment for depression. It is a large clinical area which encompasses a variety of techniques and therapeutic approaches such as psychoeducation (Zaretsky et al., 2008), cognitive restructuring (Neimeyer et al., 2008), problem solving (Salkovskis et al., 1990), behaviour management (Heyne et al., 2001), goal setting and achieving (Kootker et al., 2015), stress management (Granath et al., 2006), and relaxation (Martinez-Devesa et al., 2010).

The most frequent CBT approach used for the treatment of PND is psychoeducation, while cognitive restructuring is the second most frequent used, which is followed by problem solving. Behaviour management is the fourth most frequent, while setting goals and achieving them are less frequent, along with stress management. Relaxation is also considered a very valuable CBT technique but is used less frequently. It is worth mentioning here that all seven CBT techniques have high clinical efficacy, while it is difficult to differentiate which of the seven, if any is more efficacious than others. The sequence that are used in literature does not necessarily mean efficacy but rather the frequency that they are used as therapeutic approaches. 
Nevertheless, McGinn and Sanderson (2006) describe CBT as time efficient, highly efficacious, structured providing specific clinical protocols, and defining specific and measurable goals.

CBT is a mainstream therapeutic approach which gives emphasis on providing information and advice that mothers have access to. This is the main characteristic of psychoeducation, which is on top of the list with all seven CBT components. It is believed that by giving the right information to new mothers, it can have great therapeutic benefits for the individual. Knowing what to do and how to do it creates a sense of control and independence. The person gains valuable knowledge which is at their disposal to use. Having the knowledge raises the likelihood to motivate the person and to make positive changes (Cain et al., 2011).

Psychoeducation provides information to mothers of what is important, how to self-care, how to cope with difficulties that are common in post-partum period. It helps break the stigma and demystifies aspects of depression. It provides clarification and guidance for the individual and creates cognitive clarity of what is the best action to take. Wessely et al. (2008) describe it as a stress inoculation, where the person is equipped with techniques to cope with anxiety, although the authors here refer to anxiety that is caused by specific upcoming events such as a medical procedure. Nevertheless, stress inoculation is very useful and is seen as part of psychoeducation.

A major aspect of clinical importance for CBT is regarding thoughts and beliefs. CBT pays attention to the identification and challenging of two kinds of cognitions, the negative automatic thoughts, and the dysfunctional beliefs. Automatic negative thoughts are different than beliefs. The first is cognitive schema which form faster and manifest themselves easier. They can appear in the thought processing of the individual in a way that creates the sense they are uncontrollable. Thus, they are called automatic thoughts. They can appear in the consciousness of the individual in a chaotic way, and unexpectedly. They carry critical thinking but many times in a ruminative way. They can exacerbate anxiety or depression for various reasons and are characterised by repetition, automation, and independence. 
Negative automatic thoughts usually derive from beliefs that the person holds within themselves. These beliefs are usually formed in the early years of development and which consist the psychological make up, or else the psyche. The dysfunctional beliefs are located on a deeper level of conscious/ unconscious thought, which also relate to personal and collective values of the society the person has been brought up. The negative automatic thoughts which arise in a situation can feed back to the dysfunctional beliefs (Wenzel, 2012).

CBT's method of cognitive restructuring is about identifying and challenging thoughts and beliefs. It happens through a restructure of the cognitive schema of the individual who is challenged to find pros and cons of their existing thought processes and replace them with more constructive ones. In that way, the individual can adopt better and exhibit more flexible ways of interpreting external reality.

Problem solving is another frequent used CBT approach. It uses a linear way of thinking where the individual is encouraged to use analytical skills to solve a problem they face. According to Stewart et al. (2009) the problem-solving approach follows specific steps such as choosing the problem to work on, identifying past coping strategies and to evaluate them, while supporting the person to find new solutions and ways of how to reach their goals.

This kind of thinking is divided into two kinds, the inductive and deductive way of thinking. The inductive is when the individual can reach a conclusion by making associations and connecting different clues in a given situation. On the contrary, deductive thinking is when the individual uses the process of elimination to reach a conclusion. In that way, the individual considers different clues, and with a linear progress of thinking, the individual can identify and eliminate clues that are not compatible with the narrative of the description of events, places, activities, etc.

Behaviour management is another CBT approach used for the treatment of PND. Its main purpose is to help the individual identify positive and negative behaviours. The idea here is that the individual will be able to reduce depression and improve their mood by increasing activities that are pleasurable and rewarding, and/or decrease certain behaviours that can affect the 
person's mood in a negative way. By managing the behaviour of the person, they can affect their emotional states. Rapoport et al. (2000) talk about behaviour management in the context of weight-control paradigm with long-term lifestyle changes rather than dieting.

Goals are an important part of the person's recovery from depression. CBT puts emphasis on helping the person identifying goals that they can aim to work for. There are two aspects here. The first one is goal setting where the person is encouraged to identify goals that are realistic, measurable, and achievable. They are called SMART goals. The second aspect of the CBT approach here is about helping the person identify ways of how to reach those goals they set for themselves. CBT helps the individual set realistic and achievable goals who also identifies ways of how to accomplish those specific goals.

CBT uses a variety of ways to help the individual achieve goals such as visual aids and structured activities. One of CBT's aims is to do that in an organised manner. For example, creating a routine is one of the best and frequent ways to cope with depression, which can raise motivation and subsequently can improve the person's self-esteem. Oliver et al. (2017) emphasize that self-efficacy is a reliable indicator for the attainment of the defined goals.

Another CBT technique frequently used for the treatment of PND is through stress management. Its purpose is to create specific programs tailor made to the individual needs to find better ways of coping with stress. Groarke et al. (2012) report that cognitive behavioural stress management can help women with breast cancer reduce distress and adjust better. Some of stress management activities can be gardening, biking, meditation, connecting with family and friends amongst others. Lastly, relaxation is also another CBT approach which appears in the scientific literature.

CBT shows to be effective especially on mild to moderate range of depression in the postpartum period. It is also effective with clear positive therapeutic outcomes up to the fifth month following therapy. Another positive aspect of CBT is that it has good therapeutic application in a brief manner. It can be effective in a short-term clinical context. It is unknown whether CBT could have the same therapeutic effect on moderate to severe range of depression. In addition, 
research shows that the initial therapeutic effect diminishes past the five-month mark. Its efficacy is not clear long-term.

CBT is flexible. It can be practiced by professionals who have different backgrounds such as mental health professionals, medical doctors, nurses, and social workers. In addition, it can be also delivered by non-professionals in mental health such as health visitors or lay people.

The location of the delivery of CBT is also flexible. It can be delivered on various locations such as hospitals or clinics. CBT can also be delivered at people's houses and some research shows that women in the post-partum period do prefer to have that option as it can be less time consuming or resource demanding. It can solve issues such as the lack of transportation.

Another clinical aspect regarding CBT and the save of resources is the delivery of therapy in a group setting. CBT is usually delivered on one-to-one basis. A typical scenario is that there is a therapist and an individual client in the therapeutic room. However, there is evidence that CBT can also be delivered in group settings with good therapeutic outcomes (Thimm \& Antonsen, 2014). Although, there are other obstacles in the successful delivery of this approach, such as the possible stigma of depression, CBT delivery in groups is a therapeutic avenue with real clinical applications.

Another aspect of CBT's clinical efficacy is that it is effective in all populations from different socio-ethnic backgrounds or financial status. CBT can have good therapeutic outcomes regardless different demographic data of the treated population.

\section{Has VR been used for the treatment of PND previously?}

In the question whether VR has been used for the treatment for PND, a database search was conducted, and no research was found as such. However, it was found that technological means have been used in three studies. The technology that was used in the two studies was video recordings, while a third study examined whether CBT can be delivered online. The first 
two studies focused on Toddler-Parent Psychotherapy approach and for the evaluation and assessment of the interaction between mothers and infants. None of those studies included any VR technology.

VR has been used for the treatment of various disorders, such as anxiety disorders and phobias. It has never been used for the treatment of PND prior to the clinical trial conducted which is part of this PhD thesis. However, there has been a study which examined the effect of VR on stroke patients (Song \& Park, 2015). The purpose of that study was to investigate what was the effect of VR on patients who had suffered a stroke on matters such as balance, gait ability, depression, and interpersonal relationships. The results were positive on all categories of functioning including depression. However, it is worth noting here that this study was not solely on depression, but rather depression was part of a larger system of human functioning.

\section{Is it feasible implementing VR in combination with CBT for the treatment of PND?}

Research shows that CBT can be combined with VR successfully (Anderson et al., 2005; Peñate et al., 2008; Pot-Kolder et al., 2018). The findings from both the pilot study and the clinical trial conducted in this thesis also confirm that, indicating that the feasibility of combining VR with a traditional therapeutic method such as CBT is highly adequate. There was a consensus between most participants where they felt comfortable throughout the recruitment process. They also felt that the facilitator gave enough information about the referral process, the ethics approval and confidentiality. The participants felt that the VR session being the fourth session on both the pilot study and the clinical trial was suitable. Although the number of sessions were slightly different in the pilot study as they were not as consistent as in the clinical trial, participants felt that they had addressed their mental health needs adequately.

Most participants answered positively about the VR system and having enough information prior to using it. However, some of the participants in the pilot study felt that they needed more information about the VR system, its functionality, and purpose. This was not reported by the 
participants in the clinical trial. Participants from both pilot study and clinical trial felt that they had enough time to prepare for the VR session and to use the technology. Likewise, participants on both the pilot and the clinical trial reported that the number of questionnaires was not excessive and that they reflected adequately their mental health needs. The setting and location of the study was also considered suitable with no objections arising from the participants.

In terms of motion sickness, participants in both the pilot study and the clinical trial experienced motion sickness. Although the degree of discomfort between participants varied from mild to moderate, none wished to continue with the VR session at the time. Nevertheless, most were able to overcome the feelings of dizziness relatively fast, ranging from a few minutes to half an hour approximately.

There was a significant reduction to the percentage of the number of participants who experienced motion sickness, from the pilot study to the clinical trial. Five participants in total experienced motion sickness, with three of them being participants in the pilot study, while just two participants were in the clinical trial. Four of them found the follow up call useful made the following day, while one participant declined the offer of the phone call as she felt it was not necessary.

Most participants reported that they found the whole process of the VR session, and the implementation and use of VR technology useful in some way, and relevant. Most participants could relate to the task of tidying up the virtual environment, where they would find it stressful, while others found it therapeutic.

\section{What were the levels of acceptance of the combination of VR with CBT for the treatment of PND?}

Research shows that the combination of VR with CBT is acceptable (Nosek et al., 2016). The results from both the pilot study and the clinical trial indicate that the levels of acceptance of 
VR technology by the participants in a traditional therapeutic setting were satisfactory. The time that participants spent on the actual system was between 10 to 30 minutes. However, there was an increase of the time used from the pilot study to the clinical trial, with an average between 20 and 30 minutes during the trial. This was mainly due to the change in the protocols between the study and the trial. Participants on both the pilot study and the clinical trial found the system easy to use, without the need for professional input necessarily. This was also compatible with the identification of not having the need necessary to having to go through extensive training to prepare to use the system. There was a consensus amongst participants from the pilot study and the clinical trial that the VR system was not fragile and that the different possibilities were well integrated.

Another common theme was that participants felt comfortable and confident using the system and that the process was not either long or complicated. Participants felt that the tasks to be completed within the program were easy to handle. However, this raised the concern by some participants that they were not challenging enough. This underlined a skepticism whether the VR program could speed up the participants' recovery, both from the pilot study and the clinical trial's participants. This was also relevant to the consensus among participants from both the pilot study and the clinical trial that they would not use the system frequently. A reason for that which became apparent was the experience of motion sickness that some participants had, especially during the pilot study.

Nevertheless, there was positive feedback about the usefulness of the VR program. In general, research shows that VR can enhance decision-making (Berg \& Vance, 2017; Boejen \& Grau, 2011), and raise awareness (Wright et al., 2009). Participants' feedback in our study was that they found it to be useful and that it had practical applicability. It was feedback from the participants of the pilot study that its usefulness was on better decision-making and that it could raise awareness around coping mechanisms for stress and thus being able to find better ways of coping. This was apparent in the question about what they were doing better in their daily routines after having used the system. Participants saw value in the VR program as a training 
tool for learning new skills, or confirming already possessed ones, and that it had some psychoeducation characteristics. Participants felt that they had better prioritization skills and had become more mindful, grounding themselves to the present moment. As a result, they would have gained better awareness of their emotional state of anxiety, when trying to cope with a stressful situation and find ways to cope differently such as using breathing techniques. The VR system also acted as a reminder of achievements participants had made, which underlined a sense of self-appreciation.

Participants found a variety of things that they liked which was about the VR program, but also their experience with it. There was a positive response to the background music as relaxing, the parcel at the door, the baby's bedroom, and the realism of navigation within the virtual environment. In terms of their experience, some participants liked that they were able to complete the tasks and cope with stress at the same time. This relates to the tasks being manageable. Another positive experiential element was about learning a new skill such as slowing down and being more in the present.

The feedback from the participants between the pilot study and the clinical trial regarding what they did not like varied between them, possibly due to the fact of the use of different protocols, and an increase of technical difficulties that were experienced. Participants in the pilot study gave emphasis on the actual tasks which did not consider them as challenging enough and that they were predictable. They also felt that some stressors were irrelevant. On the contrary, participants in the trial did not like other technical difficulties they experienced such as the functionality of the joystick, the system freeze, or not being able to pick up some virtual items. However, a common theme was about the lack of options to resolve difficulties or tasks such as more ways of soothing the virtual baby just by placing it back to the cot, or to make the virtual experience more rewarding such as being able to sit on the coach with the baby and enjoy it, which was also suggested as a recommendation made by them.

In summary, we can conclude that the combination of VR with CBT for the treatment of PND was acceptable by the participants. The overall feedback was positive, not only about the VR 
system and its applicability, but also about the combination of CBT treatment with VR technology for the treatment of PND, which was encouraging.

\section{Is the combination of CBT with a VR component specifically designed for the treatment of PND effective?}

Overall, participants of both the pilot study and the clinical trial made progress. By the completion of therapy, participants were feeling better, and their mood had improved. Their sleep had also improved and had found skills and strategies to manage their stress better in stressful situations. There was a significant reduction in their tendency to ruminate and this had a positive effect as they had become more mindful where they were able to be more in the present moment. Many participants had become responsive than reactive to external stressors which would help contain negative feelings. As a result, participants had experienced improved self-esteem, and had become more confident, empowered, and with better motivation.

The question whether VR can enhance the therapeutic outcome of traditional therapies for the treatment of PND and in what ways cannot be answered definitively, due to the specific design that was used in the clinical trial. To do that, and that could be a recommendation for future research, a different design would need to be employed such as a randomised clinical trial with two independent groups. Both groups would receive the same treatment but with one of them to receive VR additionally. In that way, we would be able to compare the results from both groups and identify any differences.

Nevertheless, considering the results from both the pilot study and the clinical trial we can conclude that the combination of CBT and VR is an effective treatment for PND, and that VR can contribute as a modality to therapy for PND overall. The findings from both the clinical trial but also the pilot study, are also confirmed by other studies found in international literature. VR can enhance the traditional therapies for PND in four main areas: decision making (Mendes et 
al., 2012), awareness (Mottura et al., 2015), mindfulness (Nararro-Haro et al., 2016), and reallife applications (Rizzo et al., 2004). Those four areas are interconnected and affect in a positive way the individual. In other words, gaining awareness can lead to better decision making, which also connects with real-life applications. Another association is about awareness that can be synonymous to mindfulness.

More analytically, the decision making is a cognitive skill that VR can enhance. Participants having used the VR system, felt they could make better decisions, mainly by prioritising easier. Prioritisation can be translated into what is real and most important to the individual, which is also congruent with the person's values. This was one of the main functions of the VR system and confirms that VR can enhance that process. In the VR program, participants would be asked to prioritise between stressors. This acted in two ways, one was where some participants were able to practice that skill via the VR system, while the other aspect of usefulness was regarding VR playing the role of the reinforcer. In other words, through VR, participants were able to confirm that they were already possessing that skill. That realisation in turn, helped promote a sense of confidence (Harris et al., 2004).

The second area of VR's usefulness was about awareness. This refers to the idea that participants were able, by using the VR system, to gain insight on their existing coping mechanisms for anxiety and depression. This, in turn, helped understand better what was useful and what needed to improve to reduce depressive symptomatology. This is of tremendous clinical importance as awareness is the first step towards the initiation of behaviour change in therapy and subsequently in real life (Hopko et al., 2003).

The third area where VR had a positive impact on the therapeutic outcome overall was regarding mindfulness. This was helpful as participants were able to slow down when they were accomplishing tasks. This was particularly helpful as participants would use a different strategy than previously. Instead of rushing to complete the task, they would now start focusing on the task itself. Hafenbrack and Vohs (2018) report that mindfulness increases the focus of the 
individual on the task which enhances performance while stress reduces. Some participants found it a challenge as they had been used to be doing things fast. Many would pay value particularly to the ability to be able to do that in real life. However, when they were able to see the meaning and purpose behind slowing down, there was a positive feedback which they had found useful regarding stress. This change had also a positive effect on other aspects such as a reduction in self-criticism, or rumination. There was a noticeable theme of self-appreciation that participants would express. Another theme was about better self-acceptance which also underlines more realistic expectations.

VR can also be useful and applied in real life. It can promote a sense of better organisation. It can help promote better daily routines, which in turn can enhance a sense of control for the individual. VR can be a good stress management tool, while at the same time, it can have psychoeducational elements. VR can help the individual enhance other cognitive skills such as better analysis of a situation and which, in turn, leads to better decision making.

In summary, the preliminary data from the studies carried out in this thesis indicate that the combination of VR and CBT is useful, but at present and considering the design used, it is not possible to give a definitive answer to this question. Therefore, further research will be necessary in the future to provide more conclusive data about this question.

\section{What were methodological problems, flaws, technical difficulties, and/or limitations on the protocols and research tools?}

Implementing a VR program in a traditional therapeutic approach brought up some difficulties and limitations. The issues were on various levels and were of different nature between the pilot study and the clinical trial.

One limitation of the clinical trial was regarding its methodology. Its design was a single case design and not a between-groups design. This is limiting in the sense that it prevents some 
conclusions to be obtained. Between-groups design would allow for participants of each group to be exposed to a single experimental condition and can provide more definite answers to the research questions. However, this experimental approach is more suitable for bigger scale studies as it requires many participants, clinicians, and resources, which we verified they were not within our reach. On the contrary, the design that was used for this clinical trial is suitable for small number of participants with limited resources.

The pilot study showed a limitation in the clinical protocol where there was no follow up. However, this was corrected in the clinical trial where there was a follow up three-month postintervention. Another limitation that was also rectified was in terms of the VR stressors. The results from the pilot study showed that some of the stressors that had been chosen were considered irrelevant and not challenging. Participants of the pilot study could not relate to them. This was rectified in the clinical trial as participants chose the ones most relevant to their life circumstances, and the sequence that they were activated. However, the issue with some stressors not being challenging enough was never resolved as the option to use more challenging and complex stressors was not possible due to using the same VR technology for both the pilot study and the clinical trial. Another issue of relevance that was highlighted was certain aspects of the virtual environment which was perceived unrealistic by most of the participants on both the pilot study and the clinical trial. Unfortunately, that was not corrected as the same VR programme was used for both the pilot study and the trial.

One problem which was common in both the pilot study and the clinical trial was that the element of positive reward, or the ability to relax while using the system was missing. Participants felt that their experience could have been more relaxing and positively rewarding.

An additional matter that arose was the attrition rate and cancellations. This was encountered in the clinical trial more, and not as much in the pilot study. There were four participants who withdrew from the study following the initial assessment. It was observed that there were more cancellations in the trial and less in the pilot study. 
On a technical level, technical issues appeared on both the pilot study and the clinical trial. However, there were encountered more in the trial, possibly due the fact that the greater number of participants, and the more time that participants spent using the system in the trial than the pilot study. However, some technical issues were common such as the inability to pick up items, or the lack of options such as multi-tasking. Nevertheless, the technical issue was apparent mostly in the trial, possibly due to the extended time use of the VR program by the participants was the system freeze.

The issue of navigation was common in both the pilot study, but the issue of motion sickness and the experience of it was reduced after the protocol was altered from the pilot study to the clinical trial. There was a big reduction to the percentage of participants experiencing motion sickness from the pilot study to the clinical trial.

\section{What could be recommended for the better implementation of VR within a traditional clinical setting?}

The pilot study had made recommendations for the better implementation of VR within a traditional therapeutic approach for PND. One of them was to allow the participants to choose their stressors and for them to spend sufficient time in advance to familiarise themselves with the virtual programme. It was also recommended that the facilitator to provide adequate information about the philosophy behind the VR programme and its purpose, whether any difficulties encountered, and how to resolve issues when they arose.

The new recommendation and guidelines were implemented in the clinical trial with much better outcomes. However, the trial highlighted further recommendations to be made for better and improved implementation of VR within a traditional therapy. One suggestion is about a change in the actual protocol where participants can spend more time with the VR programme, at least in two sessions. The two VR sessions could occur in sequence one after the other or in every other session. 
Other proposed changes are on a technical level where the VR program would be upgraded. This would reduce the technical issues such as system freeze, or communication gaps between the two sides. One upgrade would be to run the system in an online program and not in a closed circuit for better performance. Another technical recommendation is on using a headset version than the desktop version for better levels of presence of the participants. Onyesolu and Eze (2011) divide VR technology into three categories with the headset version to be highly immersive.

In addition, the idea of providing more options was suggested, such as the ability to multi-task, or to make the whole virtual experience more rewarding and positive. Instead of focusing solely on the virtual stressors and how to cope with them better, it would be preferred to enrich the virtual experience with more relaxing experiential elements rather than focusing on cognitive tasks. This would, in turn, change the whole philosophy behind what characteristics the system would need to have and how to best use them. An option could be to make the scenario simpler and more adaptable to the individual needs for each participant. An example could be about a person whose primary issue would be to enhance cognitive skills, while another user would be about becoming more mindful and to raise awareness.

\section{Strengths and limitations}

This thesis is comprised of different chapters that make up of studies that have been already published or submitted to be published. Each chapter includes strengths and limitations, and this thesis should be viewed by the readers in relation to those strengths and its limitations.

1. One strength of the thesis is that it addresses a mental health issue such as port-partum depression that has important clinical and social implications. It is not uncommon for new parents to experience signs and symptoms of depression in the post-partum period. However, it becomes an important issue when the individual is not adequately supported by immediate family, extended social circle, or professionals. Signs and symptoms can 
often become intense and frequent with catastrophic consequences. This thesis explores different clinical aspects of PND and its consequences. It highlights important aspects on a clinical and theoretical level. More importantly, it examines the possibility of using VR as a possible therapeutic treatment of PND based on scientific evidence and in conjunction with international literature.

2. A second strength that this thesis presents is the logical sequence of chapters. The whole structure of the manuscript can be interpreted as a strength as there is a logical sequence to it. Firstly, there is chapter one which introduces the reader to the idea of PND, its current treatments, and an introduction to VR and the possibility as a treatment. The second chapter which is the published literature has a similar structure, but it investigates the treatments for PND in detail, especially CBT. It identifies the most well researched treatments, and what makes them efficacious. It includes the components and parameters of their successful clinical outcomes. Next, is the pilot study which examines in detail the possible combination of CBT with VR for the treatment and lays the ground for the clinical trial which is chapter 4. Chapter five which is the final chapter brings all the chapters together and answers the research questions asked in the previous chapters. It also includes recommendations for further research.

3. A third strength is about the literature review which is a narrative review. It investigates the most efficacious treatments, and it has been conducted in a systematic way. It follows the Prisma guidelines for reviews, but it does not meet all 27 criteria, which might also be viewed as a limitation on its own. As a result, it does not include any statistical analysis, or reporting of various biases. Nevertheless, it extracts specific information about clinical populations, treatment focus, quality of studies considered, the delivery of the interventions and the clinical outcomes. The review includes most frequently used CBT components for the treatment of PND, which is one of its main contributions, and was conducted in a systematic way. 
4. A fourth strength is that both pilot feasibility study and the clinical trial follow a specific protocol. That includes specific steps that were followed in both studies. All clinical and intervention protocols are based on scientific evidence that can be replicated. Another strength is that both studies included risk mitigation protocols for ensuring the well-being of the participants and minimising any potential risk, offering a risk mitigation plan, if it was needed.

5. A fifth strength is the inclusion of follow up in the clinical trial. The pilot study was lacking a follow up which was a limitation. Nevertheless, it was noted, and a change was made to allow for follow ups in the clinical trial as it provided information about the continuation of the participants' progress post- intervention.

6. Another important strength of the dissertation is regarding the information provided by the participants in both the pilot study and the clinical trial. The thesis provides valuable information and insights about what did not work well and what needs to change to make the combination of VR with CBT more efficacious. It also provides insight about what needs to change to potentially make VR technology more useful, acceptable, and functional.

Regarding the main limitations of this thesis:

1. One limitation of the thesis was that the single-case studies design chosen for the clinical trial did not permit the conclusion whether VR can enhance the therapeutic outcome of traditional therapies for PND. Although the trial shows that CBT with VR can be effective for the treatment of PND, it is difficult to identify what exactly is the role of VR and to what extent it influences the therapeutic outcome. Instead, a randomised controlled trial would need to have been employed to examine how and to what extent VR affects CBT for PND. 
2. A second limitation in the literature review was the exclusion of certain types of studies such as pilot studies, or case studies. In that way, there is the danger of missing valuable data, especially of qualitative nature.

3. A third limitation is that the focus on PND as a clinical issue was mostly on mild-tomoderate range. However, it is unknown whether the same results would be obtained about the moderate-to-severe range of PND, which could be a topic for future research.

4. A fourth limitation is that the focus of the review, the pilot study, and the clinical trial are on the treatment of the PND. It is limiting as it has a clinical narrow focus, mainly on the treatment on PND, but nothing on its prevention.

5. A fifth limitation was the selection of the stressors in the pilot study. Some of the feedback of the participants was that the pre-selection of the stressors and the sequence they were activated was not relevant to them. Nevertheless, the protocol of the clinical trial took that into consideration and made the relative changes, something that can be considered a strength.

6. A sixth limitation was regarding the clinical trial and the attrition rate of four participants initially. Although this did not put the validity of the study at risk, there is important information missing about the withdrawal of those participants from the trial, as the facilitator lost contact with two of them. One limitation was also the cancellations they were observed during the clinical trial which were more than in the pilot study.

7. A seventh limitation that occurred in both the pilot feasibility study and the clinical trial was the technical limitations that participants encountered. Unfortunately, the number of technical difficulties were more in the clinical trial, possibly since the use of the system lasted longer in the trial than in the pilot study. However, this gave good insights about what the changes that are needed to be made and are included in the section of recommendations below. 
8. A final limitation was that about the motion sickness which occurred in both the pilot study and the clinical trial. However, there was a noticeable reduction between the study and the trial in the percentage of participants who experienced that, which was very positive. Nevertheless, there are other changes that could be made in order to further reduce the experience of motion sickness.

\section{Recommendations}

For the better implementation of VR technology with a traditional therapeutic approach such as CBT in a clinical setting, the following steps are recommended:

1) The focus of therapy can change where the VR technology can possibly be used and/or tested for the prevention of PND rather than its treatment. The pilot study and the clinical trial showed that the VR technology can be used as a training tool for improving cognitive tasks or preparing to cope with stress better. This could be the focus of future research. VR can be used for the preparation of future parents to manage stress and/or to familiarise themselves with real life circumstances.

2) Participants in the pilot study and the clinical trial reported that the time of the intervention was adequate, and the number of sessions provided to them met their mental health needs. Nevertheless, one option that could be explored to see whether there are any additional clinical benefits would be to offer the sessions in a more widespread time frame. In contrast, another option could be to offer the same number of sessions in a shorter space of time with higher frequency, as Cuijpers et al. (2013) suggest. A third possible option would be for the participants to choose the number of VR sessions and the type and number of stressors, depending on their needs.

3) Another recommendation would be about the actual time spent with the VR technology. The clinical protocol of future trials could include additional VR sessions, or the VR sessions could 
replace some of the CBT components. In that way, the VR element would be more central in the overall therapeutic approach.

4) One suggestion is about updating the current VR system to reduce or avoid technical issues such as the system freeze, or the motion sickness experienced in the pilot study and the clinical trial altogether.

5) Another recommendation is about the focus of the VR programme. One change could be about making the clinical focus of the VR program more specific and narrower. Out of four areas of decision making, awareness, mindfulness, and real-life applications that users of VR technology can benefit, the VR session can focus on one of those four areas each time instead on all four of them altogether. This means that the treatment focus would have to change along with the clinical protocol.

6) There was a consensus amongst participants that the VR program was engaging. Nevertheless, it was suggested that the VR technology could be more engaging. One way to make it more immersive on a technological level is to improve the picture and sound. Gasjek (2016) describes this as having functional technology. According to Newton and Soukup (2016) the user's sense of presence can be influenced by elements such as graphics, display, and processing (Empler et al., 2015). Takatalo (2002) reports that those elements are very important in creating a virtual environment that has a flow effect or experience.

A possible option would be to use a headset version of the same system as it was suggested, instead of the desktop version. In that way, it would be about creating a deeper immersive virtual reality experience.

Another way to make the virtual experience more engaging is through storytelling (Breuleux et al., 2019). According to Rodriguez (2016) there are some guidelines that are very important for good storytelling in VR. Storytelling should be linear, where the user is able to make decisions about what to do within the environment. The user should be able to comprehend the possible consequences for whatever course of action they decide to take while in the virtual environment. 
In that way, a narrative can possibly be provided along with the VR programme. Castilla et al. (2018) have found that narratives from different virtual reality environments can enhance psychological wellbeing by using meditation and relaxation. This option could be of great interest as some possible narratives provided to patients would highlight some difficulties that a mother and family face when they have a new baby. Likewise, each participant could establish and personalize a narrative in which they would be able to learn to cope gradually with different stressors that can arise from new situations.

A major focus of the VR system used on both the pilot study and the clinical trial was on cognitive tasks, e.g., prioritizing, etc. However, PND is a mood disorder and the focus of the system could shift to more of an emotional one. Newton and Soukyp (2016) make the distinction between the cognitive aspect and the emotional engagement in the virtual experience where the details of the story are associated with cognitive functioning, while abstract concepts are associated with emotional activity. This resembles the emotion of awe that Chirico et al. talk about (2018). Awe is a complex emotion with elements of amazement and surprise that can have transformative effects in different aspects of someone's life such as the psychological realm with an increased satisfaction for life, amongst others. VR can elicit such emotion successfully.

Krapp (2005) views VR therapy as a form of art therapy. This comes into light thinking of VR of its visual representations which can be seen in the light of images and symbols, which have a healing element. Like in art therapy, the user of VR interacting with the virtual environment, and changing the result of it, can act as a medium developing images and symbols on a personal level in a very therapeutic way.

Likewise, the VR system used for the purpose of this thesis could be used with the purpose of triggering more awe emotions by focusing more on positive feelings. One way to achieve that could be by inviting its users to spend more time outside the virtual house which was greener and with less stressors. Another way could be about minimizing the stressors inside the virtual 
house. A third possible way could be about adding more pleasant stimuli such as upbeat music during the navigation within the virtual environment.

\section{Conclusion}

Considering the results from the pilot study and the clinical trial, along with the key findings of this dissertation, it can be concluded that:

- the combination of CBT with VR is feasible and the use of technology acceptable.

- the combination of CBT with VR has good therapeutic outcomes in the treatment of PND. They share common therapeutic elements such as decision making, prioritizing, insight, and stress management.

- VR can help the individual make better decisions and prioritise more effectively, raise awareness, promote self-acceptance, help someone become more responsive than reactive, help someone be more mindful while completing tasks, help someone acknowledge minor achievements, and help an individual cope better with stressful situations in real life. 


\section{References}

-Anderson, P. L., Zimand, E., Hodges, L. F., \& Rothbaum, B. O. (2005). Cognitive behavioral therapy for public-speaking anxiety using virtual reality for exposure. Depression \& Anxiety, Vol 22, Issue 3, pp 156-158. https://doi.org/10.1002/da.20090

-Beck, C. T. (2002). Theoretical perspectives of postpartum depression and their treatment implications, MCN. The American Journal of Maternal/Child Nursing, Volume 27 - Issue 5 - p 282-287.

- Berg, L. P., \& Vance, J. M. (2017). Industry use of virtual reality in product design and manufacturing: a survey. Virtual Reality, 21, 1-17. https://doi.org/10.1007/s10055-016-0293-9

-Boejen, A., \& Grau, C. (2011). Virtual reality in radiation therapy training. Surgical Oncology, Volume 20, Issue 3, pg. 185-188. https://doi.org/10.1016/j.suronc.2010.07.004

-Breuleux, Y., Coninck, B. D., \& Therrien, S. (2019). The world building framework for immersive storytelling projects. SHS Web Conf., 64 00003. https://doi.org/10.1051/shsconf/20196400003

-Cain, N., Gradisar, M., \& Moseley, L. A. (2011). Motivational school-based intervention for adolescent sleep problems. Sleep Medicine, Volume 12, Issue 3, pg. 246-251. https://doi.org/10.1016/j.sleep.2010.06.008

-Castilla, D, Botella, C., Miralles, I., Bretón-López, J., Dragomir-Davis, A. M., Zaragoza I., \& Garcia-Palacios, A. (2018). Teaching digital literacy skills to the elderly using a social network with linear navigation: A case study in a rural area. International Journal of Human-Computer Studies, 118, 24-37.

-Chirico, A., Ferrise, F., Cordella, L., \& Gaggioli, A. (2018). Designing Awe in Virtual Reality: An Experimental Study. Frontiers in Psychology, Vol 8, pg. 2351. https://doi.org/10.3389/fpsyg.2017.02351 
-Cook, E. J., \& Doyle, C. (2002). Working Alliance in Online Therapy as Compared to Face-toFace Therapy: Preliminary Results. CyberPsychology \& Behavior, Volume 5, Number 2.

-Cuijpers, P., Huibers, M., Ebert, D. D., Koole, S. L., \& Andersson, G. (2013). How much psychotherapy is needed to treat depression? A metaregression analysis. Journal of Affective Disorders. http://dx.doi.org/10.1016/j.jad.2013.02.030i

-Empler, T., Quici, F., \& Bellucci, L. (2015). Keep the revolution going. Public Awareness of Palaeontological Sites Through New Technologies. In Proceedings of the 43rd Annual Conference on Computer. Applications and Quantitative Methods In Archaeology.

-Harris, S. R., Kemmerling, R. L., \& North, M. M. (2004). Brief Virtual Reality Therapy for Public Speaking Anxiety. Cyberpsychology \& Behavior, Volume 5, Number 6. https://doi.org/10.1089/109493102321018187

-Hopko, D. R., Lejuezb, C. W., Ruggieroc, K. J., \& Eifert, G. H. (2003). Contemporary behavioral activation treatments for depression: Procedures, principles, and progress. Clinical Psychology Review, 23, 699 - 717. https://doi.org/10.1016/S0272-7358(03)00070-9

-Gajsek, D. (2016). Ultimate Beginners Guide to Virtual Reality Storytelling. https://medium.com/@dgajsek/ultimate-beginners-guide-to-virtual-reality-storytellingb00dbedbc093.

-Garcia-Palacios, A., Hoffman, H., Carlin, A., Furness III T. A., \& Botella, C. (2002). Virtual reality in the treatment of spider phobia: a controlled study. Behaviour Research and Therapy. 40, 983-993.

-Goutam, P., \& Kaushal, R. (2019). Utilization of Edinburgh Post Natal Depression Scale (EPDS) as Screening Tool for Predicting Life Events related to Anxiety \& Depression during Perinatal Period: An Implication of Preventive Psychiatry. Indian Journal of Mental Health, 6(2). 
-Granath, J., Ingvarsson, S., Von Thiele, U., \& Lundberg, U. (2006). Stress Management: A Randomized Study of Cognitive Behavioural Therapy and Yoga. Cognitive Behaviour Therapy, 35:1, 3-10. https://doi.org/10.1080/16506070500401292

-Groarke, A., Curtis, R., \& Kerin, M. (2012). Cognitive-behavioural stress management enhances adjustment in women with breast cancer. British Journal of Health Psychology. Volume18, Issue3, 623-641. https://doi.org/10.1111/bjhp.12009

-Hafenbrack, A. C., \& Vohs, K. D. (2018). Mindfulness Meditation Impairs Task Motivation but Not Performance. Organizational Behavior and Human Decision Processes, 147, 1 - 15. https://doi.org/10.1016/j.obhdp.2018.05.001

-Heyne, D., King, N. J., Tonge, B. J., \& Cooper, H. (2001). School refusal: epidemiology and management. Paediatric Drugs, 3(10):719-732. https://doi.org/10.2165/00128072-20010310000002

-Hoffman, H. G., Doctor, J. N. Patterson, D. R., Carrougher, G. J., \& Furness III, T. A. (2000). Virtual reality as an adjunctive pain control during burn wound care in adolescent patients. Pain, $85,305-309$.

-Kaltenthaler, E., Parry, G., \& Beverley, C. (2004). Computerized cognitive behaviour therapy: a systematic review. Behavioural and Cognitive Psychotherapy, Volume 32, Issue 01, pp 31-55. https://doi.org/10.1017/S135246580400102X

-Kootker, J. A., Rasquin, S. M., Smits, P., Geurts, A. C., van Heugten, C. M., \& Fasotti, L. (2015). An augmented cognitive behavioural therapy for treating post-stroke depression: description of a treatment protocol. Clinical Rehabilitation, 29(9), 833-843. https://doi.org/10.1177/0269215514559987

-Krapp, M. (2005). The computer as a helpmate for imagination. Cybertherapy Abstracts. Annual Review of Cybertherapy and Telemedicine, pg. 260-261. 
-Martinez-Devesa, P., Perera, R., Theodoulou, M., \& Waddell, A. (2010). Cognitive behavioural therapy for tinnitus. Cochrane Database of Systematic Reviews, Issue 9. Art. No.: CD005233. https://doi.org/10.1002/14651858.CD005233.pub3

-McGinn, L. K., \& Sanderson, W. C. (2006). What Allows Cognitive Behavioral Therapy to Be Brief: Overview, Efficacy, and Crucial Factors Facilitating Brief Treatment. Clinical PsychologyScience and Practice, Volume 8, Issue 1, pg. 23-37. https://doi.org/10.1093/clipsy.8.1.23

-Mendes, F. A. d. S., Pompeu, J. E., Modenesi Lobo, A., Silva, K. G. d., Paula Oliveira, T. d., Peterson Zomignani, A., \& Pimentel Piemonte, M. E. (2012). Motor learning, retention and transfer after virtual-reality-based training in Parkinson's disease - effect of motor and cognitive demands of games: a longitudinal, controlled clinical study. Physiotherapy, 98, 217-223. https://doi.org/10.1016/j.physio.2012.06.001

-Mottura, S., Fontana, L., Arlati, S., Zangiacomi, A., Redaelli, C., \& Sacco, M. (2015). A virtual reality system for strengthening awareness and participation in rehabilitation for post-stroke patients. J Multimodal User Interfaces, 9, 341-351. https://doi.org/10.1007/s12193-015-0184-5

-Mulcahy, R., Reay, R. E., Wilkinson, R. B., \& Owen, C. (2010). A randomised control trial for the effectiveness of group interpersonal psychotherapy for postnatal depression. Arch Womens Ment Health, 13:125-139. https://doi.org/10.1007/s00737-009-0101-6

-Nararro-Haro, M. V., Hoffman, H. G., Garcia-Palacios, A., Sampaio, M., Alhalabi, W., Hall, K., \& Linehan, M. (2016). The Use of Virtual Reality to Facilitate Mindfulness Skills Training in Dialectical Behavioral Therapy for Borderline Personality Disorder: A Case Study. Front. Psychol. https://doi.org/10.3389/fpsyg.2016.01573

-Neimeyer, R. A., Kazantzis, N., Kassler, D. M., Baker, K. D., \& Fletcher, R. (2008). Group Cognitive Behavioural Therapy for Depression Outcomes Predicted by Willingness to Engage in Homework, Compliance with Homework, and Cognitive Restructuring Skill Acquisition. Cognitive Behaviour Therapy, 37:4, 199-215. https://doi.org/10.1080/16506070801981240 
-Newton, K. \& Soukup, K. (2016). The storyteller's guide to the virtual reality audience. VR/AR Media Experiments. https://medium.com/stanford-d-school/the-storyteller-s-guide-to-the-virtualreality-audience-19e92da57497 The Storyteller's Guide to the Virtual Reality Audience.

-Nosek, M. A., Robinson-Whelen, S., Hughes, R. B., \& Nosek, T. M. (2016). An Internet-based virtual reality intervention for enhancing self-esteem in women with disabilities: Results of a feasibility study. Rehabilitation Psychology, 61(4), 358-370. https://doi.org/10.1037/rep0000107

-O'Higgins, M., Roberts, I. S. J., Glover, V., \& Taylor, A. (2013). Mother-child bonding at 1 year; associations with symptoms of postnatal depression and bonding in the first few weeks. Arch Womens Ment Health, 16, 381-389. https://doi.org/10.1007/s00737-013-0354-y

-Oliver, S., Fisher, K., \& Childs, S. (2017). What psychological and physical changes predict patients' attainment of personally meaningful goals six months following a CBT based pain management intervention? Disability and Rehabilitation, 39:22, 2308-2314. https://doi.org/10.1080/09638288.2016.1226415

-O'Mahen, H. A., Woodford, J., McGinley, J., Warren, F. C., Richards, D. A., Lynch, T. R., \& Taylor, R. S. (2013). Internet-based behavioral activation-Treatment for postnatal depression (Netmums): A randomized controlled trial. Journal of Affective Disorders, Volume 150, Issue 3, Pages 814-822. https://doi.org/10.1016/j.jad.2013.03.005

-Onyesolu, M. O., \& Eze, F. U. (2011). Understanding Virtual Reality Technology: Advances and Applications, Advances in Computer Science and Engineering, Dr. Matthias Schmidt (Ed.), ISBN: 978-953-307-173-2, InTech. http://www.intechopen.com/books/advances-incomputerscience-and-engineering/understanding-virtual-reality-technology-advances-andapplications.

-Peñate, W., Pitti, C. T., Bethencourt, J. M., Fuente, J. D. L., \& Gracia, R. (2008). The effects of a treatment based on the use of virtual reality exposure and cognitive-behavioral therapy applied to patients with agoraphobia. International Journal of Clinical and Health Psychology, Vol. 8, № 1, pp. 5-22. https://www.redalyc.org/articulo.oa?id=33780101 
-Pot-Kolder, R. M. C. A., Geraets, C. N. W., Veling, W., Van Beilen, M., Staring, A. B. P., Gijsman, H. J., Delespaul, P. A. E. G., \& Van Der Gaag, M. (2018). Virtual-reality-based cognitive behavioural therapy versus waiting list control for paranoid ideation and social avoidance in patients with psychotic disorders: a single-blind randomised controlled trial. The Lancet Psychiatry, Vol 5, Issue 3, pp 217-226. https://doi.org/10.1016/S2215-0366(18)30053-1

-Rapoport, L., Clark, M. \& Wardle, J. (2000). Evaluation of a modified cognitive-behavioural programme for weight management. Int $J$ Obes, 24, 1726-1737. https://doi.org/10.1038/sj.ijo.0801465

-Rizzo, A., Schultheis, M. T., Kerns, K., \& Mateer, C. (2004). Analysis of assets for virtual reality applications in neuropsychology. Neuropsychological Rehabilitation, 14 (1/2), 207-239. https://doi.org/10.1080/09602010343000183

-Rodriguez, M. (2016). Storytelling in virtual reality. Hackernoon. https://hackernoon.com/storytelling-in-virtual-reality-cf8efc5e78f1

-Rothbaum, B. O., Hodges, L., Alarcon, R., Ready, D., Shahar, F., Graap, K., Pair, J., Hebert, P., Gotz, D., Wills, B., \& Baltzell, D. (1999). Virtual Reality Exposure Therapy for PTSD Vietnam Veterans: A Case Study. Journal of Traumatic Stress, Vol. 12, No. 2.

-Salkovskis, P., Atha, C., \& Storer, D. (1990). Cognitive-Behavioural Problem Solving in the Treatment of Patients who Repeatedly Attempt Suicide a Controlled Trial. British Journal of Psychiatry, 157(6), 871-876. https://doi.org/10.1192/bjp.157.6.871

-Shorey, S., Chee, C. Y. I., Debby, E., Lau, Y., Dennis, C-L., \& Chan, Y. H. (2019). Evaluation of a Technology-Based Peer-Support Intervention Program for Preventing Postnatal Depression (Part 1): Randomized Controlled Trial. Journal of Medical Internet Research, Vol. 21, iss. 8, e12410. 
-Song, G. B., \& Park, E. C. (2015). Effect of virtual reality games on stroke patients' balance, gait, depression, and interpersonal relationships. J. Phys. Ther. Sci, 27, 2057-2060. https://www.jstage.jst.go.jp/article/jpts/27/7/27_2057/_pdf

-Stewart, C. D., Quinn, A., Plever, S., \& Emmerson, B. (2009). Comparing Cognitive Behavior Therapy, Problem Solving Therapy, and Treatment as Usual in a High Risk Population. Suicide and Life-Threatening Behavior, Vol 39 No 5, pp. 538 - 547.

-Stewart, D. E., Robertson, E., Dennis, C-L., Grace, S. L., \& Wallington, T. (2003). Postpartum depression: Literature review of risk factors and interventions. https://www.who.int/mental_health/prevention/suicide/lit_review_postpartum_depression.pdf

-Stuart, S., \& O'Hara, M. W. (1995). Interpersonal psychotherapy for postpartum depression: a treatment program. The Journal of Psychotherapy Practice and Research, 4 (1): 18 - 29.

-Takatalo, J. (2002). Presence and flow in virtual environments: An explorative study. A Master's Thesis. Department of Psychology. University of Helsinki.

-Thimm, J. C., \& Antonsen, L. (2014). Effectiveness of cognitive behavioral group therapy for depression in routine practice. BMC Psychiatry, 14, 292. https://doi.org/10.1186/s12888-0140292-x

-Wenzel, A. (2012). Modification of core beliefs in cognitive therapy, Standard and Innovative Strategies in Cognitive Behavior Therapy, Irismar Reis de Oliveira, IntechOpen. https://doi.org/10.5772/30119

-Wessely, S., Bryant, R. A., Greenberg, N., Earnshaw, M., Sharpley, J., \& Hughes, J. H. (2008). Does Psychoeducation Help Prevent Post Traumatic Psychological Distress? Psychiatry, 71(4), 287-302. Guilford Press.

-Wright, V. H., Burnham, J. J., Inman, C. T., \& Ogorchock, H. N. (2009). Cyberbullying: using virtual scenarios to educate and raise awareness. Journal of Computing in Teacher Education, Volume 26, Number 1. https://files.eric.ed.gov/fulltext/EJ856115.pdf 
-Wylie, L., Hollins Martin, C. J., Marland, G., Martin, C. R., \& Rankin, J. (2011). The enigma of post-natal depression: an update. Journal of Psychiatric and Mental Health Nursing, 18, 48-58.

-Zaretsky, A., Lancee, W., Miller, C., Harris, A., \& Parikh, S. V. (2008). Is Cognitive-Behavioural Therapy More Effective Than Psychoeducation in Bipolar Disorder? The Canadian Journal of Psychiatry, 53(7), 441-448. https://doi.org/10.1177/070674370805300709 
APPENDIX

Appendix A. Poster of the pilot feasibility study

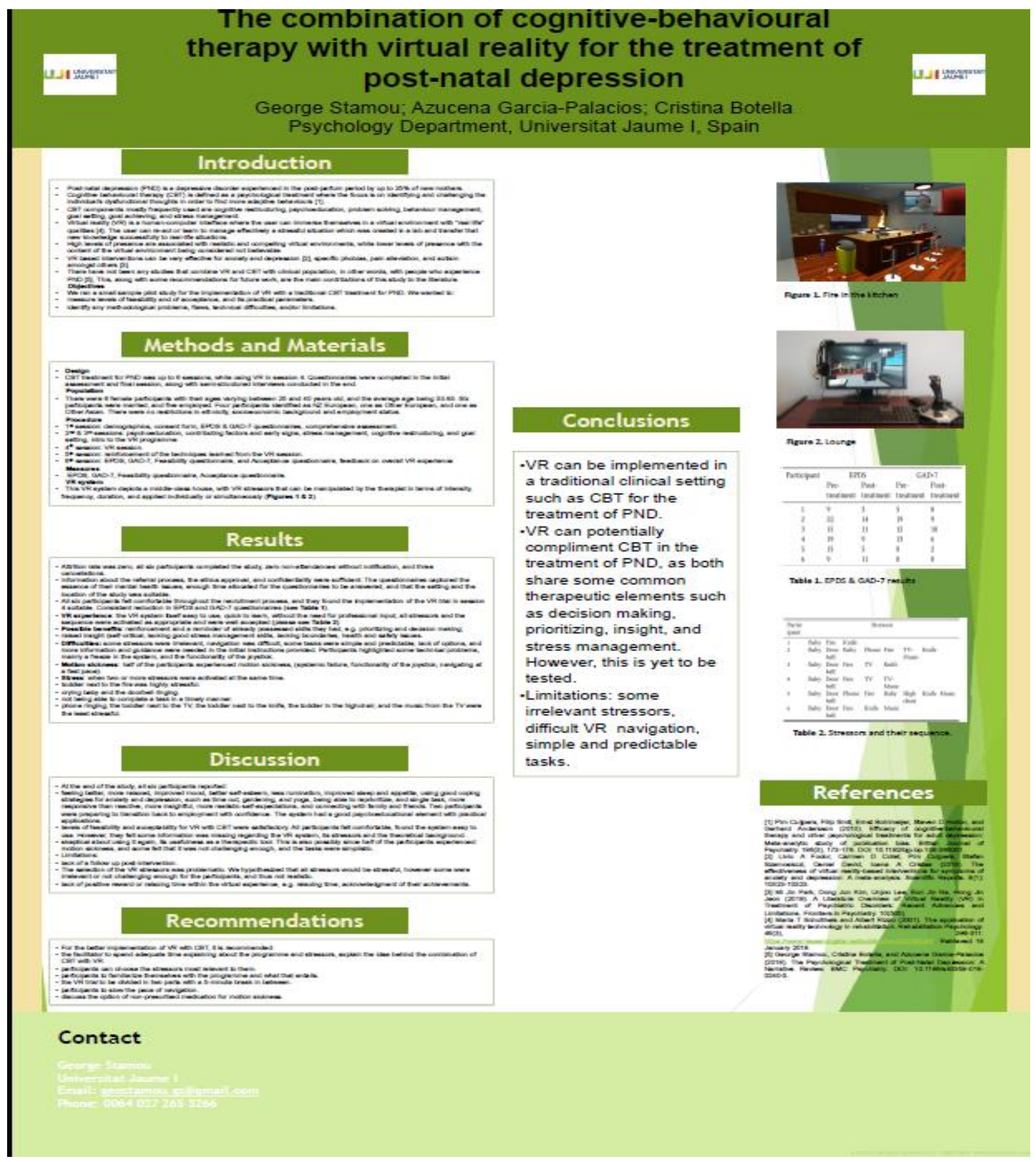


Appendix B. Assessment form

\section{Brief Intervention Service - Initial Clinical Assessment}

Name:

Address:

Phone:

NHI:

Date of Assessment:

Present during assessment:

Referrer:

GP:

Reason for Referral (referral diagnosis):

Presenting concern (consumer's reason for referral, understanding of concern):

Pregnancy / any complications:

Birth of the baby / any difficulties / trauma:

Breastfeeding / Does mom breastfeed? Yes No

If yes, are there any complications:

Physical health (perception of health, medical conditions, allergies, adverse reactions):

Current medications:

Strengths and resources available: 
Relevant background information (including family psychiatric history, psychosocial, family, relationships, education, employment):

Cultural and Spiritual (age and gender issues, sexual orientation, spirituality and/or religious, political beliefs, ethnicity, disability issues, values system):

Current situation (stressors, living, finances, social, relationships, employment, family, dependents, school):

Family violence (if yes, refer Appendix A):

Substance use (past and present - illicit drugs, treatment history, nicotine, alcohol, caffeine, sugar):

Gambling/online concerns (gaming): $\quad$ Yes $\quad$ No Not Known

Mental state examination (appearance \& behaviour, rapport, speech, thought process/language, mood, affect, thought content, perception, cognition, insight and judgement):

Current Functioning (sleep, appetite, anxiety, daily living):

Risk assessment (consider risk to self, risk to others, risk from others, risk-taking behaviours - refer Appendix A for detailed assessment tool):

\section{Consumer's expectations and goals:}

\section{Summary/formulation:}

Consumer Code of Rights (discussed at initial appointment): Yes No 


\section{Outcome measure/score:}

Plan (including what they think may be helpful):

Assessed by:

Therapist:

Designation:

Signature:

Appendix A

RISK ASSESSMENT

\section{Self-Harm/Suicide:}

Have you thought of harming yourself?

Have you tried to harm yourself in the past?

If yes, how many times?

Have you had thoughts that life isn't worth living?

Are you thinking suicide?

Yes No

Previous attempt(s) on own life?

Yes No

If suicide attempt has been made, when was the most recent time?

What did you hope would happen as a result of your attempt?

(Did they want to die, or end their pain?)

Do you still have access to the method used?

Did you use alcohol or drugs before the attempt?

What did you use? 
Do you have easy access to a weapon?

How often are you having these thoughts?

Have you thought about how you would act on these? (Is there a plan? does this plan seem feasible? Are the methods available? Is it likely to be lethal?)

Have you thought about when you might act on this plan?

Are there any things/reasons that stop you from acting on these thoughts?

Do you know anyone who has recently tried to harm themselves?

Additional information:

(from NZ Guidelines Group)

\section{Harm to Others:}

Have you thought of hurting anyone else?

If yes, have you acted on these thoughts?

Have you been involved in any fights recently?

If yes, were you using drugs or alcohol at the time?

Additional information:

Other (empathic awareness, impulse control, criminal activity)

Harm from others (family violence additional) 


\section{Appendix C. EPDS Questionnaire}

1. I have been able to laugh and see the funny side of things.

- As much as I always could

- Not quite so much now

- Definitely not so much now

- Not at all

2. I have looked forward with enjoyment to things.

As much as I ever did

- Rather less than I used to

- Definitely less than I used to

- Hardly at all

3. I have blamed myself unnecessarily when things went wrong.

Yes, most of the time

Yes, some of the time

Not very often

No, never

4. I have been anxious or worried for no good reason.

No not at all

Hardly ever

Yes, sometimes

Yes, very often

5. I have felt scared or panicky for no very good reason. 
Yes, quite a lot

Yes, sometimes

No, not much

No, not at all

6. Things have been getting on top of me.

Yes, most of the time I haven't been able to cope at all

Yes, sometimes I haven't been coping as well as usual

No, most of the time I have coped quite well

No, I have been coping as well as ever

7. I have been so unhappy that I have had difficulty sleeping.

Yes, most of the time

Yes, sometimes

Not very often

No, not at all

8. I have felt sad or miserable.

Yes, most of the time

Yes, sometimes

Not very often

No, not at all

9. I have been so unhappy that I have been crying.

Yes, most of the time

Yes, quite often

Only occasionally 
- No, never

10. The thought of harming myself has occurred to me.

Yes, quite often

Sometimes

Hardly ever

Never 


\section{Appendix D. GAD-7 questionnaire}

Over the last 2 weeks, how often have you been bothered by any of the following problems? For each question select the option that best describes the amount of time you felt that way.

\begin{tabular}{|c|c|c|c|c|}
\hline $\begin{array}{l}\text { In the last } 2 \\
\text { weeks }\end{array}$ & $\begin{array}{c}\text { Not at all } \\
0\end{array}$ & $\begin{array}{c}\text { Several days } \\
1\end{array}$ & $\begin{array}{c}\text { More half the days } \\
2\end{array}$ & $\begin{array}{c}\text { Nearly every day } \\
3\end{array}$ \\
\hline $\begin{array}{l}\text { 1. Feeling nervous, } \\
\text { anxious, or on edge }\end{array}$ & 0 & 0 & 0 & 0 \\
\hline $\begin{array}{l}\text { 2. Not being able to } \\
\text { stop worrying }\end{array}$ & 0 & 0 & 0 & 0 \\
\hline $\begin{array}{l}\text { 3. Worrying too } \\
\text { much about } \\
\text { different things }\end{array}$ & 0 & 0 & 0 & 0 \\
\hline $\begin{array}{l}\text { 4. Having trouble } \\
\text { relaxing }\end{array}$ & 0 & 0 & 0 & 0 \\
\hline $\begin{array}{l}\text { 5. Being so restless } \\
\text { that it's hard to sit } \\
\text { still }\end{array}$ & 0 & 0 & 0 & 0 \\
\hline $\begin{array}{l}\text { 6. Becoming easily } \\
\text { annoyed or irritable }\end{array}$ & 0 & 0 & 0 & 0 \\
\hline $\begin{array}{l}\text { 7. Feeling afraid as } \\
\text { if something awful } \\
\text { might happen }\end{array}$ & 0 & 0 & 0 & 0 \\
\hline
\end{tabular}

GAD-7 provisional diagnosis

Scoring - add up answers to question on GAD-7

Not at all=0; Several days $=1$; More than half the days $=2$; Nearly every day $=3$

Total score anxiety severity

$5-9 \quad$ Mild Anxiety

$10-14 \quad$ Moderate Anxiety

$15-21 \quad$ Severe Anxiety 


\section{Appendix E. Kessler-10 questionnaire}

\section{K10 Test}

These questions concern how you have been feeling over the past 30 days. Tick a box below each question that best represents how you have been.

1. During the last 30 days, about how often did you feel tired out for no good reason?

\begin{tabular}{|l|l|l|l|l|}
\hline 1. None of the time & $\begin{array}{l}\text { 2. A little of the } \\
\text { time }\end{array}$ & 3. Some of the & 4. Most of the time & 5. All of the time \\
\hline
\end{tabular}

2. During the last $\mathbf{3 0}$ days, about how often did you feel nervous?

\begin{tabular}{|l|l|l|l|l|} 
1. None of the time & $\begin{array}{l}\text { 2. A little of the } \\
\text { time }\end{array}$ & $\begin{array}{l}\text { 3. Some of the } \\
\text { time }\end{array}$ & 4. Most of the time & 5. All of the time \\
\hline
\end{tabular}

3. During the last $\mathbf{3 0}$ days, about how often did you feel so nervous that nothing could calm you down?

\begin{tabular}{|l|l|l|l|l|}
\hline 1. None of the time & $\begin{array}{l}\text { 2. A little of the } \\
\text { time }\end{array}$ & 3. Some of the & 4. Most of the time & 5. All of the time \\
& & & & \\
\hline
\end{tabular}

4. During the last 30 days, about how often did you feel hopeless?

\begin{tabular}{|l|l|l|l|l} 
1. None of the time & $\begin{array}{l}\text { 2. A little of the } \\
\text { time }\end{array}$ & $\begin{array}{l}\text { 3. Some of the } \\
\text { time }\end{array}$ & 4. Most of the time & 5. All of the time
\end{tabular}

5. During the last $\mathbf{3 0}$ days, about how often did you feel restless or fidgety?

\begin{tabular}{|l|l|l|l|l|}
\hline 1. None of the time & $\begin{array}{l}\text { 2. A little of the } \\
\text { time }\end{array}$ & $\begin{array}{l}\text { 3. Some of the } \\
\text { time }\end{array}$ & 4. Most of the time & 5. All of the time \\
\end{tabular}

6. During the last $\mathbf{3 0}$ days, about how often did you feel so restless you could not sit still?

\begin{tabular}{|l|l|l|l|l|}
\hline 1. None of the time & 2. A little of the & 3. Some of the & 4. Most of the time & 5. All of the time \\
& time & time & & \\
\hline 7. During the last 30 days, about how often did you feel depressed?
\end{tabular}

7. During the last $\mathbf{3 0}$ days, about how often did you feel depressed?

\begin{tabular}{|l|l|l|l|l|}
\hline 1. None of the time & 2. A little of the & 3. Some of the & 4. Most of the time & 5. All of the time \\
time & time & & \\
\hline
\end{tabular}


8. During the last 30 days, about how often did you feel that everything was an effort?

\begin{tabular}{|l|l|l|l|l|}
\hline 1. None of the time & $\begin{array}{l}\text { 2. A little of the } \\
\text { time }\end{array}$ & 3. Some of the & 4. Most of the time & 5. All of the time \\
\hline
\end{tabular}

9. During the last $\mathbf{3 0}$ days, about how often did you feel so sad that nothing could cheer you up?

\begin{tabular}{|l|l|l|l|l|}
\hline 1. None of the time & $\begin{array}{l}\text { 2. A little of the } \\
\text { time }\end{array}$ & $\begin{array}{l}\text { 3. Some of the } \\
\text { time }\end{array}$ & 4. Most of the time & 5. All of the time \\
\hline
\end{tabular}

10. During the last 30 days, about how often did you feel worthless?

\begin{tabular}{|l|l|l|l|l|}
\hline 1. None of the time & $\begin{array}{l}\text { 2. A little of the } \\
\text { time }\end{array}$ & $\begin{array}{l}\text { 3. Some of the } \\
\text { time }\end{array}$ & 4. Most of the time & 5. All of the time \\
\hline
\end{tabular}




\section{Appendix F. Baseline and treatment periods questionnaire (measured daily)}

Please answer the following questions by ticking the box which best describes how you feel today.

On a scale between 0-10:

1) Interest or pleasure in doing things

\begin{tabular}{|c|c|c|c|c|c|c|c|c|c|c|}
\hline $\begin{array}{l}0 \quad \text { (no } \\
\text { interest) }\end{array}$ & 1 & 2 & 3 & 4 & 5 & 6 & 7 & 8 & 9 & $\begin{array}{l}10 \\
\text { (great } \\
\text { interest) }\end{array}$ \\
\hline
\end{tabular}

2) Feeling down, depressed, or hopeless

\begin{tabular}{|c|c|c|c|c|c|c|c|c|c|c|}
\hline $\begin{array}{l}0 \quad \text { (very } \\
\text { depressed) }\end{array}$ & 1 & 2 & 3 & 4 & 5 & 6 & 7 & 8 & 9 & $\begin{array}{l}10 \text { (not } \\
\text { depressed } \\
\text { at all) }\end{array}$ \\
\hline
\end{tabular}

3) Feeling nervous, anxious, or on edge

\begin{tabular}{|l|l|l|l|l|l|l|l|l|l|l|}
\hline $\begin{array}{l}0 \text { (highly } \\
\text { anxious) }\end{array}$ & 1 & 2 & 3 & 4 & 5 & 6 & 7 & 8 & 9 & 10 (not \\
& & & & & & & & & &
\end{tabular}

4) Not being able to stop or control worrying

\begin{tabular}{|l|l|l|l|l|l|l|l|l|l|l|}
\hline $\begin{array}{l}0 \quad \text { (very } \\
\text { much } \\
\text { worried) }\end{array}$ & 1 & 2 & 3 & 4 & 5 & 6 & 7 & 8 & 9 & 10 (not \\
worried \\
at all)
\end{tabular}

5) Becoming easily annoyed or irritable

\begin{tabular}{|l|l|l|l|l|l|l|l|l|l|l|}
\hline 0 & 1 & 2 & 3 & 4 & 5 & 6 & 7 & 8 & 9 & 10 \\
\hline
\end{tabular}




\begin{tabular}{|l|l|l|l|l|l|l|l|l|l|l|}
\hline (annoyed) & & & & & & & & & & (calm) \\
\hline
\end{tabular}

6) How confident do you feel about accomplishing today's tasks?

\begin{tabular}{|l|l|l|l|l|l|l|l|l|l|l|}
\hline $\begin{array}{r}\text { (not } \\
\text { confident) }\end{array}$ & 1 & 2 & 3 & 4 & 5 & 6 & 7 & 8 & 9 & 10 (highly \\
confident)
\end{tabular}




\section{Appendix G. Session evaluation questionnaire}

1) On a scale $0-10$, how would you rate the usefulness of today's session?

\begin{tabular}{|c|l|l|l|l|l|l|l|l|l|l|}
\hline $\begin{array}{l}\text { (not } \\
\text { useful) }\end{array}$ & & & & & & & & & & $\begin{array}{c}10 \text { (very } \\
\text { useful) }\end{array}$ \\
\hline
\end{tabular}

2) On a scale $0-10$, how relevant did you find today's session to your life circumstances?

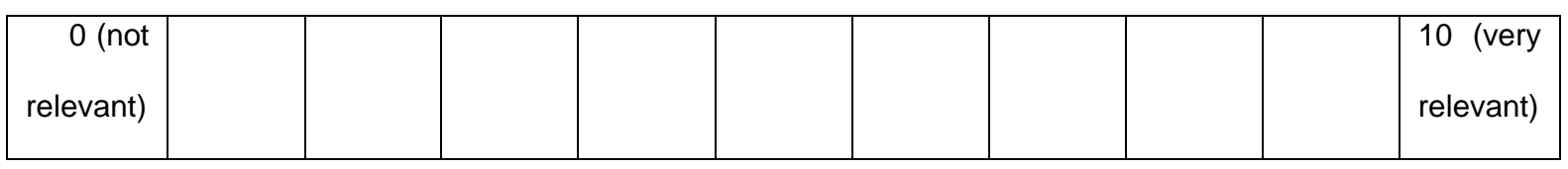

3) Was there anything in particular that you liked about today's session?

Yes, it was...

4) Was there anything in particular you did not like about today's session?

Yes, it was.... 


\section{Appendix H. VR session questionnaire}

1) On a scale $0-10$, how would you rate the usefulness of today's session?

\begin{tabular}{|c|l|l|l|l|l|l|l|l|l|l|}
\hline $\begin{array}{l}\text { (not } \\
\text { useful) }\end{array}$ & & & & & & & & & & $\begin{array}{l}10 \text { (very } \\
\text { useful) }\end{array}$ \\
\hline
\end{tabular}

2) On a scale $0-10$, how relevant did you find today's session to your life circumstances?

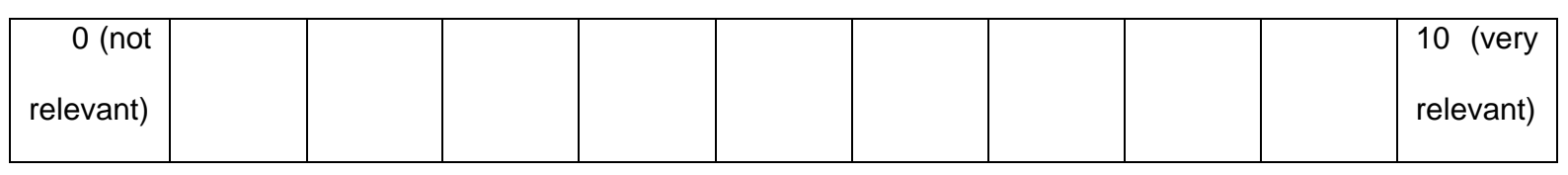

3) Was there anything in particular that you liked about today's session?

Yes, it was...

4) Was there anything in particular you did not like about today's session?

Yes, it was.... 


\section{Appendix I. Feasibility questionnaire}

The participants were asked to complete a questionnaire with 11 items in a 5 point Likert scale.

1) Did you feel comfortable throughout the recruitment process?

Yes

No

$1--\cdot---\cdot---\cdot----2$

$-3$ $-5$

2) Did the facilitator of the study give enough information about the referral process, ethics approval, and confidentiality?

Yes

No

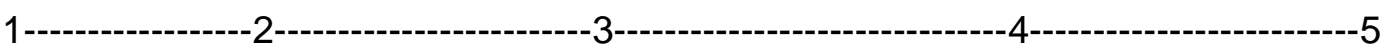

3) Was it a good idea for the VR session to be implemented in the fourth session?

$\begin{array}{lll}\text { Yes No } & \text { No }\end{array}$

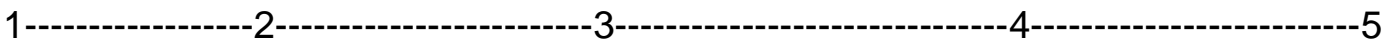

4) Did you feel the total number of sessions were adequate to address your mental health needs?

Yes

No

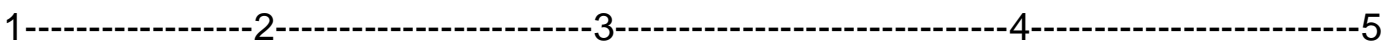

5) Did you have enough information about the VR system and how it works before you started using it?

Yes

No

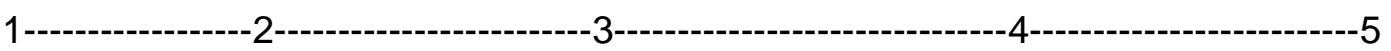

6) Did you have adequate time to prepare for the VR session? 
7) Did the questionnaires capture the essence of your mental health issues?

Yes

No

$1-$

$-3-$

$-5$

8) Do you feel you had to complete too many questionnaires?

No

Yes

$1-$

$-2-$ $-3$ $-4$ $-5$

9) Was the setting and the location of the study suitable?

Yes

No

1----------------2

$-3$ $-5$

10) If you experienced motion sickness when you used the VR system, did you think the follow up phone call was useful?

Yes

No

$1-$

$-3-$

$-5$

11) Would you change anything in the whole process? Yes / No

If yes, what would that be? 


\section{Appendix J. Acceptance questionnaire}

1. Total time I used the system...

- Less than 10 minutes

- $\quad$ 10-15 minutes

- $\quad 15-20$ minutes

- $\quad$ 20-30 minutes

- $\quad$ More than 30 minutes

2. I believe the system is easy to use.

Fully agree

Do not agree at all 1 2 3 4 5

3. I believe l'd like to use this system often.

Fully agree

Do not agree at all 1 2 3 4 5

4. I believe the system is difficult and it could be easier to use.

Do not agree at all Fully agree 1 2 3 4 5

5. I believe I'd need the support of an expert to use the system.

Do not agree at all

Fully agree 1 2 3 4 5

6. I believe the different possibilities of the system are well integrated. 
7. I believe the system is too fragile.

Do not agree at all

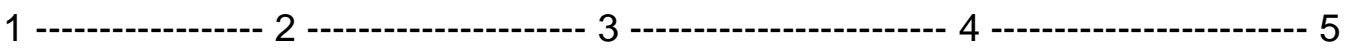

8. I believe most people would learn very quickly to use the system.

Fully agree

Do not agree at all 1

2 3

4 5

9. When going through the system, I found it too long and complicated.

Do not agree at all

Fully agree

1

2 3 4 5

10. I felt very comfortable and confident when using the system.

Fully agree

Do not agree at all 1 2 3 4 5

11. I need to learn a lot of things before knowing well how to use the system. Do not agree at all Fully agree 1 2 3 4 5

12. The choice of tasks within the treatment module is...

Easy to handle Difficult to handle

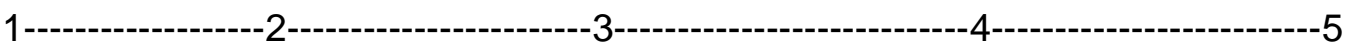


13. The system can speed up my recovery.

Fully agree

Fully disagree

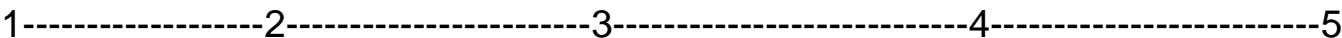

14. If it was available, l'd use it frequently.

Fully agree

Fully disagree

$1-$

$-2$

$-3-$

$-4-$ $-5$

15. In general terms, the application was easy to use.

Fully agree

Fully disagree

1

$-2$

$-3$ $-5$

16. In general terms, I believe the application is useful

Fully agree

Fully disagree

1

-2--------------------3

$4-$ $-5$

Remarks

○ What I liked the most was......

○ What I liked the least was......

○ I believe there was something missing. It was.....

o What things/tasks do I do better in my daily routines after I have used the clinical support system? 


\section{Appendix K. Information sheet - A pilot feasibility study \\ INFORMATION SHEET}

\section{The combination of cognitive-behavioural therapy with virtual reality for the treatment of post-natal depression in a brief intervention context: A pilot feasibility study.}

You have shown interest in participating in a scientific study from Universitat Jaume I (Spain). Your participation is completely voluntary. You will be asked to give your consent if you want to participate. There will be no problem if you do not want to participate. You can interrupt your participation at any time during the study. Please read carefully the following information and do not hesitate to ask, should you have any questions.

\section{Why is this study carried out?}

This study is part of the doctoral thesis of George Stamou (geostamou.gs@gmail.com). The main aim of the doctoral thesis is the design and empirical evaluation of a psychological treatment for postnatal depression supported by technology, concretely virtual reality. The specific aim of this study is to conduct a pilot and feasibility study in order to preliminary test the treatment protocol and the virtual reality modules to establish the treatment protocol that will be tested in a future randomized clinical trial.

\section{What will be the procedure implemented in the study?}

The study includes assesment sessions to evaluate your mental health status and determine if you meet the inclusion criteria to participate in the study.

If you meet the inclusion criteria you will be invited to receive a treatment program including six sessions delivered once a week. 
After finishing the treatment, there will be assessment sessions again to determine the improvement gained.

\section{Is there any risk associated with my participation?}

There is no evidence to suggest that the assessment and treatment protocol entails any risks for participants.

\section{What are the possible benefits of my participation?}

The treatment protocol included in this study has been designed to improve your mental health. Your participation in this study will also contribute to improve the mental health of other women who could benefit from this treatment in the future.

\section{How will my data be treated?}

All the relevant data will be gathered and stored in accordance with the international and national laws regarding data protection in clinical studies (for example, Declaration of Helsinki). Data will be anonimized using codes and will be treated confidentially and used only for scientific aims. All data will be erased once the investigation has come to an end.

\section{Can I decline or suspend my participation?}

Yes, you can decline to participate in the study or end your participation at any time. If you do choose to end your participation, all of your data will be erased.

\section{Who is the principal investigator in the study?}

The principal investigadors of this study are:

- Dra. Cristina Botella, Department of Basic and Clinical Psychology and Psychobiology, Jaume I University (Castellón, Spain), Phone: +34 964387 639, E-mail: botella@uji.es 
- Dra. Azucena Garcia-Palacios, Department of Basic and Clinical Psychology and Psychobiology, Jaume I University (Castellón, Spain), Phone: +34 964387 640, E-mail: azucena@uji.es

You can contact the principal investigators should you have any doubts in relation to the study, the data that is being gathered or if you wish to end your participation. 


\section{Appendix L. Information sheet - A single-case studies trial}

\section{INFORMATION SHEET}

The combination of cognitive-behavioural therapy with virtual reality for the treatment of post-natal depression in a brief intervention context: A single-case studies trial.

You have expressed your interest in volunteering in this trial organised by Universitat Jaume I (Spain). In order to participate you will need to give your consent in a written form. It is important to know that you can withdraw from the study at any given time and without any prior notice. You have the right to ask any questions that will help you clarify any grey areas and help you make informed decisions at any given moment.

\section{The purpose of this study}

The purpose of this study is to investigate whether the use of technology, more specifically virtual reality, can enhance the outcome of traditional therapies for post-natal depression. This is based on a literature review that was published in 2018 and a pilot study conducted later in the same year. This study is part of the $\mathrm{PhD}$ dissertation of George Stamou (geostamou.gs@gmail.com) which investigates the combination of virtual reality and traditional therapies for the treatment of post-natal depression.

\section{What are the requirements to be eligible for this study?}

You will need to have been referred by your general practitioner or Plunket nurse. Once the referral is received, it will be triaged to determine whether it meets the inclusion criteria of the study. You will then be contacted via phone to arrange for an initial assessment. The treatment will be 6 sessions on average and delivered weekly or fortnightly.

\section{What are the risks of this study?}

There are no risks associated with this study. 


\section{What are the possible benefits from this study?}

This study aims for the improvement of the participants' mental health needs. Its results will also be generalised and applied to other people with similar mental health issues.

\section{Confidentiality of data}

All data collected in this study will be treated in a strictly confidential manner. It will be collected and stored according to international laws regarding data protection (see Declaration of Helsinki). All data will be destroyed upon completion of the trial.

\section{Withdrawal from trial}

You can withdraw from the trial at any given time and without prior notice. All relevant information will be deleted at the same time.

\section{Who is the principal investigator in the study?}

The principal investigators of this study are:

- Dra. Cristina Botella, Department of Basic and Clinical Psychology and Psychobiology, Jaume I University (Castellón, Spain), Phone: +34 964387 639, E-mail: botella@uji.es

- Dra. Azucena Garcia-Palacios, Department of Basic and Clinical Psychology and Psychobiology, Jaume I University (Castellón, Spain), Phone: +34 964387 640, E-mail: azucena@uji.es

You can contact the principal investigators should you have any doubts in relation to the study, the data that is being gathered or if you wish to end your participation. 

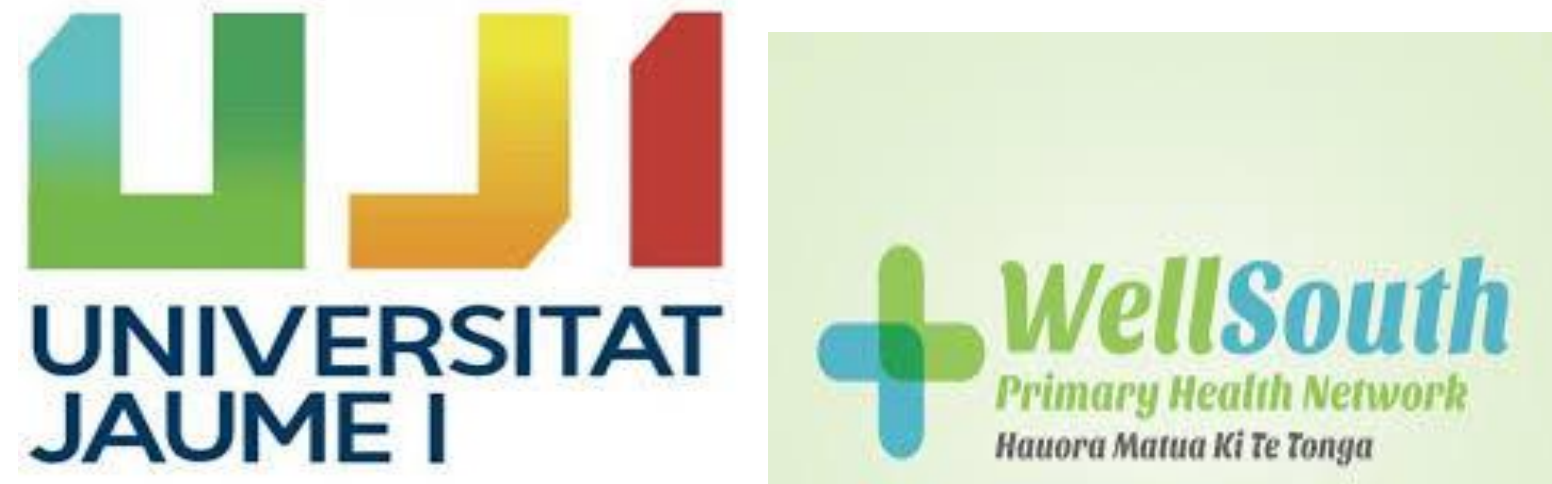


\section{Appendix M. Consent form - A pilot feasibility study \\ CONSENT FORM

\author{
I accept voluntarily participating in this study
}

\section{The combination of cognitive-behavioural therapy with virtual reality for the treatment of post-natal depression in a brief intervention context: A pilot feasibility study.}

Please, sign this consent form only if you have understood the nature and procedures of the study, and only if you do not have doubts and you have understood your rights as a participant.

If you want to participate in the study, please check the following boxes:

- I am over 18 years old and I give my consent to participate in this study.

- I certify that I have read and understood the former information, that I have received satisfactory answers to my questions about the study, and that I have been informed about my right to drop out from the study at any moment.

- I give my consent to participate in this study, understanding that this consent does not imply resignation to any of my legal rights, nor does it exempt the investigator from liability for negligence.

Name:

Date:

Location:

Signature of participant:

Signature of researcher: 
Appendix N. Consent form - A single-case studies trial

CONSENT FORM

\section{I accept voluntarily participating in this study}

The combination of cognitive-behavioural therapy with virtual reality for the treatment of post-natal depression in a brief intervention context: A single-case studies trial.

Please, read the above information carefully before you sign this consent form. It is important for you to fully understand the purpose of this study and the procedures involved in that.

By ticking the three boxed below, you declare that you consent to participate in this study

- I am over 18 years old and I give my consent to participate in this study.

- I certify that I have read and understood all information provided, that I have received satisfactory answers to my questions about the study, and that I have been informed about my right to drop out from the study at any moment.

- I give my consent to participate in this study, understanding that this consent does not imply resignation to any of my legal rights, nor does it exempt the investigator from liability for negligence.

Name:

Date: 
Location:

Signature of participant:

Signature of researcher: 


\section{Appendix O. Risk mitigation protocol - A pilot feasibility study \\ Instructions in case things do not go according to the plan.}

1. In case the system does not work for whatever reason, such as communication failure between two computers, frozen picture, repeated voice, then the client is instructed to stop using the system until therapist is able to advise them of next steps. The client can use the office phone to connect with therapist and vice versa.

2. Frozen picture can be after time session has expired but (I need to test what is the maximum capacity in terms of time? What it go over 15 minutes? 30 minutes?).

3. If there is a failure, it is a good idea to have a debriefing as usual and it is suggested that there will be a phone call as follow up the following day asking about the progress of the client, or difficulties.

4. It is a good idea to have a phone follow up the next day if possible, in case the client has a motion sickness.

5. 3 out of 6 people so far have experienced motion sickness, possibly the way to cope with that is to ask them to slow it down or slow the lever down.

6. In terms of motion sickness, maybe asking people who are more susceptible to motion sickness, e.g., past experience, maybe not eligible to participate or they need to be particularly aware.

7. (reflections) Maybe the programme needs to be individualized for each participant because different users find different components relative/ familiar/ more real to their lives and circumstances.

8. The initial assessment needs to ask about the pregnancy, if it was planned, if there were any problems, about the delivery/birth, if there were any problems, natural/ cesarean, and about breastfeeding.

9. The scaling of the answers to the questions in the first questionnaire is problematic, also the wording of questions in the first questionnaire need to change from questions to 
statements in order to answer I agree - I disagree (can't agree to a question). However, clients have understood their purpose, although one of them has N/A 3 of the questions.

10. Also be aware of negative and positive questions, maybe the answers, the positive ones need to be on the right side and negative on the left.

11. It is suggested that the mother can attend all session with the baby but it is suggested to attend the session with the VR trial without the baby so she can have a sense of freedom of physical movement and to being able to focus on the trial.

12. To combat motion sickness: it is suggested to have room temperature, not too hot or too cold, to avoid hot temperature in the room. It is suggested to offer water or a beverage to the client for consumption. It is also suggested that the client needs to have consumed food at least two hours before the VR trial takes place.

13. Another way to combat motion sickness to activate the stressors in such a way that the client has one direction without having to come back and forth, change rooms and directions continuously.

14. There have not been any DNAs, only cancellations, two or three.

15. All six participants have shown improvement on how they feel and cope, regardless of the VR system.

16. Maybe the demographics data in the Feasibility questionnaire that participants were asked to fill out again, is a duplication as they have already filled the same information in the EPDS questionnaire in the first session and the last, and it might need to be removed from the Feasibility questionnaire.

17. Change the number of questions (12 instead of 11) for the first of the two final questionnaires when I talk about the VR pilot study in the main text. 


\section{Appendix P - Risk mitigation protocol - A single-case studies trial \\ Instructions to the participants in case things do not go according to the protocol.}

1. In case the system does not work for whatever reason, such as communication failure between two computers, frozen picture, repeated voice, then the client is instructed to stop using the system until therapist is able to advise them of next steps. The client can use the office phone to connect with therapist and vice versa.

2. It is possible that the picture can freeze which most likely means that the session has expired.

3. If there is a failure in the running of the system which might result in elevated levels of stress for the client, the therapist will conduct a debrief with the client and will also do a phone call as follow up the following day asking about the progress of the client, or difficulties.

4. It is suggested that the mother can attend all session with the baby but it is suggested to attend the session with the VR trial without the baby so she can have a sense of freedom of physical movement and to being able to focus on the trial.

\section{Motion sickness}

5. It is suggested to have room temperature, not too hot or too cold, to avoid hot temperature in the room. It is suggested to offer water or a beverage to the client for consumption. It is also suggested that the client needs to have consumed food at least two hours before the VR trial takes place.

6. It is suggested for the facilitator to activate the stressors in such a sequence that the client has one direction while navigating themselves inside the virtual environment, without having to come back and forth, change rooms and directions continuously.

7. The therapist will investigate whether the participants are susceptible to motion sickness / history of motion sickness. 
8. In case they are, the facilitator will suggest for the participants to take the medication (pill) for that half an hour before the session. However, even if they say no to the pill, they can still hold the right to participate in the study if they wish to proceed.

9. The therapist will suggest for the participants to slow the navigation down within the VR environment.

10. During the trial, it is suggested for the clients to avoid any kind of physical movement, e.g., standing up, etc.

11. In case the client experiences motion sickness, the therapist to offer the client a beverage, e.g., water, soft drink, etc.

12. In case the client experiences motion sickness, the therapist is strongly suggested to conduct a debrief.

13. In case the client experiences motion sickness, the therapist will ensure they feel ok before they leave the therapist's office, and the therapist will conduct a follow up call the next day with the client. 